\title{
Arterial stiffness
}

Citation for published version (APA):

Onete, G. V. (2018). Arterial stiffness: Neuropsychiatric consequences and pathophysiologic mechanisms : late life depression, cognitive dysfuntion and advanced glycation end-products. [Doctoral Thesis, Maastricht University]. Maastricht University. https://doi.org/10.26481/dis.20181108go

\section{Document status and date:}

Published: 01/01/2018

DOI:

10.26481/dis.20181108go

Document Version:

Publisher's PDF, also known as Version of record

\section{Please check the document version of this publication:}

- A submitted manuscript is the version of the article upon submission and before peer-review. There can be important differences between the submitted version and the official published version of record.

People interested in the research are advised to contact the author for the final version of the publication, or visit the DOI to the publisher's website.

- The final author version and the galley proof are versions of the publication after peer review.

- The final published version features the final layout of the paper including the volume, issue and page numbers.

Link to publication

\footnotetext{
General rights Owners
rights.

- You may freely distribute the URL identifying the publication in the public portal. please follow below link for the End User Agreement:

www.umlib.nl/taverne-license

Take down policy

If you believe that this document breaches copyright please contact us at:

repository@maastrichtuniversity.nl

providing details and we will investigate your claim.
}

Copyright and moral rights for the publications made accessible in the public portal are retained by the authors and/or other copyright owners and it is a condition of accessing publications that users recognise and abide by the legal requirements associated with these

- Users may download and print one copy of any publication from the public portal for the purpose of private study or research.

- You may not further distribute the material or use it for any profit-making activity or commercial gain

If the publication is distributed under the terms of Article $25 \mathrm{fa}$ of the Dutch Copyright Act, indicated by the "Taverne" license above, 


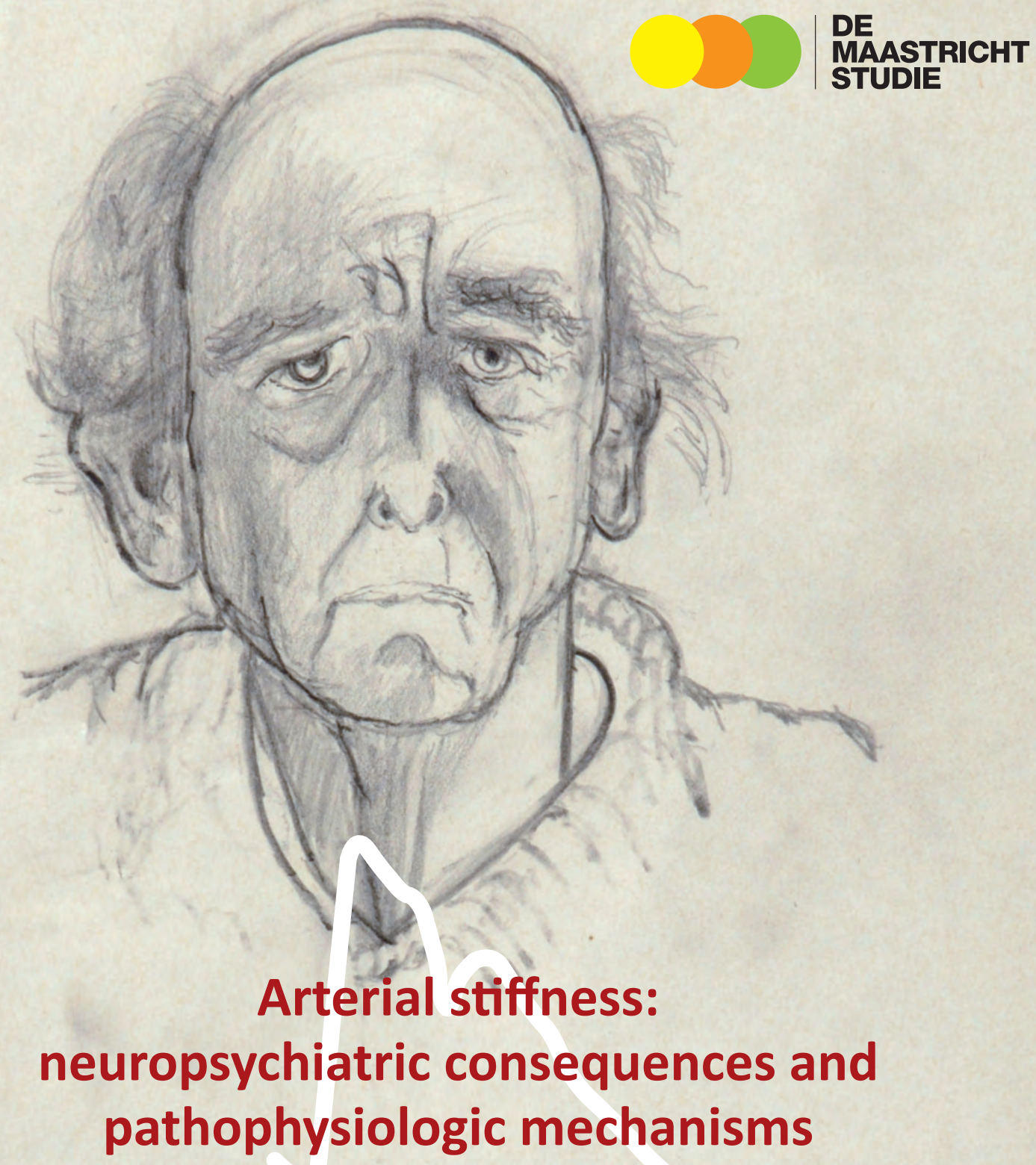

Late life depression, cognitive dysfunction

and advanced glycation end-products 

ARTERIAL STIFFNESS:

NEUROPSYCHIATRIC CONSEQUENCES AND

PATHOPHYSIOLOGIC MECHANISMS 
ISBN: 978-94-91602-69-6

Cover picture: William Utermohlen, autoportret 1996 (one year after being diagnosed with Alzheimer's dementia)

Printing and lay-out by: Proefschriftenprinten.nl - The Netherlands 


\section{ARTERIAL STIFFNESS: NEUROPSYCHIATRIC CONSEQUENCES AND PATHOPHYSIOLOGIC MECHANISMS}

Late life depression, cognitive dysfunction and advanced glycation end-products

\section{PROEFSCHRIFT}

ter verkrijging van de graad van doctor aan de Universiteit Maastricht, op gezag van de Rector Magnificus, Prof. dr. Rianne M. Letschert volgens het besluit van het College van Decanen,

in het openbaar te verdedigen op 8 November 2018 om 10:00 uur

$$
\text { door }
$$

Gabriela Veronica Onete

Geboren op 19 augustus 1986, te lasi 


\section{Promotor}

Prof. Dr. C.D.A. Stehouwer

\section{Copromotoren \\ Dr. M.T. Schram \\ Dr. R.M.A. Henry}

\section{Beoordelingscommissie}

Prof. Dr. A.A. Kroon (voorzitter)

Prof. Dr. L.M. van Bortel (Universiteit Ghent)

Prof. Dr. F. Verhey

Dr. P.J.J. Spauwen (GGZ Oost Brabant)

Dr. M.M.J. van Greevenbroek 


\section{Contents}

$\begin{array}{lll}\text { Chapter } 1 & \text { General Introduction } & 7\end{array}$

Part I Arterial Stiffness and Neuropsychiatric Disorders

Chapter 2 Arterial stiffness is associated with depression in middle-aged men

- The Maastricht Study

Chapter 3 Carotid stiffness is not associated with late-life depressive symptoms, an eight- year follow up of The Hoorn Study

Chapter 4 Association of arterial stiffness with cognitive performance at six-year follow-up: the Hoorn Study

Part II: Pathophysiologic Mechanisms of Arterial Stiffness

Chapter 5 Neither Skin Autofluorescence, nor plasma Pentosidine, CML and CEL, are associated with carotid, femoral or brachial artery stiffness

Chapter 6 General Discussion

Summary

Nederlandse Samenvatting

Publications

Knowledge Valorisation

Acknowledgements/ Dankwoord 



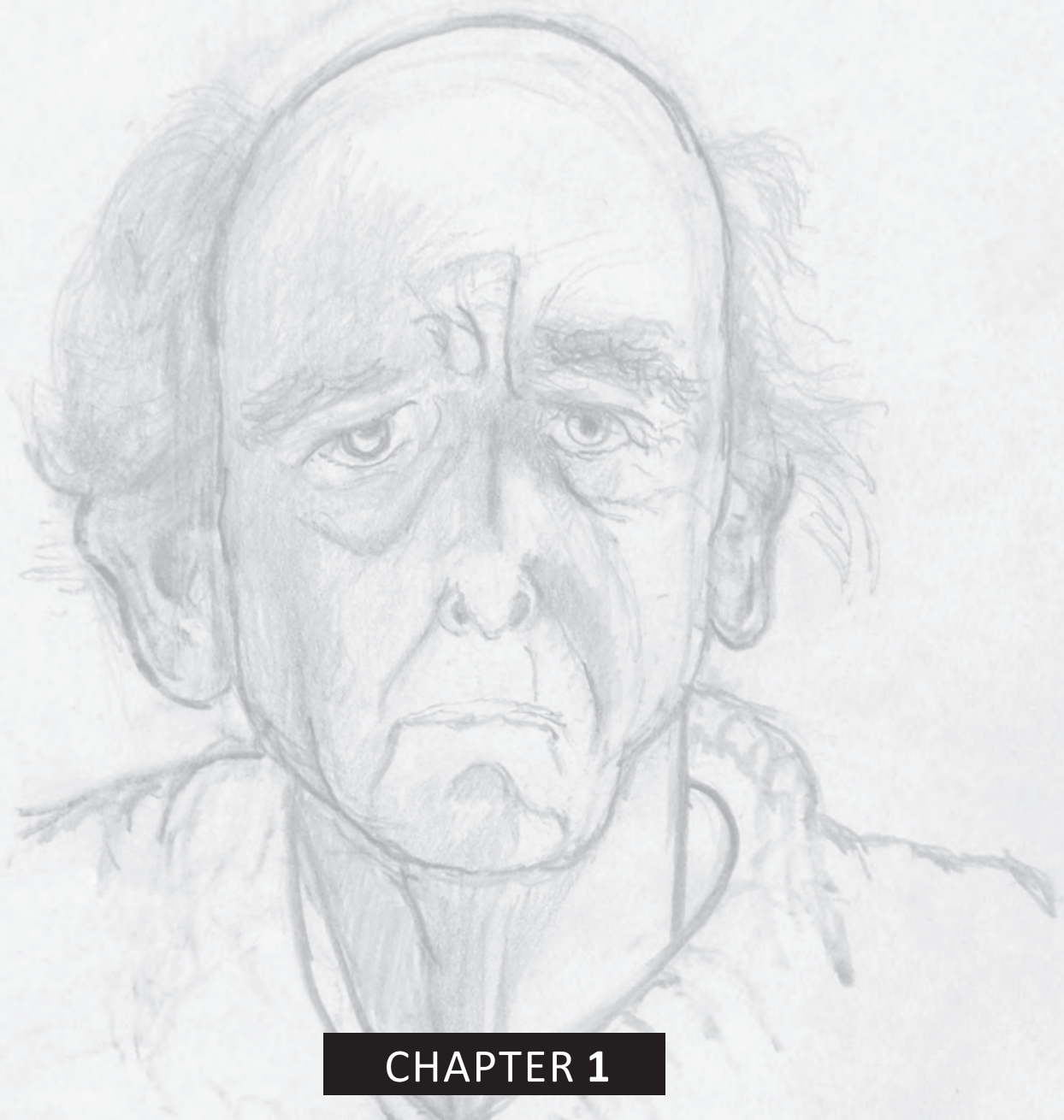

General introduction 



\section{Introduction and Aims}

Arterial stiffness is a novel CVD risk factor that may offer additional preventive and therapeutic targets for two of the most debilitating conditions in elderly individuals: latelife depression and cognitive dysfunction. The proportion of the world's older adults is estimated to almost double from $12 \%$ to $22 \%$ between 2015 and 2050 [1]. More than $20 \%$ of adults aged 60 and over suffer from at least one neuropsychiatric disorder, which account for $17.4 \%$ of Years Lived with Disability (YLDs). The most common of these neuropsychiatric disorders are dementia and depression [1]. Both disorders are highly invalidating, due to their chronic course, poor prognosis and lack of successful therapies [2,3]. Thus, additional research into their pathophysiology is required in order to uncover additional therapeutic and preventive targets. Growing evidence suggests that cerebral (micro) vascular disease is an important contributor to cognitive dysfunction, dementia and depression in late life $[4,5]$. Arterial stiffness is a modifiable CVD risk factor, which has been associated with cerebral micro- and macrovascular disease independently of traditional CVD risk factors $[6,7]$. In part 1 of this thesis we will, therefore, explore the role of arterial stiffness in the development of late-life depression and cognitive dysfunction. In part $\mathbf{2}$ we will then focus on the pathophysiology of arterial stiffening, in particular on the role of advanced glycation end products (AGEs), which may offer a target for lowering arterial stiffness.

PART 1:

Arterial Stiffness and Neuropsychiatric Disorders in Middle Age and Late Life

\section{A. Depression}

Depression is a chronic and invalidating disorder, especially in late life. According to the WHO, 6.9\% of the adult population aged 18 to 65 years suffers from a major depressive disorder (MDD) [1]. It is the leading chronic condition in Europe and is responsible for $11 \%$ of all years lived with disability. The prevalence of MDD is lower in late-life (age > 55 years) than in younger groups $[8,9]$ with an average prevalence between $0.4 \%-10.2 \%$ in the general community; which can, however, reach as high as $14-42 \%$ in nursing home residents $[9,10]$. Late-life depression (LLD) is associated with worse treatment outcomes, including partial response to antidepressant medication [11], high recurrence rates [2], and greater suicide and non-suicide mortality rates [12]. Furthermore, LLD is accompanied by cognitive deficits which may ultimately progress to dementia despite adequate anti-depressant treatments $[13,14]$. Thus, in view of the rapid increase in the numbers of older adults worldwide, LLD is an important public health concern with possible dire consequences. 
The biological basis of LLD is multifactorial and involves neurodegenerative, immune and endocrine pathways $[15,16]$; however, the pathway which focuses on the role of vascular disease [4] has received growing scientific attention in the past twenty years. This "vascular depression" hypothesis proposed that cardiovascular disease (CVD) and its risk factors predispose, precipitate or perpetuate LLD [4] through the accumulation of cerebral small vessel lesions within the brain, which disrupt the deep and frontal brain structures that are involved in mood regulation [4,17]. These changes could explain the symptoms specific to "vascular depression", such as cognitive deficits, psychomotor retardation, lack of insight, and disability disproportional to severity of depression. Consistent with this hypothesis, white matter hyperintensities (WMH) have been cross-sectionally and longitudinally associated with LLD [18]. Furthermore, a greater WMH load has been associated with and could explain the poor response of LLD to antidepressants as well as its poor prognosis $[19,20]$.

Despite the growing evidence concerning the vascular origin of LLD, the adequate management of classic CVD risk factors, such as hypertension or hyperlipidaemia has not been successful in preventing LLD [21]. Arterial stiffness is a novel CVD risk factor, which has been consistently associated with cerebral (micro)vascular disease, including WMH [6], independently of traditional CVD risk factors, therefore it may offer additional insight in the development of LLD. Furthermore, stiffening of the large elastic arteries, such as the aorta and the carotids, may offer additional targets for the prevention and treatment of LLD.

\section{Arterial stiffness and depression: open questions}

\section{The differential association of arterial stiffness with LLD according to age}

The association of arterial stiffness with LLD has been studied in three population-based studies [22-24], two of which found a significant association [22,23]. These studies included individuals > 60 years, however, arterial stiffness could be a relevant risk factor for LLD in individuals as young as 40-60 years old. Indeed, cerebral small vessel disease may develop as early as the $4^{\text {th }}$ decade [25] and elastic arteries show progressive stiffening from middleage onwards [26]. Furthermore, arterial stiffness may be a more potent CVD risk factor in middle-aged than in elderly individuals [27], possibly due to a stronger confounding effect of blood pressure in the latter group. In the elderly aortic stiffening closely mirrors the rise in systolic and pulse pressures and adds little to models that include hypertension; whereas in middle-aged individuals blood pressure is mainly driven by an elevated cardiac output and is thus poorly correlated to arterial stiffness [27]. Therefore, the association of arterial stiffness with vascular depression could also be stronger in the middle-aged group. In line with this observation, the association of CVD with depression is stronger 
in adults younger than 65 years as compared to those above $[28,29]$. Also, one cohort study did report a significant association of MDD with the augmentation index, which is an indirect measure of arterial stiffness in adults aged 22 to 66 years. Neither this, nor any of the previous studies [22-24,30,31] evaluated, however, whether the association between arterial stiffness and depression differed according to age.

\section{The differential association of arterial stiffness with LLD in men and in women}

The association of arterial stiffness with LLD could differ according to sex. Arterial stiffness is known to be substantially higher in men than in women [32,33], therefore arterial stiffness could play a more prominent role in the development of "vascular depression" in men. Depression is, however, more prevalent in women [34], therefore in this group other biological factors, such as hormonal changes [35] could play a more prominent in the development of a depressive disorder. These differences in the aetiology of LLD could be greatest at middle-age when hormonal differences between sexes are most prominent. Three [22-24] of five [22-24,30,31] studies investigated sex differences in the association of arterial stiffness with depression or depressive symptoms, however these populations were above middle-age and none of them reported any significant differences.

\section{The longitudinal association of arterial stiffness with LLD and depressive symptoms}

To our knowledge, the association of arterial stiffness with LLD has never been studied in a longitudinal setting, therefore at current no definitive inferences can be made about causality. Also, most studies to date measured aortic [22-24,30], but not carotid artery $[22,31]$ stiffness. Aortic stiffness, as measured by the carotid-femoral pulse wave velocity (cfPWV) is considered the gold standard to assess arterial stiffness; however, the carotid artery is the main blood supplier to the anterior cerebral circulation. Its stiffening, therefore, could be associated more strongly with cerebral (micro)vascular disease [36] and therefore, LLD. Of the two previous studies $[22,31]$ that included carotid stiffness measurements, one [22] found a significant association with both LLD and sub-clinical LLD symptoms in individuals aged $>60$ years; whereas the other did not report any significant associations in younger adults (aged between 22 and 66 years). In order to further analyse the etiologic role of carotid artery stiffness in LLD, we investigated the cross-sectional and longitudinal associations of several carotid stiffness parameters with depressive symptoms in elderly individuals.

\section{B. Cognitive Dysfunction}

Cognitive dysfunction and dementia are alongside depression the major cause of care dependency and disability in individuals aged 60 years and older. From middle-age onwards, cognitive abilities gradually decline. These cognitive functions, which include information processing speed, attention \& executive functions and memory are essential for goal- 
directed behaviour, such as planning, problem-solving and decision-making [37]. Although cognitive decline occurs naturally with old age, accelerated decrease of these functions can finally lead to cognitive dysfunction and ultimately dementia. In affluent countries, up to $36 \%$ of individuals above 70 years suffer from some form of cognitive dysfunction [39]. According to a recent WHO report, around 47 million people have dementia worldwide. Furthermore, the total number of people with dementia is projected to near 75 million in 2030 and almost triple by 2050 to 132 million [1].

The pathophysiology of age-related cognitive dysfunction has yet to be elucidated, however, growing evidence suggests that cerebral (micro)vascular disease plays an important role [5]. Accumulation of cerebral (micro)vascular lesions may disrupt cerebral circuits and thus impair brain functions, leading to cognitive decline $[40,41]$. The aetiology of these small vessel lesions is in itself unknown, however, CVD risk factors, such as arterial stiffness most likely play a role. Indeed, a recent systematic review by our group has shown that arterial stiffness is consistently, but weakly, associated with both cerebral (micro)vascular disease and cognitive decline [6].

\section{Arterial stiffness and cognitive dysfunction: open questions}

Most research so far has focused on the carotid-to-femoral pulse wave velocity (cfPWV), which is a measure of aortic stiffness that is considered the gold standard to assess arterial stiffness [14]. The carotid artery, however, is the main supplier to the anterior cerebral circulation and may affect the cerebral circulation to a greater extent than the aorta. Research on the association of carotid artery stiffness with cognitive function is scarce and contradicting: while two $[42,43]$ of three [42-44] population-based studies reported a significant cross-sectional association of carotid stiffness with lower cognitive performance, the largest of these cohort studies could not confirm these findings longitudinally [45]. This latter study, however, also did not find any significant longitudinal associations of the cfPWV with cognitive decline [44], contrary to previous findings [45-54]. To further elucidate the association of various markers of arterial stiffness with cognitive decline, we analysed the associations of carotid and aortic stiffness with cognitive dysfunction in a population-based cohort.

\section{Pathophysiological mechanisms linking arterial stiffness with depression and cognitive dysfunction}

According to previous hypotheses, arterial stiffness could lead to either $\operatorname{LLD}[4,17,55]$, or cognitive dysfunction $[40,41]$ through the development of cortical and subcortical cerebral (micro)vascular lesions, which directly affect and diminish cerebral functions. Cerebral small vessel disease manifests as lacunar infarcts, (large) white matter lesions, and microbleeds. The cerebral microcirculation has a low impedance that facilitates the high blood flow 
required to meet the high metabolic demands of the brain [56]. Impairment of the cushioning function of the aorta and of the carotid arteries allows greater pressure and flow pulsatility to penetrate deeply into the cerebral microcirculation, thus directly damaging the microvascular tissue and through it the surrounding tissue [57-59]. Furthermore, the excessive pressure induces arteriolar remodelling and hypertrophy, which impairs vascular reactivity and contributes to repeated episodes of microvascular ischemia and tissue damage [58,59]. Lastly, increasing arterial stiffness may cause excessive blood pressure variability $[60,61]$ which may further sensitize high-flow organs to the harmful effects of impaired microvascular vasoreactivity [59].

\section{PART 2:}

\section{Pathophysiologic Mechanisms of Arterial Stiffening Arterial Stiffness: Theory and Measurement}

Arterial stiffness is one of the hallmarks of arterial aging. Arterial stiffness describes the (loss of) elastic properties, or rigidity of the arterial walls [62]. Compliance is the inverse of arterial stiffness. The arterial system has two main functions: 1 ) to deliver an adequate supply of blood to organs and tissues (the conduit function); and 2) to smoothen the flow and pressure pulsatility generated by the intermittent contractions of the heart into a constant, nearly steady capillary flow (the cushioning function) [63]. The wide arterial radius, which offers little resistance to blood flow, is essential for the conduit function, while arterial compliance is essential for the cushioning function [64]. Arterial compliance declines with increasing distance from the heart: the central arteries (i.e., the aorta and the carotids) are more compliant than the stiffer peripheral arteries (i.e., the brachial and femoral arteries). This is due to a decrease in the ratio of elastin to collagen and an increase in the number of smooth muscle cells (SMCs) per unit volume [65]. As the cushioning function declines from the ascending aorta to the more peripheral arteries, the conduit function becomes more prominent [23]. With ageing or hypertension, the central elastic arteries stiffen at a greater rate than muscular arteries, such that the stiffness gradient is attenuated or even reversed [66-68].

\section{Measurements used to determine arterial stiffness}

Arterial stiffness can be measured regionally over the aorta, or locally at specific arterial sites, such as the carotid, femoral and brachial arteries [69].

\section{Aortic stiffness}

The carotid-femoral pulse wave velocity (cfPWV) is considered the gold standard measurement of arterial stiffness [70]. Its estimation uses the propagative model of 
the arterial system. Pressure waveforms are determined at the right common carotid and right common femoral arteries by means of applanation tonometry. Simultaneous electrocardiogram (ECG) registration synchronizes the pressure waveforms with systolic contraction of the heart (R-wave of the ECG). The pulse transit time is calculated by subtracting the time between the ECG and the proximal pulse from the time between ECG and distal pulse. The pulse wave travel distance is calculated as $80 \%$ of the straight surface distance between the two recording sites. cfPWV is calculated as the ratio between the travel distance (meters) and the transit time (seconds) [71].

\section{Local artery stiffness indices}

Carotid, femoral and brachial artery stiffness indices can be estimated without using any model of the circulation. The common carotid artery is visualized by means of an ultrasound device, which uses accurate radiofrequency signals to measure the diameter in end diastole (D), the distension, or stroke change in diameter (DD), and the intimamedia thickness (IMT) (Figure 1) [72]. Brachial systolic, diastolic, mean arterial pressure (MAP), and pulse pressure (PP) are determined repeatedly with a 5-min interval, using a blood pressure measurement device. Based on these measurements three indices can be derived. These arterial properties together with together with pulse pressure are used to

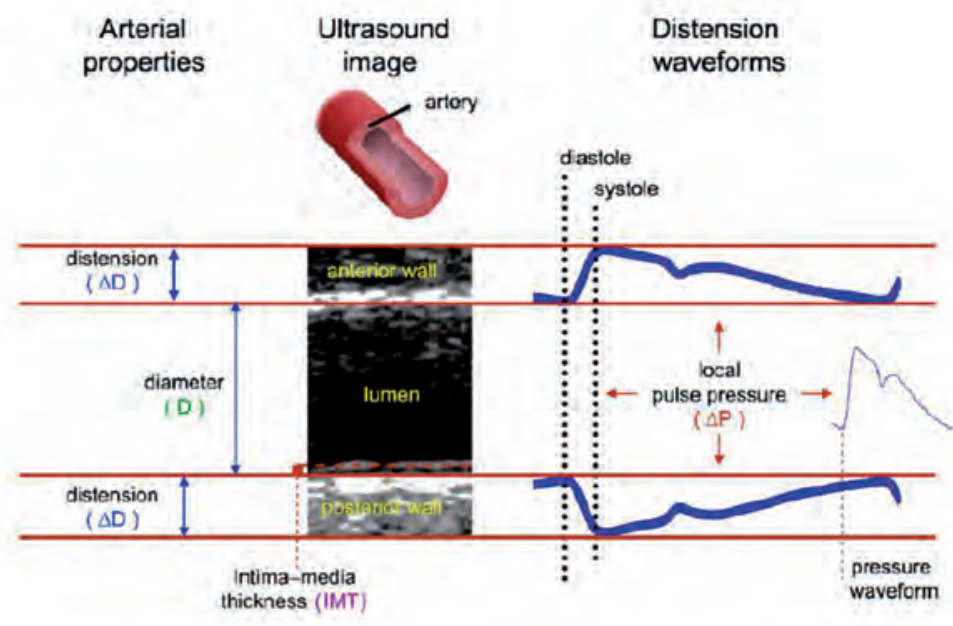

$\begin{array}{ll}\text { Distensibility Coefficient }(D C)=\left(2 \Delta D \cdot D+\Delta D^{2}\right) /\left(P P \cdot D^{2}\right) & \left(10^{-3} \mathrm{kPa}^{-1}\right) \\ \text { Compliance Coefficient }(C C)=\pi \cdot\left(2 \mathrm{D} \cdot \Delta \mathrm{D}+\Delta \mathrm{D}^{2}\right) / 4 \mathrm{PP} & \left(\mathrm{mm}^{2} \mathrm{kPa}^{-1}\right) \\ \text { Young's elastic modulus (YEM) }=\mathrm{D} /(\mathrm{IMT} \cdot \mathrm{DC}) & \left(10^{3} \mathrm{kPa}\right)\end{array}$

Figure 1: Estimates of arterial stiffness as obtained by means of non-invasive ultrasonography. Adapted from ${ }^{69}$ 
calculate local stiffness indices, such as the Distensibility Coefficient (DC), the Compliance Coefficient (CC) and, in the case of the carotid artery, Young's Elastic Modulus (YEM) [74]. The Distensibility Coefficient (DC) represents the elastic properties of the artery as a hollow structure. The Compliance Coefficient (CC) represents the buffering capacity of the carotid artery against rises in blood pressure during a systole. The carotid artery Young's Elastic Modulus (YEM) represents the stiffness of the carotid wall material at operating pressure.

Due to pulse wave amplification, peripheral pulse pressure is higher than the pulse pressure in the carotid artery, therefore central rather than brachial pulse pressures should be used to calculate carotid stiffness indices. In this thesis the carotid artery pulse pressure was estimated from the carotid artery distension wave-forms and the brachial pulse pressure, as described previously [73].

\section{Differences between aortic stiffness and local stiffness indices}

The measurement of aortic stiffness (cfPWV) reflects the elastic properties of several aortic components: from the highly elastic ascending aorta to the stiffer abdominal aorta and the increasingly muscular iliac and femoral arteries [74], whereas local stiffness indices reflect the properties of only one artery site. The carotid is a predominantly elastic artery, whereas the femoral and the brachial stiffness indices are indicative of muscular artery properties. Even though the carotid artery stems directly from the aortic arch, its behaviour more closely resembles that of the abdominal rather than of the thoracic aorta [75], as both are prone to develop atherosclerotic plaques [76] and have similar distensibilities in middle-aged and elderly individuals [77-80]. Stiffening of elastic and muscular arteries may differentially affect brain function, as the cushioning function of elastic arteries diminishes most with old age [66-68]. Furthermore, the carotid artery supplies the cerebral anterior cerebral circulation, therefore its elastic properties could be a better surrogate marker of middle-size cerebral artery stiffness than aortic stiffness. Finally, as the carotid artery is more prone to atherosclerosis its stiffening could reflect the parallel development of stenotic plaques [81], which can cause flow obstructions and thus damage the cerebral micro-circulation. In support of this hypothesis, the carotid artery appears to be more strongly associated with the outcome stroke [36], as compared to aortic stiffness.

\section{Advanced Glycation End-Products (AGEs) and Arterial Stiffness}

Aortic and carotid stiffness indices are thought to reflect age-related degradation of predominantly elastic arteries [70]; however, aortic stiffness, as measured by the cfPWV, increases faster with age, hypertension and type 2 diabetes than carotid stiffness [74]. A possible factor involved in this accelerated stiffening could be the formation of advanced glycation end-products (AGEs). AGEs are reactive compounds which are formed when glucose reacts with the amino acid residues of proteins, lipids, or nucleic acids via the non- 
enzymatic Maillard process [82] and are thus found in greater concentrations in patients with type 2 diabetes. Higher AGE concentrations have indeed been associated with a higher cfPWV in patients with diabetes [83-86], ESRD [87], and even in the general population [8891]. The cfPWV, however, cannot distinguish between the elastic properties of the highly elastic descending thoracic aorta, the stiffer abdominal aorta and the increasingly muscular iliac and femoral arteries [74]. The use of local stiffness indices could, therefore, add more insight to AGE-associated aortic stiffening.

Recently, our group has also reported that tissue AGEs, as measured by skin autoflorescence (SAF), as well as plasma pentosidine, are associated with aortic stiffness as well as central pulse pressure (a marker of ascending aortic stiffness) [85]. In order to further understand AGE-associated aortic stiffening, we investigated within the same cohort whether SAF and the plasma AGEs pentosidine, $\mathrm{n}$ \{epsilon\}-(carboxymethyl)lysine (CML), $\mathrm{n}$ \{epsilon\}(carboxyethyl)lysine (CEL) are associated with stiffness indices of the carotid, femoral and brachial arteries.

\section{Populations used in the study}

Two study populations were used throughout the study.

\section{The Maastricht Study}

The Maastricht Study is an observational prospective population-based cohort study [92] that focuses on the aetiology, pathophysiology, complications and comorbidities of type 2 diabetes mellitus (T2D) and is characterized by an extensive phenotyping approach. Eligible for inclusion were individuals aged between 40 and 75 years, living in the southern part of the Netherlands. For reasons of efficiency individuals with T2D were oversampled by design. This study includes multiple elaborate measurements of CVD risk factors, including pulse wave velocity measurements of aortic stiffness, diabetic complications, and assessment of most important cognitive domains and depression. For chapters 2,3 and 4 of the current thesis, we used cross-sectional data from the first 3451 participants, who completed the baseline survey between November 2010 and September 2013. For chapter five, we used data from the first 866 participants, who completed the baseline survey between November 2010 and March 2012.

\section{The Hoorn Study}

The Hoorn study is a longitudinal population-based cohort study, which investigates glucose metabolism, as well as cardiovascular risk factors, in the general population [93]. The study started in 1989 and included 2484 men and women aged 50 to 74 years, of 
whom 1513 participated in the second examination in 1996-98. For the current thesis, we used data from the third (2000-2001) and fourth (2005-2009) follow-up examinations. In 2000-2001, arterial stiffness and depressive symptoms measurements were carried out; whereas throughout the 2005-2009 examinations, data on depressive symptoms and cognitive performance was acquired. Arterial stiffness measurements had a belated onset and were carried out throughout the period 2007-2009.

\section{Aims and outline of the thesis}

In part 1 of this thesis we will explore the vascular origins of two of the most disabling conditions in elderly individuals, namely late-life depression and cognitive dysfunction. In particular we will investigate the role played by arterial stiffness. In part $\mathbf{2}$ of this thesis we will focus on arterial stiffening, in particular on the differential response of elastic and muscular arteries to stiffening factors, such as advanced glycation end products (AGEs).

\section{Part 1}

In chapter two of this thesis we assessed whether aortic stiffness is associated with a major depressive disorder or depressive symptoms in a population of middle-aged and elderly individuals; and whether the association differs according to age or sex.

In chapter three we investigated whether carotid artery stiffness is longitudinally associated with depressive symptoms in elderly individuals and whether the associations differs according to age or sex.

In chapter four we assessed whether either carotid artery or aortic stiffness is longitudinally associated with cognitive performance in elderly individuals.

\section{Part 2}

In chapter five we investigated arterial stiffening by evaluating the associations of advanced glycation end products (AGEs) with elastic and muscular artery stiffness indices.

In chapter six the key findings of the present thesis and their clinical implications are discussed. Also, the main methodological issues and future research implications are discussed. 


\section{References}

1 World Health Organization. Fact sheet $\mathrm{N}^{\circ} 381$ on Mental health and older adults. (available from: http://www.who. int/mediacentre/factsheets/fs381/en/)

2 Mitchell AJ, Subramaniam H. Prognosis of depression in old age compared to middle age: a systematic review of comparative studies. Am J Psychiatry. 2005;162:1588-601.

3 Reisberg B et al. The Global Deterioration Scale for Assessment of Primary Degenerative Dementia. American Journal of Psychiatry. 1982;139(9):1136-1139.

4 Alexopoulos GS. The vascular depression hypothesis: 10 years later. Biol Psychiatry. 2006; 60(12):1304-5.

5 Gorelick PB, Scuteri A, Black SE et al. Vascular Contributions to Cognitive Impairment and Dementia: A statement for Healthcare Professionals from the American Heart Associations/ American Stroke

6 Van Sloten TT, Protogerou AD, Henry RM, Schram MT, Launer LJ, Stehouwer CD. Association between arterial stiffness, cerebral small vessel disease and cognitive impairment: A systematic review and meta-analysis. Neurosci Biobehav Rev. 2015; 53:121-30.

7 Liu M, Li GL, Li Y, Wang JG. Effects of Various Antihypertensive Drugs on Arterial Stiffness and Wave Reflections. Pulse 2013;1:97-107

8 Blazer D, Burchett B, Service C, George L. The association of age and depression among the elderly: an epidemiologic exploration. J Gerontol Med Sci. 1991;46:M210-M215.

9 Beekman ATF, Copeland JRM, Prince MJ. Review of community prevalence of depression in later life. British Jounral of Psychiatry. 1999; 174: 307-311

10 Fiske A, Wethrell JL, Gatz M. Depression in Older Adults. Annu Rev Clin Psychol 2009; 5: 363-389

11 Baldwin R, Wild R. Management of depression in later life. Advances in Psychiatric treatment Feb 2004, 10 (2) $131-139$.

12 Blazer DG. Depression in late life: Review and commentary. J Gerontol. A Biol. Sci. Med. Sci 2003;58:249-65.

13 Jorm AF. History of depression as a risk factor for dementia: an updated review. Aust N Z J Psychiatry. 2001;35:776781.

14 Ownby RL, Crocco E, Acevedo A, John V, Loewenstein D. Depression and risk for Alzheimer disease: systematic review, meta-analysis, and metaregression analysis. Arch Gen Psychiatry. 2006;63:530-538.

15 Disbato BM, Sheline Y. Biological basis of late life depression. Curr Psychiatry Rep 2012; 14(4): 237-9

16 Penninx BWJH, Beekman ATF, Bandinelli S, et al. Late-life depression symptoms are associated with both hyperactivity and hypoactivity of the Hypothalamo-Pituitary-Adrenal Axis. Am J Geriatr Psychiatry 2007; 15(6): 522-529

17 Alexopoulos GS, Meyers BS, Young RC, et al. Vascular depression hypothesis. Arc Gen Psychiatry 1997; 54: $915-922$

18 Van Agtmaal MJM, Houben AJHM, Pouwer F et al. Association of Microvascular Dysfunction With Late-Life Depression A Systematic Review and Meta-analysis. JAMA Psychiatry 2017;74(7):729-739

19 Simpson S, Baldwin RC, Jackson A, Burns AS. Is subcortical disease associated with a poor response to antidepressants? Neurological, neuropsychological and neuroradiological findings in late-life depression. Psychol Med. 1998; 28:1015-1026.

20 Patankar TF, Baldwin R, Mitra D, Jeffries S, Sutcliffe C, Burns A, et al. Virchow-Robin space dilatation may predict resistance to antidepressant monotherapy in elderly patients with depression. J Affect Disord. 2007; 97:265-270.

21 Almeida OP. Vascular Depression: myth or reality> Int Psychogeriatr. 2008; 20(4): 645-52 
22 Tiemeier H, Breteler MM, van Popele NM, et al. Late-life depression is associated with arterial stiffness: a population-based study. J Am Geriatr Soc 2003; 51:1105-1110

23 Van Sloten TT, Mitchell GF, Sigurdsson S, et al. Associations between arterial stiffness, depressive symptoms and cerebral small vessel disease: cross-sectional findings from the AGES-Reykjavik Study. J Psychiatry Neurosci. 2016; 14 (3): $162-8$.

24 Lewis TT, Sutto-Tyrell K, Penninx BW, et al. Race, Psychosocial Factors, and Arortic Pulse Wave Velocity: The Health, Aging, and Body Coposition Study. J Gerontol A Biol Sci Med Sci. 2010 ; 65(10): 1079-1085

25 Smith EE, O'Donnell M, Dagenais G, et al. Early Cerebral Small Vessel Disease and Brain Volume, Cognition, and Gait. Ann Neurol 2015; 77(2): 251-261

26 Mitchell GF, Wang N, Palmisano JN, et al. Hemodynamic correlates of blood pressure across the adult age spectrum: noninvasive evaluation in the Framingham Heart Study. Circulation. 2010; 122:1379-1386.

27 Shlomo YB, Spears M, Boustred C, et al. Aortic pulse wave velocity improves cardiovascular event prediction: an individual participant meta-analysis of prospective observational data from 17,635 subjects. J Am Coll Cardiol. 2014; 63(7): 636-646.

28 Salaycik KJ, Kelly-Hayes M, Beiser A, et al. Depressive symptoms and risk of stroke: the Framingham Study. Stroke. 2007; 38(1):16-21

29 Pan A, Sun Q, Okereke OI, et al. Depression and risk of stroke morbidity and mortality: a meta-analysis and systematic review. JAMA 2011;306:1241-9.

30 Paranthaman R, Greenstein AS, Burns AS, et al. Vascular function in older adults with depressive disorder. Biol Psychiatry 2010; 68: 133-139.

31 Seldenrijk A, van Hout HP, van Marwijk HW, et al. Depression, anxiety, and arterial stiffness. Biol Psychiatry 2011; 69: 795-803.

32 Franklin SS, Gustin W, Wong ND, et al. Hemodynamic patterns of age-related changes in blood pressure. The Framingham Heart Study. Circulation. 1997; 96: 308-315;

33 Segers $\mathrm{P}$, Rietzschel ER, De Buyzere ML, et al. Noninvasive (input) impedance, pulse wave velocity, and wave reflection in healthy middle-aged men and women. Hypertension 2007; 49: 1248-1255

34 Weissman MM, Bland R, Joyce PR, et al. Sex differences in rates of depression: cross-national perspectives. J. Affect. Disord. 1993; 29: 77-84

35 Gordon JL, Girdler SS. Hormone replacement therapy in the treatment of perimenopausal depression. Curr Psychiatry Rep 2014; 16(12) 517- 525.

36 van Sloten TT, Sedaghat S, Laurent S, London GM, Pannier B, Ikram MA, Kavousi M, Mattace-Raso F, Franco OH, Boutouyrie P, Stehouwer CD. Carotid stiffness is associated with incident stroke: a systematic review and individual participant data meta-analysis. J Am Coll Cardiol. 2015 ;66(19):2116-25.

37 Deary IJ, Corley J, Gow AJ, et al. Age-associated cognitive decline. Br Med Bull 2009;92:135-52

38 Plassman BL, Langa KM, Fisher GG, et al. Prevalence of cognitive impairment without dementia in the United States. Ann Intern Med. 2008 18; 148(6): 427-34

39 Gorelick PB, Scuteri A, Black SE et al. Vascular Contributions to Cognitive Impairment and Dementia: A statement for Healthcare Professionals from the American Heart Associations/ American Stroke Association. Stroke 42(9): 2672-2713 
40 Brundel M, de Bresser J, van Dillen JJ, Kappelle LJ, Biessels GJ. Cerebral microinfarcts: a systematic review of neuropathological studies. J Cereb Blood Flow Metab. 2012;32(3):425-436

41 Van Rooden S, Good JD, van Opstal AM, et al. Increased number of microinfarcts in Alzheimer disease at 7-T MR imaging. Radiology 2014; 270(1):205-11.

42 Geijselaers SL, Sep SJ, Schram MT, et al. Carotid stiffness is associated with impairment of cognitive performance in individuals with and without type 2 diabetes. The Maastricht Study. Atherosclerosis, 2016; 253:186-193

43 Lim SL, Gao, Q, Nyunt MS et al. Vascular Health indices and cognitive domain function: Singapore longitudinal ageing studies. J. Alzheimer's Dis. JAD. 2015; 50: 27-40

44 Poels MM, van Oijen M, Mattace-Raso FU et al. Arterial stiffness, cognitive decline, and risk of dementia: the Rotterdam study. Stroke J Cereb circ. 2007; 38: 888-892

45 Watson NL, Sutton-Tyrrell K, Rosano C. et al. Arterial stiffness and cognitive decline in well-functioning older adults. J. Gerontol. Ser. A Biol. Sci. Med. Sci. 2011; 66: 1336-1342

46 Waldstein SR, Rice SC, Thayer JF. et al. Pulse pressure and pulse wave velocity are related to cognitive decline in the Baltimore Longitudinal Study of Aging. Hypertension. 2008; 51: 99-1044

47 Tsao CW, Himali JJ, Beiser AS, et al. Association of arterial stiffness with progression of subclinical brain and cognitive disease. Neurology, 2016; 86 (7): 619-62

48 Hajjar I, Goldstein FC, Martin GS, Quyyumi AA et al. Roles of arterial stiffness and blood pressure in hypertensionassociated cognitive decline in healthy adults. Hypertension. 2016; 67(1):171-175

49 Lim LS, Gao Q, Nyunt N, et al. Vascular Health indices and cognitive domain function: Singapore longitudinal ageing studies. J. Alzheimer's Dis. JAD; 2015: 27-40

50 Scuteri S, Brancati AM, Gianni W, et al. Arterial stiffness is an independent risk factor for cognitive impairment in the elderly: a pilot study. J. Hypertens; 2005 (23): 1211-1216

51 Muller M, Grobbee DE, Aleman A, et al. Cardiovascular disease and cognitive performance in middle-aged and elderly men. Atherosclerosis; 2007 (190): 143-149

52 Elias MF, Robbins MA, Budge MM, et al. Arterial pulse wave velocity and cognition with advancing age. Hypertension; 2009 (53): 668-673

53 Zhong W, Cruickshanks KJ, Schubert CR, Carlsson CM, Chappell RJ, Klein BE, Klein R, Acher CW. Pulse Wave Velocity and Cognitive Function in Older Adults. Alzheimer Dis Assoc Disord. 2013;28:44-49.

54 Hanon O, Haulon S, Lenoir H, Seux ML, Rigaud AS, Safar M, Girerd X, Forette F. Relationship between arterial stiffness and cognitive function in elderly subjects with complaints of memory loss. Stroke. 2005;36:2193-2197.

55 Herrmann LL, Le Masurier M, Emeier KP. White matter hyperintensities in late life depression: a systematic review.J Neurol Neurosurg Psychiatry. 2008; 79(6): 619-24.

56 Mitchell GF, van Buchem MA, Sigurdsson S, et al. Arterial stiffness, pressure and flow pulsatility and brain structure and function: the Age, Gene/Environment Susceptibility - Reykjavik study

57 Tzourio C, Laurent S, Debette S. Is hypertension associated with an accelerated aging of the brain? Hypertension. 2014; 63:894-903.

58 O'Rourke MF, Safar ME. Relationship between aortic stiffening and microvascular disease in brain and kidney: cause and logic of therapy. Hypertension. 2005; 46:200-204. 
59 Mitchell GF. Effects of central arterial aging on the structure and function of the peripheral vasculature: implications for end-organ damage. J Appl Physiol (1985). 2008; 105:1652-1660.

60 Schillaci G, Bilo G, Pucci G, et al. Relationship between short-term blood pressure variability and large artery stiffness in human hypertension: findings from 2 large databases. Hypertension. 2012; 60:369-377.

61 Rothwell PM. Limitations of the usual blood-pressure hypothesis and importance of variability, instability, and episodic hypertension. Lancet. 2010;375:938-948.

62 Nichols WW, O'Rourke MF (2005) McDonald's blood flow in arteries: theoretical, experimental and clinical principles. Hodder Arnold, London

63 Safar ME, O'Rourke MF, eds Arterial Stiffness in Hypertension. Amsterdam: Elsevier; 2006. Birkenhager WH, Reid Jl, eds. Handbook of Hypertension; No 23.

64 London GM, Pannier B. Arterial Stiffness: how to interpret the complex hysiology. Nephrol Dial Transplant (2010) 25: 3815-3823

65 Greenwald SE (2007) Ageing of the conduit arteries. J Pathol 211:157-172

66 Benetos A, Laurent S, Hoeks AP, Boutouyrie PH, Safar ME. Arterial alterations with aging and high blood pressure. A noninvasive study of carotid and femoral arteries. Arterioscler Thromb 1993; 13(1):90-7

67 Bortolotto LA, Hanon O, Franconi G, Boutouyrie P, Legrain S, Geired X. The aging process modifies the distensibility of elastic but not muscular arteries. Hypertension 1999; 34(4 Pt2) 889-92

68 Vermeersh SJ, Rietzschel ER, De Buyzere ML, et al. Age and gender related patterns in carotid-femoral PWV and carotid and femoral stiffness in a large healthy, middle-aged population. J Hypertens 2008; 26(7):1411-9

69 Stehouwer CDA, Henry RMA, Ferreira I. Arterial stiffness in diabetes and the meatbolic syndrome: a pathway to cardiovascular disease. Diabetologia 2008;51:527-539

70 Laurent S, Cockcroft J, van Bortel L, et al. Expert consensus document on arterial stiffness: methodological issues and clinical applications. Eur Heart J. 2006; 27(21): 2588-605.

71 Van Bortel LM, Duprez D, Starmans-Kool MJ, et al. Clinical applications of arterial stiffness, Task Force III: recommendations for user procedures. Am J Hypertens 15:445-452

72 Reneman RS, Meinders JM, Hoeks AP. Non-invasive ultrasound in arterial wall dynamics in humans: what have we learned and what remains to be solved. Eur Heart J 2005 May;26(10):960-6

73 van Bortel LM, Balkestein EJ, van der Heijden-Spek JJ, et al. Non-invasive assessment of local arterial pressure: comparison of applanation tonometry and echo-tracking. J Hypertens. 2001;19:1037-1044.

74 Paini A, Boutouyrie P, Calvet D, Tropeno Al, Laloux B, Laurent S. Carotid and Aortic Stiffness Determinants of Discrepancies. Hypertension 2006; 47(3): 371-6.

75 Edwards J. An Atlas of Acquired Diseases of the Heart and Great Vessels. Philadephia: Saunders; 1961.

76 Kemp WL, Burns DK, Brown TG. Pathology: The Big Picture. The McGraw-Hill Companies; 2008. Chapter 9

77 Ahlgren AR, Hansen F, Sonesson B, Länne T. Stiffness and diameter of the common carotid artery and abdominal aorta in women. Ultrasound Med Biol. 1997; 23(7): 983-8

78 Hirai T, Sasayama S, Kawasaki T, Yagi S. Stiffness of systemic arteries in patients with myocardial infarction: a noninvasive method to predict severity of coronary atherosclerosis. Circulation1989;80:78-86.

79 Länne T, Hansen F, Mange11 P, Sonesson B. Differences in mechanical properties of the common carotid artery and abdominal aorta in healthy males. J Vast Surg 1994;20:218-225. 
80 Jiang L, Huijun C, Rui L, Xu H, et al. Association of Arterial Distensibility Between Carotid Arteries and Abdominal Aorta by MR. J Magn Reson Imaging. 2015

81 Witteman JC, Grobbee DE, Valkenburg HA, et al. J-shaped relation between change in diastolic blood pressure and progression of aortic atherosclerosis. Lancet 1994; 343: 504-7

82 Sell DR, Monnier VM. Moelcular Basis of Artreial Stiffening: Role of Glycation - A Mini Review. Gerontology 2012; 58:227-237

83 Yoshida N, Okumura K, Aso Y. High serum pentosidine concentrations are associated with increased arterial stiffness and thickness in patients with type 2 diabetes. Metabolism. 2005; 54(3):345-50.

84 Llauradó G, Ceperuelo-Mallafré V, Vilardell C, Simó R, Gil P, Cano A, Vendrell J, González-Clemente JM. Advanced glycation end products are associated with arterial stiffness in type 1 diabetes. J Endocrinol. 2014 Jun;221(3):40513.

85 van Eupen MG, Schram MT, van Sloten TT, et al. Skin Autoflorescence and Pentosidine Are Associated With Aortic Stiffening: The Maastricht Study. Hypertension. 2016; 68(4): 956-63

86 Couppé C, Dall CH, Svensson RB, et al. Skin autofluorescence is associated with arterial stiffness and insulin level in endurance runners and healthy controls - Effects of aging and endurance exercise. Exp Gerontol. 2017; 91:9-14

87 Koyama H, Tanaka S, et al. Skin autofluorescence, a marker for advanced glycation end product accumulation, is associated with arterial stiffness in patients with end-stage renal disease. Metabolism. 2008 Oct;57(10):1452-7.

88 Watfa G, Soulis G, Tartagni E, Kearney-Schwartz A, Borghi C, Salvi P, Benetos A. Relationship between tissue glycation measured by autofluorescence and pulse wave velocity in young and elderly non-diabetic populations. Diabetes Metab. 2012 Nov;38(5):413-9.

89 Semba RD, Najjar SS, Sun K, Lakatta EG, Ferrucci L. Serum carboxymethyl-lysine, an advanced glycation end product, is associated with increased aortic pulse wave velocity in adults. Am J Hypertens. 2009;22(1):74-9.

90 Semba RD, Sun K, Schwartz AV, et al. Serum carboxymethyl-lysine, an advanced glycation end product, is associated with arterial stiffness in older adults. J Hypertens. 2015; 33(4):797-803

91 McNulty M, Mahmud A, Feely J. Advanced glycation end-products and arterial stiffness in hypertension. Am J Hypertens. 2007;20:242-247.

92 Schram MT, Sep SJ, van der Kallen CJ, et al. The Maastricht Study: an extensive phenotyping study on determinants of type 2 diabetes, its complications and its comorbidities. Eur J Epidemiol.2014;29(6):439-51.

93 Mooy JM, Grootenhuis PA, de Vries H, et al. Prevalence and determinants of glucose intolerance in a Dutch Caucasian population: the Hoorn study. Diabetes Care. 1995; 18: 1270-1273 


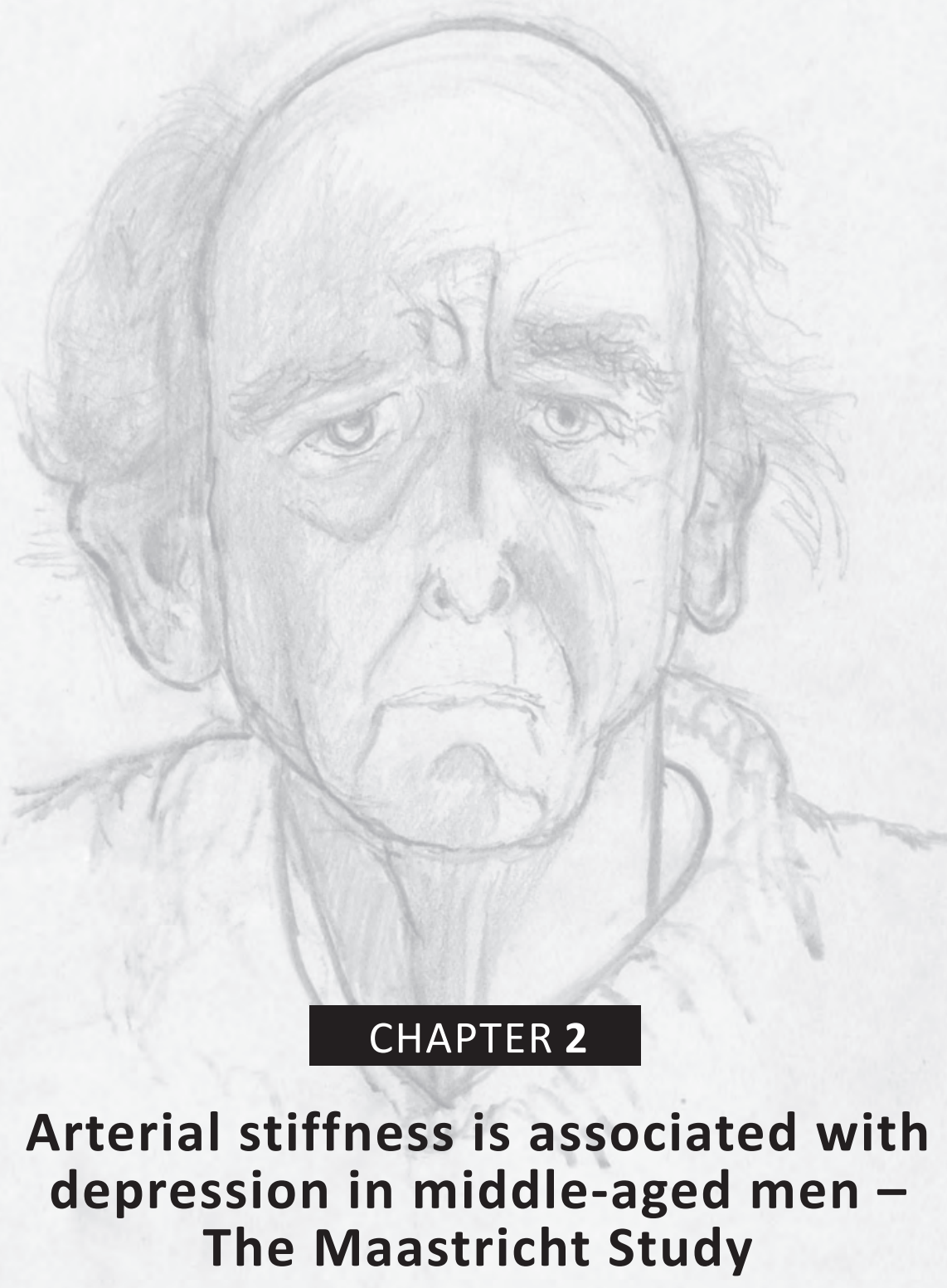

Veronica G Onete, Ronald MA Henry, Simone J.S. Sep, Annemarie Koster, Carla J. van der Kallen, Pieter C. Dagnelie, Nicolaas Schaper, Sebastian Köhler, Koen Reesink, Coen DA Stehouwer, Miranda T Schram 


\section{Abstract}

\section{Background}

Arterial stiffening may underlie the association of depression with cardiovascular disease (CVD), but reported data are inconsistent. We investigated the associations of aortic stiffness with major depressive disorder (MDD) and depressive symptoms, and whether these differed by sex and age.

\section{Methods}

We measured carotid to femoral pulse wave velocity (cfPWV) by applanation tonometry, and depression with the MINI diagnostic interview and PHQ-9 questionnaire in 2757 participants from The Maastricht Study (51\% men, age 59.8 $\$ 8.1$ years, $27 \%$ type 2 diabetes (T2DM)). Logistic and negative binominal models were adjusted for age, T2DM, MAP and CVD risk factors. Results are presented as ORs or rate ratios $[95 \% \mathrm{Cl}]$ per $1 \mathrm{SD}$ cfPWV. Interactions for sex and age were significant $(p<0.05)$.

\section{Results}

cfPWV was associated with MDD in men, but not women $\leq 60$ years, fully adjusted ORs were 2.36 [1.45-3.84] and 1.57 [0.93-2.66], respectively. The ORs were not significant in individuals > 60 years (men: 1.03 [0.63 - 1.68], women: 0.64 [0.32 - 1.31]). Similarly, cfPWV was associated with a higher PHQ-9 score in men, but not women $\leq 60$ years (rate ratio 1.28 [1.09 - 1.52] and 1.11 [0.99 - 1.23], respectively). Associations were not significant in individuals > 60 years (men: 0.96 [0.84 - 1.08], women: 1.00 [0.90 - 1.12]).

\section{Limitations}

We cannot rule-out reversed causation in this cross-sectional study.

\section{Discussion}

Greater aortic stiffness is associated with MDD and depressive symptoms among middleaged men and to a lesser extent in women, while this association was not observed in old age. 


\section{Introduction}

Arterial stiffening is considered a potential mechanism that could underlie the consistently observed association of depression with cardiovascular disease (CVD) $)^{1-3}$. Arterial stiffening may cause damage to the cerebral vasculature which is characterised by low impedance, as it increases pressure and flow pulsatility which are harmful to the cerebral microcirculation ${ }^{4}$. The vascular depression hypothesis states that the accumulation of (micro)vascular damage in the frontal-subcortical mood regulatory circuit of the brain may ultimately cause depression ${ }^{5-6}$. High pulse wave velocity has indeed been associated with cerebral small vessel disease ${ }^{7}$, and could consequently be involved in the pathophysiology of depression.

Conflicting results have been reported on the association of aortic stiffness with both the presence of a major depression disorder ${ }^{8-10}$ and depressive symptoms ${ }^{11,12}$, which may be caused by suboptimal study designs and/or assessment of arterial stiffness and depression. A significant association of aortic stiffness with depression was observed in the populationbased Rotterdam Study ${ }^{10}$ and the AGES-Reykjavik Study ${ }^{11}$, while no association was found with depressive symptoms in the Health ABC Study ${ }^{12}$. This contradiction could be explained by differences in the age range between these study populations ( 55 years and over in the Rotterdam Study versus 70 to 79 years in the Health ABC Study), and by the use of questionnaire data in the latter study as an estimate of depressive symptoms, which is less accurate than a diagnostic interview. In addition, (borderline) significant associations between aortic stiffness and a major depressive disorder were found in two relatively small cross-sectional studies ${ }^{8,9}$. Both the statistical power and the generalizability of the results might have been hampered in these studies as they had a case-control design, and in one less accurate measures to assess aortic stiffness were used ${ }^{9}$, while the population of the other ${ }^{8}$ was rather small. Moreover, a recent systematic review, has shown that the association of depression with stroke is heterogeneous and differs among subgroups of age, BMI, smoking status, and type of depression measurement ${ }^{13}$. Furthermore, the Framingham Study has shown that the association of CVD with depression is stronger in middle-age $(<65 \text { years), than in old age ( } \geq 65 \text { years })^{14}$. The association of intermediate measures of cardiovascular risk, such as aortic stiffness, and depression could also differ in middle-age versus old age. However, none of the previous studies evaluated whether this association differs according to age. In addition, men and women appear to differ in both their cardiovascular risk profile and depressive symptoms. Aortic stiffness is known to be substantially higher in men than in women ${ }^{15,16}$, while depression appears to be more prevalent among women ${ }^{17}$. These sex differences may be even more prominent at middle age, when hormonal differences between sexes are greatest, and women may have the highest cardiovascular protection from reproductive hormones. To date, three out of four studies investigated sex differences in the association of cfPWV with depression 
or depressive symptoms, but these populations were above middle-age; none of them reported any significant differences. Of these four studies, only the Rotterdam Study ${ }^{10}$ used a structured interview to diagnose a major depressive disorder.

In view of the above, we investigated the association of the cfPWV with both major depressive disorder (MDD) and with depressive symptoms in a Caucasian populationbased cohort study aged 40 to 75 years. We specifically examined whether any associations differed according to age and/or sex.

\section{Methods}

\section{Study Population}

We used data from The Maastricht Study, an observational prospective population-based cohort study. The rationale and methodology have been described previously ${ }^{18}$. In brief, the study focuses on the etiology, pathophysiology, complications and comorbidities of type 2 diabetes mellitus (T2DM) and is characterized by an extensive phenotyping approach. Eligible for participation were all individuals aged between 40 and 75 years and living in the southern part of the Netherlands. Participants were recruited through mass media campaigns and from the municipal registries and the regional Diabetes Patient Registry via mailings. Recruitment was stratified according to known T2DM status, with an oversampling of individuals with T2DM, for reasons of efficiency. The present report includes cross-sectional data from the first 3451 participants who completed the baseline survey between November 2010 and September 2013. Participants were mainly Caucasian (98.6\%). The examinations of each participant were performed within a time window of three months. The study has been approved by the institutional medical ethical committee (NL31329.068.10) and the Minister of Health, Welfare and Sports of the Netherlands (Permit 131088-105234-PG). All participants gave written informed consent.

Figure 1 shows the flow diagram of the study population. After exclusion of individuals without data on cfPWV ( $n=572)$, the MINI diagnostic interview and PHQ-9 were available in 2757 and 2529 participants, respectively. Individuals with missing data on covariates, such as prior CVD, smoking status and alcohol use $(n=111)$ were older, had more T2DM and a higher cfPWV than the individuals included in the final models (Supplemental Table 1).

\section{Carotid to femoral pulse wave velocity}

All measurements were carried out by trained vascular technicians unaware of the participants' clinical or diabetes status, in a dark, quiet temperature controlled room (21$23^{\circ} \mathrm{C}$ ). Participants were asked to refrain from smoking and drinking coffee, tea or alcoholic 


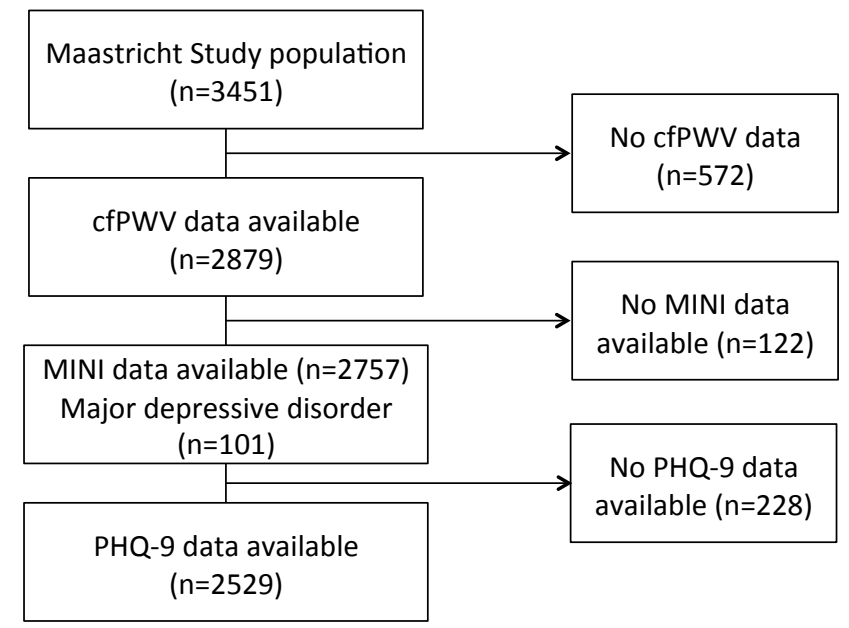

Figure 1: Flow diagram

beverages three hours prior to the study. Participants were allowed to have a light meal (breakfast or lunch). All measurements were performed in supine position after 10 minutes of rest. Talking or sleeping was not allowed during the examination.

Carotid to femoral pulse wave velocity (cfPWV) was determined according to recent guidelines ${ }^{19}$ with the use of applanation tonometry (SphygmoCor, Atcor Medical, Sydney, Australia). Pressure waveforms were determined at the right common carotid and right common femoral arteries. Difference in the time of pulse arrival from the R-wave of the electrocardiogram between the two sites (transit time) was determined with the intersecting tangents algorithm. The pulse wave travel distance was calculated as $80 \%$ of the direct straight distance (measured with an infantometer) between the two arterial sites. The median of three consecutive cfPWV (defined as traveled distance/transit time) recordings was used in the analyses. Brachial systolic, diastolic, mean arterial pressure (MAP) and heart rate were determined repeatedly during cfPWV assessment with a 5-min interval, using an oscillometric device (Accutorr Plus, Datascope Inc., Montvale, NJ, USA) and the average of these measurements was calculated.

Reproducibility of cfPWV measurements was assessed in 12 individuals (6 men; 60.8 16.8 years; 6 T2DM) who were examined by two observers at two occasions spaced one week apart. The intra- and inter-observer intra-class correlation coefficients (ICC) were 0.87 and 0.69 . 


\section{Assessment of depression}

Depressive disorder was assessed by the Mini-International Neuropsychiatric Interview $(\mathrm{MINI})^{20}$. The MINI is a short diagnostic structured interview, used to assess the presence of minor or major depressive disorder (MDD) in the preceding 2 weeks according to the DSM-IV (Diagnostic and Statistical Manual of Mental Disorders, Fourth Edition) ${ }^{21}$. MDD was diagnosed if participants had at least one core symptom (depressed mood or anhedonia) and at least four other symptoms of depression (weight change, change in appetite, insomnia/hypersomnia, psychomotor agitation/retardation, fatigue/loss of energy, guilt/ worthlessness, diminished ability to think/concentrate or indecisiveness and suicidal thoughts/plans). For sensitivity analyses we defined a minor depression episode as the presence of at least one core symptom and one to three other symptoms of depression, and early onset depression as MDD prior to the age of $40^{22}$.

Depressive symptoms were assessed by a validated Dutch version of the 9-item Patient Health Questionnaire (PHQ-9) ${ }^{23}$. The PHQ-9 is a self-administered questionnaire based on the DSM-IV ${ }^{21}$ criteria for MDD. It comprises of nine items rated on a four-point scale, ranging from $0=$ "not at all" to $3=$ "nearly every day". Response options can generate a continuous score ranging from 0 (no symptoms) to 27 (all symptoms present nearly every day). Both cognitive symptoms of depression, comprising thoughts about oneself and problems of the mind, and somatic symptoms, comprising various bodily sensations that a depressed individual perceives as unpleasant or worrisome, are measured with the PHQ- $9^{24}$.

\section{General characteristics and covariates}

Web-based questionnaires were used to obtain information regarding smoking status (never/former/current), alcohol consumption, educational level, physical activity and prior $\mathrm{CVD}^{18}$. Alcohol consumption was classified as none, low (1-7 glasses/ week for women, 1-14 glasses for men), and high (>7 glasses/ week for women, $>14$ for men). Educational level was divided into three categories: [1] low (i.e. no education, primary education, lower vocational education); [2] intermediate (i.e. intermediate general secondary education, intermediate vocational education, higher general secondary education), and [3] high (i.e. higher vocational education or university). Physical activity was collected by means of a modified version of the Champs questionnaire ${ }^{18}$. Prior CVD was defined as a history of myocardial infarction, stroke, or vascular surgery (including angioplasty) of coronary, carotid, abdominal aortic, or peripheral arteries based on the Rose questionnaire ${ }^{25}$. Glucose metabolism status was defined according to the WHO 2006 Criteria ${ }^{26}$ by use of a 75 grams oral glucose tolerance test. Both fasting glucose and 2-hour post load glucose concentrations were analysed using a standard enzymatic hexokinase reference method. Serum concentrations of total cholesterol, high-density lipoprotein (HDL) cholesterol, and triglycerides were measured using an automatic analyzer (Beckman Synchron LX20, 
Beckman Coulter Inc., Brea, USA). Glomerular Filtration Rate (GFR) was estimated with the CKD-EPI equation based on the combination of serum creatinine and serum cystatin C. ${ }^{18}$ Body mass index (BMI), waist-to-hip ratio, and medication use were determined as described previously ${ }^{18}$. Exogenous oestrogen medication was defined as either hormone replacement therapy, or the contraceptive pill. Office blood pressure was calculated as the average of at least three blood pressure readings (Omron 705IT, Japan) performed after a minimum of 10 min of seated rest. Hypertension was defined as an office systolic blood pressure $>140 \mathrm{mmHg}$ or as an office diastolic blood pressure $>90 \mathrm{mmHg}$ and/or the use of blood pressure lowering medication.

\section{Statistical analysis}

All analyses were performed with IBM SPSS Statistics Version 22.0 (IBM Corp., Armonk, NY, USA). In order to account for the differences in the distribution of the cfPWV between the sexes, the cfPWV was introduced as a sex-specific Z-score in all models.

Baseline characteristics of the study population were compared between individuals with and without MDD, for normally distributed continuous variables by means of a t-test, for non-normally distributed variables by means of a Mann-Whitney test, and for dichotomous or ordinal variables by means of a chi-squared test. A two-tailed $P$ value of less than 0.05 was considered statistically significant. We used logistic regression analyses to investigate the association between cFPW and MDD. We used negative binomial regression analyses to examine the association between cfPWV and depressive symptoms in order to account for the marked floor effect of the PHQ-9 distribution ${ }^{27}$. Both regression analyses were adjusted for multiple confounders according to the following models: model 1) crude, model 2) age, sex, T2DM, model 3) additionally adjusted for MAP, model 4) additionally adjusted for smoking, alcohol use, BMI, mean heart rate, hypertension, prior CVD and the use of lipid modifying medication. Models were adjusted for T2DM, in order to account for the oversampling of these individuals in the Maastricht Study. Also, T2DM has been associated with both a higher aortic stiffness ${ }^{28}$ and a greater chance of developing MDD ${ }^{29}$, therefore it was considered a confounder. MAP and mean heart rate directly influence stiffness measurements; therefore, they were accounted for in the models. The following cardiovascular risk factors, which have been associated with both arterial stiffening and depression, were also added as confounders: smoking, high alcohol intake, BMI, hypertension, prior CVD and the use of lipid modifying medication. Interactions for age, sex and T2DM were carried out in model 2 and were considered statistically significant with a p-value $<0.10$. 
Table 1: Demographic and clinical characteristics of the study population

\begin{tabular}{|c|c|c|}
\hline & $\begin{array}{l}\text { No Depressive Disorder } \\
\qquad(\mathrm{n}=2656)\end{array}$ & $\begin{array}{l}\text { Major Depressive Disorder } \\
\qquad(\mathrm{n}=101)\end{array}$ \\
\hline \multicolumn{3}{|l|}{ Demographics } \\
\hline Age, years & $59.9 \pm 8.1$ & $58.6 \pm 8.1$ \\
\hline Female sex, \% & 48.6 & 47.5 \\
\hline Education level, low/medium/high, \% & $32 / 29 / 39$ & $49 / 30 / 22$ \\
\hline \multicolumn{3}{|l|}{ Cardio-metabolic risk factors } \\
\hline $\mathrm{BMI}, \mathrm{kg} / \mathrm{m} 2$ & $26.9 \pm 4.3$ & $28.4 \pm 5.1$ \\
\hline Waist-to-hip ratio & $0.94 \pm 0.09$ & $0.96 \pm 0.10$ \\
\hline Glucose metabolism status, NGM/IGM/DM2, \% & $57 / 15 / 27$ & $41 / 10 / 49$ \\
\hline Total cholesterol, mmol/L & $5.24 \pm 1.16$ & \\
\hline HDL cholesterol, mmol/L & $1.52 \pm 0.47$ & $5.06 \pm 1.13$ \\
\hline LDL cholesterol, mmol/L & $3.10 \pm 1.03$ & $1.36 \pm 0.45$ \\
\hline Total to HDL cholesterol ratio & $3.70 \pm 1.18$ & $2.99 \pm 1.14$ \\
\hline Systolic blood pressure, mmHg & $135 \pm 18$ & $4.03 \pm 1.35$ \\
\hline Diastolic blood pressure, $\mathrm{mmHg}$ & $76 \pm 10$ & $136 \pm 18$ \\
\hline Mean arterial pressure, mmHg & $97 \pm 10$ & $77 \pm 11$ \\
\hline Heart rate, beats per minute & $63 \pm 9$ & $97 \pm 11$ \\
\hline Hypertension, \% & 55.2 & $65 \pm 10$ \\
\hline Prior CVD, \% & 16.1 & 58.4 \\
\hline eGFR, mL/min per 1.73 m2 & $88.3 \pm 14.7$ & 21.6 \\
\hline Life style factors & & $87.8 \pm 16.0$ \\
\hline Smoking, never/former/current, \% & $34 / 53 / 13$ & \\
\hline Alcohol use, none/low/high, $\%$ & 17 / 56 / 27 & $22 / 52 / 27$ \\
\hline $\begin{array}{l}\text { Physical activity per week (hours/week), } \\
\text { median [IOR]* }\end{array}$ & $13.3[8.3-18.8]$ & $35 / 43 / 22$ \\
\hline $\begin{array}{l}\text { High-intensity physical activity per week } \\
\text { (hours/week), median [IOR]* }\end{array}$ & $4.5[2.3-8.0]$ & $\begin{array}{c}10.5[6.0-16.5] \\
3.0[0.8-5.5]\end{array}$ \\
\hline \multicolumn{3}{|l|}{ Medication use } \\
\hline Glucose lowering drugs, $\%$ & 21.7 & 42.6 \\
\hline Anti-hypertensive drugs, $\%$ & 38.5 & 46.5 \\
\hline Lipid modifying drugs, \% & 36.2 & 43.6 \\
\hline Antidepressive drugs, $\% * *$ & $6.4(170)$ & $25.7(26)$ \\
\hline \multicolumn{3}{|l|}{ Stiffness related indices } \\
\hline Carotid to femoral PWV, m/s & $8.99 \pm 2.14$ & $9.52 \pm 2.84$ \\
\hline Pulse pressure, mmHg & $51 \pm 10$ & $51 \pm 10$ \\
\hline \multicolumn{3}{|l|}{ Depressive symptoms } \\
\hline PHQ-9 score & $2.0[0.0-4.0]$ & $10.0[7.0-16.0]$ \\
\hline
\end{tabular}

Results are presented as $\%(\mathrm{n})$, mean \pm standard deviation or median [interquartile range].

* Data on physical activity was available in 2409 participants. ${ }^{*}$ Antidepressive drugs according to sex: $8.9 \%$ in nondepressed women vs $4.0 \%$ in non-depressed men and $33.3 \%$ in depressed women vs. $18.9 \%$ in depressed in men 


\section{Results}

\section{General characteristics}

Table 1 shows the general characteristics of the study population according to the presence of MDD. Mean age was $59.8 \pm 8.1$ years, and $48.8 \%$ of participants were women. In total 101 (3.6\%) participants had MDD.

Participants with MDD smoked more often, used less alcohol, and were less physically active than participants without MDD. They had a worse metabolic risk factor profile, including more T2DM, higher BMI, lower HDL cholesterol and higher total cholesterol-to-HDL ratio. Other cardiovascular risk factors, such as the glomerular filtration rate, prior CVD, systolic and diastolic blood pressure, hypertension, the use of blood pressure lowering and lipid modifying medication were not different between individuals with and without MDD. CfPWV was slightly higher in patients with MDD than in those without $(p=0.07)$.

\section{Association of cfPWV with MDD}

CfPWV was statistically significantly associated with MDD after adjustment for age, sex and T2DM: the OR [95\% $\mathrm{Cl}]$ per SD of cfPWV was 1.24 [1.01-1.51]. The association between cfPWV and MDD differed with age (p-interaction 0.043) and sex (p-interaction 0.015); no significant interaction was observed for T2DM ( $p$-interaction 0.22). Analyses were, therefore, stratified according to age (in 5-year age-categories) and sex. Based on the results we stratified the analyses according to the median age of the population $(\leq 60,>60$ years; analyses for the full population, and according to the cut-offs 55,60 and 65 years are shown in Supplemental Table 7).

Table 2: The association between cfPWV and major depressive disorder stratified by age and sex

\begin{tabular}{|c|c|c|c|c|}
\hline & \multicolumn{2}{|c|}{ Age $\leq 60$ years } & \multicolumn{2}{|c|}{ Age $>60$ years } \\
\hline & Men & Women & Men & Women \\
\hline & $(\mathrm{n}=612,27$ cases $)$ & $(n=746,35$ cases $)$ & $(n=800,21$ cases $)$ & ( $n=599,18$ cases $)$ \\
\hline Model 1 & $2.49[1.64-3.78]$ & $1.42[0.95-2.10]$ & $1.41[1.04-1.91]$ & $0.72[0.44-1.19]$ \\
\hline Model 2 & $2.37[1.54-3.64]$ & $1.27[0.84-1.93]$ & $1.37[0.99-1.90]$ & $0.54[0.31-0.94]$ \\
\hline Model 3 & $2.23[1.42-3.52]$ & $1.34[0.84-2.15]$ & $1.33[0.93-1.90]$ & $0.60[0.33-1.08]$ \\
\hline Model 4* & $2.36[1.45-3.84]$ & $1.57[0.93-2.66]$ & $1.03[0.63-1.68]$ & $0.64[0.32-1.31]$ \\
\hline
\end{tabular}

Results are expressed as OR [95\% CI]; per standard deviation higher cfPWV the OR for major depressive disorder was 2.49 [1.64 - 3.78] in men $\leq 60$ years. Model 1 crude; Model 2: adjusted for age, type 2 diabetes; Model 3: additionally adjusted for mean arterial pressure; Model 4: additionally adjusted for heart rate, bmi, lipid medication, smoking, alcohol use prior CVD and hypertension;

* 111 participants (7 cases) equally distributed among the groups had missing values on covariates and dropped out of the analyses 
As shown in Table 2 , in men $\leq 60$ years, cfPWV was significantly associated with MDD, after adjustment for age, T2DM and MAP: OR 2.23 [1.42-3.52]. This OR was slightly higher in the fully adjusted model: 2.36 [1.45-3.84]. In women $\leq 60$ years, cfPWV was not significantly associated with MDD, after adjustment for age, T2DM and MAP: OR 1.34 [0.84-2.15]. The fully adjusted OR remained not significant: 1.57 [0.93-2.66]. In both men and women $>60$ years, cfPWV was not significantly associated with MDD and the fully adjusted ORs were considerably lower in women than in men (Table 2, Figure 2).

\section{Associations of cfPWV with depressive symptoms}

CfPWV was significantly associated with more depressive symptoms, after adjustment for age, sex and T2DM the rate ratio (RR) per 1 SD higher cfPWV was 1.07 [1.01-1.13]. The association between cfPWV and depressive symptoms differed with age ( $p$-interaction 0.036); however, no significant interactions were observed for sex ( $p$-interaction 0.59 ) or T2DM ( $p$-interaction 0.94). For consistency reasons, we stratified the results according to both age and sex.

As shown in Table 3, in men $\leq 60$ years, 1 SD cfPWV was significantly associated with more depressive symptoms after adjustment for age, T2DM and MAP (RR 1.28 [1.09-1.52]). This association remained unchanged in the fully adjusted model (RR 1.28 [1.09-1.52]). In women $\leq 60$ years, 1 SD cfPWV was significantly associated with more depressive symptoms in the crude model (RR 1.13 [1.03-1.23]). This association was attenuated by additional adjustments for age, sex and T2DM, especially by T2DM (RR 1.09 [0.996-1.21]). In both men and women $>60$, cfPWV was not significantly associated with depressive symptoms (Table 3, Figure 3).

Table 3: The association between cfPWV and depressive symptoms stratified by age and sex

\begin{tabular}{|c|c|c|c|c|}
\hline & \multicolumn{2}{|c|}{ Age $\leq 60$ years } & \multicolumn{2}{|c|}{ Age $>60$ years } \\
\hline & $\begin{array}{c}\text { Men } \\
(n=582)\end{array}$ & $\begin{array}{l}\text { Women } \\
(n=722)\end{array}$ & $\begin{array}{c}\text { Men } \\
(\mathrm{n}=761)\end{array}$ & $\begin{array}{c}\text { Women } \\
(n=579)\end{array}$ \\
\hline Model 1 & $1.28[1.11-1.48]$ & $1.13[1.03-1.23]$ & $1.12[1.01-1.23]$ & $1.02[0.93-1.12]$ \\
\hline Model 2 & $1.22[1.04-1.42]$ & $1.09[0.996-1.21]$ & $1.07[0.96-1.20]$ & $0.98[0.90-1.07]$ \\
\hline Model 3 & $1.28[1.09-1.52]$ & $1.12[0.996-1.25]$ & $1.04[0.92-1.17]$ & $1.00[0.90-1.11]$ \\
\hline Model $4^{*}$ & $1.28[1.09-1.52]$ & 1.11 [0.99 - 1.23] & $0.96[0.84-1.08]$ & $1.00[0.90-1.12]$ \\
\hline
\end{tabular}

Results are expressed as rate ratio [ $95 \% \mathrm{CI}$; per standard deviation a higher cfPWV score was associated with higher depressive symptoms. Model 1 crude; Model 2: adjusted for age, type 2 diabetes; Model 3: additionally adjusted for mean arterial pressure; Model 4: additionally adjusted for heart rate, bmi, lipid medication, smoking, alcohol use prior CVD and hypertension; ${ }^{*} 90$ participants equally distributed among the groups had missing values on covariates and dropped out of the analyses 


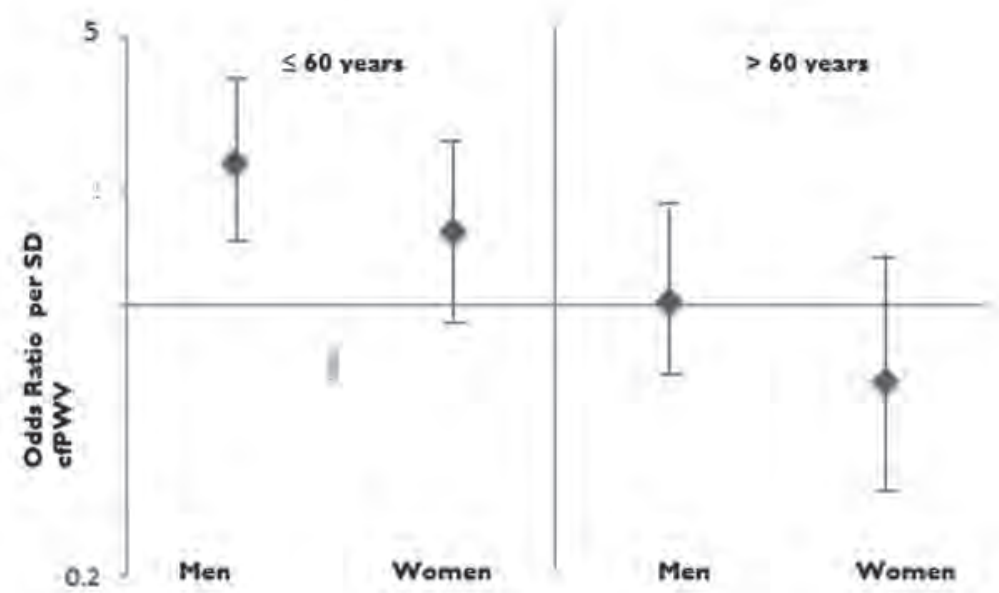

Figure 2: The assocation between cfPWV and major depressive disorder stratified by age and sex. Per SD higher cfPWV, men and women x 60 years have a higher risk of major depressive disorder, although this was not statistically significant for women. The presented ORs were adjusted for age, mean arterial pressure, heart rate, BMI, lipid medication, smoking, prior CVD, alcohol use and hypertension

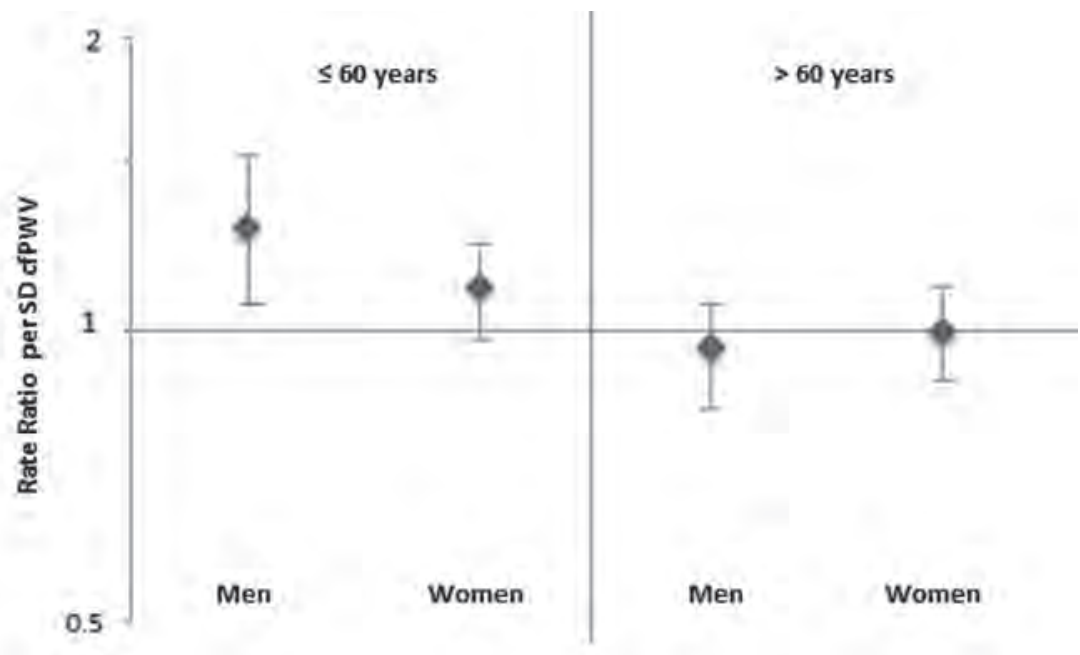

Figure 3: The assocation between cfPWV and depressive symptoms stratified by age and sex. Per SD higher cfPWV, men and women $x 60$ years have a higher risk of depressive symptoms, although this was not statistically significant for women. The presented rat were adjusted for age, type 2 diabetes, mean arterial pressure, heart rate, BMI, lipid medication, smoking, prior CVD, alcohol use and hypertension 


\section{Additional analyses}

When we excluded individuals with extreme cfPWV values ( $\pm 3 S D$, outlier analyses) the association of cfPWV with MDD and depressive symptoms did not materially change. To acknowledge differences in etiology between early and late onset depression, we excluded individuals with a first depression episode before 40 years of age ( $n=407)$; this did not change the results (Supplemental Tables 2 and 3). Also, when we excluded all participants who used anti-depressants $(n=196)$ the results did not materially change (Supplemental Tables 2 and 3). Anti-depressants could be prescribed for both depressive and anxiety disorders; therefore, the models were additionally adjusted for anti-depressant use and

again this did not materially change the results (Supplemental Tables 4 and 5). Also, in order to adjust for various co-morbidities of depression, models were additionally adjusted for antipsychotic, anxiolytic and sleep medication, but this did not change the observed associations. When major and minor depression were combined as an outcome measure, the results did not change (Supplemental Table 6). Lastly, in order to exclude the possibility that T2DM oversampling biased the associations, the analyses were repeated in individuals without T2DM ( $n=2008)$ the results remained unchanged (Supplemental Tables 2 and 3).

When we additionally adjusted the analyses for education level and moderate to vigorous self-reported physical activity (available in $n=2409$ ), the results did not materially change (Supplemental Tables 4 and 5). Lastly, adjustment for the use of exogenous hormone replacement medication did not materially alter the observed ORs and rate ratios in women.

\section{Discussion}

The present study shows that a higher aortic stiffness is associated with a major depressive disorder and the presence of depressive symptoms in men $\leq 60$ years, and to a lesser extent in women of the same age, although not statistically significant. We found no association between aortic stiffness and depression in men and women $>60$ years.

The association in men $\leq 60$ years was independent of other cardiovascular risk factors. Most studies to date have analysed the association in populations $>60$ years. Only the NESDA study ${ }^{9}$ included participants between the ages of 20 and 66 years and observed an association between the augmentation index, which is a composite measure of early arterial wave reflection due to greater arterial stiffness, and MDD. However, the authors did not evaluate whether the association differed according to age due to the relative young sample. Of the studies that included participants $>60$ years, two studies ${ }^{8,12}$ did not find significant associations between aortic stiffness and depression in old participants, one ${ }^{8}$ had a small sample size $(n=46)$ including only few cases $(n=25)$, while the other ${ }^{12}$ only included 
participants from a limited age range (70 to 79 years). Aortic stiffness was associated with both a depressive disorder and depressive symptoms in The Rotterdam Study ${ }^{10}$, and with depressive symptoms in the AGES-Reykjavik Study as diagnostic interviews were not available ${ }^{11}$. The observed associations were, however, relatively small as compared to our results in the $\leq 60$ years group. It may be plausible to assume that the association between aortic stiffness and depression, may be overshadowed in later life by the development of CVD especially in individuals at risk due to greater aortic stiffness. In later life, other factors such as CVD and atherosclerosis, may play a more prominent role in the development of depression than aortic stiffness. In a longitudinal study, Kim et al. ${ }^{30}$ found, for example, that CVD, such as pre-existing heart disease and stroke, but not hypertension, was associated with incident depression in community participants aged 65 years and older. Stroke could directly lead to depression through the direct damage to the cortical and sub-cortical areas of the brain that are involved in mood regulation ${ }^{31}$. In patients with myocardial infarction co-morbid carotid atherosclerosis ${ }^{32}$, rather than aortic stiffness, could accelerate microvascular damage in the mood regulatory regions of the brain and thus lead to vascular depression. Myocardial infarction is, for example, associated with an increased risk of cerebrovascular disease independent of age or hypertension ${ }^{33}$.

The association between aortic stiffness and depression was stronger in men than in women $\leq 60$ years. Although, the association was only statistically significant in middleaged men, we cannot rule out the presence of an association in middle-aged women. Only a few previous large cross-sectional studies carried out interaction analyses for sex ${ }^{10-}$ ${ }^{12}$, and none reported any significant differences. However, the mean age of these study populations was $\geq 70$ years, while our observed sex-interaction occurred in patients $\leq 60$ years of age. A possible explanation for the interaction might be that in women $\leq 60$ years, hormonal fluctuations as seen during the menstrual cycle and the perimenopause, rather than aortic stiffness could predispose women $\leq 60$ years to depression ${ }^{34}$. Reproductive hormones are also thought to have a protective effect on the vasculature, especially prior to menopause $\mathrm{e}^{15,16}$ thus further diminishing the association of PWV with depression in women. Exogenous hormone supplementation such as hormone replacement therapy and contraception, could also be a confounder, but in our study such medication was infrequent and did not affect the observed associations. An alternative explanation may include the large heterogeneity of a depressive disorder, which might result in important differences of this diagnosis among men and women. Also, the possibility that the described sex differences are due to the play of chance cannot be ruled out.

Aortic stiffness was associated more strongly with MDD than with depressive symptoms. This could be attributed to the misclassification of depressive symptoms as MDD by the PHQ-910,24. Furthermore, the association of aortic stiffness with depressive symptoms may 
not be linear: it could be stronger in individuals, who fulfil the diagnostic criteria for MDD. This threshold of severity could be captured better by a diagnostic instrument, such as the MINI. Finally, the weaker association of aortic stiffness with depressive symptoms could also explain the lack of an interaction with sex in these analyses.

Multiple mechanisms could explain the association of aortic stiffness and depression. First, according to the vascular depression hypothesis, cardiovascular risk factors, such as arterial stiffness, may lead to the accumulation of cerebral small vessel lesions in the mood regulatory centres of the brain ${ }^{35}$, which may result in the development of depression ${ }^{5,6}$. A recent study by van Sloten et al. ${ }^{8}$ indeed showed that the presence of supra-tentorial cerebral white matter hyperintensities (WMH) and subcortical infarcts together explained part of the association between PWV and depression. Second, arterial stiffness may lead to greater oscillations in wall sheer stress, which may induce endothelial dysfunction as well as the production of low grade inflammatory markers by the endothelium ${ }^{36}$. Endothelial dysfunction could lead to depression through a disturbance of the process of neurogenesis ${ }^{37,38}$, through small vessel disease ${ }^{39}$, or speculatively through decreased cerebrovascular reactivity ${ }^{40}$. Systemic low grade inflammation, on the other hand, could, via multiple pathways, stimulate the production of pro-inflammatory markers by microglial cells in the brain, which could induce symptoms of depression ${ }^{41-43}$. Fourth, other factors, such as autonomic and hypothalamic-pituitary-adrenal dysfunction may underlie both arterial stiffness ${ }^{44,45}$ and depression ${ }^{46,47}$. Finally, behavioural risk factors, such as high alcohol intake, smoking, and physical inactivity are bi-directionally associated with depression ${ }^{3,48-50}$ and may also lead to arterial stiffening ${ }^{51-53}$, thus confounding the association. However, in our study additional adjustments for alcohol use, smoking, and physical activity did not materially alter the results.

\section{Limitations}

The strengths of this study include the large sample size, the large number of depression cases, and the advanced phenotyping, including the use of the gold standard method to assess aortic stiffness, the assessment of depression with the help of a questionnaire as well as a diagnostic interview, and the measurement of many potential confounding factors, which could be accounted for in the fully adjusted models. However, due to the crosssectional design, reversed causation cannot be ruled out. For example, treatment for MDD has been shown to improve arterial stiffness ${ }^{54}$. Also, aortic stiffness has been associated with a current, but not a remitted depression ${ }^{9}$. Additionally, misclassification of MDD could have occured. Most participants who used anti-depressants (87\%) did not have MDD. We could not discriminate between anti-depressants prescribed for anxiety, depression, or 
neuropathic pain, since indications were not recorded. Yet, the exclusion of participants who used anti-depressants ( $n=196)$, or additional adjustments for antidepressant use, did not alter our results. Selection bias may have further influenced our results, as participants who suffer from severe MDD were unlikely to be included in the study. Therefore, our results may be an underestimation of the actual association. Also, the individuals with missing data on covariates were excluded in the final models. However, the percentage of missing data was fairly small (4\%), therefore imputation of missing data is unlikely to influence the results ${ }^{55}$. Further, above 60 years, competing risk could have resulted in an underrepresentation of depression cases, as participants with greater aortic stiffness are at increased fatal CVD risk. Although we have adjusted for multiple confounders, residual confounding due to other chronic medical conditions, such as asthma, COPD, cancer or arthritis, which may be comorbid to depression ${ }^{61}$ and, which could lead to arterial stiffening, cannot be ruled out. Lastly, the association of CVD markers with depression may differ according to race or ethnicity ${ }^{57-60}$, however, our study population mainly consists of Caucasians, therefore we could not investigate such effects.

\section{Conclusion}

This study shows that a higher aortic stiffness is associated with MDD and depressive symptoms in middle-aged men and to a lesser extent in middle-aged women, while this association was not observed in old age. 
Supplemental Table 1: Baseline characteristics of participants with available and with missing data on covariates

\begin{tabular}{|c|c|c|c|c|}
\hline & $\begin{array}{l}\text { Available Data } \\
\qquad(\mathrm{n}=2646)\end{array}$ & $\begin{array}{l}\text { Missing Data } \\
\quad(n=111)\end{array}$ & Missing & p-value \\
\hline \multicolumn{5}{|l|}{ Demographics } \\
\hline Age, years & $59.7 \pm 8.1$ & $61.4 \pm 8.2$ & 0 & 0.034 \\
\hline Female sex, $\%$ & 48.4 & 57.7 & 0 & 0.056 \\
\hline Education level, low/medium/high, \% & $32.4 / 29.1 / 38.5$ & $30.0 / 31.4 / 38.6$ & 57 & 0.812 \\
\hline \multicolumn{5}{|l|}{ Cardio-metabolic risk factors } \\
\hline $\mathrm{BMI}, \mathrm{kg} / \mathrm{m} 2$ & $27.0 \pm 4.3$ & $27.2 \pm 4.9$ & 2 & 0.572 \\
\hline Waist-to-hip ratio & $0.94 \pm 0.09$ & $0.94 \pm 0.11$ & 1 & 0.734 \\
\hline $\begin{array}{l}\text { Glucose metabolism status, } \\
\text { NGM/IGM/DM2, \% }\end{array}$ & $58 / 15 / 27$ & $49 / / 10 / 41$ & 0 & 0.009 \\
\hline Total cholesterol, mmol/L & $5.24 \pm 1.16$ & $5.11 \pm 1.21$ & 0 & 0.249 \\
\hline HDL cholesterol, mmol/L & $1.52 \pm 0.48$ & $1.44 \pm 0.44$ & 0 & 0.092 \\
\hline LDL cholesterol, mmol/L & $3.10 \pm 1.04$ & $3.06 \pm 1.01$ & 0 & 0.653 \\
\hline Total to HDL cholesterol ratio & $3.71 \pm 1.19$ & $3.77 \pm 1.15$ & 0 & 0.589 \\
\hline Systolic blood pressure, mmHg & $127 \pm 14$ & $129 \pm 16$ & 1 & 0.130 \\
\hline Diastolic blood pressure, mmHg & $76 \pm 7$ & $76 \pm 7$ & 0 & 0.579 \\
\hline Mean arterial pressure, mmHg & $97 \pm 10$ & $98 \pm 12$ & 0 & 0.138 \\
\hline Heart rate, beats per minute & $63 \pm 9$ & $63 \pm 8$ & 0 & 0.392 \\
\hline Hypertension, \% & 38.5 & 44.4 & 3 & 0.215 \\
\hline Prior CVD, \% & 16.4 & 9.1 & 89 & 0.358 \\
\hline eGFR, mL/min per 1.73 m2 & $88.4 \pm 14.7$ & $85.8 \pm 17.5$ & 0 & 0.063 \\
\hline \multicolumn{5}{|l|}{ Life style factors } \\
\hline Smoking, never/former/current, \% & $33.6 / 52.8 / 13.6$ & $37.7 / 47.5 / 14.8$ & 50 & 0.732 \\
\hline Alcohol use, none/low/high, $\%$ & 18.0/55.0/27.0 & $17.9 / 60.7 / 21.4$ & 55 & 0.545 \\
\hline \multicolumn{5}{|l|}{ Medication use } \\
\hline Glucose lowering drugs, $\%$ & 21.8 & 36.1 & 3 & $<0.001$ \\
\hline Anti-hypertensive drugs, \% & 38.5 & 44.4 & 3 & 0.215 \\
\hline Lipid modifying drugs, $\%$ & 36.2 & 39.8 & 3 & 0.450 \\
\hline Antidepressive drugs, $\%$ & 7.0 & 11.1 & 3 & 0.100 \\
\hline \multicolumn{5}{|l|}{ Stiffness related indices } \\
\hline Carotid to femoral PWV, m/s & $8.98 \pm 2.13$ & $9.67 \pm 2.87$ & 0 & 0.014 \\
\hline Pulse pressure, $\mathrm{mmHg}$ & $51 \pm 10$ & $53 \pm 11$ & 1 & 0.090 \\
\hline Major depression disorder, \% & 3.6 & 6.3 & 0 & 0.130 \\
\hline
\end{tabular}

Results are presented as $\%(\mathrm{n})$, mean \pm standard deviation or median [interquartile range]. 
Supplemental Table 2: The association between cfPWV and a major depression disorder stratified by age and sex in the full population, after the exclusion of participants with early onset depression, after the exclusion of participants with anti-depression medication, and after the exclusion of participants with type 2 diabetes

\begin{tabular}{|c|c|c|c|c|}
\hline \multicolumn{5}{|c|}{ Full population } \\
\hline & \multicolumn{2}{|c|}{ Age $\leq 60$ years } & \multicolumn{2}{|c|}{ Age $>60$ years } \\
\hline & Men & Women & Men & Women \\
\hline & ( $n=612,27$ cases $)$ & ( $n=746,35$ cases $)$ & ( $n=800,21$ cases $)$ & ( $n=599,18$ cases) \\
\hline Model 4 & $2.36[1.45-3.84]$ & $1.57[0.93-2.66]$ & $1.03[0.63-1.68]$ & $0.64[0.32-1.31]$ \\
\hline \multicolumn{5}{|c|}{ Participants with early onset depression excluded } \\
\hline & Men & Women & Men & Women \\
\hline & ( $n=517,18$ cases $)$ & ( $n=585,24$ cases $)$ & ( $n=729,15$ cases $)$ & ( $n=519,14$ cases) \\
\hline Model 4 & $1.79[0.89-3.63]$ & $1.51[0.79-2.91]$ & $1.20[0.68-2.11]$ & $0.81[0.38-1.71]$ \\
\hline \multicolumn{5}{|c|}{ Participants with anti-depressive medication excluded } \\
\hline & Men & Women & Men & Women \\
\hline & ( $\mathrm{n}=572,17$ cases $)$ & ( $n=674,28$ cases) & ( $n=768,15$ cases $)$ & ( $n=544,15$ cases) \\
\hline Model 4 & $2.39[1.35-4.23]$ & $1.50[0.81-2.78]$ & $1.17[0.69-1.96]$ & $0.67[0.31-1.45]$ \\
\hline \multicolumn{5}{|c|}{ Participants with type 2 diabetes excluded } \\
\hline & Men & Women & Men & Women \\
\hline & ( $\mathrm{n}=427,9$ cases) & ( $n=620,25$ cases) & ( $\mathrm{n}=458,7$ cases) & ( $n=436,6$ cases $)$ \\
\hline Model 4* & $2.48[1.06-5.78]$ & $1.54[0.82-2.88]$ & $0.96[0.33-2.83]$ & $0.33[0.08-1.44]$ \\
\hline
\end{tabular}

Results are expressed as OR [95\% Cl] per standard deviation higher cfPWV. Model 4: adjusted for age, type 2 diabetes, mean arterial pressure, heart rate, bmi, lipid medication, smoking, alcohol use prior CVD and hypertension. * Model 4 was not adjusted for type 2 diabetes 
Supplemental Table 3: The association between cfPWV and depressive symptoms stratified by age and sex in the full population, after the exclusion of participants with early onset depression, after the exclusion of participants with anti-depression medication, and after the removal of participants with type 2 diabetes

\begin{tabular}{|c|c|c|c|c|}
\hline \multicolumn{5}{|c|}{ Full population (as in article) } \\
\hline & \multicolumn{2}{|c|}{ Age $\leq 60$ years } & \multicolumn{2}{|c|}{ Age $>60$ years } \\
\hline & $\begin{array}{c}\text { Men } \\
(n=582)\end{array}$ & $\begin{array}{l}\text { Women } \\
(\mathrm{n}=722)\end{array}$ & $\begin{array}{c}\text { Men } \\
(n=761)\end{array}$ & $\begin{array}{c}\text { Women } \\
(n=579)\end{array}$ \\
\hline Model 4 & $1.28[1.09-1.52]$ & $1.11[0.99-1.23]$ & $0.96[0.84-1.08]$ & $1.00[0.90-1.12]$ \\
\hline \multicolumn{5}{|c|}{ Participants with early onset depression removed } \\
\hline & $\begin{array}{c}\text { Men } \\
(n=480)\end{array}$ & $\begin{array}{l}\text { Women } \\
(n=546)\end{array}$ & $\begin{array}{c}\text { Men } \\
(n=660)\end{array}$ & $\begin{array}{l}\text { Women } \\
(n=482)\end{array}$ \\
\hline Model 4 & $1.30[1.07-1.57]$ & $1.10[0.97-1.27]$ & $0.96[0.84-1.09]$ & $1.02[0.91-1.14]$ \\
\hline \multicolumn{5}{|c|}{ Participants with anti-depressive medication removed } \\
\hline & $\begin{array}{c}\text { Men } \\
(n=528)\end{array}$ & $\begin{array}{l}\text { Women } \\
(\mathrm{n}=632)\end{array}$ & $\begin{array}{c}\text { Men } \\
(n=693)\end{array}$ & $\begin{array}{l}\text { Women } \\
(n=503)\end{array}$ \\
\hline Model 4 & $1.20[1.01-1.42]$ & $1.13[0.997-1.26]$ & $-0.05[0.95-1.08]$ & $1.01[0.91-1.12]$ \\
\hline \multicolumn{5}{|c|}{ Participants with type 2 diabetes removed } \\
\hline & $\begin{array}{c}\text { Men } \\
(\mathrm{n}=344)\end{array}$ & $\begin{array}{l}\text { Women } \\
(n=465)\end{array}$ & $\begin{array}{c}\text { Men } \\
(\mathrm{n}=388)\end{array}$ & $\begin{array}{l}\text { Women } \\
(\mathrm{n}=357)\end{array}$ \\
\hline Model 4* & $1.27[1.03-1.57]$ & $1.12[0.99-1.28]$ & $0.94[0.79-1.12]$ & $1.02[0.90-1.15]$ \\
\hline
\end{tabular}

Results are expressed as rate ratio $[95 \% \mathrm{Cl}]$ per standard deviation higher cfPWV. Model 4: adjusted for age, type 2 diabetes, mean arterial pressure, heart rate, bmi, lipid medication, smoking, alcohol use prior CVD and hypertension. *Model 4 was not adjusted for type 2 diabetes. 
Supplemental Table 4: the association between cfPWV and major depressive disorder stratified by age and sex in the fully adjusted model as well as after additional adjustments for anti-depressive medication, education level, and moderate to vigorous physical activity

\begin{tabular}{|c|c|c|c|c|}
\hline & \multicolumn{2}{|c|}{ Age $\leq 60$ years } & \multicolumn{2}{|c|}{ Age $>60$ years } \\
\hline & $\begin{array}{c}\text { Men } \\
\text { ( } n=612,27 \text { cases })\end{array}$ & $\begin{array}{c}\text { Women } \\
(n=746,35 \text { cases })\end{array}$ & $\begin{array}{c}\text { Men } \\
(n=800,21 \text { cases }) \\
\end{array}$ & $\begin{array}{c}\text { Women } \\
(\mathrm{n}=599,18 \text { cases })\end{array}$ \\
\hline Model 4 & $2.36[1.45-3.84]$ & $1.57[0.93-2.66]$ & $1.03[0.63-1.68]$ & $0.64[0.32-1.31]$ \\
\hline $\begin{array}{l}\text { Model } 4 \text { + anti-depressive } \\
\text { medication }\end{array}$ & $2.21[1.35-3.62]$ & $1.54[0.91-2.61]$ & $0.94[0.57-1.57]$ & $0.64[0.31-1.29]$ \\
\hline Model 4 + educational level & $2.25[1.37-3.69]$ & $1.57[0.91-2.71]$ & $1.01[0.62-1.65]$ & $0.62[0.31-1.27]$ \\
\hline $\begin{array}{l}\text { Model } 4+\text { moderate to } \\
\text { vigurous physical activity* }\end{array}$ & $2.69[1.4-4.99]$ & $1.53[0.85-2.75]$ & $1.05[0.62-1.78]$ & $0.74[0.26-2.07]$ \\
\hline
\end{tabular}

Results are expressed as OR [95\% Cl] per standard deviation higher cfPWV. Model 4: adjusted for age, type 2 diabetes, mean arterial pressure, heart rate, bmi, lipid medication, smoking, alcohol use prior CVD and hypertension

* 429 participants ( 48 cases), mostly in the women $\leq 60$ years and $>60$ years categories had missing values and dropped out of the analyses

Supplemental Table 5: the association between cfPWV and depressive symptoms stratified by age and sex in the fully adjusted model as well as after additional adjustments for anti-depressive medication, education level, and moderate to vigorous physical activity

\begin{tabular}{lcccc}
\hline & \multicolumn{2}{c}{ Age $\leq 60$ years } & \multicolumn{2}{c}{ Age >60 years } \\
\cline { 2 - 5 } & $\begin{array}{c}\text { Men } \\
(\mathrm{n}=582)\end{array}$ & $\begin{array}{c}\text { Women } \\
(\mathrm{n}=722)\end{array}$ & $\begin{array}{c}\text { Men } \\
(\mathrm{n}=761)\end{array}$ & $\begin{array}{c}\text { Women } \\
(\mathrm{n}=579)\end{array}$ \\
\hline Model 4 & $\mathbf{1 . 2 8}[\mathbf{1 . 0 9 - 1 . 5 2 ]}$ & $1.11[0.99-1.23]$ & $0.96[0.84-1.08]$ & $1.00[0.90-1.12]$ \\
\hline $\begin{array}{l}\text { Model 4 + anti-depressive } \\
\text { medication }\end{array}$ & $\mathbf{1 . 2 3 [ 1 . 0 5 - \mathbf { 1 . 4 5 } ]}$ & $1.10[0.99-1.23]$ & $0.95[0.84-1.07]$ & $1.00[0.91-1.10]$ \\
\hline Model 4 + educational level & $\mathbf{1 . 2 7 [ 1 . 0 8 - \mathbf { 1 . 4 9 } ]}$ & $1.08[0.97-1.22]$ & $0.96[0.85-1.08]$ & $1.01[0.91-1.12]$ \\
\hline $\begin{array}{l}\text { Model 4 + moderate to } \\
\text { vigurous physical activity* }\end{array}$ & $\mathbf{1 . 2 8}[\mathbf{1 . 0 9 - 1 . 5 1 ]}$ & $1.08[0.97-1.22]$ & $0.95[0.84-1.08]$ & $1.02[0.92-1.13]$ \\
\hline
\end{tabular}

Results are expressed as rate ratio $[95 \% \mathrm{Cl}$ ] per standard deviation higher cfPWV. Model 4: adjusted for age, type 2 diabetes, mean arterial pressure, heart rate, bmi, lipid medication, smoking, alcohol use prior CVD and hypertension *153 participants, equally distributed among the groups, had missing values on covariates and dropped out of the analyses 
Supplemental Table 6: Association between cfPWV and minor and major depressive disorder stratified by age and sex

\begin{tabular}{|c|c|c|c|c|}
\hline & \multicolumn{2}{|c|}{ Age $\leq 60$ years } & \multicolumn{2}{|c|}{ Age $>60$ years } \\
\hline & Men & Women & Men & Women \\
\hline & $(n=612,43$ cases $)$ & $(n=746,46$ cases $)$ & $(\mathrm{n}=800,31$ cases $)$ & $(\mathrm{n}=599,31$ cases $)$ \\
\hline Model 4 & $1.99[1.40-2.83]$ & $1.35[0.95-1.92]$ & $1.31[0.99-1.71]$ & $0.95[0.68-1.32]$ \\
\hline Model 4 & $1.83[1.26-2.65]$ & $1.17[0.80-1.70]$ & $1.25[0.93-1.68]$ & $0.81[0.57-1.17]$ \\
\hline Model 4 & $1.91[1.28-2.84]$ & $1.16[0.76-1.77]$ & $1.16[0.84-1.60]$ & $0.86[0.58-1.28]$ \\
\hline Model $4^{*}$ & $1.84[1.22-2.77]$ & $1.28[0.80-2.05]$ & $0.99[0.64-1.52]$ & $0.95[0.61-1.47]$ \\
\hline
\end{tabular}

Results are expressed as $\mathrm{OR}[95 \% \mathrm{Cl}]$; per standard deviation increase in cfPWV the $\mathrm{OR}$ for major and minor depressive disorder was 1.99 [1.40 - 2.83] in men below 60 years of age. Model 1 crude; Model 2: adjusted for age, type 2 diabetes; Model 3: additionally adjusted for mean arterial pressure; Model 4: additionally adjusted for heart rate, bmi, lipid medication, smoking and alcohol use, hypertension and prior CVD.

* 119 participants ( 15 cases) equally distributed among the groups had missing values on covariates and dropped out of the analyses

Supplemental Table 7: The association of aortic stiffness and a major depressive disorder in the full population and according to the following age cut-offs: 55,60 and 65 years

\begin{tabular}{|c|c|c|c|c|c|c|c|}
\hline & $\begin{array}{c}\text { Total } \\
\text { population } \\
\text { ( } n=2757 \\
101 \text { cases) }\end{array}$ & $\begin{array}{c}\text { Age } \leq 55 \\
(n=785 \\
35 \text { cases })\end{array}$ & $\begin{array}{l}\text { Age }>55 \\
(n=1972 \\
66 \text { cases })\end{array}$ & $\begin{array}{l}\text { Age } \leq 60 \\
(n=1358 \\
62 \text { cases })\end{array}$ & $\begin{array}{l}\text { Age }>60 \\
(n=1399 \\
39 \text { cases })\end{array}$ & $\begin{array}{l}\text { Age } \leq 65 \\
(n=2014 \\
79 \text { cases })\end{array}$ & $\begin{array}{c}\text { Age }>65 \\
(n=743 \\
22 \text { cases })\end{array}$ \\
\hline Model 1 & $\begin{array}{c}1.23 \\
{[1.03-1.46]}\end{array}$ & $\begin{array}{c}1.84 \\
{[1.23-2.73]}\end{array}$ & $\begin{array}{c}1.21 \\
{[0.99-1.49]}\end{array}$ & $\begin{array}{c}1.84 \\
{[1.40-2.41]}\end{array}$ & $\begin{array}{c}1.11 \\
{[0.85-1.46]}\end{array}$ & $\begin{array}{c}1.50 \\
{[1.21-1.85]}\end{array}$ & $\begin{array}{c}0.95 \\
{[0.65-1.39]}\end{array}$ \\
\hline Model 2 & $\begin{array}{c}1.24 \\
{[1.01-1.51]}\end{array}$ & $\begin{array}{c}1.57 \\
{[1.02-2.41]}\end{array}$ & $\begin{array}{c}1.18 \\
{[0.94-1.48]}\end{array}$ & $\begin{array}{c}1.68 \\
{[1.26-2.25]}\end{array}$ & $\begin{array}{c}0.98 \\
{[0.72-1.31]}\end{array}$ & $\begin{array}{c}1.52 \\
{[1.20-1.92]}\end{array}$ & $\begin{array}{c}0.80 \\
{[0.53-1.21]}\end{array}$ \\
\hline Model 3 & $\begin{array}{c}1.23 \\
{[0.99-1.53]}\end{array}$ & $\begin{array}{c}1.38 \\
{[0.84-2.27]}\end{array}$ & $\begin{array}{c}1.23 \\
{[0.96-1.57]}\end{array}$ & $\begin{array}{c}1.68 \\
{[1.22-2.32]}\end{array}$ & $\begin{array}{c}0.99 \\
{[0.72-1.37]}\end{array}$ & $\begin{array}{c}1.50 \\
{[1.15-1.94]}\end{array}$ & $\begin{array}{c}0.85 \\
{[0.55-1.32]}\end{array}$ \\
\hline Model $4^{*}$ & $\begin{array}{c}1.20 \\
{[0.94-1.53]}\end{array}$ & $\begin{array}{c}1.60 \\
{[0.92-2.78]}\end{array}$ & $\begin{array}{c}1.14 \\
{[0.85-1.51]}\end{array}$ & $\begin{array}{c}1.79 \\
{[1.27-2.53]}\end{array}$ & $\begin{array}{c}0.83 \\
{[0.57-1.23]}\end{array}$ & $\begin{array}{c}1.33 \\
{[0.98-1.80]}\end{array}$ & $\begin{array}{c}1.04 \\
{[0.64-1.69]}\end{array}$ \\
\hline
\end{tabular}

Results are expressed as OR [95\% CI]. Per standard deviation higher cfPWV the OR for major depressive disorder was 1.23 [1.03-1.46] in the total population. Model 1: crude; Model 2: adjusted for age, type 2 diabetes; Model 3: additionally adjusted for mean arterial pressure; Model 4: additionally adjusted for heart rate, bmi, lipid medication, smoking, alcohol use prior CVD and hypertension;

* 111 participants (7 cases) equally distributed among the groups had missing values on covariates and dropped out of the analyses 


\section{References}

1 Van Dooren FEP, Nefs G, Schram MT, et al. Depression and risk of mortality in peope with diabetes mellitus: a systematic review and meta-analysis. Plos One 2013; 8(3): 1210-25

2 Pan A, Sun Q, Okereke Ol, et al. Depression and risk of stroke morbidity and mortliaty; a meta-analysis and systematic review. JAMA 2011; 306:1241-9

3 Nicholson A, Kuper H, Hemingway H. Depression as an aetiologic and prognostic factor in coronary heart disease: a metaanalysis of 6362 events among 146538 participants in 54 observational studies. Eur Heart J 2006; 27: 2763 - 2774.

4 Mitchell GF. Arterial Stiffness and Hypertension. Hypertension 2014; 64: 13-18.

5 Alexopoulos GS, Meyers BS, Young RC, et al. Vascular depression hypothesis. Arc Gen Psychiatry 1997; 54: $915-922$

6 Krishnan KR, Hays JC, Blazer DG. MRI-defined vascular depression. Am J Psychiatry 1997; 154: 497-501.

7 Van Sloten TT, Protogeru AD, Henry RM, Schram MT, Launer LJ, Stehouwer CD. Association between arterial stiffness, cerebral small vessel disease and cognitive impairment: A systematic review and meta-analysis. Neurosci Biobehav Rev. 2015; 53:121-30

8 Paranthaman R, Greenstein AS, Burns AS, et al. Vascular function in older adults with depressive disorder. Biol Psychiatry 2010; 68: 133-139.

9 Seldenrijk A, van Hout HP, van Marwijk HW, et al. Depression, anxiety, and arterial stiffness. Biol Psychiatry 2011; 69: 795-803.

10 Tiemeier H, Breteler MM, van Popele NM, et al. Late-life depression is associated with arterial stiffness: a population-based study. J Am Geriatr Soc 2003; 51:1105-1110

11 Van Sloten TT, Mitchell GF,Sigurdsson S, et al. Associations between arterial stiffness, depressive symptoms and cerebral small vessel disease: cross-sectional findings from the AGES-Reykjavik Study. J Psychiatry Neurosci. 2016; 14 (3): $162-8$

12 Lewis TT, Sutto-Tyrell K, Penninx BW, et al. Race, Psychosocial Factors, and Arortic Pulse Wave Velocity: The Health, Aging, and Body Coposition Study. J Gerontol A Biol Sci Med Sci. 2010 ; 65(10): 1079-1085

13 Pan A, Sun Q, Okereke OI, et al. Depression and risk of stroke morbidity and mortality: a meta-analysis and systematic review. JAMA 2011;306:1241-9.

14 Salaycik KJ, Kelly-Hayes M, Beiser A, et al. Depressive symptoms and risk of stroke: the Framingham Study. Stroke. 2007; 38(1):16-21

15 Franklin SS, Gustin W, Wong ND, et al. Hemodynamic patterns of age-related changes in blood pressure. The Framingham Heart Study. Circulation. 1997; 96: 308-315;

16 Segers P, Rietzschel ER, De Buyzere ML, et al. Noninvasive (input) impedance, pulse wave velocity, and wave reflection in healthy middle-aged men and women. Hypertension 2007; 49: 1248-1255

17 Weissman MM, Bland R, Joyce PR, et al. Sex differences in rates of depression: cross-national perspectives. J. Affect. Disord. 1993; 29: 77-84

18 Schram MT, Sep SJ, van der Kallen CJ, et al. The Maastricht Study: an extensive phenotyping study on determinants of type 2 diabetes, its complications and its comorbidities.Eur J Epidemiol.2014;29(6):439-51.

19 Van Bortel LM, Laurent S, Boutouyrie P, et al. Expert consensus document on the measurement of aortic stiffness in daily practice using carotid-femoral pulse wave velocity.Journal of hypertension.2012;30:445-8. 
20 Sheehan DV, Lecrubier Y, Sheehan KH, et al. The Mini-International Neuropsychiatric Interview (M.I.N.I.): the development and validation of a structured diagnostic psychiatric interview for DSM-IV and ICD-10. J Clin Psychiatry. 1998; 59(Suppl 20): 22-33.

21 American Psychiatric Association: Diagnostic and Statistical Manual of Mental Disorders, Fourth Edition, Text Revision. Washington, DC, 2000.

22 Korten NC, Comijs HC, Lamers F et al. Early and late onset depression in young and middle aged adults: differential symptomatology, characteristics and risk factors? J Affect Disord 2012; 138(3): 259-67.

23 Kroenke K, Spitzer RL, Williams JB. The PHQ-9: validity of a brief depression severity measure. J Gen Intern Med. 2001; 16(9): 606-13.

24 Janssen EP, Köhler S, Stehouwer CD, Schaper NC, Dagnelie PC, Sep SJ, Henry RM, van der Kallen CJ, Verhey FR, Schram MT. The Patient Health Questionnaire-9 as a Screening Tool for Depression in Individuals with Type 2 Diabetes Mellitus: The Maastricht Study. J Am Geriatr Soc. 2016 Nov;64(11):e201-e206.

25 Leng GC, Fowkes FG. The Edinburgh Claudication Questionnaire: an improved version of the WHO/Rose Questionnaire for use in epidemiological surverys. J clin Epidemiol. 1992; 45(10): 1101-9

26 WHO. Definition and Diagnosis of diabetes mellitus and intermediate hyperglycemia. 2006. www.whoint/diabetes/ publications/Definition\%20and\%20diagnosis\%20of\%20diabetes_new.pdf.

27 Sachdev PS, Parslow RA, Lux O, et al. Relationship of homocysteine, folic acid and vitamin B12 with depression in a middle-aged community sample. Psychol Med 2005; 35(4): 529-38.

28 Schram MT, Henry RM, van Dijk RA et al; Increased central artery stiffness in impaired glucose metabolism and type 2 diabetes: the Hoorn Study. Hypertension 2004; 43:176-81.

29 Mezuk B, Eaton WW, Albrecht S, Golden SH. Depression and type 2 diabetes over the lifespan: a meta-analysis. Diabetes Care 2008;31:2383-2390.

30 Kim JM, Stewart R, Sung-Wan K, et al. Vascular risk factors and incident late-life depression in a Korean population. Br J Psychiatry. 2006; 189: 26-30.

31 Robinson RG, Jorge RE. Post-Stroke Depression: A Review. Am J Psychiatry 2015.173(3):221-31.

32 Hess DC, D’Cruz IA, Adams RJ, et al. Coronary artery disease, myocardial infarction, and brain embolism. Neurol Clin. 1993;11:399-417.

33 Witt BJ, Brown RD, Jr, Jacobsen SJ, et al. A community-based study of stroke incidence after myocardial infarction. Ann Intern Med. 2005;143:785-92.

34 Gordon JL, Girdler SS. Hormone replacement therapy in the treatment of perimenopausal depression. Curr Psychiatry Rep 2014; 16(12) 517- 525.

35 Mitchell GF, van Buchem MA, Sigurdsson S, et al. Arterial stiffness, pressure and flow pulsatility and brain structure and function: the Age,Gene/Environment Susceptibility-Reykjavik study.Brain2011;134:3398-407

36 Chappell DC, Varner SE, Nerem RM, et al. Oscillatory shear stress stimulates adhesion molecule expression in cultured human endothelium. Circ Res 1998; 82(5): 532-539.

37 Shen Q, Goderie SK, Jin L, et al. Endothelial cells stimulate self-renewal and expand neurogenesis of neural stem cells. Science 2004; 304: 1338-1340.

38 Zhao C, Deng W, Gage FH. Mechanisms and functional implications of adult neurogenesis. Cell 2008; 132 : 645-660. 
39 Hoth KF, Tate DF, Poppas A, et al. Endothelial Function and White Matter Hyperintensities in Older Adults With Cardiovascular Disease. Stroke 2007; 38(2): 308-312.

40 Lemke H, de Castro AG, Schlattmann P, et al. Cerebrovascular reactivity over time-course - from major depressive disorder to remission. J Psychiatr Res 2010; 44: 132-136.

41 Dantzer R, O'Conner JC, Freund GG, et al. From inflammation to sickness and depression: when the immune system subjugates the brain. Nat Rev Neurosci 2008; 9: 45-56

42 Alexopoulos GS, Morimoto SS. The inflammation hypothesis in geriatric depression. Int J Geriatr Psychiatry. 2011;26(11):1109-1118.

43 Miller AH, Maletic V, Raison CL. Inflammation and its discontents: The role of cytokines in the pathophysiology of major depression. Biol Psychiatry. 2009;65(9):732-741.

44 Van Ittersum FJ, Schram MT, van der Heijden-Spek JJ, et al. Autonomic nervous function, arterial stiffness and blood pressure in patients with Type I diabetes mellitus and normal urinary albumin excretion. J Hum Hypertens. 2004; 18(11):761-8.

45 Himeno A, Satoh-Asahara N, Usui T, et al. Salivary cortisol levels are associated with outcomes of weight reduction therapy in obese Japanese patients. Metabolism. 2012; 61(2): 255-61.

46 Rottenberg J. Cardiac vagal control in depression: A critical analysis. Biol Psychol 2007; 74: $200-211$.

47 Bremmer MA, Deeg DJ, Beekman AT, et al. Major depression in late life is associated with both hypo- and hypercortisolemia. 2007; 62(5): 479-86.

48 Luijendijk HJ, Stricker BH, Hofman A, et al. Cerebrovascular risk factors and incident depression in communitydwelling elderly. Act Psychiatr Scand. 2008; 118(2): 139-48.

49 Chang SC, Pan A, Kawachi I, et al. Risk factors for late-life depression: A prospective cohort study among older women. Prev Med. 2016; 91:144-151.

50 Adamson BC, Yang Y, Motl RW. Association between compliance with physical activity guidelines, sedentary behavior and depressive symptoms. Prev Med 2016; 91: 152-157.

51 Saini S, Saxena Y, Gupta R. Arterial Compliance and Autonomic Functions in Adult Male Smokers. J Clin Diagn Res. 2016; 10(5): 12-6.

52 Kesse-Guyot E, Vergnaud AC, Fezeu L, et al. Associations between dietary patterns and arterial stiffness, carotid artery intima-media thickness and atherosclerosis.Eur J Cardiovasc Prev Rehabil2010;17(6): 718-24.

53 Endes S, Schaffner E, Caviezel S. et al. Long-term physical activity is associated with reduced arterial stiffness in older adults: longitudinal results of the SAPALDIA cohort study. Age Ageing 2016; 45: 110-5.

54 Oulis $P$, Kouzoupis A, Kyrkou K, et al. Reversal of increased arterial stiffness in severely depressed women after 6-week antidepressant treatment. J Affect Disord 2010; 122:164-166.

55 Schafer JL. Multiple imputation: a primer. Stat Methods Med Res. 1999; 8(1):3-15

56 Watkins DC, Assari S, Johnson-Lawrence V. Race and Ethnic Group Differences in Comorbid Major Depressive Disorder, Generalized Anxiety Disorder, and Chronic Medical Conditions. J Racial Ethn Health Disparities 2015; 2 (3): 385-394

57 Assari S. Race and Ethnic Differences in Additive and Multiplicative Effects of Depression and Anxiety on Cardiovascular Risk. Int J Prev Med 2016; 7:22.

58 Case SM, Stewart JC. Race/ethnicity moderates the relationship between depressive symptom severity and C-reactive protein: 2005-2010 NHANES data. Brain Behav Immun. 2014;41:101-8. 
59 Lewis TT, Guo H, Lunos S, Mendes de Leon CF, Skarupski KA, Evans DA, Everson-Rose SA. Depressive symptoms and cardiovascular mortality in older black and white adults: evidence for a differential association by race. Circ Cardiovasc Qual Outcomes 2011; 4(3):293-9.

60 Assari S, Sonnega A. Racial Differences in the Predictive Role of High Depressive Symptoms on Incident Heart Disease Over 18 Years: Results From the Health and Retirement Study. Res Cardiovasc Med. 2017; 6(1):e34767. 


\section{CHAPTER 3}

\section{Carotid stiffness is not associated with late-life depressive symptoms, an eight-year follow up of the Hoorn Study}

Veronica G Onete, Ronald MA Henry, Katja van den Hurk, Jacqueline M Dekker, Giel Nijpels, Femke Rutters, Joline Beulens, Coen DA Stehouwer, Miranda T Schram 


\section{Abstract}

\section{Introduction}

Carotid stiffness is a risk factor for cerebral (micro-)vascular lesions; therefore, it could cause vascular depression. This hypothesis has never been studied longitudinally. We investigated the association of (changes in) carotid stiffness with depressive symptoms over 8 years of follow-up in a sample of the Hoorn Study.

\section{Methods}

In the Hoorn study ( $n=515$, age $69.3 \pm 6.3,49.3 \%$ women, $21.2 \%$ type 2 diabetes), carotid stiffness and depressive symptoms were measured in 2000-2001 and 2007-2009 with ultrasound and a CES-D questionnaire, respectively. We used linear regression to assess the associations of carotid stiffness with depressive symptoms. Analyses were adjusted for age, sex, glucose metabolism, education, mean arterial pressure, and CVD risk factors. Results are presented as regression coefficients $[95 \% \mathrm{Cl}]$ per $1 \mathrm{SD}$ lower Distensibility Coefficient (DC), or higher Young's Elastic Modulus (YEM).

\section{Results}

Carotid DC and YEM were cross-sectionally associated with depressive symptoms at baseline in the crude, but not in the fully adjusted models: -0.15 [-0.88;0.58], 0.52 [-0.18;1.22]. Carotid DC and YEM were not associated with depressive symptoms at follow-up either in the crude, or in the fully adjusted models: -0.33 [-1.22;0.56], -0.41 [-1.23;0.41]. Changes in carotid DC and YEM over 8 years were not associated with depressive symptoms at followup, either in the crude, or in fully adjusted models: 0.47 [-0.35;1.28], $0.47[-0.37 ; 1.30]$.

\section{Conclusion}

Carotid stiffness was not associated with depressive symptoms in cross-sectional or longitudinal analyses over a follow-up period of 8 years. Our results may point to a modest association, thus our results should be replicated in larger cohorts. 


\section{Introduction}

Arterial stiffness could play a role in the pathogenesis of vascular depression. The prevalence of late-life depressive symptoms ranges between $9 \%$ and $24 \%$ in individuals living in the general population and can reach up to $43.9 \%$ in nursing home residents [1-3]. Over $50 \%$ of individuals with late-life depressive symptoms show cerebral (micro) vascular lesions on MRI, which define a vascular depression [4-8], as compared to $8 \%$ to $28 \%$ of healthy individuals [8]. Due to its association with cerebral vascular disease, late life depression is less responsive to antidepressant drugs and has a poor prognosis [9]. It is possible, however, that drugs used for the prevention and treatment of cerebrovascular disease may reduce the risk for vascular depression or improve its outcomes. Arterial stiffness has been associated previously with cerebral small vessel disease [11,12] and stroke [13]. It impairs the cushioning function of the large elastic vessels, such as the carotid arteries or aorta, and therefore leads to greater pressure and flow pulsatility into the low-impedance microvasculature of the brain [14]. Since the brain microcirculation is particularly vulnerable to pressure fluctuations, this may cause microvascular damage $[1,12]$ and result in disruption of the frontal-subcortical mood regulatory circuits of the brain $[1,10]$.

To date, there is limited cross-sectional evidence of an association between arterial stiffness and depression. Four out of five studies [15-19] observed an association between aortic stiffness and either a depressive disorder [16-18] or depressive symptoms [15]. In addition, studies that specifically investigated the association between stiffness of the carotid artery, the artery that supplies the cerebral circulation, and depression have shown conflicting results $[16,18]$. Although the Rotterdam Study observed a significant association with both depressive symptoms and a major depressive disorder [16]; the NESDA Study did not confirm these findings [18]. Furthermore, the association of arterial stiffness with depression has never been studied in a longitudinal setting, therefore at current no inferences can be made about the causality of the association.

In view of these considerations, we used data from the population-based Hoorn study to investigate 1) the cross-sectional association of carotid stiffness with depressive symptoms; and 2) the longitudinal association of carotid stiffness with depressive symptoms after a follow-up period of 8 years. Lastly, we investigated whether changes in carotid stiffness over 8 years were associated with depressive symptoms at follow-up. 


\section{Methods}

\section{Study population}

The Hoorn study is a longitudinal population-based cohort study, which investigates glucose metabolism, as well as cardiovascular risk factors, in the general population [20]. The study started in 1989, included 2484 men and women aged 50 to 74 years, of whom 1513 participated in the second examination in 1996-98. For this study, we used data from the third and fourth follow-up examinations. In the third assessment in 2000-2001, 648 individuals participated. Individuals with type 2 diabetes (T2D) were oversampled by design [21]. For the 2007-2009 examinations, all surviving participants of the 2000-2001 cohort, who were still living in Hoorn ( $n=485$ ) were re-invited, of whom 371 agreed to participate. Carotid stiffness and depression screening measurements were carried out during the examinations in 2000-2001 and 2007-2009. In this paper, the 2000-2001 cohort was used as the baseline sample, while the 2007-2009 examination was used as the followup measurement.

\section{Cross-sectional analyses}

Of the 648 individuals included in the baseline examination, 588 had qualitatively satisfactory ultrasound data, of whom 515 had data on depressive symptoms. The main reason for missing ultrasound data was poor detection of the arterial wall attributable to obesity (BMI missing ultrasound data vs BMI available ultrasound data 30.5 vs. 27.0 kg/m2; $\mathrm{p}<0.001)$.

\section{Longitudinal analyses}

Of the 588 participants with baseline carotid artery measurements 96 died before the follow-up examination, 44 had moved out of Hoorn, and 94 declined to participate. Of the remaining 354 participants, 318 had data on depressive symptoms at follow-up. In total 295 participants had carotid stiffness data at baseline and follow up (Figure 1 ).

\section{Carotid Stiffness}

Carotid stiffness was assessed at the right common carotid artery according to international guidelines, as described previously [21]. Briefly, a single observer visualised each artery with an ultrasound scanner (350 Series [7.5-MHz linear probe], Pie Medical, the Netherlands) connected to a personal computer equipped with wall track software and an acquisition system (Wall Track System, Pie Medical). The carotid walls were detected by the software: the diameter and intima-media thickness (IMT) were assessed during the diastole, while the distension was defined as the movement of the carotid wall as a function of systolic duration. At each site, 3 consecutive 4-second measurements were carried out and the mean diameter, IMT and distension were used in the analyses. During the measurements, 


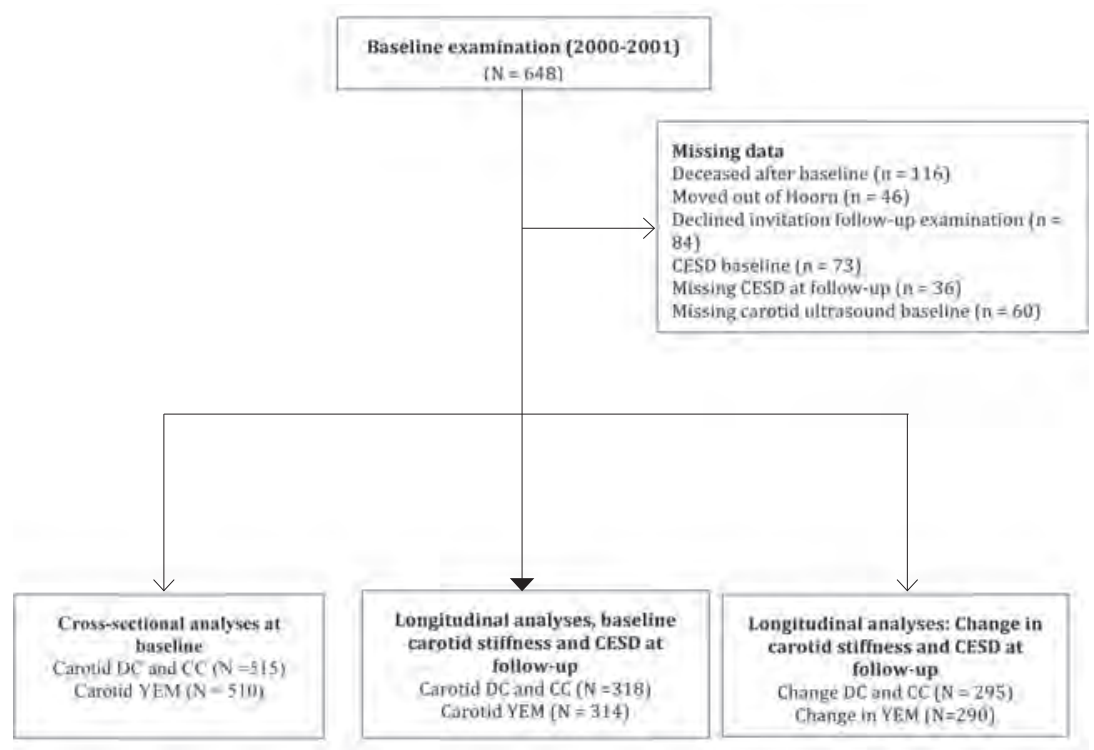

Figure 1: Flow Diagram

brachial systolic and diastolic pressures were assessed during the vascular measurements in the left upper arm at 5-minute intervals with an oscillometric device (Collin Press-Mate, BP-8800).

The distensibility coefficient were calculated as follows:

Distensibility coefficient $(D C)=\left(2 \Delta D \cdot D+\Delta D^{2}\right) /\left(\Delta P \bullet D^{2}\right)$ in $10^{-3} \bullet \mathrm{kPa}^{-1}$

where $\Delta D$ is distension, $D$ is diameter, and $\Delta P$ is pulse pressure (defined as systolic pressure - diastolic pressure). The Young's elastic modulus (YEM) was calculated for the carotid artery, according to the formula:

$\mathrm{YEM}=$ diameter/(IMT $\bullet$ distensibility coefficient) in $\mathrm{kPa}$

DC represents carotid stiffness; and the YEM represents the stiffness of the carotid artery wall material at operating pressure.

\section{Depressive symptoms}

Depressive symptoms were assessed by a validated Dutch version of the 20-item Centre for Epidemiologic Studies Depression Scale (CES-D) [22]. Scores on the CES-D range from 0 to 60 . Higher scores on this scale indicate the presence of more (severe) depressive symptoms. In the present study, the CES-D was used as a continuous variable. 


\section{Other measurements}

Education level, smoking, physical activity and medication use were assessed by means of a questionnaire [23]. Body mass index (BMI), office blood pressure, glucose metabolism status, micro-albuminuria, serum total, high- (HDL), and low-density lipoprotein (LDL) cholesterol and triglycerides were determined as described previously [24]. Glomerular filtration rate was estimated with the 4 variable MDRD equation ( $\mathrm{GGFR}_{\mathrm{MDRD}}$ ) [25]. Finally, prior CVD and hypertension were defined as described elsewhere $[23,26]$.

\section{Statistical analyses}

All analyses were performed with IBM SPSS Statistics Version 22.0 (IBM Corp., Armonk, NY, USA). Characteristics of the study population were compared according to baseline CES-D tertiles by means of an ANOVA test for normally distributed continuous variables, and by means of a linear-by linear chi-squared test for dichotomous or ordinal variables. Continuous variables with a skewed distribution were log10-transformed. A two-tailed $P$ value of less than 0.05 was considered statistically significant.

We performed one cross-sectional and two longitudinal linear regression analyses to assess the association between carotid stiffness (determinant) and depressive symptoms (outcome). In cross-sectional analyses, we used carotid stiffness indices and depressive symptoms at baseline. In the first longitudinal analysis, carotid stiffness indices at baseline and depressive symptoms at follow-up were used. These analyses were adjusted for possible confounders as measured at baseline as follows: model 1) crude, model 2) age, sex, glucose metabolism status and education level, model 3) additionally adjusted for mean arterial pressure (MAP), model 4) additionally adjusted for smoking, BMI, hypertension, prior CVD, lipid modifying medication, triglycerides, total to HDL cholesterol ratio and $\mathrm{GFR}_{\text {MDRD. }}$

The association of changes in carotid stiffness with depressive symptoms at follow-up was assessed as follows: carotid stiffness at follow-up was the main determinant, depressive symptoms at follow-up was the main outcome and the association was then adjusted for baseline carotid stiffness [27]. The models were further adjusted for confounders measured at baseline as follows: model 1) baseline carotid stiffness, model 2) additionally adjusted for age, sex, glucose metabolism status and education level, model 3) additionally adjusted for MAP at baseline and MAP at follow-up, model 4) additionally adjusted for smoking, BMI, hypertension, prior CVD, lipid modifying medication, triglycerides, total to $\mathrm{HDL}$ cholesterol ratio and $\mathrm{EGFR}_{\text {MDRD }}$. Due to the direct physical effects of MAP on carotid stiffness measurements [28], we adjusted our models for MAP as measured at baseline and at follow-up. We preferred to use linear regression over GEE for the longitudinal analyses as we only had data at two time points. Also the use of GEE would have accentuated betweensubjects relationships rather than within-subjects relationships [29]. 
Arterial stiffness has been associated with depression in old-aged individuals ( $>60$ years) [15], but not in the oldest old (> 70 years) [19], therefore we introduced interaction terms for age. The association of subclinical vascular disease with depressive symptoms has been shown to be stronger old-aged men than in old-aged women [30], therefore we also introduced interaction terms for sex. Lastly, in order to account for the oversampling of T2D, we introduced interaction terms for glucose metabolism status. None of these interactions were statistically significant $(p>0.10)$.

\section{Results}

\section{General characteristic}

Table 1 shows the characteristics of the study population according to tertiles of the depressive symptom score at baseline. Mean age was $69.3 \pm 6.3$ years and $49.3 \%$ of participants were women. Participants with the highest depressive symptoms score were older, were more often women, had a lower education level and were less physically active than the participants who reported the least depression symptoms. They also had a more adverse cardio-metabolic risk factor profile, including a higher BMI, more T2D, and also more intensive use of blood pressure lowering medication. Other cardiovascular risk factors, such as the eGFR ${ }_{M D R D}$, prior CVD, the cholesterol to HDL ratio, triglycerides, and the use of lipid modifying medication did not differ across tertiles of depressive symptoms. Finally, the DC showed a decreasing trend, while the carotid YEM showed an increasing trend across the tertiles of depressive symptoms, however the p-trend for the DC was not statistically significant. The clinical characteristics of the study population with baseline carotid stiffness measurements $(n=588)$ according to the availability of follow-up data are shown in Supplemental Table 1. Individuals with follow-up data were younger and had a more favourable CVD risk profile than the individuals without follow-up data.

\section{Cross-sectional association of carotid stiffness indices and depressive symptoms}

As shown in Table 2, the carotid DC and YEM were cross-sectionally associated with depressive symptoms in the crude model, but the associations were rendered nonsignificant after adjustment for age, sex, glucose metabolism status and education level. Additional adjustments for mean arterial pressure (model 3) and other cardiovascular risk factors (model 4) did not change the associations.

\section{Longitudinal association of carotid stiffness with depressive symptoms at follow-up}

As shown in Table 3, neither the baseline carotid DC nor the YEM were associated with depressive symptoms at follow-up in any of the models. When we further adjusted these analyses for depressive symptoms at baseline the results remained unchanged (Supplemental Table 2). 
Table 1: Clinical characteristics of the study population according to tertiles of depressive symptoms at baseline

\begin{tabular}{|c|c|c|c|c|}
\hline & $\begin{array}{l}\text { Lower Tertile } \\
\text { (CESD score } 0 \text { - 4) } \\
(n=181)\end{array}$ & $\begin{array}{l}\text { Middle Tertile } \\
\text { (CESD score 5-9) } \\
\quad(n=166)\end{array}$ & $\begin{array}{c}\text { Upper tertile } \\
\text { (CESD score 10-34) } \\
(n=168)\end{array}$ & p-trend \\
\hline \multicolumn{5}{|c|}{ Demographics } \\
\hline Age, years & $68 \pm 6$ & $69 \pm 6$ & $71 \pm 7$ & $<0.001$ \\
\hline Female sex, $\%$ & 42.0 & 48.2 & 58.3 & 0.002 \\
\hline Education level low/medium/high, \% & 74/8/18 & 79/9/12 & $84 / 9 / 8$ & 0.010 \\
\hline \multicolumn{5}{|c|}{ Lifestyle factors } \\
\hline Smoking, never/former/current, \% & $36 / 50 / 14$ & $34 / 49 / 18$ & $38 / 38 / 24$ & 0.287 \\
\hline Physical activity, hours/week & $24[14-35]$ & $19[12-28]$ & $18[9-31]$ & 0.001 \\
\hline $\begin{array}{l}\text { At least } 2.5 \text { hours of moderate to high } \\
\text { intensity physical activity per week, } \%\end{array}$ & 77.9 & 74.7 & 66.1 & 0.013 \\
\hline \multicolumn{5}{|c|}{ Cardio-metabolic risk factors } \\
\hline $\mathrm{BMI}, \mathrm{kg} / \mathrm{m} 2$ & $26.7 \pm 3.5$ & $26.7 \pm 3.2$ & $27.6 \pm 4.0$ & 0.039 \\
\hline NGM/IGM/DM2, \% & $53 / 31 / 16$ & $56 / 24 / 20$ & $40 / 32 / 28$ & 0.006 \\
\hline Total-to-HDL cholesterol ratio & $4.20 \pm 1.20$ & $4.36 \pm 1.17$ & $4.31 \pm 1.26$ & 0.429 \\
\hline Triglycerides, $\mathrm{mmol} / \mathrm{L}$ & $1.3[0.9-1.7]$ & $1.3[1.0-1.75]$ & $1.3[1.0-1.8]$ & 0.285 \\
\hline Fasting glucose, $\mathrm{mmol} / \mathrm{L}$ & $5.99 \pm 1.03$ & $6.09 \pm 1.59$ & $6.42 \pm 1.52$ & 0.011 \\
\hline $\mathrm{HbA} 1 \mathrm{c} \%$ & $5.93 \pm 0.64$ & $5.90 \pm 0.77$ & $6.12 \pm 0.74$ & 0.011 \\
\hline $\mathrm{eGFR}_{\mathrm{MDRO}^{\prime}} \mathrm{ml} / \mathrm{min} / 1.73 \mathrm{~m} 2$ & $65.2 \pm 10.0$ & $63.7 \pm 10.0$ & $62.7 \pm 11.1$ & 0.070 \\
\hline Hypertension, \% & 68.3 & 63.9 & 68.5 & 0.997 \\
\hline Prior CVD, $\%$ & 42.0 & 55.4 & 51.2 & 0.08 \\
\hline \multicolumn{5}{|c|}{ Medication use } \\
\hline Lipid modifying medication, $\%$ & 14.9 & 15.1 & 15.5 & 0.885 \\
\hline Blood pressure lowering medication, $\%$ & 27.6 & 32.5 & 57.1 & 0.003 \\
\hline Anti-depressive medication, $\%$ & 1.7 & 1.2 & 4.8 & 0.069 \\
\hline \multicolumn{5}{|c|}{ Stiffness indices } \\
\hline Carotid DC, $10^{\wedge}-3 / \mathrm{kPa}$ & $11.5 \pm 4.1$ & $11.4 \pm 4.0$ & $10.5 \pm 4.4$ & 0.055 \\
\hline Carotid YEM, $10^{\wedge} 3 \mathrm{kPa}$ & $0.93 \pm 0.43$ & $0.94 \pm 0.40$ & $1.09 \pm 0.61$ & 0.007 \\
\hline Carotid artery diameter, mm & $7.89 \pm 1.13$ & $7.95 \pm 1.14$ & $8.00 \pm 1.15$ & 0.657 \\
\hline Carotid artery distension, $\mathrm{mm}$ & $0.36 \pm 0.12$ & $0.36 \pm 0.10$ & $0.34 \pm 0.11$ & 0.423 \\
\hline Intima media thickness (IMT) & $0.87 \pm 0.17$ & $0.86 \pm 0.16$ & $0.87 \pm 0.18$ & 0.940 \\
\hline $\mathrm{SBP}, \mathrm{mmHg}$ & $140 \pm 18$ & $140 \pm 18$ & $144 \pm 21$ & 0.060 \\
\hline $\mathrm{DBP}, \mathrm{mmHg}$ & $77 \pm 9$ & $76 \pm 10$ & $77 \pm 9$ & 0.425 \\
\hline $\mathrm{MAP}, \mathrm{mmHg}$ & $98 \pm 11$ & $97 \pm 12$ & $99 \pm 12$ & 0.209 \\
\hline Heart Rate, bpm & $62 \pm 9$ & $62 \pm 9$ & $63 \pm 9$ & 0.491 \\
\hline Brachial PP, mmHg & $63.2 \pm 13.6$ & $64.0 \pm 13.1$ & $67.4 \pm 16.7$ & 0.019 \\
\hline
\end{tabular}

Data are presented as $\%$, mean $\pm S D$, or median [interquartile range]. CVD = cardiovascular disease; SBP = Mean systolic blood pressure during stiffness measurements; DBP = Mean diastolic blood pressure during stiffness measurements; $\mathrm{MAP}=$ mean arterial pressure during stiffness measurements; Heart Rate $=$ Mean heart rate during stiffness measurements, Brachial PP = mean pulse pressure during stiffness measurements 
Table 2: Cross-sectional association of carotid stiffness indices with depressive symptoms at baseline

\begin{tabular}{lcc}
\hline Model & $\begin{array}{c}\text { Carotid DC } \\
(\mathbf{n}=\mathbf{5 1 5})\end{array}$ & $\begin{array}{c}\text { Carotid YEM } \\
(\mathbf{n}=\mathbf{5 1 0})\end{array}$ \\
\hline Model 1 & $\mathbf{0 . 5 5}(\mathbf{0 . 0 2} \mathbf{1 . 0 8})$ & $\mathbf{0 . 8 2}(\mathbf{0 . 2 8} \mathbf{1 . 3 5})$ \\
Model 2 & $-0.07(-0.68 ; 0.54)$ & $0.48(-0.13 ; 1.08)$ \\
Model 3 & $-0.11(-0.80 ; 0.59)$ & $0.58(-0.10 ; 1.25)$ \\
Model 4* $^{*}$ & $-0.15(-0.88 ; 0.58)$ & $0.52(-0.18 ; 1.22)$ \\
\hline
\end{tabular}

Results are expressed as regression coefficients $(95 \% \mathrm{CI}$ ) per 1 SD lower distensibility (DC) and 1 SD higher Young's Elastic Modulus (YEM); for example 1SD lower carotid DC was associated with a $0.55(0.02 ; 1.08)$ higher CES-D score in crude analyses.Model 1: crude; model 2: adjusted for age, sex, glucose metabolism status, education; model 3: model $2+$ mean arterial pressure; model 4: model 3 + BMI, hypertension, smoking, triglycerides, total-to-HDL ratio, lipid modifying medication, eGFRMDRD, and prior CVD

Table 3: Longitudinal association of baseline carotid stiffness indices with depressive symptoms at follow-up

\begin{tabular}{lcc}
\hline Model & $\begin{array}{c}\text { Carotid DC } \\
(\mathbf{n = 3 1 8})\end{array}$ & $\begin{array}{c}\text { Carotid YEM } \\
(\mathbf{n}=\mathbf{3 1 4})\end{array}$ \\
\hline Model 1 & $0.24(-0.43 ; 0.92)$ & $-0.06(-0.73 ; 0.61)$ \\
Model 2 & $-0.38(-1.14 ; 0.38)$ & $-0.40(-1.11 ; 0.30)$ \\
Model 3 & $-0.27(-1.12 ; 0.58)$ & $-0.36(-1.15 ; 0.43)$ \\
Model 4* & $-0.33(-1.22 ; 0.56)$ & $-0.41(-1.23 ; 0.41)$ \\
\hline
\end{tabular}

Results are expressed as regression coefficients $(95 \% \mathrm{CI})$ per 1 SD lower distensibility (DC) and 1 SD higher Young's Elastic Modulus (YEM); for example, 1SD lower carotid DC was associated with a $0.24(-0.43 ; 0.92)$ higher CES-D score at follow-up in crude analyses. Model 1: crude; model 2: adjusted for age, sex, glucose metabolism status, education; model 3: model $2+$ mean arterial pressure; model 4: model $3+\mathrm{BMI}$, hypertension, smoking, triglycerides, total to HDL ratio, lipid modifying medication, eGFRMDRD, and prior CVD

Table 4: Longitudinal association of the change in carotid stiffness indices with depressive symptoms at follow-up

\begin{tabular}{lcc}
\hline Model & $\begin{array}{c}\text { Change in Carotid DC } \\
(\mathbf{n}=\mathbf{2 9 5})\end{array}$ & $\begin{array}{c}\text { Change in Carotid YEM } \\
(\mathbf{n}=\mathbf{2 9 0})\end{array}$ \\
\hline Model 1 & $0.52(-0.23 ; 1.25)$ & $0.51(-0.22 ; 1.25)$ \\
Model 2 & $0.50(-0.24 ; 1.23)$ & $0.53(-0.19 ; 1.26)$ \\
Model 3 & $0.47(-0.33 ; 1.26)$ & $0.49(-0.31 ; 1.29)$ \\
Model $4 *^{*}$ & $0.47(-0.35 ; 1.28)$ & $0.47(-0.37 ; 1.30)$ \\
\hline
\end{tabular}

Results are expressed as regression coefficients $(95 \% \mathrm{CI})$ per 1 SD lower distensibility (DC) and 1 SD higher Young's Elastic Modulus (YEM); for example, 1SD lower carotid DC was associated with a $0.24(-0.43 ; 0.92)$ higher CES-D score at follow-up in crude analyses. Model 1: crude; model 2: adjusted for age, sex, glucose metabolism status, education; model 3: model 2 + mean arterial pressure; model 4: model $3+\mathrm{BMI}$, hypertension, smoking, triglycerides, total to $\mathrm{HDL}$ ratio, lipid modifying medication, eGFRMDRD, and prior CVD 


\section{Longitudinal association of change in carotid stiffness with depressive symptoms at follow-up}

The change in carotid DC was not associated with depressive symptoms at follow up in any of the models (Table 4). Similarly, the change in carotid YEM was not associated with more depressive symptoms at follow-up in any of the models (Table 4). When we further adjusted the analyses for depressive symptoms at baseline the results remained unchanged (Supplemental Table 3).

\section{Additional analyses}

When individuals with clinically relevant depressive symptoms (CESD $\geq 16)(n=22)$, and/ or the use antidepressant medication $(n=5)$, or with a missing baseline CESD score $(n=$ 32) were excluded from the analyses, the results were not altered (Supplemental Table $4)$. When we excluded individuals with extreme values ( $\pm 3 S D$ ) in carotid stiffness the associations did not change.

Additional adjustments for baseline heart rate, physical activity or micro-albuminuria did not alter the associations. When we additionally adjusted for baseline carotid intima media thickness as a marker of subclinical atherosclerosis the results were not altered. Additional adjustments for newly prescribed antihypertensive medication throughout follow-up, did not materially change the results. When BMI was replaced by height and weight the results did not materially change. Lastly, when MAP was replaced by either the pulse pressure, or the mean systolic blood pressure during the vascular measurements the results were not altered.

\section{Discussion}

This study shows that carotid stiffness is not associated with depressive symptoms in cross-sectional analyses, or in longitudinal analyses over a follow-up period of 8 years. In addition, changes in carotid stiffness over 8 years are not associated with depressive symptoms at follow-up.

To our knowledge, we are the first to investigate the longitudinal association of carotid stiffness with depressive symptoms in elderly individuals, however, we did not find any statistically significant associations. In longitudinal analyses, one SD greater carotid stiffness at baseline was associated with a - 0.33 [-1.22; 0.56] lower CES-D score at follow-up; while an increase in carotid stiffness over 8 years was associated with a $0.47[-0.35 ; 1.28]$ greater CES-D score at follow-up. As the CES-D score ranges from 0 to 60 points, these modest effect sizes, are unlikely to have been clinically relevant, even had they been statistically significant. 
In the cross-sectional analyses, greater carotid stiffness was only modestly associated with more depressive symptoms in the crude models, however the associations were greatly attenuated after adjustment for confounding factors as age and sex. To date, only two crosssectional studies investigated the association of the carotid DC with a major depressive disorder $[16,18]$ or with depressive symptoms [18]. In concordance with our results, the NESDA study [18] did not find a significant association of carotid DC with a major depressive disorder. However, the individuals included in this study were younger (mean age: 42 years as compared to 68 years in our study). Because vascular depression is hypothesised to occur especially in later life, any association with carotid stiffness may not be present in younger individuals with early onset depression. In contrast to our findings, the Rotterdam Study [16] did find a significant association of carotid stiffness with both a major depressive disorder and clinically relevant depressive symptoms (CESD $\geq 16$ ). This study had a larger sample size than ours and included individuals with more severe depressive symptoms, therefore it may have had more power to detect any cross-sectional associations.

The strengths of this study include its longitudinal design as well as the advanced phenotyping with the measurement of many potential confounding factors, which were accounted for in the fully adjusted models. However, our findings may have been hampered by several limitations. Firstly, we had a small sample size ( $n$ 300-500), with relatively low levels of depressive symptoms, which limits the precision of our regression coefficients and reduces the chances to find any association. Secondly, the use of self-reported depressive symptoms instead of a diagnostic interview may have attenuated the associations, possibly due to the misclassification of symptoms of impaired daily functioning as depressive symptoms [31]. Thirdly, our study might have been hampered by survival bias, as a large proportion of the individuals with baseline carotid stiffness were not included in the follow-up measurements. These participants were older and had a more adverse CVD risk profile (including stiffer carotid arteries) than the individuals who were included in the longitudinal analyses, thus they had a greater chance of dropping out due to CVD related morbidity and mortality. In turn, this could have attenuated the longitudinal associations with vascular depression. Furthermore, survival bias could have been accentuated by the adverse CVD profile of the study population, which was due to the advanced age (mean age 68 years), the high prevalence of prior CVD and of T2D. This more adverse CVD risk profile could have weakened the individual association of arterial stiffness with CVD and vascular depression [32,33]. Lastly, individuals with the stiffest arteries at baseline may have been treated more intensively for hypertension than the remainder of the population, due to their adverse cardiovascular risk profile [34]. As blood pressure lowering medication may improve arterial stiffness [35], this could have introduced bias towards the null. 
Even though our results were not significant, the associations of carotid stiffness with depressive symptoms seemed plausible a priori. Cardiovascular risk factors, such as arterial stiffness, may lead to the accumulation of cerebral small vessel lesions in the mood regulatory centres of the brain [31,11], which may result in the development of depression $[5,12]$. Also, arterial stiffening could lead to depression through endothelial cell dysfunction [36-41] and low grade inflammation [42-46].

\section{Conclusion}

In conclusion, we have shown that carotid stiffness was not associated with depressive symptoms in cross-sectional analyses, nor in longitudinal analyses over a follow-up period of 8 years. In addition, changes in carotid stiffness over 8 years were also not associated with depressive symptoms at follow-up. Further studies with larger sample size and less attrition are needed to consolidate these results. 
Supplemental Table 1: Clinical characteristics of the individuals with baseline carotid stiffness according to follow-up status

\begin{tabular}{|c|c|c|c|}
\hline & $\begin{array}{l}\text { Lower Tertile } \\
\text { (CESD score } 0 \text { - 4) } \\
(n=181)\end{array}$ & $\begin{array}{l}\text { Middle Tertile } \\
\text { (CESD score 5-9) } \\
(n=166)\end{array}$ & $\begin{array}{c}\text { Upper tertile } \\
\text { (CESD score 10-34) } \\
(n=168)\end{array}$ \\
\hline \multicolumn{4}{|c|}{ Demographics } \\
\hline Age, years & $69.6 \pm 6.4$ & $71.8 \pm 6.7$ & $67.8 \pm 5.6$ \\
\hline Female sex, $\%$ & 51 & 51 & 51 \\
\hline Education level low/medium/high, \% & $80 / 8 / 12$ & $85 / 6 / 9$ & $76 / 9 / 15$ \\
\hline \multicolumn{4}{|c|}{ Lifestyle factors } \\
\hline Smoking, never/former/current, \% & $37 / 46 / 18$ & $32 / 45 / 23$ & $40 / 46 / 14$ \\
\hline Physical activity, hours/week & $23.2[11.3-31.0]$ & $21.7[9.0-30.0]]$ & $24.4[13.0-31.5]$ \\
\hline $\begin{array}{l}\text { At least } 2.5 \text { hours of moderate to high } \\
\text { intensity physical activity per week, } \%\end{array}$ & 72.7 & 70.7 & 74.4 \\
\hline \multicolumn{4}{|c|}{ Cardiometabolic risk factors } \\
\hline $\mathrm{BMI}, \mathrm{kg} / \mathrm{m} 2$ & $27.0 \pm 3.6$ & $27.0 \pm 3.7$ & $27.0 \pm 3.5$ \\
\hline NGM/IGM/DM2, \% & $48 / 29 / 23$ & $42 / 31 / 27$ & $53 / 27 / 19$ \\
\hline Total-to-HDL cholesterol ratio & $4.26 \pm 1.24$ & $4.25 \pm 1.20$ & $4.27 \pm 1.28$ \\
\hline Triglycerides, mmol/L & $1.47[1.00-1.70]$ & $1.30[1.00-1.73]$ & $1.30[1.0-1.7]$ \\
\hline Fasting glucose, $\mathrm{mmol} / \mathrm{L}$ & $6.19 \pm 1.42$ & $6.4 \pm 1.6$ & $6.04 \pm 1.20$ \\
\hline $\mathrm{HbA1c} \%$ & $6.0 \pm 0.7$ & $6.1 \pm 0.7$ & $5.9 \pm 0.7$ \\
\hline $\mathrm{eGFR}_{\mathrm{MDRD}^{\prime}} \mathrm{ml} / \mathrm{min} / 1.73 \mathrm{~m} 2$ & $63.8 \pm 10.4$ & $63.1 \pm 10.6$ & $64.3 \pm 10.2$ \\
\hline Hypertension, \% & 67 & 73 & 62 \\
\hline Prior CVD, \% & 50.4 & 54.1 & 47.3 \\
\hline \multicolumn{4}{|c|}{ Medication use } \\
\hline Lipid modifying medication, $\%$ & 15.7 & 17.4 & 14.2 \\
\hline Blood pressure lowering medication, $\%$ & 34.4 & 41.1 & 28.7 \\
\hline Anti-depressive medication, \% & 2.2 & 2.6 & 1.9 \\
\hline \multicolumn{4}{|c|}{ Stiffness indices } \\
\hline Carotid DC, $10^{\wedge}-3 / \mathrm{kPa}$ & $10.9 \pm 4.2$ & $9.6 \pm 3.9$ & $12.0 \pm 4.2$ \\
\hline Carotid YEM, $10^{\wedge} 3 \mathrm{kPa}$ & $1.02 \pm 0.57$ & $1.17 \pm 0.68$ & $0.90 \pm 0.42$ \\
\hline Carotid artery diameter, mm & $7.98 \pm 1.13$ & $8.13 \pm 1.09$ & $7.85 \pm 1.15$ \\
\hline Carotid artery distension, $\mathrm{mm}$ & $0.35 \pm 0.11$ & $0.32 \pm 0.10$ & $0.37 \pm 0.11$ \\
\hline Intima media thickness (IMT) & $0.87 \pm 0.17$ & $0.89 \pm 0.18$ & $0.84 \pm 0.16$ \\
\hline $\mathrm{SBP}, \mathrm{mmHg}$ & $142 \pm 20$ & $146 \pm 21$ & $138 \pm 18$ \\
\hline $\mathrm{DBP}, \mathrm{mmHg}$ & $76 \pm 9$ & $77 \pm 9$ & $76 \pm 9$ \\
\hline MAP, mmHg & $98 \pm 12$ & $100 \pm 12$ & $97 \pm 11$ \\
\hline Heart Rate, bpm & $62 \pm 9$ & $63 \pm 9.0$ & $61 \pm 9$ \\
\hline \multicolumn{4}{|c|}{ Depressive symptoms } \\
\hline Brachial PP, mmHg & $7.0[3.0-11.0]$ & $7.0[3.0-12.0]$ & $6.0[3.0-10.0]$ \\
\hline
\end{tabular}

Data are presented as $\%$, mean $\pm S D$, or median [interquartile range]. $C V D=$ cardiovascular disease; $S B P=$ Mean systolic blood pressure during stiffness measurements; DBP = Mean diastolic blood pressure during stiffness measurements; MAP = mean arterial pressure during stiffness measurements; Heart Rate $=$ Mean heart rate during stiffness measurements. ${ }^{*}$ Data available in $\mathrm{n}=515 / 233 / 282$ ) 
Supplemental Table 2: Longitudinal association of baseline carotid stiffness indices with depressive symptoms at follow-up, additionally adjusted for baseline depression symptoms

\begin{tabular}{lcc}
\hline Model & $\begin{array}{c}\text { Carotid DC } \\
(\mathbf{n}=\mathbf{3 1 8})\end{array}$ & $\begin{array}{c}\text { Carotid YEM } \\
(\mathbf{n}=\mathbf{3 1 4})\end{array}$ \\
\hline Model 4 & $-0.33(-1.22 ; 0.56)$ & $-0.41(-1.23 ; 0.41)$ \\
Model 4 + baseline & $-0.33(-1.15 ; 0.49)$ & $-0.64(-0.09 ; 1.38)$ \\
CES-D score & & \\
\hline
\end{tabular}

Results are expressed as regression coefficients $(95 \% \mathrm{Cl})$ per 1 SD lower distensibility (DC) and compliance coefficient (CC) and 1 SD higher Young's Elastic Modulus (YEM); for example 1SD lower carotid DC was associated with a -0.15 $(-0.88 ; 0.58)$ higher CES-D score at follow-up in model 4.

Supplemental Table 3: Longitudinal association of the change in carotid stiffness indices with depressive symptoms at follow-up, additionally adjusted for baseline depression symptoms

\begin{tabular}{lcc}
\hline Model & $\begin{array}{c}\text { Change in Carotid DC } \\
(\mathbf{n}=\mathbf{2 9 5})\end{array}$ & $\begin{array}{c}\text { Change in Carotid YEM } \\
(\mathbf{n}=\mathbf{2 9 0})\end{array}$ \\
\hline Model 4 & $0.47(-0.35 ; 1.28)$ & $0.47(-0.37 ; 1.30)$ \\
Model 4 + baseline & $0.29(-0.49 ; 1.07)$ & $0.42(-1.21 ; 0.36)$ \\
CES-D score & & \\
\hline
\end{tabular}

Results are expressed as regression coefficients (95\% CI) per 1 SD lower distensibility (DC) and 1 SD higher Young's Elastic Modulus (YEM) at follow-up adjusted for respective stiffness indices measured at baseline; for example 1SD lower carotid DC at follow-up, adjusted for carotid DC at baseline was associated with a $0.47(-0.35 ; 1.28)$ higher CES-D score at follow-up in model 4.

Supplemental Table 4: Longitudinal association of baseline carotid stiffness indices with depression symptoms at follow-up in participants free of depression at baseline

\begin{tabular}{lcc}
\hline Model & $\begin{array}{c}\text { Carotid DC } \\
(\mathbf{n}=\mathbf{2 8 2})\end{array}$ & $\begin{array}{c}\text { Carotid YEM } \\
(\mathbf{n}=\mathbf{2 7 9})\end{array}$ \\
\hline Model 1 & $0.16(-0.53 ; 0.85)$ & $-0.11(-0.80 ; 0.57)$ \\
Model 2 & $-0.41(-1.17 ; 0.36)$ & $-0.39(-1.09 ; 0.31)$ \\
Model 3 & $-0.39(-1.25 ; 0.47)$ & $-0.40(-1.18 ; 0.39)$ \\
Model 4 & $-0.47(-1.37 ; 0.44)$ & $-0.45(-1.26 ; 0.37)$ \\
Model 5 & $-0.33(-1.14 ; 0.48)$ & $-0.63(-1.36 ; 0.09)$ \\
\hline
\end{tabular}

Results are presented as regression coefficients (95\% CI) per 1 SD lower distensibility (DC) and 1 SD higher Young's Elastic Modulus (YEM); for example, 1SD lower carotid DC was associated with a $0.16(-0.53 ; 0.85)$ higher CES-D score at follow-up in crude analyses. Model 1: crude; model 2: adjusted for age, sex, glucose metabolism status, education; model 3: model 2 + mean arterial pressure; model 4: model 3 + BMI, hypertension, smoking, triglycerides, total to HDL ratio, lipid modifying medication, $\mathrm{GFFR}_{\mathrm{MDRD}^{\prime}}$ and prior CVD, Model 5: model 4 + baseline depression score 
Supplemental Table 5: Longitudinal association of the change in carotid stiffness with depression symptoms at follow-up in participants free of depression at baseline

\begin{tabular}{lcc}
\hline Model & $\begin{array}{c}\text { Carotid DC } \\
(\mathbf{n}=\mathbf{2 3 9})\end{array}$ & $\begin{array}{c}\text { Carotid YEM } \\
(\mathbf{n}=\mathbf{2 3 6})\end{array}$ \\
\hline Model 1 & $0.36(-0.38 ; 1.10)$ & $0.18(-0.53 ; 0.89)$ \\
Model 2 & $0.38(-0.36 ; 1.12)$ & $0.25(-0.45 ; 0.96)$ \\
Model 3 & $0.44(-0.36 ; 1.24)$ & $0.31(-0.49 ; 1.10)$ \\
Model 4 & $0.47(-0.37 ; 1.30)$ & $0.31(-0.53 ; 1.15)$ \\
Model 5 & $0.34(-0.44 ; 1.12)$ & $0.24(-0.54 ; 1.02)$ \\
\hline
\end{tabular}

Results are presented as regression coefficients (95\% CI) per 1 SD lower distensibility (DC) and compliance coefficient (CC) and 1 SD higher Young's Elastic Modulus (YEM) at follow-up adjusted for baseline stiffness; 1SD lower Carotid DC at follow-up, adjusted for baseline Carotid DC was associated with a $0.55(0.02 ; 1.08)$ higher CES-D score at follow-up. Model 1: adjusted for baseline carotid stiffness; model 2: model 1 + age, sex, glucose metabolism status, education; model 3: model 2 + mean arterial pressure at baseline and follow-up; model 4: model $3+\mathrm{BMI}$, hypertension, smoking, triglycerides, total-to-HDL ratio, lipid modifying medication, eGFR $_{\mathrm{MDRD}^{\prime}}$ prior CVD; model 5: model 4 + baseline depression score 


\section{References}

1 Beekman, A. T., Copeland, J. R. \& Prince, M. J. (1999) Review of community prevalence of depression in later life. British Journal of Psychiatry, 174, 307-311.

2 Copeland JR, Beekman AT, Braam AW, Dewey ME, Delespaul P, Fuhrer R, Hooijer, C, Lawlor BA, Kivela SL, Lobo A, Magnusson H, Mann AH, Meller I, Prince MJ, Reischies F, Roelands M, Skoog I, Turrina C, deVries MW, Wilson KC. Depression among older people in Europe: the EURODEP studies. World Psychiatry. 2004;3(1):45-49.

3 Jongenelis K, Pot AM, Eisses AM, Beekman AT, Kluiter H, van Tilburg W, Ribbe MW. [Depression among older nursing home patients. A review]. Tijdschr Gerentol Geriatr. 2003 (2): 52-9.

4 Park JH, Lee SB, Lee JJ, Yoon JC, Han JW, Kim TH, Jeong HG, Newhouse PA, Taylor WD, Kim JH, Woo JI, Kim KW. Epidemiology of MRI-defined vascular depression: A longitudinal, community-based study in Korean elders. J ffect Disord. 2015 15;180:200-6.

5 Alexopoulos GS, Meyers BS, Young RC, et al. Vascular depression hypothesis. Arc Gen Psychiatry 1997; 54: 915-922

6 Alexopoulos GS. The vascular depression hypothesis: 10 years later. Biol Psychiatry. 2006; 60(12):1304-5.

7 Herrmann LL, Le Masurier M, Emeier KP. White matter hyperintensities in late life depression: a systematic review.J Neurol Neurosurg Psychiatry. 2008; 79(6): 619-24.

8 Krishnan KR, Hays JC, Blazer DG. MRI-defined vascular depression. Am J Psychiatry 1997; 154: 497-501.

9 Vermeer SE, Longstreth WT, Jr, Koudstaal PJ. Silent brain infarcts: a systematic review. Lancet Neurology. 2007 Jul;6(7):611-9.

10 Baldwin R, Wild R. Management of depression in later life. Advances in Psychiatric treatment Feb 2004, 10 (2) $131-139$.

11 Van Sloten TT, Protogerou AD, Henry RM, Schram MT, Launer LJ, Stehouwer CD. Association between arterial stiffness, cerebral small vessel disease and cognitive impairment: A systematic review and meta-analysis. Neurosci Biobehav Rev. 2015; 53:121-30.

12 Ding J, Mitchell GF, Bots ML, Sigurdsson S, Harris TB, Garcia M, Eiriksdottir G, van Buchem MA, Gudnason V, Launer LJ. Carotid arterial stiffness and risk of incident cerebral microbleeds in older people: the the Age, Gene/ Environment Susceptibility (AGES)-Reykjavik study. Arterioscler Thromb Vasc Biol. 2015 Aug;35(8):1889-95.

13 van Sloten TT, Sedaghat S, Laurent S, London GM, Pannier B, Ikram MA, Kavousi M, Mattace-Raso F, Franco OH, Boutouyrie P, Stehouwer CD. Carotid stiffness is associated with incident stroke: a systematic review and individual participant data meta-analysis. J Am Coll Cardiol. 2015 ;66(19):2116-25.

14 Mitchell GF. Arterial Stiffness and Hypertension. Hypertension 2014; 64: 13-18.

15 Van Sloten TT, Mitchell GF, Sigurdsson S, et al. Associations between arterial stiffness, depressive symptoms and cerebral small vessel disease: cross-sectional findings from the AGES-Reykjavik Study. J Psychiatry Neurosci. 2016; 14 (3): 162-8.

16 Tiemeier H, Breteler MM, van Popele NM, et al. Late-life depression is associated with arterial stiffness: a population-based study. J Am Geriatr Soc 2003; 51:1105-1110

17 Paranthaman R, Greenstein AS, Burns AS, et al. Vascular function in older adults with depressive disorder. Biol Psychiatry 2010; 68: 133-139.

18 Seldenrijk A, van Hout HP, van Marwijk HW, et al. Depression, anxiety, and arterial stiffness. Biol Psychiatry 2011; 69: 795-803. 
19 Lewis TT, Sutto-Tyrell K, Penninx BW, et al. Race, Psychosocial Factors, and Arortic Pulse Wave Velocity: The Health, Aging, and Body Coposition Study. J Gerontol A Biol Sci Med Sci. 2010 ; 65(10): 1079-1085

20 Mooy JM, Grootenhuis PA, de Vries H, et al. Prevalence and determinants of glucose intolerance in a Dutch Caucasian population: the Hoorn study. Diabetes Care. 1995; 18: 1270-1273

21 Henry RM, Kostense PJ, Spijkerman AM, et al. Arterial stiffness increases with deteriorating glucose tolerance status: the Hoorn Study. Circulation 2003;107:2089-95.

22 Beekman AT, Deeg DJ, Van Limbeek J, Braam AW, De Vries MZ, Van Tilburg W. Criterion validity of the Center for Epidemiologic Studies Depression scale (CES-D): results from a community-based sample of older subjects in The Netherlands. Psychological Medicine 1997; 27, 231-235.

23 Schram MT, Henry RM, van Dijk RA, et al. Increased central artery stiffness in impaired glucose metabolism and type 2 diabetes: the Hoorn study. Hypertension 2004;43:176-81.

24 Spijkerman AMW, Adriaanse MC, Dekker JM, et al. Diabetic patients detected by population-based stepwise screening already have a "diabetic" cardiovascular risk profile. Diabetes Care. 2002; 25: 1784-1789.

25 Levey AS, Bosch JP, Lewis JB, Greene T, Rogers N, Roth D. A more accurate method to estimate glomerular filtration rate from serum creatinine: a new prediction equation: Modification of Diet in Renal Disease Study Group. Ann Intern Med 1999; 130:461-470

26 The sixth report of the Joint National Committee on prevention, detection, evaluation, and treatment of high blood pressure. Arch Intern Med. 1997; 157: 2413-2446.

27 Diggle PJ, Liang K-Y, Zeger SL. Analysis of longitudinal data. New York: Oxford University Press, 1995, page 4

28 Laurent S, Caviezel B, Beck L, Girerd X, Billaud E, Boutouyrie P, et al. Carotid artery distensibility and distending pressure in hypertensive humans. Hypertension 1994; 23:878 \pm 883 .

29 Twisk JW. Different statistical models to analyze epidemiological observational longitudinal data: an example from the Amsterdam Growth and Health Study. Int J Sports Med 1997; 18 (suppl 3):S216 \pm S224.

30 Prugger C, Godin O, Perier MCet al. Longitudinal association of carotid plaque presence and intima-media thickness with depressive symptoms in the elderly: the three-city study. Arterioscler Thromb Vasc Biol 2015; 35(5): 1279-83

31 Beekman AT, Deeg DJ, van Tilburg T, Smit JH, Hooijer C, van Tilburg W. Major and minor depression in later life: a study of prevalence and risk factors. J Affect Disord. 1995 24;36(1-2): 65-75

32 Dijk JM, Algra A, van der Graaf Y, Grobbee DE, Bots ML; SMART study group. Carotid stiffness and the risk of new vascular events in patients with manifest cardiovascular disease. The SMART study. Eur Heart J. 2005 Jun;26(12):1213-20. Epub 2005 Apr 11. Access

33 Jochemsen HM, Muller M, Bots ML, Scheltens P, Vincken KL, Mali WP, van der Graaf Y, Geerlings MI, SMART Study Group. Arterial stiffness and progression of structural brain changes: The SMART-MR study. Neurology 2015 Feb 3;84(5):448-55

34 https://www.nhg.org/standaarden/samenvatting/cardiovasculair-risicomanagement

35 AlGhatrif M, Strait JB, Morrell CH, Canepa M, Wright J, Elango P, et al. Longitudinal trajectories of arterial stiffness and the role of blood pressure: the Baltimore Longitudinal Study of Aging. Hypertension. 2013;62(5):934-41.

36 Mitchell GF, van Buchem MA, Sigurdsson S, et al. Arterial stiffness, pressure and flow pulsatility and brain structure and function: the Age,Gene/Environment Susceptibility-Reykjavik study.Brain2011;134:3398-407 
37 Chappell DC, Varner SE, Nerem RM, et al. Oscillatory shear stress stimulates adhesion molecule expression in cultured human endothelium. Circ Res 1998; 82(5): 532-539.

38 Shen $\mathrm{Q}$, Goderie SK, Jin L, et al. Endothelial cells stimulate self-renewal and expand neurogenesis of neural stem cells. Science 2004; 304: 1338-1340.

39 Chrinos JA. Large artery stiffness, microvascular function, and cardiovascular risk. Circ Cardiovasc Imaging 2016;9:e005903

40 Zhao C, Deng W, Gage FH. Mechanisms and functional implications of adult neurogenesis. Cell 2008; 132: 645-660.

41 Hoth KF, Tate DF, Poppas A, et al. Endothelial Function and White Matter Hyperintensities in Older Adults With Cardiovascular Disease. Stroke 2007; 38(2): 308-312.

42 Lemke H, de Castro AG, Schlattmann P, et al. Cerebrovascular reactivity over time-course - from major depressive disorder to remission. J Psychiatr Res 2010; 44: 132-136.

43 Dantzer R, O'Conner JC, Freund GG, et al. From inflammation to sickness and depression: when the immune system subjugates the brain. Nat Rev Neurosci 2008; 9: 45-56

44 Alexopoulos GS, Morimoto SS. The inflammation hypothesis in geriatric depression. Int J Geriatr Psychiatry. 2011;26(11):1109-1118.

45 Miller AH, Maletic V, Raison CL. Inflammation and its discontents: The role of cytokines in the pathophysiology of major depression. Biol Psychiatry. 2009;65(9):732-741.

46 Vecsei L, Szalardy L, Fulop F, Toldi J. Kynurenines in the CNS: recent advances and new questions. Nat Rev Drug Discov. 2013;12(1):64-82 


\section{CHAPTER 4}

\section{Association of arterial stiffness with cognitive performance at six-year follow-up: the Hoorn Study}

Veronica G Onete, Ronald MA Henry, Katja van den Hurk, Jacqueline M Dekker, Giel Nijpels, Femke Rutters, Petra Elders, Joline Beulens, Coen DA Stehouwer, Miranda T Schram 


\section{Abstract}

\section{Background}

Arterial stiffness is a CVD risk factor, which could contribute to the development of cognitive decline. Aortic stiffness has been consistently associated with cognitive performance and decline. However, data on carotid arterial stiffness in relation to cognitive performance are scarce, eventhough carotid stiffening may particularly affect the cerebral (micro-) circulation.

\section{Objectives}

We investigated the association of carotid and aortic stiffness with cognitive performance at six years of follow-up.

\section{Design}

Prospective cohort study.

\section{Setting}

The Hoorn Study, a population-based study, artificially enriched with type 2 diabetes (T2D) individuals.

\section{Participants}

364 participants (age $67.6 \pm 5.4$ years, $49.3 \%$ women, $19 \%$ T2D).

\section{Measurements}

Carotid artery stiffness (distensibility coefficient (DC) and Young's Elastic Modulus (YEM)) and aortic stiffness (carotid-femoral pulse wave velocity (cfPWV)) were assessed between 2000-2001 in $n=364$ and $n=155$ subjects respectively. Cognitive function tests for information processing speed, attention \& executive function and memory were assessed between 2005-2009. Linear regression analyses adjusted for age, follow-up duration, sex, and baseline variables of glucose metabolism, IQ, mean arterial pressure and CVD risk factors were used. Results are presented as regression coefficients $[95 \% \mathrm{Cl}]$ per 1 SD lower carotid DC, higher YEM or higher CfPWV.

\section{Results}

Lower carotid DC and higher YEM were significantly associated with lower processing speed and attention \& executive function in crude analyses, carotid DC: -0.210 [-0.297; -0.122], $-0.109[-0.177 ;-0.040]$ and YEM: -0.167 [-0.257; -0.078], -0.089 [-0.158; -0.020]; but the association attenuated after adjustment for age and follow-up duration. Fully adjusted regression coefficients were $-0.053[-0.152 ; 0.046]$ for carotid DC and $-0.008[-0.091 ; 0.076]$ 
for YEM. Carotid DC and YEM were not associated with memory function. Higher cfPWV was significantly associated with lower processing speed both in the crude $(-0.215$ [-0.328;$0.101]$ ) and the fully adjusted models: -0.144 [-0.267;-0.021]. CfPWV was not associated with attention \& executive function or memory function.

\section{Conclusion}

Carotid artery stiffness was associated with lower processing speed and attention \& executive function at six years of follow-up, however, the association greatly attenuated after adjustment for age and follow-up duration. Aortic stiffness was independently associated with lower processing speed at six years of follow-up, but not with attention \& executive function, or memory function.

\section{Key Words}

Aortic stiffness, carotid stiffness, cognitive decline, cognitive dysfunction. 


\section{Introduction}

In affluent countries, up to $36 \%$ of individuals above 70 years of age suffer from cognitive dysfunction [1] and thus are at an increased risk of developing dementia [2]. The above will have a considerable impact on the delivery of future health care in these countries, amongst others due to ageing of their populations [3].

Currently, there are no effective therapeutic strategies to treat cognitive dysfunction or to halt its progression to dementia. Consequently, there is a growing need to further elucidate its pathophysiology. Growing evidence suggests that arterial stiffness underlies the development of cognitive dysfunction in older individuals. Stiffening of the large elastic vessels, such as the aorta and the carotid arteries impairs their cushioning function, which allows greater pressure and flow pulsatility to reach the cerebral microvasculature [4], thus causing cerebral small vessel disease $[4,5]$. Accumulation of these (micro)vascular lesions may disrupt cerebral circuits and thus impair brain functions, leading to cognitive decline $[6,7]$. Indeed, in a recent meta-analysis by our group, greater stiffness of the aorta was associated with cognitive dysfunction [8].

Most previous studies on the association between arterial stiffness and cognitive dysfunction have focused upon aortic stiffness as measured by the carotid-to-femoral pulse wave velocity (cfPWV) [8]. It can be hypothesized, however, that stiffening of the carotid arteries, as measured by the distensibility coefficient (DC) and the Young's Elastic Modulus (YEM) may affect pressure and flow pulsatility upon the cerebral vasculature to a greater extent than aortic stiffening, considering their localization, anatomy and function [9]. Data on the association between carotid arterial stiffness and cognitive dysfunction is scarce and the results published thus far are contradicting. For instance, out of the four cross-sectional studies [10-13] three [10-12] reported a significant association between greater carotid arterial stiffness and cognitive dysfunction, whereas the sole longitudinal study [13] did not.

In view of these considerations we investigated whether carotid and aortic stiffness indices, such as the Carotid DC, Carotid YEM and the cfPWV, were associated with processing speed, attention \& executive function, and memory function after a follow-up period of six years by using data from the population-based Hoorn study. 


\section{Methods}

\section{Study population}

The Hoorn study is a longitudinal population-based cohort study, which investigates glucose metabolism, as well as cardiovascular risk factors, in the general population [14]. The study started in 1989, included 2484 men and women aged 50 to 74 years, of whom 1513 participated in the second examination in 1996-98. For this study, we used data from the third and fourth follow-up examinations. In the third assessment in 2000-2001, 648 individuals participated, individuals with impaired glucose metabolism and type 2 diabetes (T2D) were oversampled by design [15]. For the 2005-2009 examinations, all surviving participants of the 2000-2001 cohort, who were still living in Hoorn and could give an

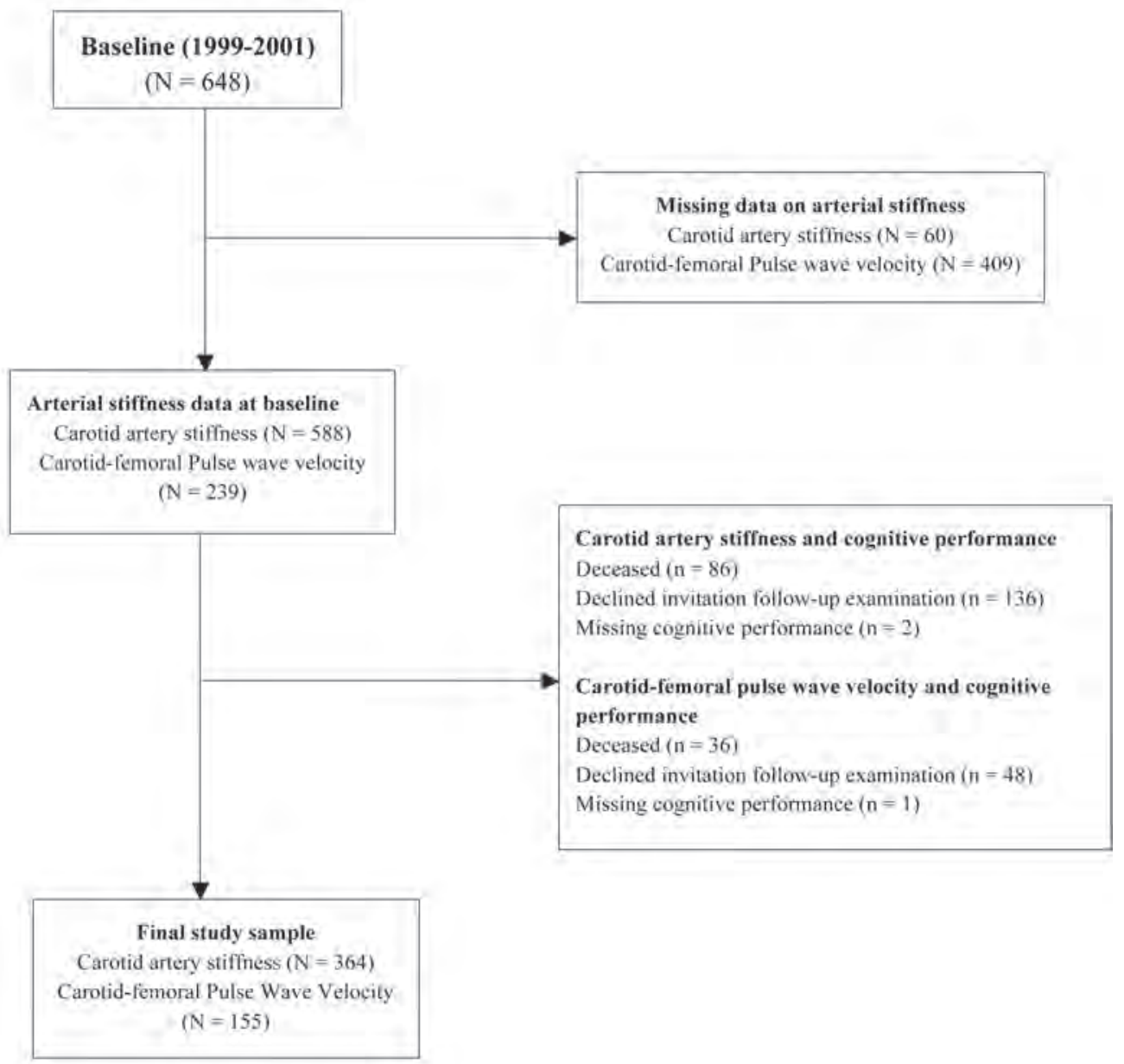

Figure 1: Flow Diagram 
informed consent $(n=505)$ were re-invited for neuropsychological examinations, of whom 380 agreed to participate. Carotid artery stiffness and carotid-femoral pulse wave velocity (cfPWV) measurements were carried out during the third examination (2000-2001), while cognitive performance was measured in the fourth examination (2005-2009).

Out of 648 participants in the third examination, 588 had a carotid artery measurement. During follow-up, 86 died prior to the fourth examination and 136 either declined to participate or had moved out of Hoorn. A total of 366 participants took part in the followup examination, of whom 364 had satisfactory data on cognitive performance (see Flow Diagram, Figure 1).

At the third examination, cfPWV was available in 239 participants, due to the belated acquisition of the device. Of these 36 died prior to the follow-up examination and 48 either declined to participate or had moved out of Hoorn. A total of 156 participants took part in the follow-up examination, of whom 155 had satisfactory data on cognitive performance.

\section{Arterial Stiffness Measurements}

\section{Carotid artery stiffness indices}

Carotid artery stiffness was assessed at the right common carotid artery according to international guidelines, as described previously [15]. Briefly, a single observer visualized the right carotid artery with an ultrasound scanner (350 Series [7.5-MHz linear probe], Pie Medical, the Netherlands) connected to a personal computer equipped with wall track software and an acquisition system (Wall Track System, Pie Medical). The carotid artery walls were detected by the software: the diameter and intima-media thickness (IMT) were assessed during the diastole, while the distension was defined as the movement of the carotid artery wall as a function of systolic duration. At each site, 3 consecutive 4-second measurements were carried out and the mean diameter, IMT and distension were used in the analyses. During the measurements, brachial systolic and diastolic pressures were assessed during the vascular measurements in the left upper arm at 5-minute intervals with an oscillometric device (Collin Press-Mate, BP-8800).

The distensibility coefficient was calculated as follows:

Distensibility coefficient $(D C)=\left(2 \Delta D \cdot D+\Delta D^{2}\right) /\left(\Delta P \bullet D^{2}\right)$ in $10^{-3} \bullet \mathrm{kPa}^{-1}$

where $\Delta \mathrm{D}$ is distension, $\mathrm{D}$ is diameter, and $\Delta \mathrm{P}$ is the brachial pulse pressure (defined as systolic pressure - diastolic pressure). The Young's elastic modulus (YEM) was calculated for the carotid artery, according to the formula: 
YEM=diameter/ (IMT • distensibility coefficient) in $\mathrm{kPa}$

DC represents carotid artery stiffness; and the YEM represents the stiffness of the carotid artery wall material at operating pressure.

\section{Calibrated carotid artery stiffness indices}

In a sensitivity analysis, the carotid artery pulse pressure was estimated from the carotid artery distension wave-forms and the brachial pulse pressure, as described previously [16]. The calibrated stiffness indices of the carotid artery were re-calculated using the carotid pulse pressure instead of the brachial artery pulse pressure, according to the formulas described above.

\section{Carotid-femoral Pulse Wave Velocity (cfPWV)}

The distance travelled by the pulse wave from the carotid artery, along the aorta, to the femoral artery was estimated using body height, as suggested by Weber et al. [17]. The carotid-femoral transit time was determined according to the time-decay method by using the distension curves of the right common carotid and the right femoral arteries and a simultaneous electrocardiograph trigger [18]. Pulse wave velocity was calculated as the ratio between distance travelled and travel time [19].

\section{Cognitive performance}

An extensive standardized neuropsychological test battery was obtained at the follow-up examination, including twelve verbal and non-verbal tasks, administered in a fixed order. The tasks were divided into six cognitive domains to reduce the number of neuropsychological variables and for clinical clarity. This division was made a priori, according to standard neuropsychological practice and cognitive theory, as described in detail in Lezak et al. [20]. In the current article, we focused on the cognitive domains which have been associated previously with arterial stiffness, namely information processing speed, attention \& executive function, and memory function [4,21,22]. The domain 'information processing speed' was assessed by the Trail Making Test Part A, the Stroop Colour-Word Test (parts I and II), and the subtest Digit Symbol of the WAIS-III. The domain 'attention and executive function' was assessed by the Trail Making Test Part B, the Stroop Colour-Word Test (part III), the Brixton Spatial Anticipation Test, a verbal fluency test using the $\mathrm{N}$ and $\mathrm{A}$, and category fluency using animal names. The domain 'memory' included tests for four subdomains: 'working memory' assessed by the forward and backward digit span of the Wechsler Adult Intelligence Scale-III (WAIS-III) and the Corsi Block-Tapping Task; 'immediate memory and learning rate', including verbal memory assessed by the Rey Auditory Verbal Learning Test and 'visual memory' assessed by the Location Learning Test; 'forgetting rate' assessed by the delayed task of the Rey Auditory Verbal Learning Test and of the Location Learning Test, and 'incidental memory' assessed by the delayed trial of the Rey-Osterrieth Complex 
Figure. Raw test scores were standardized into z-scores, after which cognitive domain scores were obtained by averaging the z-scores of the tests, which comprised that domain. Depressive symptoms were assessed with the validated Dutch version of the 20-item Centre for Epidemiologic Studies Depression Scale (CES-D) [23]. Scores on the CES-D range from 0 to 60 . Higher scores on this scale indicate the presence of more (severe) depressive symptoms. The presence of a depressive disorder was defined as CES-D score $\geq 16$ or the use of anti-depression medication at follow-up. Pre-morbid intelligence quotient (IQ) was estimated with the Dutch version of the National Adult Reading Test [24]. Estimated IQ was used instead of education level because, in the present population, access to education was linked to socio-economic factors instead of merit.

\section{Other measurements}

Glucose tolerance was defined according to the 1999 WHO criteria [25], based on a glucose tolerance test, fasting glucose measurements, as well as the use of glucose lowering medication [14]. Education level, smoking, physical activity and medication use were assessed by means of a questionnaire [15]. Body mass index (BMI), office blood pressure, glucose metabolism status, (micro)albuminuria, serum total, high- (HDL), and low-density lipoprotein (LDL) cholesterol and triglycerides were determined as described previously [26]. Glomerular filtration rate was estimated with the 4 variable MDRD equation (eGFR ${ }_{M D R D}$ ) [27]. Finally, prior CVD and hypertension were defined as described elsewhere [14,28].

\section{Statistical analyses}

All analyses were performed with IBM SPSS Statistics Version 22.0 (IBM Corp., Armonk, NY, USA). The associations of carotid stiffness or cfPWV with domains of cognitive performance six years later were assessed by means of linear regression analyses. Carotid artery stiffness and cfPWV were introduced as a sex-specific z-score [29]. Cognitive test scores were inversed if necessary, such that a lower score reflected lower cognitive performance and were introduced as z-scores. The analyses were adjusted for possible confounders as measured at baseline. Also, all models were adjusted for follow-up time in years, as the follow-up time had a range of 4 years (2005-2009). Lastly, depression is known to influence cognitive function, therefore, the models were also adjusted for depression at followup. The analyses were carried out according to the following models: model 1) crude, model 2) adjusted for age, sex, IQ, follow-up duration, model 3) additionally adjusted for mean arterial pressure (MAP), model 4) additionally adjusted for the following baseline measures: glucose metabolism status, heart rate, smoking, height, weight, hypertension, prior CVD, lipid modifying medication, triglycerides, total to HDL cholesterol ratio, eGFR ${ }_{M D R D}$ and depression at follow-up. Please note that lower values of Carotid DC but higher values of cfPWV and YEM reflect greater arterial stiffness. 


\section{Results}

\section{Baseline characteristics}

The clinical characteristics of the study population with carotid artery stiffness data ( $\mathrm{n}=$ 364) are shown in Table 1, mean age was $67.6 \pm 5.4$ years, $49.3 \%$ were women and the mean follow-up duration was $5.79 \pm 1.08$ years. Individuals with carotid artery stiffness measurements but without cognitive function data at follow-up ( $n=224$ ) were older and had a worse CVD risk profile than individuals with cognitive function data (Supplemental Table 1). The population with cfPWV data $(n=155)$ had comparable characteristics to the population with carotid artery stiffness data, but used less glucose lowering and blood pressure lowering drugs (Supplemental Table 1).

\section{Carotid artery stiffness and cognitive performance}

As shown in Table 2, in the crude model, lower carotid DC was associated with lower information processing speed and attention \& executive functions at follow-up, regression coefficients $[95 \% \mathrm{Cl}]$ were $-0.210[-0.297 ;-0.122]$ and $-0.109[-0.177 ;-0.040]$ per SD, respectively. The associations were attenuated and no longer statistically significant after adjustments for age, sex, follow-up duration and IQ (model 2, Table 2), especially due to the addition of age and follow-up duration. Further adjustments for MAP, other CVD risk factors and the presence of a depression disorder at follow-up did not alter the results (models 3 and 4, Table 2). The carotid DC was not associated with lower memory function either in the crude, or in the fully adjusted models (Table 2). Similarly, a higher YEM was associated with lower information processing speed and attention \& executive scores at follow-up, in the crude model, regression coefficients $[95 \% \mathrm{Cl}]$ were $-0.167[-0.257 ;-0.078]$ and $-0.089[-0.158 ;-0.020]$, respectively. However, the associations were attenuated and no longer statistically significant after adjustment for age, sex, follow-up duration and IQ (model 2, Table 2). Further adjustments did not alter the results (models 3 and 4, Table 2). YEM was not associated with lower memory function either in the crude, or in the fully adjusted models.

When we explored the association of individual elements of the stiffness indices with cognitive dysfunction neither the carotid diameter, carotid distension, nor the carotid or brachial pulse pressures were associated with any of the domains of cognitive performance (Supplemental Table 2).

\section{Carotid-femoral Pulse Wave Velocity and cognitive performance}

As shown in Table 3, higher cfPWV was associated with lower information processing speed at follow-up in the crude model, the regression coefficient $[95 \% \mathrm{Cl}]$ was $-0.215[-0.328$; -0.101]. The associations were attenuated but remained statistically significant after 
Table 1: Clinical characteristics of the study population at baseline

Study population with carotid artery stiffness data

( $n=364$ )

\section{Demographics}

Age, years

$67.6 \pm 5.4$

Female sex, \%

49.3

Education level, low/medium/high, \%

$20 / 40 / 40$

\section{Cardio-metabolic risk factors}

$\mathrm{BMI}, \mathrm{kg} / \mathrm{m} 2$

$27.1 \pm 3.4$

Waist-to-hip ratio

$0.92 \pm 0.10$

Glucose metabolism status, NGM/IGM/T2D, \%

$54 / 28 / 19$

Total cholesterol, $\mathrm{mmol} / \mathrm{L}$

$5.72 \pm 1.04$

$\mathrm{HDL}$ cholesterol, $\mathrm{mmol} / \mathrm{L}$

$1.43 \pm 0.41$

LDL cholesterol, $\mathrm{mmol} / \mathrm{L}$

$3.61 \pm 0.92$

Total to HDL cholesterol ratio

$4.26 \pm 1.25$

Triglycerides, $\mathrm{mmol} / \mathrm{L}$

$1.3[1.0-1.8]$

Systolic blood pressure, $\mathrm{mmHg}$

$138.1 \pm 17.6$

Diastolic blood pressure, $\mathrm{mmHg}$

$76.0 \pm 8.9$

Mean arterial pressure, $\mathrm{mmHg}$

$96.7 \pm 10.8$

Heart rate, beats per minute

$61.6 \pm 9.1$

Hypertension, \%

63.7

Prior CVD, \%

46.1

MDRD, $\mathrm{mL} / \mathrm{min}$ per $1.73 \mathrm{~m} 2$

$64.4 \pm 9.9$

\section{Lifestyle factors}

Smoking, never/former/current, \%

Physical activity per week (hours/week), median [IQR]*

\section{Medication}

Glucose lowering drugs, $\%$

Anti-hypertensive drugs, $\%$

Lipid modifying drugs, $\%$

\section{Arterial Stiffness}

Carotid Distensibility Coefficient (DC), $10^{\wedge}-3 / \mathrm{kPa}$

$11.9 \pm 4.2$

Carotid Young's Elastic Modulus, $10^{\wedge}-3 \mathrm{kPa}$

$0.90 \pm 0.40$

Carotid to femoral PWV, $\mathrm{m} / \mathrm{s}^{*}$

$9.88 \pm 3.28$

Pulse pressure, $\mathrm{mmHg}$

$62.2 \pm 13.2$

\section{Follow-up (2005-1009)}

Follow-up time, years

$5.79 \pm 1.08$

Intelligence Quotient (IO)

$98.00 \pm 12.98$

CES-D $\geq 16, \%$

Anti-depressive medication, \%

Depression, \%

Results are presented as $\%(\mathrm{n})$, mean \pm standard deviation or median [interquartile range].

${ }^{*}$ Available in $\mathrm{n}=155$ individuals. 
Table 2: Associations of carotid artery stiffness indices with cognitive performance domains at follow-up

\begin{tabular}{|c|c|c|c|}
\hline & $\begin{array}{c}\text { Attention \& Executive } \\
\text { Functions }\end{array}$ & Information Processing Speed & Memory \\
\hline \multicolumn{4}{|c|}{ Carotid Distensibility Coefficient $(n=364)$} \\
\hline Model 1 & $-0.109[-0.177 ;-0.040]$ & $-0.210[-0.297 ;-0.122]$ & $-0.049[-0.098 ; 0.001]$ \\
\hline Model 2* & $-0.034[-0.099 ; 0.031]$ & $-0.074[-0.006 ; 0.155]$ & $-0.002[-0.051 ; 0.048]$ \\
\hline Model 3 & $-0.028[-0.103 ; 0.047]$ & $-0.069[-0.161 ; 0.023]$ & $0.005[-0.052 ; 0.062]$ \\
\hline Model $4 * *$ & $-0.008[-0.091 ; 0.076]$ & $-0.053[-0.152 ; 0.046]$ & $0.010[-0.053 ; 0.074]$ \\
\hline \multicolumn{4}{|c|}{ Young's Elastic Modulus $(n=358)$} \\
\hline Model 1 & $-0.089[-0.158 ;-0.020]$ & $-0.167[-0.257 ;-0.078]$ & $-0.022[-0.072 ; 0.028]$ \\
\hline Model 2* & $-0.030[-0.092 ; 0.033]$ & $-0.063[-0.140 ; 0.014]$ & $0.015[-0.033 ; 0.062]$ \\
\hline Model 3 & $-0.026[-0.096 ; 0.044]$ & $-0.054[-0.141 ; 0.033]$ & $0.027[-0.026 ; 0.080]$ \\
\hline Model $4 * *$ & $-0.019[-0.092 ; 0.055]$ & $-0.036[-0.123 ; 0.052]$ & $0.030[-0.025 ; 0.086]$ \\
\hline
\end{tabular}

Results are presented as regression coefficients [95\% Confidence Interval] per standard deviation lower sex adjusted Carotid Distensibility Coefficient or higher sex-adjusted Young's Elastic Modulus. In the crude model, 1SD lower carotid distensibility was associated with $-0.109[-0.177 ;-0.040]$ lower attention \& executive functions score. Model 1: crude, Model 2: age, follow-up time, sex, IQ, Model 3: Model 2 + map, Model 4: Model 3 +, glucose metabolism status, height, weight, heart rate, MDRD, Total-HDL ratio, triglycerides, lipid modifying medications, hypertension, smoking, prior CVD, depression at follow-up. ${ }^{*} 5$ missing in model $2,{ }^{* *} 20$ missing in model 4

Table 3: Associations of carotid-femoral pulse wave velocity with cognitive performance domains at follow-up

\begin{tabular}{lccc}
\hline & $\begin{array}{c}\text { Attention \& Executive } \\
\text { Functions }(\mathbf{n}=\mathbf{1 5 4})\end{array}$ & $\begin{array}{c}\text { Information Processing Speed } \\
(\mathbf{n}=\mathbf{1 5 5})\end{array}$ & $\begin{array}{c}\text { Memory } \\
(\mathbf{n}=\mathbf{1 5 5})\end{array}$ \\
\hline Model 1 & $-0.042[-0.125 ; 0.041]$ & $\mathbf{- 0 . 2 1 5}[-\mathbf{0 . 3 2 8} ;-\mathbf{0 . 1 0 1}]$ & $-\mathbf{0 . 0 8 6}[-\mathbf{0 . 1 6 6} ;-\mathbf{0 . 0 0 7}]$ \\
Model 2* $_{\text {Model 3 }}$ & $0.024[-0.050 ; 0.097]$ & $\mathbf{- 0 . 1 2 0}[-\mathbf{0 . 2 2 6} ;-\mathbf{- 0 . 0 1 4}]$ & $-0.047[-0.125 ; 0.031]$ \\
Model 4** $^{*}$ & $0.038[-0.037 ; 0.114]$ & $\mathbf{- 0 . 1 1 8}[-\mathbf{0 . 2 2 7} ;-\mathbf{0 . 0 0 8}]$ & $-0.054[-0.135 ; 0.026]$ \\
\hline
\end{tabular}

Results are presented as regression coefficients [ $95 \%$ Confidence Interval] per standard deviation higher sex adjusted carotid-femoral Pulse Wave Velocity (cfPWV). In the crude model, 1 sex adjusted SD higher cfPWV was associated with $-0.043[-0.127 ; 0.041]$ lower attention \& executive funcion score.

Model 1: crude, Model 2: age, follow-up time, sex, IQ, Model 3: Model $2+$ map, Model 4: Model $3+$, glucose metabolism status, height, weight, heart rate, MDRD, Total-HDL ratio, triglycerides, lipid modifying medications, hypertension, smoking, prior CVD, depression at follow-up. ${ }^{*} 3$ missing in model $2,{ }^{* *} 6$ missing in model 4 
adjustments for age, sex, follow-up duration, IQ: -0.120 [-0.226; -0.014]. The association remained significant in the fully adjusted model: $-0.144[-0.267 ;-0.021]$. Higher cfPWV was also associated with lower memory function at follow-up in the crude model, the regression coefficient $[95 \% \mathrm{Cl}]$ was $-0.086[-0.166 ;-0.007]$. However, the associations were attenuated and were no longer statistically significant after adjustment for age, sex, follow-up duration and IQ (model 2, Table 3). CfPWV was not associated with attention \& executive function either in the crude, or in the fully adjusted model (Table 3).

Calculations using the regression coefficients of age and aortic stiffness (from the fully adjusted model) showed that one standard deviation increase in aortic stiffness was comparable with 3 years of ageing in the domain of information processing speed.

\section{Additional analyses}

When we excluded individuals with carotid artery $(n=5)$, or aortic ( $n=2)$ stiffness values greater than or lower than 3SD (outlier analyses), the associations did not materially change. When carotid artery stiffness indices were calibrated for carotid pulse pressure (cPP, $n=326$ ), the associations with domains of cognitive performance did not change (Supplemental Table 3).

When IQ was replaced by education level, and when height and weight were replaced by $\mathrm{BMI}$, the associations were not altered. When the models were additionally adjusted for incident stroke $(n=7)$, the associations were not altered. Similarly, when the associations were adjusted for the start of anti-hypertensive medication through-out the follow-up period, the results did not change.

\section{Discussion}

In this study, carotid artery stiffness was not significantly associated with any of the cognitive domains (information processing speed, attention \& executive function, or memory function) as measured at six years of follow-up. Aortic stiffness was modestly associated with lower information processing speed, but not with executive functions or memory.

To date, only few studies have investigated the association of carotid artery stiffness with cognitive performance [10-13]. Our findings are in accordance with the only other longitudinal population-based study available [13]. We found regression coefficients that were close to zero, with very broad confidence intervals, therefore it is unlikely that a larger study population would have yielded a significant association for carotid artery stiffness. 
In contrast, we did observe that higher aortic stiffness was associated with information processing speed at follow-up. The associations remained significant even after adjustment for many potential confounding factors. These findings are in agreement with previous studies that have reported significant associations of aortic stiffness with at least one cognitive domain [30-33] or with global cognitive scores [34-39]. Only two of these studies did assess information processing speed, of which one [30] showed a significant crosssectional, but not a longitudinal association; while the other [13] did not report any significant associations. As opposed to our study, these studies used only one test to assess processing speed, which might have hampered the power of their estimations. Indeed, in this study aortic stiffness was significantly associated with the domain score, while the associations with individual tests were only borderline significant.

There are several other potential reasons why we could not find a longitudinal association of carotid artery stiffness with cognitive performance. Firstly, our study might have been hampered by attrition bias, as a relatively large proportion of the individuals with baseline carotid stiffness did not participate in the follow-up measurements. These participants were older and had a more adverse CVD risk profile (including stiffer carotid arteries) than the individuals who were included in the longitudinal analyses, therefore they may have had a greater risk of cognitive dysfunction. This could have attenuated the longitudinal associations with cognitive dysfunction. Attrition bias could have been accentuated by the adverse CVD profile of the study population, which was due to the advanced age (mean age 68 years), the high prevalence of prior CVD and of T2D. Nonetheless, we did find an association of aortic stiffness with cognitive performance in a much smaller sample, therefore it is less likely that this played a decisive role. Secondly, competing risks could have resulted in an attenuation of the association with cognitive performance, as participants with greater arterial stiffness were also at increased risk of fatal CVD risk. Thirdly, individuals with the stiffest arteries could have been treated more intensively for hypertension than the remainder of the population due to their adverse cardiovascular risk profile [40]. As blood pressure lowering medication might improve arterial stiffness [41], this could have introduced bias towards the null. Finally, carotid stiffness may be less robust than aortic stiffness as its calculation requires the use of three ultrasound measured variables, each with its own measurement error. These short comings were partly compensated, however, by averaging data from three consecutive measurements.

There are several pathophysiologic mechanisms through which arterial stiffness could lead to cognitive decline. Firstly, arterial stiffness can lead to the development of cerebral small vessel lesions $[4,5]$. The cerebral microcirculation has a low impedance that facilitates the high blood flow required to meet the high metabolic demands of the brain [42]. The impairment of the cushioning function of the aorta allows greater pressure and flow 
pulsatility to penetrate deeply into the cerebral microcirculation, thus directly damaging the surrounding tissue [43-45]. Furthermore, the excessive pressure induces arteriolar remodelling and hypertrophy, which impairs vascular reactivity and contributes to repeated episodes of microvascular ischemia and tissue damage $[44,45]$. The accumulation of these (micro)vascular lesions may disrupt cerebral circuits and thus impair brain functions, leading to a decline in cognitive performance [6,7]. Secondly, arterial stiffness may lead to greater oscillations in wall shear stress, which may induce endothelial dysfunction as well as the production of low grade inflammatory markers by the endothelium [46-48]. Endothelial dysfunction could lead to cognitive decline through a disturbance of the process of neurogenesis $[49,50]$, through small vessel disease $[6,7]$, or through decreased cerebrovascular reactivity [51]. Systemic low-grade inflammation, on the other hand, could lead to cognitive decline by augmenting $\beta$ amyloid deposits [42-54] or by enhancing small vessel disease by promoting atherosclerosis of the large vessels [55].

In this study, only aortic, but not carotid artery stiffness was associated with cognitive performance. A possible explanation for this effect could be that the measurement of aortic stiffness (cfPWV) includes both elastic and muscular artery properties, whereas carotid artery stiffness mainly measures elastic properties [19]. The middle-sized cerebral arteries, which supply the cerebral anterior cerebral circulation, also have a muscular wall, therefore the cfPWV could reflect their stiffness levels better than the more elastic carotid arteries. Also, the aorta stiffens at a disproportionate rate compared to the carotid artery in response to old age, hypertension and T2D [56]. Due to the adverse CVD risk profile of our study population, this would have allowed the better detection of any associations of aortic, rather than carotid stiffness with cognitive performance.

Lastly, it is important to acknowledge that the modest effect sizes that we identified for aortic stiffness; however, reported associations may have been underestimated by potential over adjustment for multiple confounders, such as hypertension and other vascular risk factors that may lie in the causal pathway. Relatively speaking, one standard deviation higher pulse wave velocity was comparable with approximately 3 years of ageing in the domain of processing speed, which may be considered clinically relevant.

In conclusion, this study shows that greater carotid stiffness is not longitudinally associated with lower processing speed, attention \& executive function, or memory scores after a follow-up period of six years. Greater aortic stiffness, on the other hand, is modestly associated with lower information processing speed, but not with lower attention \& executive function, or memory function. 
Supplemental Table 1: Clinical characteristics of the study population according with carotid stiffness or pulse wave velocity measurements

\begin{tabular}{|c|c|c|}
\hline & $\begin{array}{l}\text { Study population with } \\
\text { cfPWV data } \\
(\mathrm{n}=155)\end{array}$ & $\begin{array}{l}\text { Baseline data but no } \\
\text { follow-up data } \\
\text { (n= 224) }\end{array}$ \\
\hline \multicolumn{3}{|l|}{ Demographics } \\
\hline Age, years & $66.8 \pm 4.9$ & $72.8 \pm 6.6$ \\
\hline Female sex, $\%$ & 49.4 & 53.1 \\
\hline Education level, low/medium/high, \% & $16 / 37 / 47$ & $48 / 40 / 12$ \\
\hline \multicolumn{3}{|l|}{ Cardio-metabolic risk factors } \\
\hline $\mathrm{BMI}, \mathrm{kg} / \mathrm{m} 2$ & $26.4 \pm 2.7$ & $26.8 \pm 3.9$ \\
\hline Waist-to-hip ratio & $0.92 \pm 0.09$ & $0.93 \pm 0.09$ \\
\hline Glucose metabolism status, NGM/IGM/T2D, \% & $53 / 32 / 16$ & $39 / 31 / 30$ \\
\hline Total cholesterol, mmol/L & $5.75 \pm 0.98$ & $5.76 \pm 1.03$ \\
\hline HDL cholesterol, mmol/L & $1.42 \pm 0.39$ & $1.44 \pm 0.42$ \\
\hline LDL cholesterol, mmol/L & $3.63 \pm 0.85$ & $3.68 \pm 0.90$ \\
\hline Total to HDL cholesterol ratio & $4.33 \pm 1.41$ & $3.99 \pm 1.24$ \\
\hline Triglycerides, mmol/L & $1.3[1.0-1.8]$ & $1.3[1.0-1.7]$ \\
\hline Mean Systolic blood pressure, mmHg & $136.9 \pm 16.2$ & $147.6 \pm 21.8$ \\
\hline Mean Diastolic blood pressure, $\mathrm{mmHg}$ & $76.6 \pm 8.4$ & $77.5 \pm 9.5$ \\
\hline Mean arterial pressure, $\mathrm{mmHg}$ & $96.7 \pm 9.8$ & $100.6 \pm 12.4$ \\
\hline Heart rate, beats per minute & $65.9 \pm 7.9$ & $63.3 \pm 9.2$ \\
\hline Hypertension, \% & 58.3 & 72.8 \\
\hline Prior CVD, \% & 42.9 & 57.1 \\
\hline eGFR, mL/min per $1.73 \mathrm{~m} 2$ & $64.7 \pm 10.4$ & $62.3 \pm 11.1$ \\
\hline \multicolumn{3}{|l|}{ Lifestyle factors } \\
\hline Smoking, never/former/current, \% & $41 / 43 / 17$ & $34 / 42 / 23$ \\
\hline $\begin{array}{l}\text { Physical activity per week (hours/week), } \\
\text { median [IQR]* }\end{array}$ & $21.5[14.1-31.0]$ & $21.2[8.13-29.8]$ \\
\hline \multicolumn{3}{|l|}{ Medication } \\
\hline Glucose lowering drugs, $\%$ & 4.5 & 12.1 \\
\hline Anti-hypertensive drugs, $\%$ & 23.1 & 38.8 \\
\hline Lipid modifying drugs, $\%$ & 14.7 & 13.4 \\
\hline \multicolumn{3}{|l|}{ Arterial Stiffness } \\
\hline Carotid Distensibility Coefficient, & $12.0 \pm 4.02$ & $9.34 \pm 3.8$ \\
\hline Carotid Young's Elastic Modulus & $0.89 \pm 0.40$ & $1.23 \pm 0.72$ \\
\hline Carotid to femoral PWV, $\mathrm{m} / \mathrm{s}^{*}$ & $9.75 \pm 3.26$ & $11.1 \pm 5.50$ \\
\hline Pulse pressure, $\mathrm{mmHg}$ & $60.3 \pm 13.4$ & $70.5 \pm 17.0$ \\
\hline \multicolumn{3}{|l|}{ Follow-up (2005-1009) } \\
\hline Follow-up time, years & $5.69 \pm 0.97$ & - \\
\hline Intelligence Quotient (IO) & $98.00 \pm 12.69$ & - \\
\hline CES-D $\geq 16$ & 8.4 & - \\
\hline Anti-depressive medication, \% & 3.6 & - \\
\hline Depression, $\%$ & 11.0 & - \\
\hline
\end{tabular}

Results are presented as $\%(\mathrm{n})$, mean \pm standard deviation or median [interquartile range]

${ }^{*}$ Available in $n=83$ /individuals 
Supplemental Table 2: Associations of carotid diameter, carotid distensibility, brachial and calibrated pulse pressures with cognitive performance domains at follow-up

\begin{tabular}{|c|c|c|c|}
\hline & Attention \& Executive Functions & Information Processing Speed & Memory \\
\hline \multicolumn{4}{|c|}{ Carotid Diameter $(n=363)$} \\
\hline Model 1 & $-0.055[-0.123 ; 0.014]$ & $-0.157[-0.247 ;-0.067]$ & $-0.013[-0.062 ; 0.037]$ \\
\hline Model 2* & $-0.013[-0.078 ; 0.052]$ & $-0.058[-0.139 ; 0.022]$ & $0.010[-0.039 ; 0.059]$ \\
\hline Model 3 & $-0.007[-0.074 ; 0.060]$ & $-0.051[-0.134 ; 0.033]$ & $0.013[-0.037 ; 0.064]$ \\
\hline Model 4** & $-0.018[-0.092 ; 0.057]$ & $-0.047[-0.136 ; 0.041]$ & $-0.008[-0.064 ; 0.048]$ \\
\hline \multicolumn{4}{|c|}{ Carotid Distension ( $\mathrm{n}=363$ ) } \\
\hline Model 1 & $-0.066[-0.134 ; 0.003]$ & $-0.108[-0.198 ;-0.018]$ & $-0.052[-0.102 ;-0.003]$ \\
\hline Model 2* & $-0.019[-0.080 ; 0.042]$ & $-0.041[-0.116 ; 0.035]$ & $-0.026[-0.072 ; 0.020]$ \\
\hline Model 3 & $-0.017[-0.078 ; 0.044]$ & $-0.038[-0.114 ; 0.037]$ & $-0.026[-0.072 ; 0.021]$ \\
\hline Model $4 * *$ & $0.005[-0.062 ; 0.071]$ & $-0.031[-0.0110 ; 0.048]$ & $-0.016[-0.066 ; 0.034]$ \\
\hline \multicolumn{4}{|c|}{ Brachial Pulse Pressure $(n=363)$} \\
\hline Model 1 & $-0.090[-0.158 ;-0.022]$ & $-0.147[-0.206 ;-0.028]$ & $-0.014[-0.063 ; 0.036]$ \\
\hline Model 2* & $-0.034[-0.097 ; 0.030]$ & $-0.033[-0.112 ; 0.045]$ & $-0.031[-0.017 ; 0.079]$ \\
\hline Model 3 & $-0.028[-0.109 ; 0.053]$ & $-0.011[-0.112 ; 0.090]$ & $0.056[-0.005 ; 0.117]$ \\
\hline Model $4 * *$ & $-0.043[-0.129 ; 0.042]$ & $-0.026[-0.128 ; 0.076]$ & $0.048[-0.017 ; 0.112]$ \\
\hline \multicolumn{4}{|c|}{ Carotid Pulse Pressure $(n=326)$} \\
\hline Model 1 & $-0.071[-0.001 ; 0.144]$ & $-0.158[-0.248 ;-0.067]$ & $-0.030[-0.082 ; 0.022]$ \\
\hline Model 2* & $0.004[-0.063 ; 0.071]$ & $-0.082[-0.162 ;-0.162]$ & $-0.015[-0.035 ; 0.065]$ \\
\hline Model 3 & $0.024[-0.060 ; 0.107]$ & $-0.091[-0.190 ;-0.008]$ & $-0.033[-0.029 ; 0.096]$ \\
\hline Model $4 * *$ & $0.019[-0.076 ; 0.115]$ & $-0.071[-0.182 ; 0.040]$ & $0.009[-0.063 ; 0.081]$ \\
\hline \multicolumn{4}{|c|}{$\begin{array}{l}\text { Results are presented as regression coefficients [ } 95 \% \text { Confidence Interval] per standard deviation higher carotid } \\
\text { diameter, brachial or calibrated pulse pressure and lower carotid distension. In the crude model, } 1 \text { SD higher carotid } \\
\text { diameter was associated with }-0.055 \text { [-0.123; } 0.014] \text { lower attention \& executive function score. Model } 1 \text { : crude, Model } \\
\text { 2: age, follow-up time, sex, IQ, Model } 3: \text { Model } 2+\text { map, Model } 4 \text { : Model } 3+\text {, glucose metabolism status, height, weight, } \\
\text { heart rate, MDRD, Total-HDL ratio, triglycerides, lipid modifying medications, hypertension, smoking, prior CVD, depres- } \\
\text { sion at follow-up. }{ }^{*} 5 \text { missing in model } 2,{ }^{* *} 20 \text { missing in model }\end{array}$} \\
\hline
\end{tabular}


Supplemental Table 3: Associations of calibrated carotid stiffness indices with cognitive performance domains at follow-up

\begin{tabular}{|c|c|c|c|}
\hline & Attention \& Executive Functions & Information Processing Speed & Memory \\
\hline \multicolumn{4}{|c|}{ Calibrated Carotid Distensibility Coefficient $(\mathrm{n}=326)$} \\
\hline Model 1 & $-0.132[-0.199 ;-0.066]$ & $-0.175[-0.264 ;-0.086]$ & $-0.035[-0.086 ; 0.017]$ \\
\hline Model 2* & $-0.047[-0.110 ; 0.016]$ & $-0.038[-0.120 ; 0.044]$ & $0.016[-0.036 ; 0.067]$ \\
\hline Model 3 & $-0.046[-0.116 ; 0.024]$ & $-0.029[-0.121 ; 0.062]$ & $0.025[-0.033 ; 0.082]$ \\
\hline Model 4** & $-0.034[-0.110 ; 0.042]$ & $-0.005[-0.102 ; 0.092]$ & $0.024[-0.039 ; 0.089]$ \\
\hline \multicolumn{4}{|c|}{ Calibrated Young's Elastic Modulus ( $\mathrm{n}=322$ ) } \\
\hline Model 1 & $-0.121[-0.188 ;-0.054]$ & $-0.175[-0.264 ;-0.085]$ & $-0.010[-0.062 ; 0.042]$ \\
\hline Model 2* & $-0.044[-0.105 ; 0.016]$ & $-0.058[-0.137 ; 0.021]$ & $0.035[-0.014 ; 0.085]$ \\
\hline Model 3 & $-0.042[-0.108 ; 0.025]$ & $-0.052[-0.139 ; 0.034]$ & $-0.049[-0.006 ; 0.103]$ \\
\hline Model 4** & $-0.033[-0.102 ; 0.035]$ & $-0.031[-0.119 ; 0.056]$ & $-0.048[-0.009 ; 0.104]$ \\
\hline
\end{tabular}

Results are presented as regression coefficients [95\% Confidence Interval] per standard deviation lower sex adjusted Calibrated Carotid Distensibility Coefficient or higher sex-adjusted Calibrated Young's Elastic Modulus. In the crude model, 1SD higher calibrated carotid distensibility was associated with $0.136[0.069 ; 0.202]$ higher attention \& executive function score. Model 1: crude, Model 2: age, follow-up time, sex, IQ, Model 3: Model 2 + map, Model 4: Model 3 +, glucose metabolism status, height, weight, heart rate, MDRD, Total-HDL ratio, triglycerides, lipid modifying medications, hypertension, smoking, prior CVD, depression at follow-up. ${ }^{*} 4$ missing in model $2,{ }^{* *} 19$ missing in model 4 


\section{References}

1 Plassman BL, Langa KM, Fisher GG, et al. Prevalence of cognitive impairment without dementia in the United States. Ann Intern Med. 2008 18; 148(6): 427-34

2 Mitchell AJ, Shiri_Feshki M. Rate of progression of mild cognitive impairment to dementia--meta-analysis of 41 robust inception cohort studies. Acta Psychiatr Scand 2009; 119(4): 252-65

3 United Nations. "World Population Ageing 2013".

4 Mitchell GF. Arterial Stiffness and Hypertension. Hypertension 2014; 64: 13-18.

5 Ding J, Mitchell GF, Bots ML, et al. Carotid arterial stiffness and risk of incident cerebral microbleeds in older people: the the Age, Gene/Environment Susceptibility (AGES)-Reykjavik study. Arterioscler Thromb Vasc Biol. 2015; 35(8):1889-95.

6 Brundel M, de Bresser J, van Dillen JJ, Kappelle LJ, Biessels GJ. Cerebral microinfarcts: a systematic review of neuropathological studies. J Cereb Blood Flow Metab. 2012;32(3):425-436

7 Van Rooden S, Good JD, van Opstal AM, et al. Increased number of microinfarcts in Alzheimer disease at 7-T MR imaging. Radiology 2014; 270(1):205-11.

8 Van Sloten TT, Protogerou AD, Henry RM, Schram MT, Launer LJ, Stehouwer CD. Association between arterial stiffness, cerebral small vessel disease and cognitive impairment: A systematic review and meta-analysis. Neurosci Biobehav Rev. 2015; 53:121-30.

9 van Sloten TT, Sedaghat S, Laurent S, London GM, Pannier B, Ikram MA, Kavousi M, Mattace-Raso F, Franco OH, Boutouyrie P, Stehouwer CD. Carotid stiffness is associated with incident stroke: a systematic review and individual participant data meta-analysis. J Am Coll Cardiol. 2015 ;66(19):2116-25.

10 Geijselaers SL, Sep SJ, Schram MT, et al. Carotid stiffness is associated with impairment of cognitive performance in individuals with and without type 2 diabetes. The Maastricht Study. Atherosclerosis, 2016; 253:186-193

11 Lim SL, Gao, Q, Nyunt MS et al. Vascular Health indices and cognitive domain function: Singapore longitudinal ageing studies. J. Alzheimer's Dis. JAD. 2015; 50: 27-40

12 Tarumi T, Gonzales MM, Fallow B, et al. Central artery stiffness, neuropsychological function, and cerebral perfusion in sedentary and central perfusion in sedentary and endurance-trained middle-aged adults. J Hypertens, 2013; 31(12): $2400-9$

13 Poels MM, van Oijen M, Mattace-Raso FU et al. Arterial stiffness, cognitive decline, and risk of dementia: the Rotterdam study. Stroke J Cereb circ. 2007; 38: 888-892

14 Mooy JM, Grootenhuis PA, de Vries H, et al. Prevalence and determinants of glucose intolerance in a Dutch Caucasian population: the Hoorn study. Diabetes Care. 1995; 18: 1270-1273

15 Henry RM, Kostense PJ, Spijkerman AM, et al. Arterial stiffness increases with deteriorating glucose tolerance status: the Hoorn Study. Circulation 2003;107:2089-95.

16 van Bortel LM, Balkestein EJ, van der Heijden-Spek JJ, et al. Non-invasive assessment of local arterial pressure: comparison of applanation tonometry and echo-tracking. J Hypertens. 2001;19:1037-1044.

17 Weber T, Ammer M, Rammer M, et al. Noninvasive determination of carotid-femoral pulse wave velocity depends critically on assessment of travel distance: a comparison with invasive measurement. J Hypertens 2009; 27:162430. 
18 Schram MT, Henry RM, van Dijk RA, et al. Increased central artery stiffness in impaired glucose metabolism and type 2 diabetes: the Hoorn study. Hypertension 2004;43:176-81.

19 Laurent S, Cockcroft J, van Bortel L, et al. Expert consensus document on arterial stiffness: methodological issues and clinical applications. Eur Heart J. 2006; 27(21): 2588-605

20 Lezak M, Howieson D, Loring D. Neuropsychological Assessment 2004 4th New York Oxford University Press

21 Hachinski V, ladecola C, Petersen RC et al. National Institute of Neurological Disorders and Stroke-Canadian Stroke Network vascular cognitive impairment harmonization standards. Stroke 2006; 37: 2220-2241

22 van den Berg E, Kloppenborg RP, Kessels RP, Kappelle LJ, Biessels GJ. Type 2 diabetes mellitus, hypertension, dyslipidemia and obesity: a systematic comparison of their impact on cognition. Biochim Biophys Acta. 2009; 1792: 470-481

23 Beekman AT, Deeg DJ, Van Limbeek J, Braam AW, De Vries MZ, Van Tilburg W. Criterion validity of the Center for Epidemiologic Studies Depression scale (CES-D): results from a community-based sample of older subjects in The Netherlands Psychol Med 199727 231-235

24 Schmand B, Lindenboom J, van Harskamp F. Nederlandse Leestest voor Volwassenen 1992 Lisse, The Netherlands Swets \& Zeitlinger

25 World Health Organization IDF Definition and Diagnosis of Diabetes Mellitus and Intermediate Hyperglycemia: Report of a WHO/IDF Consultation 2006Geneva, Switzerland WHO Document Production Services

26 Spijkerman AMW, Adriaanse MC, Dekker JM, et al. Diabetic patients detected by population-based stepwise screening already have a "diabetic" cardiovascular risk profile. Diabetes Care. 2002; 25: 1784-1789.

27 Levey AS, Bosch JP, Lewis JB, Greene T, Rogers N, Roth D. A more accurate method to estimate glomerular filtration rate from serum creatinine: a new prediction equation: Modification of Diet in Renal Disease Study Group. Ann Intern Med 1999; 130:461-470

28 The sixth report of the Joint National Committee on prevention, detection, evaluation, and treatment of high blood pressure. Arch Intern Med. 1997; 157: 2413-2446.

29 van Sloten TT, Mitchell GF, Sigurdsson S, et al. Arterial stiffness, depressive symptoms and mediation by cerebral small vessel disease: The AGES-Reykjavik Study. J Psychiatry Neurosci. 2016;41(3): 162-8.

30 Watson NL, Sutton-Tyrrell K, Rosano C. et al. Arterial stiffness and cognitive decline in well-functioning older adults. J. Gerontol. Ser. A Biol. Sci. Med. Sci. 2011; 66: 1336-1342

31 Waldstein SR, Rice SC, Thayer JF. et al. Pulse pressure and pulse wave velocity are related to cognitive decline in the Baltimore Longitudinal Study of Aging. Hypertension. 2008; 51: 99-1044

32 Tsao CW, Himali JJ, Beiser AS, et al. Association of arterial stiffness with progression of subclinical brain and cognitive disease. Neurology, 2016; 86 (7): 619-62

33 Hajjar I, Goldstein FC, Martin GS, Quyyumi AA et al. Roles of arterial stiffness and blood pressure in hypertensionassociated cognitive decline in healthy adults. Hypertension. 2016; 67(1):171-175

34 Lim LS, Gao Q, Nyunt N, et al. Vascular Health indices and cognitive domain function: Singapore longitudinal ageing studies. J. Alzheimer's Dis. JAD; 2015: 27-40

35 Scuteri S, Brancati AM, Gianni W, et al. Arterial stiffness is an independent risk factor for cognitive impairment in the elderly: a pilot study. J. Hypertens; 2005 (23): 1211-1216

36 Muller M, Grobbee DE, Aleman A, et al. Cardiovascular disease and cognitive performance in middle-aged and elderly men. Atherosclerosis; 2007 (190): 143-149 
37 Elias MF, Robbins MA, Budge MM, et al. Arterial pulse wave velocity and cognition with advancing age. Hypertension; 2009 (53): 668-673

38 Zhong W, Cruickshanks KJ, Schubert CR, Carlsson CM, Chappell RJ, Klein BE, Klein R, Acher CW. Pulse Wave Velocity and Cognitive Function in Older Adults. Alzheimer Dis Assoc Disord. 2013;28:44-49.

39 Hanon O, Haulon S, Lenoir H, Seux ML, Rigaud AS, Safar M, Girerd X, Forette F. Relationship between arterial stiffness and cognitive function in elderly subjects with complaints of memory loss. Stroke. 2005;36:2193-2197.

40 https://www.nhg.org/standaarden/samenvatting/cardiovasculair-risicomanagement

41 Al Ghatrif M, Strait JB, Morrell CH, Canepa M, Wright J, Elango P, et al. Longitudinal trajectories of arterial stiffness and the role of blood pressure: the Baltimore Longitudinal Study of Aging. Hypertension. 2013;62(5):934-41.

42 Mitchell GF, van Buchem MA, Sigurdsson S, et al. Arterial stiffness, pressure and flow pulsatility and brain structure and function: the Age, Gene/Environment Susceptibility - Reykjavik study

43 Tzourio C, Laurent S, Debette S. Is hypertension associated with an accelerated aging of the brain? Hypertension. 2014; 63:894-903.

44 O'Rourke MF, Safar ME. Relationship between aortic stiffening and microvascular disease in brain and kidney: cause and logic of therapy. Hypertension. 2005; 46:200-204.

45 Mitchell GF. Effects of central arterial aging on the structure and function of the peripheral vasculature: implications for end-organ damage. J Appl Physiol (1985). 2008; 105:1652-1660.

46 Chappell DC, Varner SE, Nerem RM, et al. Oscillatory shear stress stimulates adhesion molecule expression in cultured human endothelium. Circ Res 1998; 82(5): 532-539.

47 Shen $\mathrm{Q}$, Goderie SK, Jin L, et al. Endothelial cells stimulate self-renewal and expand neurogenesis of neural stem cells. Science 2004; 304: 1338-1340.

48 Chrinos JA. Large artery stiffness, microvascular function, and cardiovascular risk. Circ Cardiovasc Imaging 2016;9:e005903

49 Zhao C, Deng W, Gage FH. Mechanisms and functional implications of adult neurogenesis. Cell 2008; 132: 645-660.

50 Hoth KF, Tate DF, Poppas A, et al. Endothelial Function and White Matter Hyperintensities in Older Adults With Cardiovascular Disease. Stroke 2007; 38(2): 308-312.

51 Lemke H, de Castro AG, Schlattmann P, et al. Cerebrovascular reactivity over time-course - from major depressive disorder to remission. J Psychiatr Res 2010; 44: 132-136

52 Engelhart MJ, Geerlings MI, Meijer J, et al. Inflammatory proteins in plasma and the risk of dementia. Arch Neurol 2004;61:668-672

53 Zhao C, Deng W, Gage FH. Mechanisms and functional implications of adult neurogenesis. Cell 2008; 132: 645-660.

54 Hoth KF, Tate DF, Poppas A, et al. Endothelial Function and White Matter Hyperintensities in Older Adults With Cardiovascular Disease. Stroke 2007; 38(2): 308-312.

55 Ross R. Atherosclerosis - an inflammatory disease, N Engl J Med. 1999;340:115-126

56 Paini A, Boutouyrie P, Calvet D, Tropeano Al, Laloux B, Laurent S. Carotid and aortic stiffness: determinants of discrepancies. Hypertension 2006; 47:371 - 376 


\section{CHAPTER 5}

\section{Neither skin autofluorescence, nor plasma pentosidine, CML and CEL, are associated with carotid, femoral or brachial artery stiffness}

Veronica G. Onete, Miranda T. Schram, Simone J.S. Sep, Annemarie Koster, Carla J. van der Kallen, Pieter C. Dagnelie, Nicolaas Schaper, Ronald M. Henry, Casper G. Schalkwijk, Coen D.A. Stehouwer 


\section{Abstract}

\section{Background}

Stiffening of the carotid and femoral arteries is a cardiovascular disease (CVD) risk factor. Advanced Glycation End Product (AGE) accumulation in the vascular wall could contribute to this process. AGEs have been associated with the cfPWV, which represents the mixed elastic and muscular aorta; however, data on solely elastic or muscular arteries is lacking. We, therefore, investigated the associations of skin autofluorescence and plasma AGEs pentosidine, CML and CEL with the carotid, femoral and brachial artery stiffness indices.

\section{Method}

In the Maastricht Study (age 60 \pm 9 years, 45\% women, 29\% type 2 diabetes, $n=808$ ), tissue AGEs were measured by Skin Autofluorescence (SAF), while and plasma pentosidine, $\mathrm{n}\{$ epsilon\}(carboxymethyl)lysine(CML), $\mathrm{n}\{$ epsilon\}(carboxyethyl)lysine(CEL) were measured in plasma. The Young's Elastic Modulus (YEM) of the carotid, and distensibility coefficient (DC) of the carotid ( $n=808)$, femoral $(n=762)$ and brachial arteries $(n=740)$ were measured by ultrasound. Linear regression analyses were used to assess the association of AGEs with arterial stiffness parameters, adjusted for age, sex, glucose metabolism status, MAP and/ or PP, and other CVD risk factors. Results are presented as regression coefficients $[95 \% \mathrm{Cl}]$ per unit higher AGEs.

\section{Results}

SAF was associated with the carotid DC and YEM in the crude models: $-2.07[-2.70 ;-1.43]$ and $0.11[0.06 ; 0.15]$, but not after full adjustments: $0.41[-0.24 ; 1.06]$ and $-0.03[-0.08 ; 0.03]$. SAF was associated with a larger carotid lumen diameter in the crude and fully adjusted models: 274.6 [179.8;369.4] and 169.4 [62.2;276.6]. SAF was not associated with the femoral or brachial DC. Of the plasma AGEs, pentosidine was associated with the carotid YEM in the crude: 0.23 [0.07;0.39] and fully adjusted models: 0.19 [0.02;0.36], however, these associations lost significance after exclusion of stiffness outliers $( \pm 3 \mathrm{SD})$.

\section{Conclusion}

SAF and plasma AGEs pentosidine, CML and CEL were not associated with either elastic or muscular artery stiffness; but SAF is associated with carotid artery dilatation. 


\section{Introduction}

Arterial stiffening has been shown to be an independent cardiovascular (CVD) risk factor in the general population [1-4], as well as in patients with type 2 diabetes (T2D) [5] and end stage renal disease (ESRD) [6,7]. Loss of arterial elastic function steadily progresses throughout old age; however, it is accelerated in T2D and ESRD patients [8,9]. A possible mechanism of accelerated arterial stiffening could be the formation of advanced glycation end-products (AGEs). AGEs are reactive compounds which are formed at an accelerated rate in hyperglycaemic conditions, when glucose reacts with the amino acid residues of proteins, lipids, or nucleic acids via the non-enzymatic Maillard process [10]. Classically, this involves the formation of the reversible Amadori products, which then undergo additional reactions, such as dehydration, fragmentation, or oxidation resulting in the formation of irreversible AGEs [10].

The association of AGEs with aortic stiffness, as measured by the cfPWV has been shown in patients with diabetes [11-14], ESRD [15], and even in the general population [16-19], however the association of AGEs with carotid arterial stiffness has been investigated only in small, selected populations, which have yielded contradicting results. While one study showed that pentosidine was significantly associated with carotid artery stiffness in dialysis patients [20]; another did not find a significant association of CML with carotid artery stiffness in the general population [21]. Both these studies might have also been hampered by the measurement of plasma AGEs, which do not always reflect tissue AGE accumulation accurately [22]. Skin Autofluorescence (SAF) assesses accumulation of certain AGEs in the skin and may therefore offer an additional estimate of tissue AGE concentrations. Recently, our group has indeed shown in a population-based cohort that SAF and plasma pentosidine are associated with both aortic stiffness and central pulse pressure (ie. a marker of ascending aortic stiffness) [13]. Yet, the cfPWV is unable to distinguish between the properties of the aortic segments from the highly elastic descending thoracic aorta to the increasingly muscular abdominal aortic, iliac and femoral arteries. The use of stiffness indices of individual arteries could add more insight to AGE-associated aortic stiffening. The carotid is a predominantly elastic artery, which is stiffer than the thoracic aorta, but which is thought to resemble the elastic properties of the abdominal aorta [23]; whereas the femoral and the brachial stiffness indices are indicative of muscular artery properties. Both the carotid and the femoral stiffness indices have been shown to predict CVD events independent of each-other [4], which suggests that CVD risk factors, such as AGEs may differentially affect elastic and muscular arteries. 
In order to further understand AGE-associated arterial stiffening, we investigated whether $\mathrm{SAF}$ and the plasma AGEs pentosidine, $\mathrm{n}$ \{epsilon\}-(carboxymethyl)lysine (CML), $\mathrm{n}$ \{epsilon\}(carboxyethyl)lysine (CEL) are associated with local stiffness indices of the carotid, femoral or brachial arteries in a population-based cohort study.

\section{Methods}

\section{Study Population}

We used data from The Maastricht Study, an observational prospective population-based cohort focuses on the aetiology, pathophysiology, complications and comorbidities of type 2 diabetes mellitus (T2D) and is characterized by an extensive phenotyping approach. Eligible for participation were all individuals aged between 40 and 75 years and living in the southern part of the Netherlands. Participants were recruited through mass media campaigns and from the municipal registries and the regional Diabetes Patient Registry via mailings. Recruitment was stratified according to known T2DM status, with an oversampling of individuals with T2DM, for reasons of efficiency. The present report includes cross-sectional data from the first 866 participants, who completed the baseline survey between November 2010 and March 2012. The examinations of each participant were performed within a time window of three months. The study has been approved by the institutional medical ethical committee (NL31329.068.10) and the Minister of Health, Welfare and Sports of the Netherlands (Permit 131088-105234-PG). All participants gave written informed consent.

\section{Arterial stiffness}

Arterial stiffness was assessed non-invasively by means of vascular ultrasound and applanation tonometry. All measurements (approximately $45 \mathrm{~min}$ ) were done by trained vascular technicians unaware of the participants' clinical or diabetes status. Measurements took place in a quiet temperature-controlled room $\left(21-23^{\circ} \mathrm{C}\right)$ and were performed in supine position, after $10 \mathrm{~min}$ of rest. Talking or sleeping was not allowed during the examination. A three-lead electrocardiogram was recorded continuously during the measurements to facilitate automatic signal processing. In addition, brachial systolic, diastolic, and mean arterial pressure (MAP), as well as the heart rate were determined repeatedly with a 5-min interval, using an oscillometric device (Accutorr Plus, Datascope Inc., Montvale, NJ, USA), and the average of these measurements was calculated.

Elastic properties of the left common carotid (at least $10 \mathrm{~mm}$ proximal to the carotid bulb), right common femoral and right brachial arteries were obtained by using an ultrasound scanner equipped with a 7.5-MHz linear probe (MyLab 70, Esaote Europe B.V., Maastricht, the Netherlands). This setup enabled the measurement of diameter (D), distension (DD) 
and intima-media thickness (IMT) as described in more detail elsewhere [24,25]. In brief, during the ultrasound measurements, a B-mode image based on $19 \mathrm{M}$-lines was depicted on screen and an online echo-tracking algorithm showed real-time anterior and posterior arterial wall displacements. The $\mathrm{M}$-mode recordings were composed of 19 simultaneous recordings at a frame rate of $498 \mathrm{~Hz}$. The distance between the $\mathrm{M}$-line recording positions was $0.96 \mathrm{~mm}$, thus, a total segment of $18.24 \mathrm{~mm}$ of each artery was covered by the scan plane. For offline processing, the radiofrequency signal was fed into a dedicated PC-based acquisition system (ART.LAB, Esaote Europe B.V. Maastricht, the Netherlands) with a sampling frequency of $50 \mathrm{MHz}$ Data processing was performed in MatLab (version 7.5,

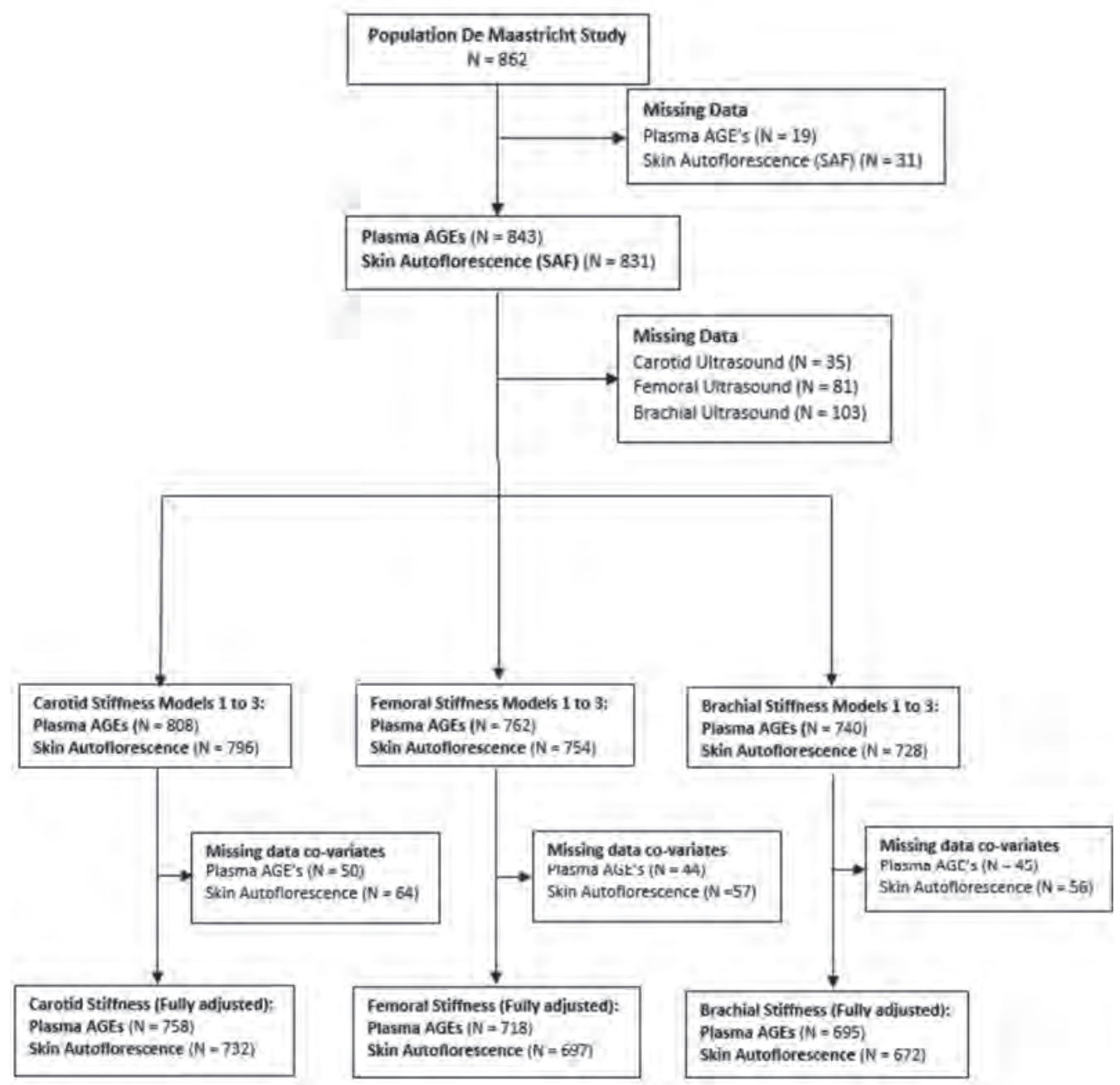

Figure 1. Flow Diafram 
Mathworks, Natick, MA, USA). The distension waveforms were obtained from the radio frequency data with the use of a wall track algorithm [24]. Carotid IMT was defined as the distance of the posterior wall from the leading edge interface between lumen and intima to the leading edge interface between media and adventitia [25]. The median InterAdventitial Diameter (IAD), Lumen Diameter (LD), distension (systolic diameter change), and Intime Media Thickness (IMT) of three measurements were used in the analyses. Combined with brachial pulse pressure (PP), these measures were used to calculate the following conventional stiffness indices [26]:

Distensibility Coefficient (DC)

$D C=\left(2 \Delta D \cdot I A D+\Delta D^{2}\right) /\left(P P \cdot I A D^{2}\right) \quad\left(10^{-3} \mathrm{kPa}^{-1}\right)$

Young's elastic modulus (YEM) (Carotid Artery Only):

YEM = IAD / (IMT · DC) $\quad\left(10^{3} \mathrm{kPa}\right)$

, where $\mathrm{D}$ is the diastolic Carotid Diameter and $\Delta \mathrm{D}$ is the carotid distension. The $\mathrm{DC}$ represents arterial stiffness, while the YEM represents the stiffness of the arterial wall material at operating pressure. Please note that lower values of DC, but higher values of YEM reflect greater arterial stiffness.

Lastly, the diastolic Lumen Diameter was calculated for the carotid artery as follows:

$(L D)=I A D-2 * I M T$.

\section{Local carotid pulse pressure}

Pulse pressure at the carotid artery was calculated by calibrating the systolic-diastolic amplitude of the carotid artery tonometry waveform (sys-dias) tono $_{\text {o }}$ to pressure, assuming a constant difference between mean arterial pressure (MAP) and diastolic pressure (DP) along the large arteries: PPcar $=(\text { sys-dias })_{\text {tono }} *(\text { MAP-DP })_{\text {brach }} /(\text { mean-dias })_{\text {tono }}$.

This procedure is the same as those described by Kelly and Fitchett. [27] and Van Bortel et al. [28], except that the MAP and DP values at the brachial artery were taken as the respective averages over the vascular measurements (i.e. over a 30 to $45 \mathrm{~min}$ period) as obtained with a validated commercial oscillometric device (Accutorr Plus, Datascope Inc., Montvale, NJ, USA). Cited procedures considered the mean-diastolic difference as obtained from a measured brachial artery pressure or diameter waveform.

The calibrated DC (CaI DC) and the calibrated (Cal YEM) were re-calculated for the carotid artery by replacing the brachial PP with the local carotid PP. 


\section{Reproducibility}

Reproducibility was assessed in 12 individuals ( 6 men; $60.8 \pm 6.8$ years; 6 with type 2 diabetes) who were examined by two observers at two occasions spaced one week apart. The intra- and inter-observer intra-class correlation coefficients were for the carotid DC 0.85 and 0.73 , for the YEM 0.72 and 0.71 and for the femoral DC 0.49 and 0.32 , respectively.

\section{Skin Autofluorescence (SAF)}

All participants were asked to refrain from smoking and caffeine at least 3 hours before the measurements. A light meal (breakfast or lunch), low in fat content, was allowed. SAF was measured with the AGE Reader (DiagnOptics Technologies BV, Groningen, The Netherlands). The AGE reader is a desktop device that uses the characteristic fluorescent properties of certain AGEs to estimate the level of AGE accumulation in the skin. Technical details of this non-invasive method have been described more extensively elsewhere [29]. In short, the AGE Reader illuminates a skin surface of $4 \mathrm{~cm}^{2}$ guarded against surrounding light, with an excitation wavelength range of 300 to $420 \mathrm{~nm}$, with a peak excitation of $370 \mathrm{~nm}$. SAF was calculated as the ratio between the emission light from the skin in the wavelength range of 420 to $600 \mathrm{~nm}$ (fluorescence) and excitation light that is reflected by the skin (300-420 nm), multiplied by 100 and expressed in arbitrary units. Participants were asked not to use any sunscreen or self-browning creams on their lower arms within 2 days before the measurement. SAF was measured at room temperature in a semidark environment, whereas participants were at rest in a seated position. The inner side of the forearm $\approx 4 \mathrm{~cm}$ below the elbow fold of a participant was positioned on top of the device, as described by the manufacturer. The mean of 3 consecutive measurements was used in the analyses. Reproducibility was assessed in 14 individuals without diabetes mellitus ( 6 men; 32.2 \pm 7.1 years). The intraclass correlation coefficient of 3 intraindividual consecutive SAF measurements was 0.83 (95\% confidence interval $[\mathrm{Cl}], 0.65-0.94)$. SAF was calculated offline by automated analysis using AGE Reader software, version 2.3, and was observer independent. There were no significant differences between fasting and nonfasting measurements (mean difference $=0.01$ arbitrary units; $P=0.73$ ). Reproducibility in individuals with T2DM has been evaluated previously [29] with an overall Altman error percentage of $5.03 \%$ for measurements taken over a single day. Skin pigmentation is known to influence the measurement of SAF [30]. Therefore, in participants with dark-coloured skin with a reflectance of $6 \%$ to $10 \%$, a validated reflectance-dependent correction was made by the software [30]. Measurements in participants with dark-coloured skin and a mean reflectance below $6 \%$ are considered unreliable and are therefore not used to calculate SAF by the software. Therefore, these participants were automatically excluded $(n=1)$. Additionally, a single SAF value above 10 arbitrary units was considered as unreliable; these individual measurements $(n=3)$ were manually excluded, and the mean of the remaining 2 measurements was used in analyses. 


\section{Analysis of Protein-Bound AGEs and Lysine in Plasma}

Plasma AGEs were measured in EDTA samples obtained from fasting venous blood, which were stored at $-80{ }^{\circ} \mathrm{C}$ until analysis. Protein-bound pentosidine was quantified using highperformance liquid chromatography with fluorescence detection, as described in detail elsewhere [31]. Intra- and interassay coefficients of variation, as analysed in this study, were $6.5 \%$ and $7.8 \%$ for pentosidine, respectively. Protein-bound $\mathrm{N} \varepsilon$-(carboxymethyl)lysine $(\mathrm{CML})$ and $\mathrm{N} \varepsilon$-(carboxyethyl)lysine (CEL) and lysine were quantified using ultra-performance liquid chromatography tandem mass-spectrometry [32]. Intra- and inter assay coefficients of variation were $4.5 \%$ and $6.7 \%$ for $\mathrm{CML}, 6.2 \%$ and $10.3 \%$ for $\mathrm{CEL}$, and $5.0 \%$ and $5.3 \%$ for lysine. Concentrations of protein-bound pentosidine, CML, and CEL were adjusted for levels of lysine and expressed as $\mathrm{nmol} / \mathrm{mmol}$ lysine.

\section{Covariates}

Height, weight and body mass index (BMI) were measured as previously described [33]. Smoking and prior CVD were assessed by means of web-based questionnaires. Smoking was divided into three categories: never, former and current smoking. Prior CVD was defined as a history of myocardial infarction, stroke, or vascular surgery (including angioplasty) of coronary, carotid, abdominal aortic, or peripheral arteries based on the Rose questionnaire [34]. The use of blood-pressure and glucose lowering, as well as, lipid modifying medication was inventoried during a medication interview as described previously [33]. Office blood pressure was calculated as the average of at least three blood pressure readings (Omron 705IT, Japan) performed after a minimum of $10 \mathrm{~min}$ of seated rest. Hypertension was defined as an office systolic blood pressure $>140 \mathrm{mmHg}$ or as an office diastolic blood pressure $>90 \mathrm{mmHg}$ and/or the use of blood pressure lowering medication. To assess glucose metabolism status, all participants (except those who used insulin) underwent a standardized 2-hour 75-g oral glucose tolerance test after an overnight fast. For safety reasons, participants with a fasting glucose level above $11.0 \mathrm{mmol} / \mathrm{L}$, as determined by a finger prick, did not undergo the oral glucose tolerance test. For these individuals, fasting glucose level and information about diabetes medication use were used to assess glucose metabolism status. Glucose metabolism status was defined according to the World Health Organization 2006 criteria as normal glucose metabolism (NGM), prediabetes, and T2DM [35]. Serum concentrations of total cholesterol, high-density lipoprotein (HDL) cholesterol, and triglycerides were measured using an automatic analyser (Beckman Synchron LX20, Beckman Coulter Inc., Brea, USA). Glomerular Filtration Rate (GFR) was estimated with the CKD-EPI equation based on the combination of serum creatinine and serum cystatin C [36]. Albuminuria was based on the average of one or preferably two 24-h urine collections and was defined as an urinary albumin excretion $\geq 30 \mathrm{mg} / 24 \mathrm{~h}$. 


\section{Statistical analyses}

All analyses were performed with IBM SPSS Statistics Version 22.0 (IBM Corp., Armonk, NY, USA). Characteristics of the study population were compared according to Carotid YEM tertiles by means of an ANOVA test for normally distributed continuous variables, and by means of a linear-by linear chi-squared test for dichotomous or ordinal variables. Continuous variables with a skewed distribution were log10-transformed. A two-tailed $P$ value of less than 0.05 was considered statistically significant.

Firstly, we assessed the associations of AGEs with the carotid YEM and the DC of all arteries by means of linear regression analyses. The models were adjusted for possible confounders as follows: model 1) crude, model 2) adjusted for age, sex, glucose metabolism status (GMS), model 3) additionally adjusted for mean arterial pressure (MAP), model 4) additionally adjusted for heart rate, height, weight, smoking, lipid-modifying and bloodpressure-lowering medication, triglycerides, total to HDL cholesterol ratio, prior CVD, eGFR and albuminuria. (Note that lower values of Carotid DC but higher values of YEM reflect greater arterial stiffness.)

Secondly, we analysed the association of AGEs with the arterial distension, which is an indirect measure of arterial stiffness. These models were additionally adjusted for the diastolic arterial diameter and PP as follows: model 1) adjusted for the diastolic arterial diameter, model 2) additionally adjusted for age, sex, GMS, model 3) additionally adjusted for mean arterial pressure (MAP), model 4) additionally adjusted for heart rate, height, weight, smoking, lipid modifying and blood pressure lowering medication, triglycerides, total to HDL cholesterol ratio, prior CVD, eGFR and albuminuria, model 5) additionally adjusted for PP.

Thirdly, the associations of AGEs with arterial stiffness elements: the arterial IAD, the carotid IMT and the carotid lumen diameter was assessed by means of linear regression analyses, according to the models described above.

Due to its skewed distribution pentosidine was log10-transformed. Also, the observed associations of pentosidine with all outcome measures were not completely linear, therefore it was introduced in the regression analyses as both a continuous and as categorial variable (divided in tertiles: the lowest pentosidine tertile was used as the reference category). All other AGEs were introduced as continuous variables.

Finally, in order to account for the oversampling of T2D, we introduced interaction terms for GMS in all mode, however none of these were statistically significant $(p>0.10)$. Also, the stiffness of the carotid and femoral arteries increases more rapidly with age in women 
than in men $[37,38]$; thus, suggesting that the associations of AGEs with local stiffness indices could differ according to sex. We, therefore added interaction terms for sex in the third model, but none were statistically significant $(p>0.10)$.

\section{Results}

Carotid artery stiffness measurements were available in 825 out of 866 participants. Of these, data on SAF and plasma AGES were available in respectively $n=808$ and $n=796$. Data on co-variates, such as prior CVD, smoking status and alcohol use were missing in $n=50$ and $n=64$, respectively (see Flow Diagram). Missing carotid artery stiffness, AGEs and covariates data were mostly due to logistic reasons or technical failure. Femoral and brachial artery stiffness indices were computed in 778 and 754 individuals respectively, due to the lower quality of the ultrasound recordings as compared to carotid artery.

Table 1 shows the characteristics of the study population according to tertiles of Carotid YEM. Individuals with a higher YEM (i.e. stiffer arteries) were older and taller than the individuals with more elastic arteries. They also had a more adverse CVD risk profile with a greater weight and BMI, more T2D, higher triglyceride levels, more hypertension, higher eGFR, and higher prevalence of albuminuria, and use of blood-pressure-lowering, lipidmodifying and glucose-lowering medication, in addition to a higher systolic and diastolic blood pressure and a higher heart rate during arterial stiffness measurements.

\section{SAF and carotid artery stiffness and its elements}

Higher SAF was associated with a higher carotid YEM and a lower carotid DC, unstandardized regression coefficients $[95 \% \mathrm{Cl}]$ were $0.11\left(10^{\wedge} 3 \mathrm{kPa}\right)[0.06 ; 0.15]$ and: $-2.07\left(10^{\wedge}-3 \mathrm{kPa}\right)$ [-2.70; -1.43], in the crude models; however, the associations were attenuated and were no longer significant after adjustment for age, sex and GMS: -0.01 [-0.06;0.04] and 0.21 $[-0.47 ; 0.86]$, respectively. Additional adjustments for MAP and other CVD risk factors did not alter the associations (Models 3 and 4, Table 2).

Higher SAF was significantly associated with a greater carotid IAD in the crude models, $378.9 \mu \mathrm{m}$ [271.0;486.9], in the fully adjusted models 163.3 [42.2;284.4], as well as after additional adjustment for the brachial PP (Table 3) or the carotid PP (Supplemental Table 4). Similarly, higher SAF was associated with a higher carotid Lumen Diameter in the crude: 274.6 $\mu \mathrm{m}$ [179.8;369.4] and in the fully adjusted models: 170.2 [63.2;277.1], as well as after additional adjustment for the brachial PP (Table 3) and the carotid PP (Supplemental Table 4). SAF was not significantly associated with either the carotid distension, the carotid IMT, the brachial PP or the carotid PP in the fully adjusted models (Table 3). 
Table 1: Baseline Characteristics according to tertiles of the Carotid Young Elastic Modulus (YEM) ( $n=825)$

\begin{tabular}{|c|c|c|c|c|}
\hline & $\begin{array}{l}\text { 1st tertile } \\
(\mathrm{n}=275)\end{array}$ & $\begin{array}{l}\text { 2nd tertile } \\
(\mathrm{n}=275)\end{array}$ & $\begin{array}{l}\text { 3rd tertile } \\
(\mathrm{n}=275)\end{array}$ & p-linear \\
\hline \multicolumn{5}{|l|}{ Demographics } \\
\hline Age, years & $55.8 \pm 8.7$ & $60.5 \pm 8.1$ & $63.5 \pm 6.7$ & $<0.001$ \\
\hline Female sex, $\%$ & 45.8 & 44.7 & 45.8 & 1.00 \\
\hline \multicolumn{5}{|l|}{ Cardio-metabolic risk factors } \\
\hline Smoking, never/former/current, \% & $32.1 / 46.4 / 21.5$ & $29.7 / 56.5 / 13.8$ & $30.2 / 56.0 / 13.8$ & 0.310 \\
\hline Height, m & $172.7 \pm 8.2$ & $171.9 \pm 9.6$ & $170.4 \pm 8.5$ & 0.01 \\
\hline Weight, kg & $78.2 \pm 15.2$ & $81.9 \pm 15.5$ & $81.8 \pm 15.0$ & 0.01 \\
\hline $\mathrm{BMI}, \mathrm{kg} / \mathrm{m} 2$ & $26.2 \pm 4.6$ & $27.6 \pm 4.2$ & $28.2 \pm 4.5$ & $<0.001$ \\
\hline Glucose metabolism status, NGM/IGM/DM2, \% & $64.0 / 15.6 / 20.4$ & $54.5 / 14.9 / 30.5$ & 45.5/17.5/37.1 & $<0.001$ \\
\hline Total cholesterol, $\mathrm{mmol} / \mathrm{L}$ & $5.2 \pm 1.1$ & $5.3 \pm 1.2$ & $5.2 \pm 1.3$ & 0.823 \\
\hline HDL cholesterol, mmol/L & $1.4 \pm 0.5$ & $1.3 \pm 0.4$ & $1.3 \pm 0.4$ & 0.093 \\
\hline LDL cholesterol, mmol/L & $3.3 \pm 0.9$ & $3.3 \pm 1.1$ & $3.2 \pm 1.1$ & 0.811 \\
\hline Total to HDL cholesterol ratio & $4.1 \pm 1.3$ & $4.2 \pm 1.2$ & $4.3 \pm 1.2$ & 0.449 \\
\hline Triglycerides, mmol/L & $1.1[0.8-1.6]$ & $1.2[0.9-1.8]$ & $1.4[1.0-2.0]$ & $<0.001$ \\
\hline Systolic blood pressure, mmHg & $120.9 \pm 12.7$ & $130.2 \pm 12.4$ & $135.6 \pm 14.6$ & $<0.001$ \\
\hline Diastolic blood pressure, $\mathrm{mmHg}$ & $73.2 \pm 6.6$ & $77.7 \pm 6.6$ & $79.1 \pm 8.0$ & $<0.001$ \\
\hline Mean arterial pressure, mmHg & $92.1 \pm 9.0$ & $99.0 \pm 9.0$ & $102.3 \pm 10.4$ & $<0.001$ \\
\hline Heart rate beats per minute & $61.0 \pm 7.7$ & $63.6 \pm 8.7$ & $65.6 \pm 9.3$ & $<0.001$ \\
\hline Hypertension, \% & 40.7 & 62.2 & 71.2 & $<0.001$ \\
\hline Prior CVD, \% & 14.8 & 20.2 & 20.0 & 0.121 \\
\hline eGFR, mL/min per $1.73 \mathrm{~m} 2$ & $91.3 \pm 15.4$ & $87.7 \pm 15.1$ & $84.8 \pm 14.7$ & $<0.001$ \\
\hline Microalbuminuria, $\%$ & 5.9 & 7.3 & 10.8 & $0 . .037$ \\
\hline \multicolumn{5}{|l|}{ Medication use } \\
\hline Anti-hypertensive drugs, $\%$ & 30.2 & 40.7 & 47.6 & $<0.001$ \\
\hline Lipid modifying drugs, \% & 28.4 & 38.9 & 44.0 & $<0.001$ \\
\hline Glucose lowering drugs, $\%$ & 16.4 & 24.7 & 27.6 & 0.002 \\
\hline \multicolumn{5}{|l|}{ Stiffness related indices } \\
\hline $\begin{array}{l}\text { Carotid Artery Distensibility Coefficient (DC), } \\
10^{\wedge}-3 / \mathrm{kPa}\end{array}$ & $18.7 \pm 4.0$ & $13.1 \pm 2.2$ & $8.9 \pm 2.2$ & $<0.001$ \\
\hline Carotid Artery Distensibility, um & $416[357-484]$ & 338 [284 - 401] & $254[209-304]$ & $<0.001$ \\
\hline Carotid Artery Inter-Adventitia Diameter, um & $7625.3 \pm 805.7$ & $7860.8 \pm 892.4$ & $8012.2 \pm 834.8$ & $<0.001$ \\
\hline Carotid Artery Lumen Diameter, um & $5894.0 \pm 666.7$ & $6154.5 \pm 752.4$ & $6333.4 \pm 748.1$ & $<0.001$ \\
\hline Carotid Artery Intima Media Thickness (IMT), um & $865.7 \pm 155.7$ & $853.2 \pm 144.7$ & $839.4 \pm 155.1$ & 0.129 \\
\hline Brachial Pulse Pressure, mmHg & $47.6 \pm 9.0$ & $52.5 \pm 9.3$ & $56.5 \pm 11.0$ & $<0.001$ \\
\hline Calibrated Carotid Artery Pulse Pressure, mmHg & $45.6 \pm 12.1$ & $51.9 \pm 13.4$ & $56.3 \pm 15.0$ & $<0.001$ \\
\hline \multicolumn{5}{|l|}{ Advanced Glycation End Products } \\
\hline Pentosidine, $\mathrm{nmol} / \mathrm{mmol}$ & $0.46[0.38-0.54]$ & $0.47[0.39-0.56]$ & $0.48[0.38-0.60]$ & 0.204 \\
\hline $\mathrm{CML}, \mathrm{nmol} / \mathrm{mmol}$ & $75.5 \pm 15.8$ & $74.9 \pm 14.5$ & $73.0 \pm 13.9$ & 0.127 \\
\hline $\mathrm{CEL}, \mathrm{nmol} / \mathrm{mmol}$ & $33.3 \pm 9.9$ & $34.4 \pm 9.8$ & $34.7 \pm 11.0$ & 0.243 \\
\hline Skin Auto-Florescence (SAF), AU & $2.6 \pm 0.5$ & $2.7 \pm 0.6$ & $2.8 \pm 0.5$ & $<0.001$ \\
\hline
\end{tabular}

Results are presented as $\%$, mean \pm standard deviation or median [interquartile range] 
Table 2. The Association of plasma Advanced Glycation End Products (AGEs) and Skin Autofluorescence (SAF) with carotid, femoral and brachial stiffness indices

\begin{tabular}{|c|c|c|c|c|c|}
\hline \multirow[t]{2}{*}{ Plasma AGEs } & \multirow[t]{2}{*}{ Models } & \multicolumn{2}{|c|}{$\begin{array}{l}\text { Carotid Artery } \\
(\mathrm{N}=808)\end{array}$} & \multirow{2}{*}{$\begin{array}{c}\text { Femoral Artery } \\
(\mathrm{N}=762) \\
\text { Distensibility } \\
\text { Coefficient (DC) }\end{array}$} & \multirow{2}{*}{$\begin{array}{c}\begin{array}{c}\text { Brachial Artery } \\
\text { (N = 740) }\end{array} \\
\text { Distensibility } \\
\text { Coefficient (DC) } \\
\end{array}$} \\
\hline & & $\begin{array}{l}\text { Distensibility } \\
\text { coefficient (DC) }\end{array}$ & $\begin{array}{l}\text { Young Elastic } \\
\text { Modulus (YEM) }\end{array}$ & & \\
\hline \multirow{4}{*}{ Pentosidine } & Model 1 & $-2.75(-4.85 ;-0.54)$ & $0.23(0.07 ; 0.39)$ & $-1.93(-5.70 ; 1.84)$ & $-0.84(-2.56 ; 0.88)$ \\
\hline & Model 2 & $-0.27(-2.21 ; 1.66)$ & $0.14(-0.02 ; 0.29)$ & $-2.53(-6.42 ; 1.35)$ & $-1.12(-2.90 ; 0.65)$ \\
\hline & Model 3 & $0.05(-1.70 ; 1.79)$ & $0.12(-0.03 ; 0.27)$ & $-2.09(-5.82 ; 1.65)$ & $-1.05(-2.77 ; 0.68)$ \\
\hline & Model $4^{*}$ & $-0.52(-2.46 ; 1.43)$ & $0.19(0.02 ; 0.36)$ & $-2.65(-6.91 ; 1.61)$ & $-1.72(-3.77 ; 0.32)$ \\
\hline \multirow{4}{*}{ CEL } & Model 1 & $-0.02(0.05 ; 0.02)$ & $0.002(0.00 ; 0.005)$ & $-0.06(-0.12 ;-0.00)$ & $-0.03(-0.06 ;-0.01)$ \\
\hline & Model 2 & $-0.01(-0.04 ; 0.02)$ & $0.002(0.00 ; 0.004)$ & $-0.06(-0.11 ; 0.02)$ & $-0.03(-0.05 ; 0.00)$ \\
\hline & Model 3 & $-0.01(-0.04 ; 0.01)$ & $0.002(0.00 ; 0.004)$ & $-0.06(-0.12 ;-0.01)$ & $-0.03(-0.05 ;-0.02)$ \\
\hline & Model $4^{*}$ & $0.01(-0.02 ; 0.03)$ & $0.001(-0.002 ; 0.003)$ & $-0.06(-0.12 ;-0.00)$ & $-0.03(-0.05 ; 0.002)$ \\
\hline \multirow{4}{*}{ CML } & Model 1 & $0.02(-0.01 ; 0.04)$ & $-0.001(-0.003 ; 0.001)$ & $0.02(-0.03 ; 0.06)$ & $-0.01(-0.02 ; 0.01)$ \\
\hline & Model 2 & $0.02(-0.00 ; 0.04)$ & $-0.001(-0.002 ; 0.001)$ & $0.01(-0.03 ; 0.05)$ & $-0.01(-0.03 ; 0.01)$ \\
\hline & Model 3 & $0.02(-0.002 ; 0.04)$ & $-0.001(-0.002 ; 0.001)$ & $0.01(-0.03 ; 0.05)$ & $-0.01(-0.03 ; 0.01)$ \\
\hline & Model $4^{*}$ & $0.003(-0.02 ; 0.02)$ & $0.001(-0.001 ; 0.003)$ & $-0.001(-0.05 ; 0.04)$ & $-0.01(-0.03 ; 0.01)$ \\
\hline \multirow[t]{2}{*}{ Tissue AGEs } & Models & \multicolumn{2}{|c|}{$\begin{array}{l}\text { Carotid Artery } \\
\text { (N = 796) }\end{array}$} & $\begin{array}{l}\text { Femoral Artery } \\
(\mathrm{N}=754)\end{array}$ & $\begin{array}{c}\text { Brachial Artery } \\
\quad(\mathrm{N}=729)\end{array}$ \\
\hline & & $\begin{array}{c}\text { Distensibility } \\
\text { coefficient (DC) }\end{array}$ & $\begin{array}{c}\text { Young Elastic } \\
\text { Modulus (YEM) }\end{array}$ & $\begin{array}{c}\text { Distensibility } \\
\text { Coefficient (DC) }\end{array}$ & $\begin{array}{c}\text { Distensibility } \\
\text { Coefficient (DC) }\end{array}$ \\
\hline \multirow{4}{*}{$\begin{array}{l}\text { Skin Autofluor- } \\
\text { escence (SAF) }\end{array}$} & Model 1 & $-2.07(-2.70 ;-1.43)$ & $0.11(0.06 ; 0.15)$ & $-0.75(-1.85 ; 0.36)$ & $-0.24(-0.72 ; 0.23)$ \\
\hline & Model 2 & $0.21(-0.47 ; 0.86)$ & $-0.01(-0.06 ; 0.04)$ & $-0.84(-2.11 ; 0.44)$ & $-0.30(-0.84 ; 0.24)$ \\
\hline & Model 3 & $0.14(-0.45 ; 0.72)$ & $-0.01(-0.06 ; 0.04)$ & $-0.89(-2.11 ; 0.34)$ & $-0.33(-0.86 ; 0.20)$ \\
\hline & Model $4 * *$ & $0.41(-0.24 ; 1.06)$ & $-0.03(-0.08 ; 0.03)$ & $-0.40(-1.80 ; 1.00)$ & $-0.40(-1.01 ; 0.21)$ \\
\hline
\end{tabular}

* 50/44/45 additional individuals excluded due to missing data on co-variates for the carotid/femoral/ brachial stiffness models respectively

** 64/57/56 additional individuals excluded due to missing data on co-variates for the carotid/femoral/ brachial stiffness models respectively 
Table 3. The Association of plasma Advanced Glycation End Products (AGEs) and Skin Autofluorescence (SAF) with the carotid Inter-Adventitia Diameter (IAD), Lumen Diameter (LD), Distension ( D), Intima Media Thickness (IMT) and brachial and calibrated carotid Pulse Pressure (PP)

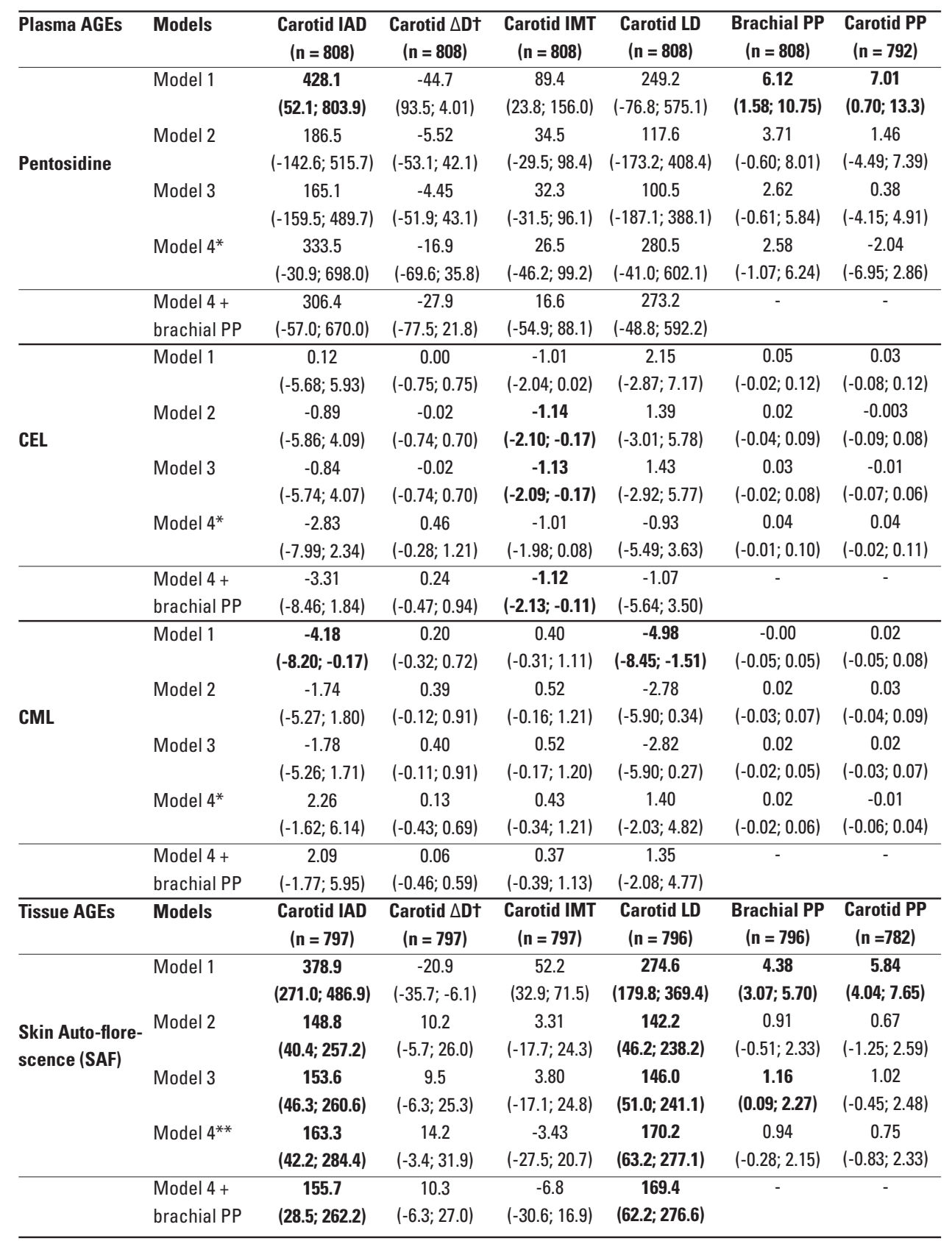

*50 additional individuals excluded due to missing data on co-variates $\quad{ }^{*} 64$ additional individuals excluded due to missing data on co-variates † Model 1 additionally adjusted for the Carotid IAD 


\section{Plasma AGEs and carotid artery stiffness and its elements}

When analysed as a continuous variable, higher pentosidine concentrations were significantly associated with a higher carotid YEM in the crude model: $0.23\left(10^{\wedge} 3 \mathrm{kPa}\right)$ [0.07;0.39]. The association was attenuated but remained borderline significant after adjustment for age, sex and GMS: 0.14 [-0.02;0.29]. After additional adjustments for MAP and other CVD risk factors, the regression coefficient was enhanced and became significant: 0.19 [0.02;0.36]. This was especially due to the addition of heart rate, weight and triglycerides in the final model. Similarly, when pentosidine was analysed in tertiles, the highest pentosidine tertile was significantly associated with a higher carotid YEM, in the crude: 0.09 [0.03;0.15] and in the fully adjusted models: 0.09 [0.03;0.15]. Higher pentosidine concentrations were associated with a lower carotid DC in the crude model -2.75 [-4.85; -0.54], but not in the fully adjusted models (Table 2). Similarly, neither of the pentosidine tertiles were significantly associated with a lower carotid DC in any of the models (Supplemental Table 1a).

The highest pentosidine tertile was significantly associated with a lower carotid distension after adjustment for the carotid IAD: -23.5 $\mu$ m [-42.3; -4.7] (Model 1, Supplemental Table 1b). The association was attenuated in the fully adjusted models: $-18.2[-38.1 ; 1.7]$, but became significant when the fully adjusted model was additionally adjusted for the brachial PP: -19.4 [-38.1; -0.61], but not when additionally adjusted for the carotid PP: -15.8 [-35.0; 3.4].

Plasma CEL and CML were not associated with either the carotid DC, the carotid YEM or their elements in the fully adjusted models (Table 2). Although CEL was not significantly associated with the Carotid IMT in either the crude: $-1.01 \mu \mathrm{m}$ [-2.04; 0.02], or the fully adjusted models: -1.01 [-1.98; 0.08]; the association became significant after the additional adjustment for the brachial PP: -1.12 [-2.13; -0.11], or the carotid PP: -1.10 [-2.13; -0.08$]$. Neither of the plasma AGEs were associated with the brachial PP or the carotid PP in any of the models.

\section{AGEs and muscular artery stiffness and their elements}

SAF was not associated with either the femoral DC, the brachial DC or any of their elements in the fully adjusted models (Tables 2 and 4). Higher pentosidine concentrations were also not associated with either the brachial DC or the femoral DC, when pentosidine was analysed as a continuous variable. The highest pentosidine tertile was, however, borderline significantly associated with a lower brachial DC in the crude model: -0.64 $\left(10^{\wedge}-3 \mathrm{kPa}\right)[-1.29 ; 0.02]$. This association was enhanced and became significant after adjustment for age, sex and GMS: $-0.77[-1.45 ;-0.08]$ and additional adjustments for MAP and CVD risk factors did not alter the association (Supplemental Table 2). Higher 
Table 4. The Association of plasma Advanced Glycation End Products (AGEs) and Skin Autofluorescence (SAF) with the Inter-Adventitia Diameter (IAD) and Distension ( $\triangle \mathrm{D})$ of the femoral and brachial arteries

\begin{tabular}{|c|c|c|c|c|c|}
\hline & Models & $\begin{array}{l}\text { Femoral IAD } \\
(n=762)\end{array}$ & $\begin{array}{c}\text { Femoral } \Delta \mathrm{D} \dagger \\
(\mathrm{n}=762)\end{array}$ & $\begin{array}{c}\text { Brachial IAD } \\
(n=740)\end{array}$ & $\begin{array}{c}\text { Brachial } \Delta D T \\
(n=740)\end{array}$ \\
\hline \multirow{5}{*}{ Pentosidine } & Model 1 & $864.7[162.6 ; 1566.8]$ & $1.5[-102.5 ; 105.6]$ & $402.3[34.8 ; 769.7]$ & $-1.5[-27.8 ; 24.7$ \\
\hline & Model 2 & $582.4[-77.8 ; 1242.6]$ & $-34.5[-140.7 ; 71.7]$ & $307.1[14.6 ; 600.0]$ & $-7.3[-34.2 ; 19.5]$ \\
\hline & Model 3 & $560.5[-98.2 ; 1219.1]$ & $-30.9[-136.7 ; 74.9]$ & 305.8 [70.5; 529.3] & $-7.2[-34.0 ; 19.7]$ \\
\hline & Model $4^{*}$ & $587.1[-132.2 ; 1306.4]$ & $-37.7[-157.6 ; 82.2]$ & $425.3[92.0 ; 758.7]$ & $-15.6[-46.8 ; 15.7]$ \\
\hline & $\begin{array}{l}\text { Model } 4+ \\
\text { brachial PP }\end{array}$ & $649.1[-61.5 ; 1359.6]$ & $-41.4[-161.4 ; 78.6]$ & $448.7[116.8 ; 780.6]$ & $-19.9[-50.8 ; 10.9]$ \\
\hline \multirow{5}{*}{ CEL } & Model 1 & $-6.0[-16.6 ; 4.6]$ & $-1.4[-2.9 ; 0.2]$ & $5.0[-0.6 ; 10.7]$ & $-0.25[-0.65 ; 0.2]$ \\
\hline & Model 2 & $-1.6[-11.4 ; 8.2]$ & $-1.2[-2.8 ; 0.3]$ & $4.2[-0.2 ; 8.6]$ & $-0.25[-0.66 ; 0.2]$ \\
\hline & Model 3 & $-1.3[-11.0 ; 8.5]$ & $-1.3[-2.8 ; 0.3]$ & $4.3[-0.1 ; 8.6]$ & $-0.26[-0.66 ; 0.2]$ \\
\hline & Model $4^{*}$ & $1.6[-8.4 ; 11.6]$ & $-1.2[-2.8 ; 0.5]$ & $2.5[-2.2 ; 7.1]$ & $-0.28[-0.71 ; 0.2]$ \\
\hline & $\begin{array}{l}\text { Model } 4+ \\
\text { brachial PP }\end{array}$ & $3.1[-6.8 ; 13.0]$ & $-1.2[-2.9 ; 0.4]$ & $3.0[-1.6 ; 7.6]$ & $-0.36[-0.78 ; 0.1]$ \\
\hline \multirow{5}{*}{ CML } & Model 1 & $15.1[7.8 ; 22.4]$ & $0.6[-0.5 ; 1.7]$ & $-2.7[-6.5 ; 1.2]$ & $-0.13[-0.41 ; 0.14]$ \\
\hline & Model 2 & $13.7[6.8 ; 20.6]$ & $0.6[-0.5 ; 1.7]$ & $-0.1[-3.1 ; 3.0]$ & $-0.12[-0.40 ; 0.16]$ \\
\hline & Model 3 & $13.6[6.7 ; 20.5]$ & $0.6[-0.5 ; 1.7]$ & $-0.1[-3.2 ; 3.0]$ & $-0.12[-0.40 ; 0.16]$ \\
\hline & Model $4^{*}$ & $13.7[6.2 ; 21.2]$ & $0.5[-0.8 ; 1.8]$ & $2.5[-0.9 ; 5.9]$ & $-0.14[-0.46 ; 0.18]$ \\
\hline & $\begin{array}{l}\text { Model } 4+ \\
\text { brachial PP }\end{array}$ & $13.9[6.6 ; 21.3]$ & $0.5[-0.8 ; 1.7]$ & $2.6[-0.8 ; 6.1]$ & $-0.17[-0.48 ; 0.15]$ \\
\hline \multirow[t]{2}{*}{ Tissue AGEs } & Models & $\begin{array}{c}\text { Femoral IAD } \\
(n=754)\end{array}$ & $\begin{array}{c}\text { Femoral } \Delta \mathrm{D} \dagger \\
(\mathrm{n}=754)\end{array}$ & $\begin{array}{c}\text { Brachial IAD } \\
(n=728)\end{array}$ & $\begin{array}{c}\text { Brachial } \Delta \mathrm{DT} \\
(\mathrm{n}=728)\end{array}$ \\
\hline & Model 1 & $-336.1[-542.6 ;-129.6]$ & $-1.1[-31.8 ; 29.5]$ & $165.9[59.7 ; 272.0]$ & $6.1[-1.2 ; 13.4]$ \\
\hline \multirow{4}{*}{$\begin{array}{l}\text { Skin Autofluo- } \\
\text { rescence (SAF) }\end{array}$} & Model 2 & $-366.1[-711.9 ;-138.5]$ & $-30.4[-65.4 ; 4.5]$ & $37.5[-57.1 ; 132.0]$ & $-0.4[-8.7 ; 7.8]$ \\
\hline & Model 3 & $-263.9[-578.6 ;-149.2]$ & $-30.5[-65.2 ; 4.3]$ & $38.1[-56.6 ; 132.7]$ & $-0.5[-8.8 ; 7.8]$ \\
\hline & Model $4^{* *}$ & $-223.6[-458.5 ; 11.3]$ & $-17.8[-57.2 ; 21.6]$ & $85.0[-21.6 ; 191.6]$ & $-2.8[-12.3 ; 6.7]$ \\
\hline & $\begin{array}{l}\text { Model } 4+ \\
\text { brachial PP }\end{array}$ & $-197.3[-430.1 ; 35.4]$ & $-18.8[-58.3 ; 20.6]$ & $92.2[-14.1 ; 198.5]$ & $-4.2[-13.5 ; 5.2]$ \\
\hline
\end{tabular}

\footnotetext{
*44/45 additional individuals excluded due to missing data on co-variates for the carotid/femoral/ brachial stiffness models respectively

**57/56 additional individuals excluded due to missing data on co-variates for the carotid/femoral/ brachial stiffness models respectively

† Model 1 additionally adjusted for the Femoral IAD

१ Model 1 additionally adjusted for the Brachial IAD
}

pentosidine concentrations were also significantly associated with a greater brachial IAD in the crude $402.3 \mu \mathrm{m}[34.8 ; 769.7]$ and fully adjusted models 425.3 [92.0;758.7] as well as after additional adjustment for the brachial PP: 448.7 [116.8;780.6] (Table 4). Similarly, the highest pentosidine tertile was significantly associated with a higher brachial IAD, in all the models (Supplemental Table 2). 
Higher CEL concentrations were significantly associated with a lower Femoral DC in the crude $-0.06\left(10^{\wedge}-3 \mathrm{kPa}\right)[-0.12 ;-0.00]$ as well as in the fully adjusted models: $-0.06[-0.12$; -0.00]. Similarly, CEL was significantly associated with a lower brachial DC in the crude -0.03 $\left(10^{\wedge}-3 \mathrm{kPa}\right)[-0.06 ;-0.01]$, but not in the fully adjusted models, even though the size of the regression coefficient remained unaltered: -0.03 [-0.05; 0.002] (Table 2). CEL was not associated with any of the femoral DC and brachial DC components, or with the brachial PP in either the crude, or the fully adjusted models (Table 4).

CML was not associated with either the femoral DC, or the brachial DC in any of the statistical models (Table 2). Higher CML concentrations were, however, significantly associated with a greater femoral IAD in the crude:15.1 $\mu \mathrm{m}$ [7.8;22.4], in the fully adjusted models: 13.7 [6.2;21.2], as well as after additional adjustment for the brachial PP: 13.9 [6.6;21.3] (Table 4).

\section{Additional Analyses}

Firstly, carotid artery stiffness indices were replaced by calibrated carotid artery stiffness indices ( $n=791$ ). When pentosidine was used as a continuous variable, the association of plasma pentosidine with the calibrated carotid YEM was attenuated and was no longer significant in the fully adjusted models 0.08 (10^3 kPa) [-0.10;0.25] (Supplemental Table 1). The association of the third pentosidine tertile with the calibrated carotid YEM remained, however, significant in the fully adjusted models: $0.07\left(10^{\wedge} 3 \mathrm{kPa}\right)[0.01 ; 0.14]$.

Secondly, we re-evaluated all significant associations after the exclusion of individuals with extreme values of arterial stiffness and their formula elements ( $\pm 3 S D$ ). When carotid IAD outliers were removed $(n=8)$, the association with SAF was severely attenuated and was no longer significant. When the carotid Lumen Diameter outliers were removed $(n=6)$, the association with SAF remained significant: $126.3 \mu \mathrm{m}$ [28.6;223.9]. When YEM outliers ( $\mathrm{n}=$ 10) were removed, the association with plasma pentosidine was attenuated and was no longer significant: $0.06\left(10^{\wedge} 3 \mathrm{kPa}\right)[-0.07 ; 0.19]$. The association of the highest pentosidine tertile with the carotid YEM was also attenuated but remained borderline significant: $0.04\left(10^{\wedge} 3 \mathrm{kPa}\right)[-0.00 ; 0.09]$. After the exclusion of carotid distension outliers $(n=7)$, the association with the third pentosidine tertile was attenuated but remained borderline significant: $-17.0 \mu \mathrm{m}[-35.9 ; 2.0]$. When carotid IMT outliers $(\mathrm{N}=11)$ were removed, the association with CEL was no longer significant: $0.56 \mu \mathrm{m}[-1.51 ; 0.38]$. After the exclusion of femoral DC outliers ( $n=8$ ), the association with CEL was no longer significant: -0.04 $[-0.09 ; 0.01]$. When femoral IAD outliers $(n=3)$ were excluded, the association with the CML was unaltered. After the removal of brachial DC $(n=10)$ outliers, the association with the highest pentosidine tertile was unaltered. Similarly, when brachial IAD outliers were excluded $(n=3)$, the associations with both the continuous pentosidine variable and the 
third pentosidine tertile remained significant. Lastly, when plasma AGEs or SAF outliers were removed, none of the associations were altered.

\section{Discussion}

This study had four main findings. Firstly, SAF was not associated with any of the carotid, femoral or brachial stiffness indices, but was robustly associated with a greater lumen diameter. Secondly, higher pentosidine concentrations were significantly associated with a higher carotid YEM, a lower carotid distension and a lower brachial DC; however, these associations were (partly) dependent on outliers. Lastly, plasma pentosidine and CML were robustly associated with a greater brachial IAD and a greater femoral IAD, respectively. We did not find any evidence that these associations differed according to GMS status.

We have shown that tissue AGEs, as measured by SAF, are not associated with the carotid, femoral or brachial artery stiffness. Of the plasma AGEs, only the cross-linking AGE pentosidine was associated with the carotid YEM, the carotid distension and the brachial DC. Most of these results were no longer significant after the removal of outliers, therefore, we cannot exclude that these findings are spurious. Most [11-16], but not all [39] previous studies have shown a significant association of SAF and pentosidine with aortic stiffness, as measured by the carotid-femoral Pulse Wave Velocity (cfPWV) in patients with diabetes [11$13], \operatorname{ESRD}[15]$, and even in the general population $[15,16]$. To date, only one previous study investigated the association of plasma pentosidine with carotid stiffness in dialysis patients [20] and reported a significant association with the carotid DC. Possibly the association of AGEs with carotid stiffness is stronger in high carbonyl environments, such as in ESRD patients than in individuals from the general population; therefore, we may have lacked the power to identify any associations. Nonetheless, our group has recently shown within this same study population that SAF and plasma pentosidine are significantly associated with a higher cfPWV as well as a higher central (ascending aortic) pulse pressure [13]. The lack of (consistent) associations with local stiffness indices in this study suggests that the aorta may be more prone to AGE-associated stiffening than any other artery. Although both the carotid and the aorta are considered elastic vessels, the carotid artery structurally and functionally resembles the stiffer abdominal aorta and thus may be less prone to ageing and stiffening than the more elastic thoracic aorta [40]. Indeed, the aorta has been shown to stiffen twice as fast as the carotid artery in T2D patients [23]. Muscular arteries seem less affected by stiffening factors, such as old age and hypertension than the carotid artery $[41,42]$, and may, therefore, be least affected by AGE accumulation. Indeed, the association of pentosidine with the brachial DC was smaller than the association with the carotid YEM. 
In additional analyses, SAF was robustly associated with a wider carotid lumen diameter; but not with any of the other stiffness components. We also found a significant association of SAF with a larger carotid Inter-Adventitial Diameter (IAD), which was largely dependent on outliers and was, therefore considered spurious. Carotid artery dilation has been described in normal ageing [43], as well as in patients with ESRD [44,45] and T2D [46], though in most cases the IAD widens to a greater extent than the lumen diameter. These changes are thought to reflect a hypertrophic outward remodelling response of the carotid artery to either a rise in the distending pressure [46] or to flow obstruction by atherosclerotic plaque [47]. Our associations were independent, however of hemodynamic distending factors, such as PP, MAP and use of blood pressure lowering medication. Also, atherosclerotic associated dilation is aimed at maintaining a constant lumen diameter despite obstructive atherosclerotic plaque and it is achieved through IAD widening [48]; whereas in our study SAF was robustly associated with a widening of the lumen diameter but not of the IAD. Furthermore, our associations were independent of the carotid IMT and were also present after we excluded individuals with an IMT $>0.9 \mathrm{~mm}$ as well as those with prior CVD, therefore it is less-likely that our associations are mediated by plaque formation. This might suggest that tissue AGE accumulation plays an intrinsic role in carotid artery dilation. SAF is a non-specific measure of tissue AGE concentrations, which has been shown to correlate with both fluorescent (ie. pentosidine) and non-fluorescent (ie. CML, CEL) AGE concentrations in the skin [29], as well as in cardiovascular tissue [49]. Plasma AGE concentrations, however, may not reflect adequately tissue AGE levels; as they are formed through the glycation of plasma proteins, which are metabolized considerably faster (days to weeks) than the long-lived proteins of the skin or vascular tissue [22]. In our study, only plasma pentosidine correlated weakly, though significantly with SAF $(r=0.17, p<0.001)$, whereas CEL and CML did not. The lack of significant associations of plasma AGEs with the carotid lumen diameter does not exclude therefore, that the accumulation of any, or all, of these AGEs contributes to carotid dilatation.

In our study, SAF was associated carotid artery dilation, but not with a concomitant thickening of the arterial wall, as measured by the IMT or the IAD. This points to a defect in mechano-transduction, which is the feedback system that maintains circumferential wall stress by stimulating arterial wall thickening in response to increases in the arterial diameter or the PP through collagen deposition and smooth muscle cell proliferation [44]. Although the mechanisms of defective mechano-transduction have yet to be elucidated, such maladaptive IMT changes have been described previously in T2D [46] and chronic kidney disease [44] patients, in response to increasing PP and arterial diameter, respectively. This defect in arterial wall thickening could be due to use of lipid-modifying or bloodpressure lowering medication (especially RAS inhibitors). Such medication is known for its anti-proliferative properties [50] and is extensively prescribed especially in high CVD risk 
groups, such as T2D patients. Our associations were, however, independent of medication use. Another possible explanation would be that IMT hypertrophy occurs more readily in response to a higher (local) PP [46], than in response to a larger diameter [44] as carotid dilation allows the artery to increase its compliance and thus decrease its pulse pressure [51]. Nevertheless, despite these changes, elastic fibre degradation ought to ultimately lead arterial stiffening, as pulsatile stress is transferred to the more rigid collagen fibres in the arterial wall [52]. AGE formation could further augment arterial stiffening by stimulating the production of collagen by smooth muscle cells (SMCs) or by cross-linking with collagen, thus making it less susceptible to degradation [53]. Possibly, we may have captured these processes in their incipient phase when the carotid artery was still able to maintains its compliance. Alternatively, the relative thinning of the arterial wall could have also allowed the carotid artery to maintain its distensibility despite any stiffening. Indeed, although the associations were not significant, a higher SAF tended to be associated with both a higher DC and a lower YEM of the carotid artery in the fully adjusted models, which suggests a paradoxical improvement in its elastic properties with AGE accumulation.

Besides these pathophysiological considerations, the lack of significant associations of AGEs with local stiffness indices could be attributed to several methodological shortcomings. Firstly, the study sample was relatively small, therefore it may not provide adequate power to accurately detect any associations of AGEs with local stiffness indices. Secondly, individuals with T2D could have been treated more intensively with blood-pressurelowering and lipid-modifying medication than the remainder of the population as indicated by current guidelines [54]. As these medications could decrease arterial stiffness [55], oxidative stress [56], as well as AGEs [57] this might have attenuated any associations. Thirdly, measurement error of local stiffness indices could have distorted the associations. The calculation of local stiffness requires the use of three ultrasound measured variables, each with its own measurement error. Although we tried to compensate for these short comings by averaging data from three consecutive measurements, these errors might have resulted in the large number of influential outliers observed in our study. Lastly, associations with muscular artery stiffness indices might have further been attenuated by the relatively lower intra- and interobserver reproducibility of their measurement as compared to carotid artery measurements. Due to the high concentrations of SMCs within their walls, which allows short-term alterations in smooth muscle tone to influence arterial diameter and stiffness [58]. Even though only two individuals carried out these measurements; it is more likely the associations with elastic artery stiffness indices are more robust as they are not prone to such limitations. 


\section{Conclusion}

This study shows that the accumulation of tissue AGEs, as measured by SAF is not associated with the stiffness of either the carotid, femoral or brachial arteries; but is associated with carotid artery dilatation. Of the plasma AGEs, higher pentosidine concentrations might be associated with both carotid and brachial artery stiffening, however, our results were largely dependent on outliers, thus additional research is required to confirm our findings. 
Supplemental Table 1a. The association of plasma Pentosidine tertiles with carotid artery stiffness indices calibrated with either the brachial or the carotid pulse pressure

\begin{tabular}{|c|c|c|c|}
\hline \multicolumn{2}{|c|}{$\begin{array}{c}\text { Plasma Pentosidine } \\
\text { Models }\end{array}$} & \multirow{2}{*}{$\begin{array}{l}\text { Carotid Distensibility Coefficient } \\
\text { (DC) }(\mathbf{n}=\mathbf{8 0 8}) \\
0.15[-0.68 ; 0.98]\end{array}$} & \multirow{2}{*}{$\begin{array}{l}\text { Carotid Young Elastic Modulus } \\
\text { (YEM) (n= 808) } \\
-0.02[-0.08 ; 0.05]\end{array}$} \\
\hline Model 1 & $\mathrm{~T} 2$ & & \\
\hline & $\mathrm{T} 3$ & $-1.15[-1.98 ;-0.31]$ & $0.09[0.03 ; 0.15]$ \\
\hline \multirow[t]{2}{*}{ Model 2} & $\mathrm{~T} 2$ & $0.21[-0.52 ; 0.95]$ & $-0.01[-0.07 ; 0.05]$ \\
\hline & T3 & $-0.11[-0.86 ; 0.65]$ & $0.05[-0.01 ; 0.11]$ \\
\hline \multirow[t]{2}{*}{ Model 3} & $\mathrm{~T} 2$ & $-0.02[-0.68 ; 0.65]$ & $0.002[-0.06 ; 0.06]$ \\
\hline & T3 & $-0.04[-0.72 ; 0.64]$ & $0.05[-0.01 ; 0.10]$ \\
\hline \multirow[t]{2}{*}{ Model 4* } & $\mathrm{T} 2$ & $-0.32[-1.01 ; 0.37]$ & $0.03[-0.03 ; 0.09]$ \\
\hline & $\mathrm{T} 3$ & $-0.55[-1.29 ; 0.19]$ & $0.09[0.03 ; 0.15]$ \\
\hline \multicolumn{2}{|c|}{ Plasma Pentosidine } & Calibrated Carotid Distensibility & Calibrated Carotid Young \\
\hline \multicolumn{2}{|c|}{ Models } & Coefficient (DC) ( $n=791)$ & Elastic Modulus (YEM) $(n=791)$ \\
\hline \multirow[t]{2}{*}{ Model 1} & T2 & $0.51(-0.56 ; 1.57)$ & $-0.02(-0.09 ; 0.04)$ \\
\hline & T3 & $-1.34(-2.40 ;-0.27)$ & $0.10(0.03 ; 0.16)$ \\
\hline \multirow[t]{2}{*}{ Model 2} & $\mathrm{~T} 2$ & $0.68(-0.24 ; 1.60)$ & $-0.02(-0.08 ; 0.04)$ \\
\hline & T3 & $0.18(-0.76 ; 1.12)$ & $0.04(-0.02 ; 0.10)$ \\
\hline \multirow[t]{2}{*}{ Model 3} & $\mathrm{~T} 2$ & $0.29(-0.50 ; 1.09)$ & $-0.01(-0.06 ; 0.05)$ \\
\hline & T3 & $0.34(-0.47 ; 1.14)$ & $0.04(-0.02 ; 0.09)$ \\
\hline \multirow[t]{2}{*}{ Model 4** } & $\mathrm{T} 2$ & $-0.06(-0.88 ; 0.77)$ & $0.01(-0.05 ; 0.07)$ \\
\hline & T3 & $-0.31(-1.20 ; 0.57)$ & $0.07(0.01 ; 0.14)$ \\
\hline
\end{tabular}

* 50 participants excluded due to missing data on various co-variates

** 49 participants excluded due to missing data on carotid pulse pressure

Supplemental Table 1b. The association of plasma Pentosidine tertiles with the carotid artery Distension $(\Delta \mathrm{D})$, Lumen Diameter (LD) and calibrated carotid Pulse Pressure

\begin{tabular}{|c|c|c|c|c|}
\hline \multicolumn{2}{|c|}{$\begin{array}{c}\text { Plasma Pentosidine } \\
\text { Models }\end{array}$} & \multirow{2}{*}{$\begin{array}{c}\text { Carotid } \Delta \mathrm{D} \dagger \\
(\mathrm{n}=808) \\
-13.5[-32.3 ; 5.2]\end{array}$} & \multirow{2}{*}{$\begin{array}{c}\text { Carotid LD } \\
(\mathrm{n}=808) \\
-91.9[-217.9 ; 34.1]\end{array}$} & \multirow{2}{*}{$\begin{array}{l}\text { Carotid Pulse Pressure } \\
\qquad(\mathrm{n}=792) \\
-2.94[-5.34 ;-0.53]\end{array}$} \\
\hline Model 1 & $\mathrm{~T} 2$ & & & \\
\hline & T3 & $-23.5[-42.3 ;-4.7]$ & $4.51[-121.6 ; 130.6]$ & $2.11[-0.29 ; 4.52]$ \\
\hline \multirow[t]{2}{*}{ Model 2} & $\mathrm{~T} 2$ & $-9.6[-27.8 ; 8.4]$ & $-75.8[-186.4 ; 34.8]$ & $-2.89[-5.12 ;-0.66]$ \\
\hline & T3 & $-6.1[-24.6 ; 12.4]$ & $-56.6[-169.7 ; 56.4]$ & $-0.09[-2.34 ; 2.19]$ \\
\hline \multirow[t]{2}{*}{ Model 3} & $\mathrm{~T} 2$ & $-10.5[-28.6 ; 7.5]$ & $-63.6[-173.1 ; 45.9]$ & $1.87[-3.57 ;-0.16]$ \\
\hline & T3 & $-5.7[-24.1 ; 12.8]$ & $-60.2[172.0 ; 51.6]$ & $-0.38[-2.12 ; 1.35]$ \\
\hline \multirow[t]{2}{*}{ Model $4^{*}$} & $\mathrm{~T} 2$ & $-17.6[-36.2 ; 0.9]$ & $35.7[-78.3 ; 149.7]$ & $-1.57[-3.26 ; 0.11]$ \\
\hline & T3 & $-18.2[-38.1 ; 1.7]$ & $26.1[-96.1 ; 148.2]$ & $-1.07[-2.87 ; 0.73]$ \\
\hline Model 4 + & $\mathrm{T} 2$ & $-15.2[-32.7 ; 2.2]$ & $37.1[-76.9 ; 151.1]$ & - \\
\hline brachial PP & T3 & $-19.4[-38.1 ;-0.61]$ & $25.3[-96.9 ; 147.6]$ & - \\
\hline
\end{tabular}


Supplemental Table 2. The association of plasma Pentosidine tertiles with the brachial Artery Distensibility Coefficient (DC), Inter-Adventitia Diameter (IAD), Distension ( $\triangle \mathrm{D}$ ) and brachial Pulse Pressure (PP)

\begin{tabular}{|c|c|c|c|c|c|}
\hline \multicolumn{2}{|c|}{$\begin{array}{c}\text { Plasma } \\
\text { Pentosidine }\end{array}$} & \multirow{2}{*}{$\begin{array}{c}\begin{array}{c}\text { Brachial DC } \\
(\mathbf{n}=740)\end{array} \\
0.03[-0.63 ; 0.69]\end{array}$} & \multirow{2}{*}{$\begin{array}{c}\begin{array}{c}\text { Brachial IAD } \\
(\mathbf{n}=740)\end{array} \\
-27.1[-168.0 ; 113.7]\end{array}$} & \multirow{2}{*}{$\begin{array}{c}\text { Brachial } \Delta D \dagger \\
(\mathbf{n}=740) \\
-3.4[-13.4 ; 6.7]\end{array}$} & \multirow{2}{*}{$\begin{array}{c}\text { Brachial PP } \\
(\mathbf{n}=\mathbf{8 2 6}) \\
-1.50[-3.21 ; 0.22]\end{array}$} \\
\hline Model 1 & T2 & & & & \\
\hline & T3 & $-0.64[-1.29 ; 0.02]$ & $161.7[20.7 ; 302.7]$ & $-6.2[-16.3 ; 3.9]$ & $1.91[0.19 ; 3.63]$ \\
\hline \multirow[t]{2}{*}{ Model 2} & T2 & $0.04[-0.71 ; 0.63]$ & $-24.3[-135.1 ; 86.4]$ & $-3.4[-13.5 ; 6.7]$ & $-1.01[-2.71 ; 0.51]$ \\
\hline & T3 & $-0.77[-1.45 ;-0.08]$ & $115.4[2.6 ; 228.1]$ & $-9.2[-19.5 ; 1.2]$ & $0.84[-0.81 ; 2.49]$ \\
\hline \multirow[t]{2}{*}{ Model 3} & T2 & $-0.17[-0.82 ; 0.49]$ & $-22.4[-133.4 ; 88.6]$ & $-3.7[-13.9 ; 6.4]$ & $-0.42[-1.63 ; 0.80]$ \\
\hline & T3 & $-0.74[-1.40 ;-0.07]$ & $115.0[2.1 ; 227.8]$ & $-9.1[-19.4 ; 1.2]$ & $0.52[-0.81 ; 2.49]$ \\
\hline \multirow[t]{2}{*}{ Model 4* } & T2 & $-0.24[-0.94 ; 0.47]$ & $5.6[-109.2 ; 120.5]$ & $-4.6[-15.3 ; 6.1]$ & $-0.25[-1.52 ; 1.03]$ \\
\hline & T3 & $-0.83[-1.59 ;-0.07]$ & $163.9[40.5 ; 287.3]$ & $-9.8[-21.4 ; 1.8]$ & $0.36[-1.01 ; 1.74]$ \\
\hline \multirow[t]{2}{*}{ Model 4 + PP } & T2 & - & $2.8[-111.5 ; 117.1]$ & $-4.2[-14.7 ; 6.4]$ & - \\
\hline & T3 & - & 165.1 [42.4; 287.9] & $-10.3[-21.7 ; 1.1]$ & - \\
\hline
\end{tabular}

† Model 1 additionally adjusted for the Brachial IAD

*45 additional individuals excluded due to missing data on co-variates 
Supplemental Table 3. The Association of plasma and tissue Advanced Glycation End Products (AGEs) with carotid stiffness indices calibrated for the carotid pulse pressure

\begin{tabular}{|c|c|c|c|}
\hline Plasma AGEs & Models & $\begin{array}{l}\text { Calibrated Carotid Distensibility } \\
\text { Coefficient (DC) } \\
\text { (N=791) }\end{array}$ & $\begin{array}{l}\text { Calibrated Carotid } \\
\text { Young Elastic Modulus } \\
\text { (YEM) (N = 791) }\end{array}$ \\
\hline \multirow{4}{*}{ Pentosidine } & Model 1 & $-2.97[-5.80 ;-0.14]$ & $0.19(0.02 ; 0.36)$ \\
\hline & Model 2 & $0.72[-1.75 ; 3.19]$ & $0.06(-0.11 ; 0.22)$ \\
\hline & Model 3 & $1.13[-1.00 ; 3.25]$ & $0.04(-0.12 ; 0.19)$ \\
\hline & Model 4* & $0.56[-1.89 ; 3.00]$ & $0.08(-0.10 ; 0.25)$ \\
\hline \multirow{4}{*}{ CEL } & Model 1 & $-0.01[-0.06 ; 0.03]$ & $0.002[-0.001 ; 0.004]$ \\
\hline & Model 2 & $-0.01[-0.05 ; 0.03]$ & $0.001[-0.001 ; 0.004]$ \\
\hline & Model 3 & $-0.01[-0.04 ; 0.02]$ & $0.001[-0.001 ; 0.004]$ \\
\hline & Model $4^{*}$ & $0.01[-0.03 ; 0.04]$ & $0.001[-0.002 ; 0.003]$ \\
\hline \multirow{4}{*}{ CML } & Model 1 & $0.02[-0.01 ; 0.05]$ & $0.000[-0.002 ; 0.001]$ \\
\hline & Model 2 & $0.02[-0.03 ; 0.05]$ & $0.000[-0.002 ; 0.001]$ \\
\hline & Model 3 & $0.02[0.02 ; 0.05]$ & $0.000[-0.002 ; 0.001]$ \\
\hline & Model 4* & $0.01[-0.01 ; 0.04]$ & $0.000[-0.002 ; 0.002]$ \\
\hline \multirow[t]{4}{*}{ Tissue AGEs } & Models & Calibrated Carotid Distensibility & Calibrated Carotid \\
\hline & & Coefficient (DC) & Young Elastic Modulus \\
\hline & & $(N=781)$ & (YEM) ( $N=781)$ \\
\hline & Model 1 & $-2.72[-3.52 ;-1.92]$ & $0.11[0.06 ; 0.16]$ \\
\hline \multirow{3}{*}{$\begin{array}{l}\text { Skin Auto-Florescence } \\
\text { (SAF) }\end{array}$} & Model 2 & $0.28[-0.52 ; 1.07]$ & $-0.02[-0.07 ; 0.03]$ \\
\hline & Model 3 & $0.17[-0.52 ; 0.85]$ & $-0.02[-0.06 ; 0.03]$ \\
\hline & Model $4^{* *}$ & $0.21[-0.56 ; 0.97]$ & $-0.02[-0.07 ; 0.04]$ \\
\hline
\end{tabular}

*39 additional individuals excluded due to missing data on co-variates

**53 additional individuals excluded due to missing data on co-variates 
Supplemental Table 4: The association of Skin Auto-Florescence (SAF) with the carotid Inter-Adventitia Diameter (IAD), Distension ( $\triangle \mathrm{D}$ ), Intima Media Thickness (IMT) and Lumen Diameter (LD) adjusted for the carotid pulse pressure (PP)

\begin{tabular}{llcccc}
\hline Tissue AGEs & Models & $\begin{array}{c}\text { Carotid IAD } \\
(\mathbf{n}=\mathbf{7 9 7})\end{array}$ & $\begin{array}{c}\text { Carotid } \Delta \mathbf{D}+ \\
(\mathbf{n}=\mathbf{7 9 7})\end{array}$ & $\begin{array}{c}\text { Carotid IMT } \\
(\mathbf{n}=797)\end{array}$ & $\begin{array}{c}\text { Carotid LD } \\
(\mathbf{N}=797)\end{array}$ \\
\hline Skin Auto- & Model 4 + PP & $155.7(28.5 ; 262.2)$ & $10.3(-6.3 ; 27.0)$ & $-6.8(-30.6 ; 16.9)$ & $169.4(62.2 ; 276.6)$ \\
Florescence & Model 4+ & $144.1(24.2 ; 264.1)$ & $12.6(-4.3 ; 29.4)$ & $-5.1(-29.2 ; 19.0)$ & $154.3(48.7 ; 260.0)$ \\
(SAF) & calibrated PP* & & & & \\
\hline
\end{tabular}

† Model 1 additionally adjusted for the Carotid IAD

*13 additional individuals excluded due to missing data on co-variates 


\section{References}

1 Laurent S, Boutouyrie P, Asmar R, Gautier I, Laloux B, Guize L, Ducimetiere P, Benetos A. Aortic stiffness is an independent predictor of all-cause and cardiovascular mortality in hypertensive patients. Hypertension. 2001;37:1236-1241.

2 Boutouyrie P, Tropeano Al, Asmar R, Gautier I, Benetos A, Lacolley P, Laurent S. Aortic stiffness is an independent predictor of primary coronary events in hypertensive patients: a longitudinal study. Hypertension. 2002;39:10 -15. Mitchell GF, Hwang SJ, Vasan RS et al. Arterial Stiffness and cardiovascular events: the Framingham Heart Study. Circulation. 2010; 121(4): 505-11.

4 Van Sloten, Schram MT, van der Hurk K, et al. Local stiffness of the carotid and femoral artery is associated with incident cardiovascular events and all-cause mortality: the Hoorn Study. J Am Coll Cardiol. 2014; 63(17): 1739-1747 Cruickshank K, Riste L, Anderson SG, Wright JS, Dunn G, Gosling RG. Aortic pulse-wave velocity and its relationship to mortality in diabetes and glucose intolerance: an integrated index of vascular function? Circulation. 2002;106:20852090.

6 Blacher J, Guerin AP, Pannier B, Marchais SJ, Safar ME, London GM. Impact of aortic stiffness on survival in endstage renal disease. Circulation. 1999;99:2434-2439.

7 Blacher J, Pannier B, Guerin AP, Marchais SJ, Safar ME, London GM. Carotid Stiffness as a predictor of cardiovascular and all-cause mortality in end-stage renal disease. Hypertension. 1998; 32(3): 570-4

8 Henry RMA, Kostense PJ, Spijkerman AMW, et al. Arterial stiffness increases with deteriorating glucose tolerance status. The Hoorn Study. Circulation.2003; 107: 2089-2095.

9 Pannier B, Guérin AP, Marchais SJ, Métivier F, London GM: Arterial stricture and function in end-stage renal disease. Artery Res 2007;1:79-88.

10 Sell DR, Monnier VM. Moelcular Basis of Artreial Stiffening: Role of Glycation - A Mini Review. Gerontology 2012; 58:227-237

11 Yoshida N, Okumura K, Aso Y. High serum pentosidine concentrations are associated with increased arterial stiffness and thickness in patients with type 2 diabetes. Metabolism. 2005; 54(3):345-50

12 Llauradó G, Ceperuelo-Mallafré V, Vilardell C, Simó R, Gil P, Cano A, Vendrell J, González-Clemente JM. Advanced glycation end products are associated with arterial stiffness in type 1 diabetes. J Endocrinol. 2014 Jun;221(3):40513.

13 van Eupen MG, Schram MT, van Sloten TT, et al. Skin Autoflorescence and Pentosidine Are Associated With Aortic Stiffening: The Maastricht Study. Hypertension. 2016; 68(4): 956-63

14 Couppé C, Dall CH, Svensson RB, et al. Skin autofluorescence is associated with arterial stiffness and insulin level in endurance runners and healthy controls - Effects of aging and endurance exercise. Exp Gerontol. 2017; 91:9-14

15 Koyama H, Tanaka S, et al. Skin autofluorescence, a marker for advanced glycation end product accumulation, is associated with arterial stiffness in patients with end-stage renal disease. Metabolism. 2008 Oct;57(10):1452-7.

16 Watfa G, Soulis G, Tartagni E, Kearney-Schwartz A, Borghi C, Salvi P, Benetos A. Relationship between tissue glycation measured by autofluorescence and pulse wave velocity in young and elderly non-diabetic populations. Diabetes Metab. 2012 Nov;38(5):413-9.

17 Semba RD, Najjar SS, Sun K, Lakatta EG, Ferrucci L. Serum carboxymethyl-lysine, an advanced glycation end product, 
is associated with increased aortic pulse wave velocity in adults. Am J Hypertens. 2009;22(1):74-9.

18 Semba RD, Sun K, Schwartz AV, et al. Serum carboxymethyl-lysine, an advanced glycation end product, is associated with arterial stiffness in older adults. J Hypertens. 2015; 33(4):797-803

19 McNulty M, Mahmud A, Feely J. Advanced glycation end-products and arterial stiffness in hypertension. Am J Hypertens. 2007;20:242-247.

20 Zhou Y, Yu Z, Jia H, et al. Association of serum pentosidine with arterial stiffness in hemodialysis patients. Artif Organs. 2010;34(3):193-9.

21 Baumann M, Richart T, Sollinger D, et al. Association between carotid diameter and the advanced glycation end product N-epsilon-carboxymethyllysine (CML). Cardiovasc Diabetol. 2009;8:45.

22 Smit AJ, Hartog JW, Voors AA, van Veldhuisen DJ. Advanced glycation endproducts in chronic heart failure. Ann NY Acad Sci. 2008;1126:225-230.

23 Paini A, Boutouyrie P, Calvet D, Tropeno Al, Laloux B, Laurent S. Carotid and Aortic Stiffness Determinants of Discrepancies. Hypertension 2006; 47(3): 371-6.

24 Hermeling, E, Reesink, KD, Kornmann, LM, et al., The dicrotic notch as alternative time-reference point to measure local pulse wave velocity in the carotid artery by means of ultrasonography, Journal of hypertension, 2009;27:20282035.

25 Willekes, C, Hoeks, AP, Bots, ML, et al., Evaluation of off-line automated intima-media thickness detection of the common carotid artery based on M-line signal processing, Ultrasound in medicine \& biology, 1999;25:57-64.

26 Reneman, RS, Meinders, JM and Hoeks, AP, Non-invasive ultrasound in arterial wall dynamics in humans: what have we learned and what remains to be solved, European heart journal, 2005;26:960-966.

27 Kelly, R and Fitchett, D, Noninvasive determination of aortic input impedance and external left ventricular power output: a validation and repeatability study of a new technique, Journal of the American College of Cardiology, 1992;20:952-963.

28 Van Bortel, LM, Balkestein, EJ, van der Heijden-Spek, JJ, et al., Non-invasive assessment of local arterial pulse pressure: comparison of applanation tonometry and echo-tracking, Journal of hypertension, 2001;19:1037-1044.

29 Meerwaldt R, Graaff R, Oomen PH, et al. Simple non-invasive assessment of advanced glycation endproduct accumulation. Diabetologia. 2004;47:1324-1330.

30 Koetsier M, Nur E, Chunmao H, et al. Skin color independent assessment of aging using skin autofluorescence. Opt Express. 2010;18:14416-14429.

31 Scheijen JL, van de Waarenburg MP, Stehouwer CD, Schalkwijk CG. Measurement of pentosidine in human plasma protein by a single-column high-performance liquid chromatography method with fluorescence detection. J Chromatogr B Analyt Technol Biomed Life Sci. 2009;877:610-614.

32 Hanssen NM, Engelen L, Ferreira I et al. Plasma levels of advanced glycation endproducts N $\varepsilon$-(carboxymethyl)lysine, $\mathrm{N} \varepsilon$-(carboxyethyl)lysine, and pentosidine are not independently associated with cardiovascular disease in individuals with or without type 2 diabetes: the Hoorn and CODAM studies. J Clin Endocrinol Metab. 2013;98:E1369-E1373.

33 Schram MT, Sep SJ, van der Kallen CJ, et al. The Maastricht Study: an extensive phenotyping study on determinants of type 2 diabetes, its complications and its comorbidities.Eur J Epidemiol.2014;29(6):439-51.

34 Leng GC, Fowkes FG. The Edinburgh Claudication Questionnaire: an improved version of the WHO/Rose Questionnaire for use in epidemiological surverys. J clin Epidemiol. 1992; 45(10): 1101-9 
35 WHO. Definition and Diagnosis of diabetes mellitus and intermediate hyperglycemia. 2006. www.whoint/diabetes/ publications/Definition\%20and\%20diagnosis\%20of\%20diabetes_new.pdf

36 Inker LA, Schmid CH, Tighiouart $\mathrm{H}$ et al. Estimating glomerular filtration rate from serum creatinine and cystatin $\mathrm{C}$. N Engl J Med 2012; 367: $20-29$

37 Engelen L, Bossuyt J, Ferreira I, et al. Reference values for local arterial stiffness. Part A: carotid artery. Journal of Hypertension 2015; 33:1981-1996

38 Bossuyt J, Engelen L, Ferreira I, et al. Reference values for local aterial stiffness. Part B: femoral artery. Journal of Hypertension 2015; 33: 1997-2009

39 Liu CY, Huang QF, et al. A Comparative Study on Skin and Plasma Advanced Glycation End Products and Their Associations with Arterial Stiffness. Pulse (Basel). 2017 Jan;4(4):208-218.

40 Edwards J. An Atlas of Acquired Diseases of the Heart and Great Vessels. Philadephia: Saunders; 1961.

41 Laurent S, Girerd X, Mourad JJ, et al Elastic modulus of the radial artery wall material is not increased in patients with essential hypertension. Arterioscler Thromb. 1994;14:1223-1231.

42 Boutouyrie P, Laurent S, Benetos A, Girerd XJ, Hoeks AP, Safar ME. Opposing effects of ageing on distal and proximal large arteries in hypertensives. J Hypertens. 1992;10(suppl):S87-S91.

43 Benetos A, Laurent S, Hoeks AP, Boutouyrie PH, Safar ME. Arterial alterations with aging and high blood pressure. A noninvasive study of carotid and femoral arteries. Arterioscler Thromb. 1993;13:90 -97.

44 Briet M, Bozec E, Laurent S,et al. Arterial stiffness and enlargement in mild-to-moderate chronic kidney disease. Kidney Int 2006, 69(2):350-357.

45 London, G.M., Marchais, S.J., Safar, M.E. et al. Aortic and large artery compliance in end-stage renal failure. Kidney Int. 1990; 37: 137-142

46 Henry RMA, Kostense PJ, Dekker JM, et al. Carotid Artery Remodelling. A Maladaptive Phenomenon in Type 2 Diabetes but not in Impaired Glucose Metabolism: The Hoorn Study. Stroke. 2004; 35: 671-6.

47 Glagov, S., Weisenberg, E., Zarins, CK., Stankunavicius, R., Kolettis, GJ. Compensatory enlargement of human atherosclerotic coronary arteries. N Engl J Med. 1987; 316 (22): 1371-5.

48 Glagov S, Zarins C, Giddens DP, Ku DN. Hemodynamics and atherosclerosis. Insights and perspectives gained from studies of human arteries. Arch Pathol Lab Med. 1988; 112:1018-1031.

49 Hofmann B, Jacobs K, Navarrete Santos A, et al. Relationship between cardiac tissue glycation and skin autofluorescence in patients with coronary artery disease. Diabetes Metab 2015;41:410-15.

50 Lonn E, Yusuf S, Dzavik V, et al. Effects of ramipril and vitamin E on atherosclerosis: The study to evaluate carotid ultrasound changes in patients treated with ramipril and vitamin E (SECURE). Circulation 103: 919-925, 2001

51 Farasat SM, Morrell CH, Scuteri A, et al. Pulse pressure is inversely related to aortic root diameter. Implications for the pathogenesis of Systolic hypertension. Hypertension. 2008;51: 196-202

52 O’Rourke MF, Hashimoto J. Mechanical Factors in Arterial Aging. A Clinical Prospective. J Am Coll Cardiol. 2007; 50(1): 1-13

53 Brownlee M. Biochemistry and molecular cell biology of diabetic complications. Nature. 2001;414:813-820.

54 https://www.nhg.org/standaarden/samenvatting/cardiovasculair-risicomanagement

55 Shahin Y, Khan JA, Chetter I. Angiotensin converting enzyme inhibitors effect on arterial stiffness and wave reflections: a meta-analysis and meta-regression of randomised controlled trials. Atherosclerosis 2012;221:18-33. 
56 Murrow JR, Sher S, Ali S, et al. The differential effect of statins on oxidative stress and endothelial function: atorvastatin versus pravastatin. J Clin Lipidol. 2012; 6(1): 42-49

57 Nenna A, Nappi F, Singh SSA, et al. Pharmacologic Approaches Against Advanced Glycation End Products (AGEs) in Diabetic Cardiovascular Disease. Res Cardiovasc Med 23; 4(2):e26949

58 Akhtar R. In vitro characterisation of arterial stiffening: From the macro- to the nano-scale. Artery Research 2014; 8:1-8 


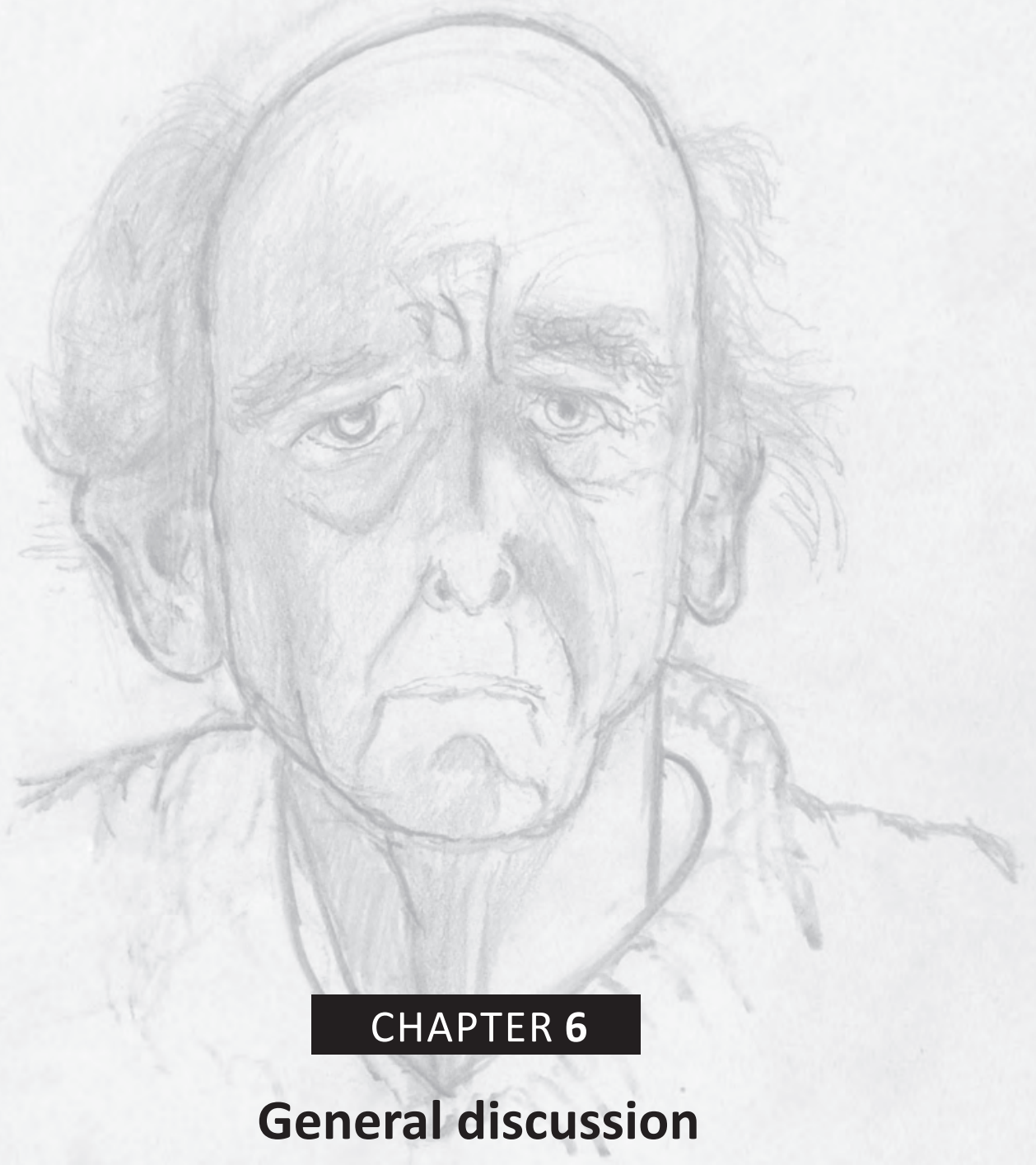





\section{PART I:}

\section{Arterial Stiffness and Neuropsychiatric Disorders}

\section{Main Findings and Clinical Implications}

\section{Arterial stiffness and depression in middle-aged individuals}

In chapter $\mathbf{2}$ of this thesis we found that aortic stiffness, as measured by the carotidfemoral pulse wave velocity (cfPWV), was cross-sectionally associated with depression and depressive symptoms in middle-aged ( 40 - 60 years) men and to a lesser extent in middleaged women. Most studies to date have concentrated on elderly populations ( $>60$ years) [1-4], therefore this is the first study to show that aortic stiffness, which is the gold standard of arterial stiffness measurements, could contribute to the development of depression in individuals as young as 40-60 years. Although we only found a statistically significant association in middle-aged men, we cannot rule out the presence of an association in middle-aged women. This thesis highlights, therefore the need to incorporate CVD risk factor screening and management in the treatment of depression in middle-aged patients; though middle-aged men may profit from arterial de-stiffening therapies more than middleaged women. Unfortunately, due to the cross-sectional design of our study we cannot prove causality, nor can we exclude reverse causality as more severe depressive symptoms have been associated with greater arterial stiffness even in teenagers [5], and treatment of a major depressive disorder can improve arterial stiffness [6], as well as hypertension [7]. Thus, our results need to be confirmed by other (longitudinal) population-based studies before they are implemented in clinical practice.

Anti-hypertensive drugs are currently the most efficient arterial de-stiffening therapy available. All tension lowering drugs can indirectly lower arterial stiffness by reducing blood pressure [8]. However, ACE-inhibitors, angiotensin receptor blockers and calcium-channels antagonists are also thought to have artery-modifying properties, thus reducing arterial stiffness beyond blood pressure $[9,10]$. Nonetheless, recent evidence suggests that blood pressure control, rather than the use of any specific antihypertensive drugs delays arterial stiffness progression over ten years of follow-up [11]. In patients with depression, two trials have shown that the calcium-channel inhibitor nimodipine reduces the time to remission of a major depression episode in a population of middle-aged and elderly individuals [12,13], however these studies were small and have yet to be confirmed in larger settings. Arterial stiffness may also be reduced through life-style interventions, such as aerobic exercise [14$17]$, dairy enriched [18] and low-sodium diets $[19,20]$. 
Lastly, new arterial de-stiffening drugs are being developed [21]. Several pre-clinical trials have shown the beneficial effects of A-II type 2 receptor activation by compound 21 [22]. Also, specific AGE reducing therapies [23] could reduce arterial stiffness without affecting mean arterial pressure, however, additional research is required to confirm their safety and effectiveness in the general population.

Arterial stiffness and depression in elderly individuals (> 60 years)

In chapter $\mathbf{2}$ of this thesis we found that aortic stiffness was not associated with either a late-life depression (LLD), or with more self-reported depressive symptoms in elderly (aged between 60 and 78 years) individuals. Also, in chapter 3 we found that carotid stiffness was not associated with depressive symptoms either cross-sectionally or longitudinally over a follow-up period of 8 years in a population- based cohort of even older individuals (age $69.3 \pm 6.3$ ). Our findings may not necessarily contradict the vascular depression hypothesis [24] as we may have lacked the power to detect any significant associations due to the small number of depression cases in each cohort. Furthermore, the added value of arterial stiffness as a CVD risk factor decreases with old age as systolic hypertension reflects arterial stiffness more accurately than in younger age groups [25]. Indeed, the larger Rotterdam Study did show that both aortic and carotid artery stiffness indices are associated with LLD, as well as sub-clinical depressive symptoms [2]. Similarly, aortic stiffness was associated with more depressive symptoms in the large AGES-Reykjavik Study [3].

Nevertheless, the modest associations in our study, as well as in the aforementioned studies might indicate that population-wide interventions that reduce arterial stiffness or hypertension may not be efficacious in preventing LLD in the elderly. Indeed, despite intensified CVD risk factor management in the past 20 years, the prevalence of LLD was similar in our study as to that reported by Beekman et al. in a systematic review in 1999 [26] and to that reported by Tiemeier et al. in the Rotterdam population between the years 1997-1999 [2]. Furthermore, several large population-based trials have shown that intensified hypertension management in the elderly does not lead to significant decreases in clinically relevant depressive symptoms, despite lowering the risk of developing overt CVD, such as stroke, MI or PAD [27-30].

\section{Carotid artery stiffness and cognitive performance in elderly individuals}

In chapter 4, we found that carotid artery stiffness was significantly associated with lower processing speed and attention \& executive function, but not with memory in crude analyses; however, the associations were attenuated and no longer statistically significant after adjustment for age and follow-up duration. Aortic stiffness, however, was independently associated with lower processing speed, but not with a lower attention $\&$ executive function, or memory function at six years of follow-up. Our findings are in 
accordance with previous studies that showed that the cfPWV is consistently, though weakly longitudinally associated with cognitive performance and decline [31]; whereas carotid stiffness is not [32]. In our study, one standard deviation higher aortic stiffness was comparable with approximately 3 years of ageing in the domain of information processing speed; therefore, the association seems clinically relevant. Nevertheless, mild cognitive impairment and dementia may not necessarily form a continuum [33], as most individuals with mild cognitive impairment will not develop dementia [34]. Therefore, additional research is required to confirm the role of aortic stiffness in the development of dementia.

\section{Pathophysiological mechanisms behind the associations of arterial stiffness with neuropsychiatric disorders}

\section{Arterial stiffness and depression}

Arterial stiffness could lead to depression through the development of (micro)vascular disease, which directly affects and diminishes cerebral functions [35]. Stiffening of the large elastic vessels, such as the carotid arteries or the aorta impairs their cushioning function, which allows greater pressure and flow pulsatility to penetrate the low impedance cerebral (micro)vasculature, thus directly damaging the cerebral microcirculation and, through it the surrounding tissue [36-38]. Furthermore, the excessive pulsatile pressure induces arteriolar remodelling and hypertrophy, which impairs vascular reactivity and contributes to repeated episodes of microvascular ischemia and tissue damage [37,38]. Lastly, increasing arterial stiffness may cause excessive blood pressure variability $[39,40]$, which may further sensitize high-flow organs to the harmful effects of impaired microvascular vasoreactivity [38].

Differential roles of aortic and carotid artery stiffness in the development of cognitive dysfunction

Similar considerations can be made regarding the role of arterial stiffness in the development of cognitive dysfunction. Indeed, LLD is associated with $\mathrm{MCl}$ [35] and may progress to dementia [41], thus reflecting their shared biologic substrate of cerebral (micro) vascular disease. Yet, in chapter 4, we found that aortic, but not carotid artery stiffness was longitudinally associated with cognitive dysfunction. This could be explained through several mechanisms. Firstly, the aorta has been shown to stiffen faster than the carotid artery in response to old age, hypertension and type 2 diabetes (T2D) [42]. Due to the adverse CVD risk profile of the Hoorn Study population, the cfPWV may have, therefore, been more able to detect any differences in cognitive performance than carotid artery stiffness. Secondly, aortic stiffness could reflect the elastic properties of the middle-sized muscular cerebral arteries more accurately than the carotid arteries, due to its muscular 
artery components [43]. Thirdly, aortic stiffness is a more accurate marker of (sub-clinical) heart failure and CHD than carotid artery stiffness [44]. These, in turn, are risk factors for cerebral (micro)vascular disease and cognitive decline[45], which may enhance any associations of aortic stiffness with cognitive dysfunction. Lastly, aortic stiffening has also been associated with amyloid- $\beta$ deposition and may therefore play a more direct role in Alzheimer dementia [46]. Nevertheless, we were only able to compare aortic and carotid stiffness within the same study population in one small study and we were unable to carry out any (meaningful) interaction analyses with for example T2D due to the small sample size. Therefore, our results must be confirmed by other large population-based studies.

\section{PART 2:}

\section{Pathophysiological mechanisms of arterial stiffening}

\section{Advanced Glycation End Products (AGEs) and local stiffness indices}

In chapter 5 we explored the pathophysiological mechanisms behind arterial stiffening in old age and type 2 diabetes (T2D) by investigating the associations of tissue and plasma advanced glycation end-products (AGEs) with stiffening of the carotid, femoral and brachial arteries. In our study, tissue AGE accumulation, as measured by Skin Auto-Fluorescence (SAF), was associated with a greater carotid lumen diameter but not with the stiffening of any of the included arteries. Of the plasma AGEs, only pentosidine was associated with the absolute distension and the Young Elastic Modulus (YEM) of the carotid artery, as well as with the distensibility coefficient (DC) of the brachial artery. However, these results were largely dependent on several outliers and were, therefore, considered spurious.

Our lack of significant results could, nevertheless, offer additional insight into AGE associated arterial stiffening. We cannot exclude the presence of any associations as we may have lacked the power to detect them due to the relatively small study sample and the preferential attenuation of both arterial stiffness and AGE concentrations in T2D patients due to the use of more intensive use of blood-pressure-lowering and lipid-modifying therapies [10,47]. Yet, despite these limitations, van Eupen et al. [48] found within the same study population that both SAF and plasma pentosidine are significantly associated with a higher cfPWV, as well as a higher central (ascending aortic) pulse pressure. Thus, taken together, these results suggest that aortic stiffness is more prone to AGE-associated stiffening than any other elastic or muscular artery. As AGEs are thought to contribute to arterial stiffening in old age and T2D, our results are in line with previous observations that in elderly individuals [49] and T2D patients [50,51] elastic arteries preferentially stiffen over muscular arteries; and that of these elastic arteries, the aorta is more prone to stiffen than 
the carotid artery in response to stiffening factors [42]. Thus, our results suggest that AGE reduction through dietary or pharmacologic interventions [23] could be less effective in reducing carotid artery stiffness than aortic stiffness in the general population or in patients with well controlled T2D; however, our findings should be confirmed by larger cohorts

Our results also suggest that AGE accumulation induces maladaptive changes of the carotid artery that could ultimately lead to arterial stiffening. In this study, SAF was robustly associated with an enlargement of the lumen diameter but not with a concomitant dilation of the IAD or a thickening of the intima media thickness (IMT). This suggests that while the carotid artery dilates, its wall mass remains unchanged and is stretched over a larger diameter, which results in a relative thinning of the arterial wall as well as higher circumferential wall stress [52]. These changes may ultimately lead to carotid artery stiffening by accelerating elastic fibre degradation [53] and could, therefore, also be a potential therapeutic target for the treatment of arterial stiffness; however, our findings have yet to be confirmed by larger observational cohorts.

\section{Pathophysiological mechanisms of AGE associated changes of elastic and muscular arteries}

The association of SAF with carotid artery dilatation is pathophysiologically plausible and may be explained by the degradation of elastin fibres by any or all of the plasma AGEs included in our study. Indeed, SAF correlates well with both fluorescent (ie. pentosidine) and non-fluorescent (ie. CML, CEL) tissue AGE concentrations [54,55]; whereas plasma AGEs may not adequately reflect tissue concentrations in individuals with a good liver and kidney function [56]. Pentosidine can cross-link with elastin, which decreases its quality and accelerates its degradation [57,58]. Secondly, CEL can induce endothelial dysfunction and thus reduce nitrogen oxide release [59], which in turn, inhibits the production of elastin by smooth muscle cells (SMCs) [60] and stimulates the release of enzymes, which degrade the elastin fibres [61]. Thirdly, CML induces the production of reactive oxygen species (ROS) and pro-inflammatory cytokines by macrophages, mesangial and endothelial cells [59] through RAGE activation. ROS directly reacts with elastin cross-links, thereby accelerating their degradation [62], while pro-inflammatory cytokines activate MMPs and other elastases that digest broken elastin molecules [63]. CML can also directly accumulate in elastin fibres [64]; where it causes fenestration of elastic laminae [65]. Nevertheless, elastic fibre degradation ought to ultimately lead arterial stiffening, as pulsatile stress is transferred to the stiffer collage fibres [66]. In our study we may have captured these processes in their incipient phase, in which the carotid artery is still able to maintain its compliance. Alternatively, the relative thinning of the arterial wall could have allowed the carotid artery to maintain its distensibility despite any stiffening. As the aorta has the highest elastin: collagen ratio of all arteries [67], it could be most prone to AGE-associated stiffening. 


\section{Methodological Considerations}

The findings of the present thesis need to be interpreted in light of the following methodological considerations.

\section{A. Confounding bias and over-adjustment bias}

Confounding is a major concern in most observational studies [68] as inappropriate adjustment for confounders can distort the reported associations. One of the main strengths of the study populations used in this thesis was the measurement of many potential confounding factors, which were accounted for in the fully adjusted models. However, this may have also resulted in the underestimation of any associations due to the overadjustment for confounders, that lie in the causal pathway (ie. mediators) [69], such as hypertension, blood pressure lowering medication and prior CVD.

\section{B. Selection Bias}

Selection bias could have also attenuated the associations of arterial stiffness with either depression (chapters $\mathbf{2}$ and $\mathbf{3}$ ) or cognitive dysfunction (chapters $\mathbf{4}$ ) as patients suffering from severe forms of either depression or cognitive dysfunction were more likely to refuse to participate in the study.

\section{Bias in longitudinal studies}

\section{Selective attrition and competing risks}

The longitudinal analyses based on the Hoorn Study (chapters 3 and 4) could have been influenced by selective attrition, as a large proportion of the individuals with baseline data did not participate in the follow-up measurements. These persons were older and had a more adverse CVD risk profile (including stiffer arteries) than the individuals who did participate in the follow-up measurements. Attrition bias could have been accentuated further by the adverse CVD profile of the study population, caused by the advanced age (mean age 68 years), the high prevalence of prior CVD and of T2D. This would have attenuated the longitudinal associations of arterial stiffness with either depressive symptoms or cognitive performance. Competitive risks and survivorship bias could have further attenuated the associations as individuals with stiffer arteries at baseline are more likely to develop fatal CVD and were, thus, not included in the follow-up measurements. Yet, in chapter 4 we did find an association of aortic stiffness with cognitive performance in a subsample of the Hoorn Study, therefore it is less likely that this selection played a decisive role, though it may have attenuated our associations. 


\section{Follow-up time}

It may be argued that the longitudinal associations of arterial stiffness with either depression or cognitive dysfunction in Chapters $\mathbf{3}$ and $\mathbf{4}$ may have been hampered by the relatively short follow-up duration. Although we are the first to investigate the longitudinal association with depression, previous longitudinal studies that reported significant associations of aortic stiffness with cognitive dysfunction had similar follow-up durations to our study (4-7 years) [70-72]. Furthermore, age-related cognitive dysfunction develops after the age of 60 years when neurodegenerative changes of the brain start to occur [73]. As the average age of the population included in chapters 3 and 4 was 68 years, six to eight years follow-up should have offered a long enough interval to detect any changes in cognitive function or depressive symptoms. Furthermore, longer follow-up durations in elderly cohorts could, in fact, bias any associations due to selective attrition of patients with a more adverse cardiovascular risk profile. For example, in the Hoorn Study, where only $50 \%$ of the population was included in the follow-up analyses either due to mortality or due to unwillingness to participate. Yet, longer follow-up periods may be of use to detect the effects of arterial stiffness on incident dementia [74].

\section{Information Bias}

Non-differential and differential misclassification of individuals may have occurred due to measurement error (information bias).

\section{Measurement of arterial stiffness}

Aortic stiffness, as assessed by the cfPWV, is considered the "gold standard" measurement of arterial stiffness and was measured according to international standards [75]. Also, both in the Maastricht Study and the Hoorn Study, data on carotid, brachial and femoral artery distensibility indices were obtained using a validated and standardized echo-tracking ultrasonography technique [76]. Brachial systolic and diastolic blood pressure was measured at 5-minute intervals with an oscillometric device and the means of these values were used to calculate brachial pulse pressure (PP). In order to account for the amplification of the PP from central to peripheral arteries, carotid artery PP was also estimated from the carotid artery distension wave-forms and the brachial pulse pressure, as described previously [77]. Carotid artery stiffness indices were, thus computed using both brachial and calibrated PP, therefore improving the validity of our findings. In chapter 5 , femoral and brachial artery stiffness measurements were shown to be more prone to measurement error as their intraand interobserver reliability were lower than those of the carotid artery measurements. This is likely due to the high concentrations of SMCs within their walls, which allows shortterm alterations in smooth muscle tone to influence arterial diameter and stiffness [78]. It is therefore, more likely that the associations with elastic artery stiffness indices are more robust as they are not prone to such limitations. 


\section{Measurement of depression}

A major depressive disorder was identified by means of a diagnostic interview (MINI) [79], whereas depressive symptoms were measured with screening instruments (PHQ9 or the CES-D) $[80,81]$. Screening instruments can misclassify depression as they do not account for the diagnostic prerequisites of having at least one core symptom of depression, or the presence of an underlying medical condition. In the elderly (>60 years), symptoms of impaired daily functioning due to chronic illnesses, could be misclassified as depressive symptoms, especially apathy, sleep or eating problems [26]. Therefore, the association of arterial stiffness with depressive symptoms may be smaller the association with a major depressive disorder. In view of these considerations, the associations found in chapter 4 should be interpreted with care as only depressive symptoms data was available.

\section{Measurement of cognitive function}

Cognitive dysfunction can be identified through global cognitive function scores or by means of neuropsychologic test batteries. Global cognitive scores, such as the MMSE screen for overall cognitive dysfunction [82], thus changes in this score are more likely to represent large decreases in cognitive performance. Neuropsychologic tests offer a more detailed quantification of the individual cognitive domains and are, therefore, more suited to detect the subtle changes in cognitive dysfunction, which are encountered in population-based studies, such as the Hoorn Study [82]. In chapter 4 in the Hoorn Study, individual neuropsychologic tests were grouped into the three cognitive domains, which have been associated previously with cardiovascular disease (CVD) $[45,83,84]$. Some have argued that the use of individual tests is preferred above the use of cognitive domain scores as many individual tests provide information on multiple domains and the classification of neuropsychologic tests into cognitive do mains is subjective, however in the Hoorn Study the division into cognitive domains was made a priori, according to standard neuropsychological practice and cognitive theory [85]. Another reason to use cognitive domains is to improve the statistical power of any associations [86]. For example, in chapter $\mathbf{4}$ we found that aortic stiffness was significantly associated with the domain score information processing speed, even though the associations with the individual tests of this domain were only borderline significant. Thus, the reliability of our findings could have been improved by the merging of several individual cognition tests.

\section{Measurement of Advanced Glycation End Products (AGEs)}

\section{Plasma AGEs}

Protein-bound pentosidine was quantified using high-performance liquid chromatography [87]; whereas protein-bound $\mathrm{N} \varepsilon$-(carboxymethyl)lysine (CML) and $\mathrm{N} \varepsilon$-(carboxyethyl) lysine (CEL) and lysine were quantified using ultra-performance liquid chromatography 
tandem mass-spectrometry [88]. This is the current method of choice to measure both free and protein-bound AGEs [89] and, in our study had very intra- and inter assay coefficients of variation < $10 \%$. Plasma AGE concentrations may not reflect adequately tissue AGE levels; as it is thought that most AGEs are intracellularly or in interstitial tissues [90]. Furthermore, plasma AGEs are bound to plasma proteins, which have a very short half-life and are cleared by the kidney and the liver, therefore, their concentrations may fluctuate over time [91-93], thus measures of tissue AGE accumulation were also included in the study.

\section{Skin Auto-Florescence (SAF)}

The AGE Reader ${ }^{\mathrm{TM}}$ measures AGE concentrations in the skin by utilizing the fluorescent properties of some of these AGEs [54]. As opposed to plasma proteins, skin tissue has a considerably longer half-life (14.8 years); thus, SAF may give a more accurate indication of AGE accumulation in the skin [54], as well in cardiovascular tissue [55]. However, SAF is a non-specific marker of AGE accumulation as it correlates with the concentrations of both the fluorescent pentosidine, as well as, of the non-fluorescent CML and CEL in skin biopsies [54]. Also, other skin fluorophores, such as keratin, vitamin D, lipofuscin, ceroid, $\mathrm{NADH}$ and pyridoxine, have overlapping excitation and emission spectra, which could therefore artificially enhance or influence SAF [94]. Nonetheless, a previous study has shown that most of the SAF variance was explained by pentosidine concentrations in the skin [95].

\section{Statistic Bias}

\section{Computation of the Young Elastic Modulus (YEM)}

The carotid YEM is meant to measure the intrinsic stiffness of the arterial wall independent of its geometry and it is calculated according to the following formula: YEM = D/IMT * 1 / DC, where D is the diastolic inter-adventitial diameter, IMT is the Intima Media Thickness, and the DC is the distensibility coefficient of the carotid artery [77]. The DC is itself a stiffness parameter and smaller values represent stiffer arteries. The inversion of the DC (ie. 1/DC term) reduces the larger DC values (more compliant arteries) to a greater extent than the smaller DC values (stiffest arteries). This can result in disproportionately high YEM values for individuals with the stiffest arteries in the population as compared with those with more compliant arteries, thus creating outliers. If significant associations are (partly) dependent on these outliers, as in chapter 5, it may be difficult to discern between true biologic relevance and statistic misinterpretation. However, the YEM may overestimate any associations with arterial stiffness due to the enhancement of the lower (stiffer) part of the DC distribution. Therefore, it is best to consider associations biologically relevant only when there are also concomitant associations with the DC or the distension. In chapter 
5, plasma pentosidine was associated with both the YEM and the carotid distension, but not with the DC; therefore, we may have identified a biologically relevant phenomenon, however larger samples are required to confirm our findings.

\section{Arterial stiffness in longitudinal data analysis}

Arterial stiffness is dependent on the distending pressure at the time of the measurement. At a higher mean arterial pressure (MAP), the systolic stress is transferred to the more rigid collagen fibres, which results in a higher arterial stiffness [66]. Most arteries are, therefore, more compliant at lower pressures than at higher pressures, thus a difference in stiffness values may not be due to a change in the arterial viscoelastic properties. Thus, any analyses regarding differences or changes in arterial stiffness should account for the MAP at the time of the measurement.

In cross-sectional analyses this is readily achieved through the adjustment for MAP. In longitudinal analyses, both mixed models and GEE also allow for the adjustment of the MAP at each time point [96]. Yet, neither of these techniques can separate the effects of longitudinal changes within an individual from those between individuals [97]. Testing within-subject associations may be a challenge. For example, (percentage)changes in arterial stiffness measurements may exaggerate any associations as they do not account for the blood pressure at the time of the measurement. Additional adjustments for either baseline MAP, or for the change in MAP may not sufficiently adjust for this bias and thus may not be able to identify solely pressure independent changes. Possibly, the use of pressure-independent stiffness markers, such as the beta-stiffness index [98] may offer a more accurate estimation of longitudinal changes in local arterial stiffness. Alternatively, an autoregressive technique, whereby all models are adjusted for the MAP at the same time point as the arterial stiffness measurement (ie. t-1) [99] could offer an elegant solution for longitudinal data analyses of all stiffness indices.

In chapter 3 of this thesis we only had data at two time points, therefore GEE was not necessarily indicated. We, therefore, analysed the longitudinal associations of changes in arterial stiffness with (changes in) depressive symptoms by means of linear regression. The follow-up depression score was the main outcome variable and the arterial stiffness at follow-up was the main determinant. The models were then adjusted for baseline arterial stiffness [100] as well as for the MAP both at both time points. This technique allowed us to reliably assess the effect of the pressure independent changes in arterial stiffness on any (changes in) self-reported depressive symptoms. 


\section{Outliers}

All arterial stiffness indices and their components, as well as all advanced glycation end products (AGEs) variables were normally distributed, however they also had several observations which were significantly different from the total population. As linear regression analyses have been shown to give biased estimations when extreme values are present we included additional outlier analyses in all our chapters. Outliers were identified by means of classic standardization [101]. Due to the large study samples (> $100)$, which according to the central limit theorem would tend to be normally distributed even if the population distribution is skewed [102], only Z-scores that exceeded 3 or -3 were considered outliers. We did not exclude these outliers from the main analyses as their values were biologically plausible and may therefore be also found in the general population. However, we carried out additional sensitivity analyses without these outliers in order to test the robustness of our statistical models. In line with previous observations, the significant linear associations in chapter $\mathbf{5}$ were largely dependent on arterial stiffness outliers, whereas the associations of the logistic regression analyses in chapter $\mathbf{2}$ were not. Thus, in chapter 5, it was difficult to discern between true biologic relevance and statistic misinterpretation; though the fact that the regression coefficients were greatly diminished after the removal of several extreme values $(<2 \%$ of the data) makes statistic misinterpretation more likely.

\section{Missing data}

Regression analyses cannot deal with missing data, therefore cases with missing values on one or more variables incorporated in the statistical models are excluded by default and may thus constitute a source of bias. Due to the large percentage of missing data this could have been an issue in chapters $\mathbf{2}$ and $\mathbf{3}$ of this thesis. In chapter $\mathbf{2}$ aortic stiffness was not measured, either due to lack of personnel (13\%), or due to measurement errors caused by obesity, the presence of tachyarrhythmias or of type 2 diabetes (1\%). Missing data due to lack of personnel could be considered Missing Completely At Random (MCAR) [103] and may therefore not represent a source of bias. Yet, in our cohort some selection may have taken place as individuals with missing data had a more adverse CVD risk profile with a higher BMI and more hypertension than individuals with aortic stiffness measurements. Even though the data seems to be Missing At Random (MAR) [103], imputation techniques were not used, as the Maastricht Study is still ongoing and is currently attempting to retrieve its missing data. Its policy is therefore not to use these techniques until this process is completed. Also, missing data on aortic stiffness did not differ with respect to depression, depressive symptoms or the use of anti-depressive medication, thus it is less likely that our associations were biased. 
In chapter 3, CES-D data was missing in 14\% of individuals both at baseline and at followup. Individuals with missing baseline CES-D data had more T2D, higher mean arterial pressure and lower (stiffer) carotid artery stiffness, but no difference in use of depression medication. This may have introduced bias towards the null in the cross-sectional analyses, however in the main longitudinal analyses this effect was probably minimal as most cases with missing CES-D data at baseline were also not included in the follow-up measurements either because they were deceased or because they refused to participate. Thus, selective attrition may have been a more prominent source of bias than selection bias due to missing data in chapter 4 . Nonetheless, in order to ensure the validity of our findings, our models were only adjusted for baseline CES-D scores in sensitivity analyses.

\section{Future research}

\section{Arterial stiffness and depression}

In this thesis, we were the first to investigate whether arterial stiffness is longitudinally associated with late-life depressive symptoms, however our study was hampered by the small sample size, the use of self-reported depressive symptoms and the low prevalence of clinically relevant depressive symptoms. In the future, larger observational studies should focus on the longitudinal association of arterial stiffness with clinically relevant depressive symptoms or with a depressive disorder as identified by a diagnostic instrument. Also, the causality of the association of aortic stiffness with depression in middle-aged individuals should be confirmed by other (longitudinal) observational studies, as should be the differential association in middle-aged men as compared to middle-aged women. Lastly, it has been previously shown that higher blood pressure in middle-aged but not elderly individuals is longitudinally associated with cognitive decline in in old age [104]. Due to their shared aetiology of cerebral micro-vascular disease, it would be of interest to analyse whether the same applies to the longitudinal association of arterial stiffness with LLD in the elderly.

Clinical trials could offer additional insight into the benefits of CVD risk factor management in the treatment outcomes of LLD. According to the vascular depression hypothesis CVD risk factors may also precipitate or perpetuate LLD symptoms. For example, depression in later life may increase the risk of developing dementia in patients with hypertension and stroke [105]; thus, high CVD risk patients may benefit from blood pressure lowering and de-stiffening therapies. Such improvements may not be well quantified by populationbased trials, where the prevalence of LLD is low. Two small trials have indeed shown that nimodipine reduces the time to remission of a major depression episode in a population of middle-aged and elderly individuals $[12,13]$. Additional replication in larger settings is, however required. 


\section{Arterial stiffness and cognitive dysfunction}

This thesis identifies aortic, but not carotid artery stiffness as a risk factor for a slower information processing speed. Our results are in concordance with a recent systematic review that has shown that greater aortic stiffness is consistently associated with cognitive decline [31]. Data on carotid artery stiffness and cognitive performance is scarce [106-108]; however, our findings are in accordance with the only other longitudinal population-based study available [32]. Yet, in contrast with previous findings [109-111], this latter study [32] also did not find a significant association of aortic stiffness with cognitive decline, possibly due to the measurement of cognitive function at only two time points. Possibly, larger observational studies that measured carotid artery stiffness and cognitive function at multiple time points would offer a better chance of identifying any associations. Also, as some have suggested that mild cognitive impairment and dementia may not necessarily form a continuum [33], the association of arterial stiffness with dementia should also be researched longitudinally in a similar fashion.

Clinical trials to date have shown a limited, though consistent benefit of arterial de-stiffening therapies on preserving cognitive function in the elderly. A recent systematic review has shown, for example, that blood pressure reduction with the diuretic indapamide or with the calcium channel blocker nitrendipine (moderately) reduces the risk of developing dementia in the elderly [112]; while another study concluded that angiotensin receptor blockers (ARBs) protect best against any type of cognitive decline, including cognitive dysfunction and dementia [113]. These effects could have been underestimated as intensive blood pressure lowering in the elderly, which is predominantly defined by isolated systolic hypertension, may excessively lower diastolic and mean arterial pressure [114-116], which, in turn, may adversely affect cognitive function [117]. Possibly, AGE reducing drugs, which improve arterial compliance without influencing mean arterial pressure, could be a safer alternative [23], however larger population-based trials are required to investigate its safety and effectiveness in the prevention of cognitive decline and dementia.

Our studies were carried out in elderly individuals (age $68 \pm 5$ years). It would be of interest, however, to assess the effects of middle-age arterial stiffness on cognitive dysfunction. For example, previous studies have suggested that middle-age hypertension is a stronger predictor of cognitive decline at an advanced age than old-age hypertension [104]. In middle-aged individuals, systolic or pulse pressures are poor surrogates for arterial stiffness, therefore arterial stiffness could be a more potent CVD risk factor in these individuals than in the elderly [25]. It would be of interest, therefore, to assess the presence and the clinical relevance of the association of arterial stiffness in middle-age with cognitive decline in old age in longitudinal population-based studies. 
Lastly, in chapter 4 we have found that aortic stiffness is associated more strongly with cognitive dysfunction and, possibly cerebral (micro)vascular disease, than carotid artery stiffness. Nevertheless, our study was small, and we were unable to carry out any (meaningful) interaction analyses with for example T2D. Therefore, more such comparisons in larger observational studies are required in order to identify any differential associations of aortic and carotid artery stiffness indices with cerebral (micro)vascular disease and neuropsychological disorders.

\section{Advanced Glycation End products (AGEs) and arterial stiffness}

Our results on the associations of plasma and tissue AGE accumulation with carotid, femoral and brachial artery stiffness and remodelling should be replicated in larger population-based cohorts. Observational studies could also focus on the effects of AGEs on carotid artery stiffness and remodelling in patients with prolonged exposure to high concentrations of AGEs, such as T2D patients with micro- and macrovascular complications or end stage renal disease patients [118]. Indeed, plasma pentosidine was associated with carotid artery stiffness in dialysis patients [119]. Observational studies that measure both tissue and plasma AGE concentrations could give additional information on the pathophysiological mechanisms behind AGE mediated changes as SAF is only a global marker of tissue AGE accumulation, which has been shown to correlate well with both fluorescent (ie. pentosidine) and non-fluorescent (CML, CEL) AGE concentrations [54].

In chapter $\mathbf{5}$ of this thesis we found that AGE accumulation is associated with a wider carotid lumen diameter, but not with its stiffness. It might be, therefore be of interest to investigate any associations with aortic geometry as well. Previous research has already shown that plasma and tissue AGEs are associated with a higher cfPWV [120-127], as well as a higher (central) pulse pressure [48, 128-130]. Although the cfPWV is relatively insensitive to aortic geometry; the central pulse pressure has been shown to be inversely associated with the aortic lumen diameter [53, 131-135]. Thus, as opposed to the dilation described by us in the carotid artery, AGE accumulation could induce a maladaptive narrowing of the ascending aorta, which may not allow it to compensate for any concomitant stiffening of its walls. Such changes may explain the disproportionate stiffening of the aorta as compared to the carotid artery in T2D patients and may potentially offer additional targets for the treatment of isolated systolic hypertension.

Lastly, our results regarding the differential associations of AGEs with central PP, aortic and carotid artery stiffness might suggest that clinical trials on AGE reducing therapies should primarily focus on their effects on aortic rather than carotid artery stiffness. 


\section{References}

1 Paranthaman R, Greenstein AS, Burns AS, et al. Vascular function in older adults with depressive disorder. Biol Psychiatry. 2010; 68: 133-139.

2 Tiemeier $\mathrm{H}$, Breteler $\mathrm{MM}$, van Popele $\mathrm{NM}$, et al. Late-life depression is associated with arterial stiffness: a population-based study. J Am Geriatr Soc. 2003; 51:1105-1110

3 Van Sloten TT, Mitchell GF,Sigurdsson S, et al. Associations between arterial stiffness, depressive symptoms and cerebral small vessel disease: cross-sectional findings from the AGES-Reykjavik Study. J Psychiatry Neurosci. 2016; 14 (3): $162-8$.

4 Lewis TT, Sutto-Tyrell K, Penninx BW, et al. Race, Psychosocial Factors, and Arortic Pulse Wave Velocity: The Health, Aging, and Body Coposition Study. J Gerontol A Biol Sci Med Sci. 2010; 65(10): 1079-1085

5 Dietz LG, Matthews KA. Depressive symptoms and Sublcinical Markers of Cardiovascular Disease in Adolescents. $J$ Adolesc Health. 2011; 48: 579-584.

6 Oulis P, Kouzoupis A, Kyrkou K, et al. Reversal of increased arterial stiffness in severely depressed women after 6-week antidepressant treatment. J Affect Disord. 2010; 122:164-166.

7 Fu W, Ma L, Zhao X, et al. Antidepressant medication can improve hypertension in elderly patients with depression. J Clin Neurosci. 2015; 22(12): 1911-5

8 Ong KT, Delerme S, Pannier B, et al. Aortic stiffness is reduced beyond blood pressure lowering by short-term and long-term antihypertensive treatment: a meta-analysis of individual data in 294 patients. J Hypertens 2011; 29:1034- 1042.

9 Shahin Y, Khan JA, Chetter I. Angiotensin converting enzyme inhibitors effect on arterial stiffness and wave reflections: a meta-analysis and meta-regression of randomised controlled trials. Atherosclerosis. 2012; 221:18-33.

10 Vlachopoulos C, Terentes-Printzios D, Tousoulis D. The pharmacodynamics of arterial stiffness. In: Laurent S, Cockcroft J, eds. Central Aortic Blood Pressure. Paris, France: Servier; 2015.

11 Gepner AD, Korcarz CE, Colangelo LA, et al. Longitudinal Effects of a Decade of Aging on Carotid Artery Stiffness: The Multi-Ethnic Study of Atherosclerosis. Stroke. 2014; 54(1): 48-53

12 Taragano FE, Bagnatti P, Allegri RF. A double-blind, randomized clinical trial to assess the augmentation with nimodipine of antidepressant therapy in the treatment of “vascular depression". Int Psychogeriatr. 2005;17:487-498.

13 Taragano FE, Allegri R, Vicario A, Bagnatti P, Lyketsos CG. A double-blind, randomized clinical trial assessing the efficacy and safety of augmenting standard antidepressant therapy with nimodipine in the treatment of 'vascular depression'. Int J Geriatr Psychicatry. 2001; 16(3): 254-60

14 van de Laar RJ, Ferreira I, van Mechelen W, Prins MH, Twisk JW, Stehouwer CD. Lifetime vigorous but not light-tomoderate habitual physical activity impacts favorably on carotid stiffness in young adults: the amsterdam growth and health longitudinal study. Hypertension. 2010; 55:33-39

15 Gando Y, Yamamoto K, Murakami H, Ohmori Y, Kawakami R, Sanada K, Higuchi M, Tabata I, Miyachi M. Longer time spent in light physical activity is associated with reduced arterial stiffness in older adults. Hypertension. 2010; 56:540-546.

16 Kitzman DW, Herrington DM, Brubaker PH, Moore JB, Eggebeen J, Haykowsky MJ. Carotid arterial stiffness and its relationship to exercise intolerance in older patients with heart failure and preserved ejection fraction. Hypertension. 2013; 61:112-119. 
17 van der Berg JD. Sedentary behavior and cardio-metabolic health: a study into the hazards of sitting too much. 2016. Chapter 8: Associations of total volume and patterns of physical activity and sedentary behaviour with aortic pulse wave velocity - The Maastricht Study

18 Crichton GE, Elias MF, Dore GA, Abhayaratna WP, Robbins MA. Relations between dairy food intake and arterial stiffness: pulse wave velocity and pulse pressure. Hypertension. 2012; 59:1044-1051.

19 He FJ, Marciniak M, Carney C, Markandu ND, Anand V, Fraser WD, Dalton RN, Kaski JC, MacGregor GA. Effects of potassium chloride and potassium bicarbonate on endothelial function, cardiovascular risk factors, and bone turnover in mild hypertensives. Hypertension. 2010; 55:681-688.

20 Hummel SL, Seymour EM, Brook RD, Kolias TJ, Sheth SS, Rosenblum HR, Wells JM, Weder AB. Low-sodium dietary approaches to stop hypertension diet reduces blood pressure, arterial stiffness, and oxidative stress in hypertensive heart failure with preserved ejection fraction. Hypertension. 2012; 60:1200-1206.

21 Mitchell GF. Arterial stiffness and hypertension. Hypertension. 2014;64:13-18.

22 Paulis L, Becker ST, Lucht K, Schwengel K, Slavic S, Kaschina E, Thone-Reineke C, Dahlof B, Baulmann J, Unger T, Steckelings UM. Direct angiotensin II type 2 receptor stimulation in Nomega-nitro-L-arginine-methyl ester-induced hypertension: the effect on pulse wave velocity and aortic remodeling. Hypertension. 2012; 59:485-492.

23 Nenna A, Nappi F, Singh SSA, et al. Pharmacologic Approaches Against Advanced Glycation End Products (AGEs) in Diabetic Cardiovascular Disease. Res Cardiovasc Med 23; 4(2):e26949

24 Alexopoulos GS, Meyers BS, Young RC, et al. Vascular depression hypothesis. Arc Gen Psychiatry 1997; 54: $915-922$

25 Shlomo YB, Spears M, Boustred C, et al. Aortic pulse wave velocity improves cardiovascular event prediction: an individual participant meta-analysis of prospective observational data from 17,635 subjects. J Am Coll Cardiol. 2014; 63(7): 636-646.

26 Beekman, A. T., Copeland, J. R. \& Prince, M. J. (1999) Review of community prevalence of depression in later life. British Journal of Psychiatry, 174, 307-311.

27 Stewart, R. A., Sharples, K. J., North, F. M., Menkes, D. B., Baker, J. and Simes, J. Long-term assessment of psychological well-being in a randomized placebo-controlled trial of cholesterol reduction with pravastatin. The LIPID Study Investigators. Archives of Internal Medicine, 2000; 160: 3144-3152.

28 Ried, L. D., Tueth, M. J., Handberg, E., Kupfer, S. and Pepine, C. J. for the INVEST Study Group. Study of Antihypertensive Drugs and Depressive Symptoms (SADD-Sx) in patients treated with a calcium antagonist versus an atenolol hypertension treatment strategy in the International Verapamil SR-Trandolapril Study (INVEST). Psychosomatic Medicine, 2006; 67; 398-406.

29 Fletcher, A. E. et al. Quality of life on randomized treatment for isolated systolic hypertension: results from the SystEur Trial. Journal of Hypertension. 2006; 20: 2069-2079.

30 Almeida OP. Vascular Depression: myth or reality> Int Psychogeriatr. 2008; 20(4): 645-52

31 Van Sloten TT, Protogerou AD, Henry RM, Schram MT, Launer LJ, Stehouwer CD. Association between arterial stiffness, cerebral small vessel disease and cognitive impairment: A systematic review and meta-analysis. Neurosci Biobehav Rev. 2015; 53:121-30.

32 Poels MM, van Oijen M, Mattace-Raso FU et al. Arterial stiffness, cognitive decline, and risk of dementia: the Rotterdam study. Stroke J Cereb circ. 2007; 38: 888-892

33 Biessels GJ, Strachan MW, Visseren FL, Kapelle LJ, Whitmer RA. Dementia and cognitive decline in type 2 diabetes 
and prediabetic stages: towards targeted interventions. Lancet Diabetes Endocrinol. 2014; 2(3): 246-55

34 Mitchell AJ, Shiri-Feshki M. Rate of progression of mild cognitive impairment to dementia--meta-analysis of 41 robust inception cohort studies. Acta Psychiatr Scand 2009; 119(4): 252-65

35 Alexopoulos GS. The vascular depression hypothesis: 10 years later. Biol Psychiatry. 2006; 60(12):1304-5.

36 Tzourio C, Laurent S, Debette S. Is hypertension associated with an accelerated aging of the brain? Hypertension. 2014; 63:894-903.

37 O'Rourke MF, Safar ME. Relationship between aortic stiffening and microvascular disease in brain and kidney: cause and logic of therapy. Hypertension. 2005; 46:200-204.

38 Mitchell GF. Effects of central arterial aging on the structure and function of the peripheral vasculature: implications for end-organ damage. J Appl Physiol (1985). 2008; 105:1652-1660.

39 Schillaci G, Bilo G, Pucci G, et al. Relationship between short-term blood pressure variability and large artery stiffness in human hypertension: findings from 2 large databases. Hypertension. 2012; 60:369-377.

40 Rothwell PM. Limitations of the usual blood-pressure hypothesis and importance of variability, instability, and episodic hypertension. Lancet. 2010; 375:938-948

41 Ownby RL, Crocco E, Acevedo A, John V, Loewenstein D. Depression and risk for Alzheimer disease: systematic review, meta-analysis, and metaregression analysis. Arch Gen Psychiatry. 2006; 63:530-538.

42 Paini A, Boutouyrie P, Calvet D, Tropeno Al, Laloux B, Laurent S. Carotid and Aortic Stiffness Determinants of Discrepancies. Hypertension 2006; 47(3): 371-6.

43 Webb AJ, Simoni M, Mazzucco S, Kuker W, Schulz U, Rothwell PM. Increased cerebral arterial pulsatility in patients with leukoaraiosis: arterial stiffness enhances transmission of aortic pulsatility. Stroke. 2012; 43:2631-2636.

44 van Sloten TT, Sedaghat S, Laurent S, London GM, Pannier B, Ikram MA, Kavousi M, Mattace-Raso F, Franco OH, Boutouyrie P, Stehouwer CD. Carotid stiffness is associated with incident stroke: a systematic review and individual participant data meta-analysis. J Am Coll Cardiol. 2015 ;66(19):2116-25.

45 Van den Hurk K, Reijmer YD, van den Berg E, et al. Heart Failure and Cognitive Function in the General Population: The Hoorn Study. Eur J Heart Fail 2011; 13(12): 1362-9

46 Hughes TM, Kuller LH, Barinas-Mitchell EJ, et al. Arterial Stiffness and $\beta$-amyloid progression in nondemented elderly adults. JAMA Neurol. 2014; 71(5): 562-8

47 Chen Y, Shen F, Liu J, Yang GY. Arterial stiffness and stroke: de-stffening strategy, a therapeutic target for stroke. Stroke and Vascular Neurology. 2017;0: e000045. doi:10.1136/svn-2016-000045

48 van Eupen MG, Schram MT, van Sloten TT, et al. Skin Autoflorescence and Pentosidine Are Associated With Aortic Stiffening: The Maastricht Study. Hypertension. 2016; 68(4): 956-63

49 Laurent S, Girerd X, Mourad JJ, et al. Elastic modulus of the radial artery wall material is not increased in patients with essential hypertension. Arterioscler Thromb. 1994;14:1223-1231.

50 Schram MT, Henry RMA, van Dijk RA, et al. Increased central artery stiffness in impaired glucose metabolism and type 2 diabetes: The Hoorn Study. Hypertension 2004; 43(2): 176-81.

51 Kimoto E, Shoji T, Shinohara K, et al. Preferential stiffening of central over peripheral arteries in type 2 diabetes. Diabetes. 2003. 2003;52:448-452

52 Briet M, Bozec E, Laurent S,et al. Arterial stiffness and enlargement in mild-to-moderate chronic kidney disease. Kidney Int 2006, 69(2):350-357. 
53 Farasat SM, Morrell CH, Scuteri A, et al. Pulse pressure is inversely related to aortic root diameter implications for the pathogenesis of systolic hypertension. Hypertension. 2018; 51:196-202

54 Meerwaldt R, Graaff R, Oomen PH, et al. Simple non-invasive assessment of advanced glycation endproduct accumulation. Diabetologia. 2004;47:1324-1330.

55 Hofmann B, Jacobs K, Navarrete Santos A, et al. Relationship between cardiac tissue glycation and skin autofluorescence in patients with coronary artery disease. Diabetes Metab 2015;41:410-15.

56 Smit AJ, Hartog JW, Voors AA, van Veldhuisen DJ. Advanced glycation endproducts in chronic heart failure. Ann NY Acad Sci. 2008;1126:225-230.

57 Gaens KH, Stehouwer CD, Schalkwijk CG. Advanced glycation endproducts and its receptor for advanced glycation endproducts in obesity. Curr Opin Lipidol. 2013;24:4-11

58 Sell DR, Monnier VM. Molecular basis of arterial stiffening: role of glycation - a mini-review. Gerontology. 2012;58:227-237.

59 Brownlee M. Biochemistry and molecular cell biology of diabetic complications. Nature. 2001;414:813-820.

60 Sugitani H, Wachi H, Tajma S, Seyama Y. Nitric Oxide Stimulates Elastin Expression in Chick Aortic Smooth Muscle Cells. Biol.Pharm.Bull. 2001; 24 (5): 461-464

61 Simmers P, Gishto A, Vyavahare N, Kothapalli CR. Nitric Oxide Stimulates Matrix Synthesis and Deposition by Adult Human Aortic Smooth Muscle Cells Within Three-Dimensional Cocultures. Tissue Eng Part A. 2015; 21(7-8):1455-70.

62 Basta G, Lazzerini G, Massaro M, Simoncini T, Tanganelli P, Fu C, Kislinger T, Stern DM, Schmidt AM, De Caterina R. Advanced glycation end products activate endothelium through signal-transduction receptor RAGE: a mechanism for amplification of inflammatory responses. Circulation. 2002;105:816-822.

63 Bierhaus A, Humpert PM, Stern DM, Arnold B, Nawroth PP. Advanced glycation end product receptor-mediated cellular dysfunction. Ann NY Acad Sci. 2005;1043:676-680.

64 Mizutari K, Ono T, Ikeda K, Kayashima K, Horiuchi S: Photoenhanced modification of human skin elastin in actinic elastosis by $\mathrm{N}$ (epsilon)-(carboxymethyl)lysine, one of the glycoxidation products of the Maillard reaction. The Journal of investigative dermatology 1997, 108(5):797-802.

65 Bruel A, Oxlund H: Changes in biomechanical properties, composition of collagen and elastin, and advanced glycation endproducts of the rat aorta in relation to age. Atherosclerosis 1996, 127(2):155-165.

66 London GM, Safar ME, Pannier B. Aortic Aging in ESRD: Structural, Hemodynamic, and Mortality implications. J Am Soc Nephrol. 2016; 27(6): 1837-46

67 Greenwald SE. Ageing of the human arteries. J Pathol. 2007; 211:157-172

68 Rothman KJ, Greenland S, Lash TJ. Modern Epidemiology. Philadelphia: Lippincott Williams And Willkins; 2008.

69 Schisterman EF, Cole SR, Platt RW. Overadjustment bias and unnecessary adjustment in epidemiologic studies. Epidemiology. 2009;20:488-495

70 Watson NL, Sutton-Tyrrell K, Rosano C. et al. Arterial stiffness and cognitive decline in well-functioning older adults. J. Gerontol. Ser. A Biol. Sci. Med. Sci. 2011; 66: 1336-1342

71 Tsao CW, Himali JJ, Beiser AS, et al. Association of arterial stiffness with progression of subclinical brain and cognitive disease. Neurology, 2016; 86 (7): 619-62

72 Hajjar I, Goldstein FC, Martin GS, Quyyumi AA et al. Roles of arterial stiffness and blood pressure in hypertensionassociated cognitive decline in healthy adults. Hypertension. 2016; 67(1):171-175 
73 Biesels GJ, Deary IJ, Ryan CM. Cognition and diabetes: a lifespan prospective. Lancet Neurol 2008;7:184-90

74 Elias FE, Torres RV, Davey A. Clinical trials of blood pressure lowering and antihypertensive medication: is cognitive measurement state-of-the-art? Am J Hypertens. 2018; 31(7): 631-642

75 Laurent S, Cockcroft J, van Bortel L, et al. Expert consensus document on arterial stiffness: methodological issues and clinical applications. Eur Heart J. 2006; 27(21): 2588-605.

76 Reneman RS, Meinders JM, Hoeks AP. Non-invasive ultrasound in arterial wall dynamics in humans: what have we learned and what remains to be solved. Eur Heart J 2005 May;26(10):960-6

77 van Bortel LM, Balkestein EJ, van der Heijden-Spek JJ, et al. Non-invasive assessment of local arterial pressure: comparison of applanation tonometry and echo-tracking. J Hypertens. 2001;19:1037-1044.

78 Akhtar R. In vitro characterisation of arterial stiffening: From the macro- to the nano-scale. Artery Research 2014; $8: 1-8$

79 Sheehan DV, Lecrubier Y, Sheehan KH, et al. The Mini-International Neuropsychiatric Interview (M.I.N.I.): the development and validation of a structured diagnostic psychiatric interview for DSM-IV and ICD-10. J Clin Psychiatry. 1998; 59(Suppl 20): 22-33.

80 Kroenke K, Spitzer RL, Williams JB. The PHQ-9: validity of a brief depression severity measure. J Gen Intern Med. 2001; 16(9): 606-13.

81 Beekman AT, Deeg DJ, Van Limbeek J, Braam AW, De Vries MZ, Van Tilburg W. Criterion validity of the Center for Epidemiologic Studies Depression scale (CES-D): results from a community-based sample of older subjects in The Netherlands. Psychological Medicine 1997; 27, 231-235.

82 ladecola C, Yaffe K, Biller J, et al. Impact of Hypertension on Cognitive Function: A Scientific Statement From the American Heart Association. Hypertension 2016; 68(6): e67-e94

83 Hachinski V, ladecola C, Petersen RC et al. National Institute of Neurological Disorders and Stroke-Canadian Stroke Network vascular cognitive impairment harmonization standards. Stroke 2006; 37: 2220-2241

84 van den Berg E, Kloppenborg RP, Kessels RP, Kappelle LJ, Biessels GJ. Type 2 diabetes mellitus, hypertension, dyslipidemia and obesity: a systematic comparison of their impact on cognition. Biochim Biophys Acta. 2009; 1792: 470-481

85 Lezak M, Howieson D, Loring D. Neuropsychological Assessment 2004 4th New York Oxford University Press

86 Brown W. Some experimental results in the correlation of mental abilities. Br J Psychol. 1910;3:296-322.

87 Scheijen JL, van de Waarenburg MP, Stehouwer CD, Schalkwijk CG. Measurement of pentosidine in human plasma protein by a single-column high-performance liquid chromatography method with fluorescence detection. J Chromatogr B Analyt Technol Biomed Life Sci. 2009;877:610-614.

88 Hanssen NM, Engelen L, Ferreira I et al. Plasma levels of advanced glycation endproducts $\mathrm{N} \varepsilon$-(carboxymethyl) lysine, $\mathrm{N} \varepsilon$-(carboxyethyl)lysine, and pentosidine are not independently associated with cardiovascular disease in individuals with or without type 2 diabetes: the Hoorn and CODAM studies. J Clin Endocrinol Metab. 2013;98:E1369E1373.

89 de Vos LC, Lefrandt JD, Dullaart RPF, Zeebregts CJ, Smit AJ. Advanced Glycation End Products: an emerging biomarker for adverse outcome in ptients with peripheral artery disease. Atherosclerosis 2016; 524:291-299

90 Giardino I, Edelstein D, Brownlee M. Nonenzymatic glycosylation in vitro and in bovine endothelial cells alters basic fibroblast growth factor activity. A model for intracellular glycosylation in diabetes. J Clin Invest. 1994;94:110-117. 
91 Miyata T, Ueda Y, Yoshida A, Sugiyama S, lida Y, Jadoul M, Maeda K, Kurokawa K, van Ypersele de Strihou C. Clearance of pentosidine, an advanced glycation end product, by different modalities of renal replacement therapy. Kidney Int. 1997;51:880-887.

92 Yagmur E, Tacke F, Weiss C, Lahme B, Manns MP, Kiefer P, Trautwein C, Gressner AM. Elevation of Nepsilon(carboxymethyl)lysine-modified advanced glycation end products in chronic liver disease is an indicator of liver cirrhosis. Clin Biochem 2006;39:39-45.

93 Sebekova K, Kupcova V, Schinzel R, Heidland A. Markedly elevated levels of plasma advanced glycation end products in patients with liver cirrhosis - amelioration by liver transplantation. $J$ Hepatol.2002;36:66-71.

94 Koetsier M, Nur E, Chunmao H, Lutgers HL, Links TP, Smit AJ, Rakhorst G, Graaff R. Skin color independent assessment of aging using skin autofluorescence. Opt Express. 2010;18:14416-14429

95 Smit AJ, Gerrits EG. Skin autofluorescence as a measure of advanced glycation endproduct deposition: A novel risk marker in chronic kidney disease. Curr Opin Nephrol Hypertens. 2010;19:527-533

96 Van Bussel BCT, Henry RMA, Schalkwijk CG, Dekker JM, Nijpels G, Stehouwer CDA. Low-grade inflammation, but not endothelial dysfunction, is associated with greater carotid stiffness in the elderly: the Hoorn Study. $J$ Hypertens. 2012;30:744-52

97 Twisk JW. Different statistical models to analyze epidemiological observational longitudinal data: an example from the Amsterdam Growth and Health Study. Int J Sports Med. 1997; 18 (suppl 3):S216-S224.

98 Rhee MY, Lee HY, Park JB. Measurements of Arterial Stiffness: Methodological Aspects. Korean Circ J. 2008; 38: 343-350

99 Twisk JWR. Applied Longitudinal Data Analysis for Epidemiology. Cambridge University Press; 2015, page 107-108 100 Diggle PJ, Liang K-Y, Zeger SL. Analysis of longitudinal data. New York: Oxford University Press, 1995, page 4

101 Rousseeuw PJ, Hubert M. Robust statistics for outlier detection. 2011; https://doi.org/10.1002/widm.2

102 Altman DG. Practical Statistics for for Medical Research. London: Chapman \& Hall, 1999, page 154

103 Little RJ, Rubin DB. Statistical analysis with missing data. 2nd ed. New York: Wiley, 2002.

104 Kennelly SP, Lawlor BA, Kenny RA. Blood pressure and dementia - a comprehensive review. Ther Adv Neurol Disord, 2009; 2(4): 241-60

105 Kohler S, Buntinx F, Palmer K, van den Akker. Depression, vascular factors, and risk of dementia in primary care: a retrospective cohort study. J Am Geriatr Soc. 2015; 63(4): 692-8.

106 Geijselaers SL, Sep SJ, Schram MT, et al. Carotid stiffness is associated with impairment of cognitive performance in individuals with and without type 2 diabetes. The Maastricht Study. Atherosclerosis, 2016; 253:186-193

107 Lim SL, Gao, Q, Nyunt MS et al. Vascular Health indices and cognitive domain function: Singapore longitudinal ageing studies. J. Alzheimer's Dis. JAD. 2015; 50: 27-40

108 Watson NL, Sutton-Tyrrell K, Rosano C. et al. Arterial stiffness and cognitive decline in well-functioning older adults. J. Gerontol. Ser. A Biol. Sci. Med. Sci. 2011; 66: 1336-1342

109 Waldstein SR, Rice SC, Thayer JF. et al. Pulse pressure and pulse wave velocity are related to cognitive decline in the Baltimore Longitudinal Study of Aging. Hypertension. 2008; 51: 99-1044

110 Tsao CW, Himali JJ, Beiser AS, et al. Association of arterial stiffness with progression of subclinical brain and cognitive disease. Neurology, 2016; 86 (7): 619-62

111 Hajjar I, Goldstein FC, Martin GS, Quyyumi AA et al. Roles of arterial stiffness and blood pressure in hypertensionassociated cognitive decline in healthy adults. Hypertension. 2016; 67(1):171-175 
112 Staessen JA, Thijs L, Richart T, Odili AN, Birkenhager WH. Placebo-controlled trials of blood pressure-lowering therapies for primary prevention of dementia. Hypertension 2011; 57:e6-7.

113 Levi Marpillat N, Macquin-Mavier I, Tropeano Al, Bachoud-Levi AC, Maison P. Antihypertensive classes, cognitive decline and incidence of dementia: a network meta-analysis. J Hypertens. 2013;31(6):1073-1082.

114 Protogerou AD, Safar ME, laria P, et al. Diastolic blood pressure and mortality in the elderly with cardiovascular disease. Hypertension 2007; 50:172.

115 Somes GW, Pahor M, Shorr RI, et al. The role of diastolic blood pressure when treating isolated systolic hypertension. Arch Intern Med 1999; 159: 2004

116 Messerli FH, Mancia G, Conti CR, et al. Dogma disputed: can aggressively lowering blood pressure in hypertensive patients with coronary artery disease be dangerous? Ann Intern Med 2006; 144:884

117 Spauwen PJJ, van Boxyel MPJ, Verhey FRJ, et al. Both low and high 24-hour diastolic blood pressure are associated with worse cognitive performance in type 2 diabetes: the Maastricht Study. Diabetes Care 2015; 38:1473-80

118 Lutgers HL, Graaff R, Links TP, et al. Skin Autoflorescence as a noninvasive marker of vascular damage in patients with type 2 diabetes. Diabetes Care 2006; 29(12): 2654-9

119 Zhou Y, Yu Z, Jia H, et al. Association of serum pentosidine with arterial stiffness in hemodialysis patients. Artif Organs. 2010;34(3):193-9.

120 Yoshida N, Okumura K, Aso Y. High serum pentosidine concentrations are associated with increased arterial stiffness and thickness in patients with type 2 diabetes. Metabolism. 2005; 54(3):345-50.

121 Llauradó G, Ceperuelo-Mallafré V, Vilardell C, Simó R, Gil P, Cano A, Vendrell J, González-Clemente JM. Advanced glycation end products are associated with arterial stiffness in type 1 diabetes. J Endocrinol. 2014 Jun;221(3):40513.

122 Couppé C, Dall CH, Svensson RB, et al. Skin autofluorescence is associated with arterial stiffness and insulin level in endurance runners and healthy controls - Effects of aging and endurance exercise. Exp Gerontol. 2017; 91:9-14

123 Koyama H, Tanaka S, et al. Skin autofluorescence, a marker for advanced glycation end product accumulation, is associated with arterial stiffness in patients with end-stage renal disease. Metabolism. 2008 Oct;57(10):1452-7.

124 Watfa G, Soulis G, Tartagni E, Kearney-Schwartz A, Borghi C, Salvi P, Benetos A. Relationship between tissue glycation measured by autofluorescence and pulse wave velocity in young and elderly non-diabetic populations. Diabetes Metab. 2012 Nov;38(5):413-9.

125 Semba RD, Najjar SS, Sun K, Lakatta EG, Ferrucci L. Serum carboxymethyl-lysine, an advanced glycation end product, is associated with increased aortic pulse wave velocity in adults. Am J Hypertens. 2009;22(1):74-9.

126 Semba RD, Sun K, Schwartz AV, et al. Serum carboxymethyl-lysine, an advanced glycation end product, is associated with arterial stiffness in older adults. J Hypertens. 2015; 33(4):797-803

127 McNulty M, Mahmud A, Feely J. Advanced glycation end-products and arterial stiffness in hypertension. Am J Hypertens. 2007;20:242-247.

128 Monnier VM, Vishwanath V, Frank KE, Elmets CA, Dauchot P, Kohn RR. Relation between complications of type I diabetes mellitus and collagenlinked fluorescence. N Engl J Med. 1986; 314:403-408.

129 Schram MT, Schalkwijk CG, Bootsma AH, Fuller JH, Chaturvedi N, Stehouwer CD; EURODIAB Prospective Complications Study Group. Advanced glycation end products are associated with pulse pressure in type 1 diabetes: the EURODIAB Prospective Complications Study. Hypertension. 2005;46:232-237. 
130 Sourris KC, Lyons JG, Dougherty SL, Chand V, Straznicky NE, Schlaich MP, Grima MT, Cooper ME, Kingwell BA, de Courten MP, Forbes JM, de Courten B. Plasma advanced glycation end products (ages) and nf-kappab activity are independent determinants of diastolic and pulse pressure. Clin Chem Lab Med. 2013:1-10.

131 Vasan RS, Larson MG, Levy D. Determinants of echocardiographic aortic root size. The Framingham Heart Study. Circulation. 1995;91: 734-740.

132 Bella JN, Wachtell K, Boman K, et al. Relation of left ventricular geometry and function to aortic root dilatation in patients with systemic hypertension and left ventricular hypertrophy (the LIFE study). Am J Cardiol. 2002;89:337341.

133 Agmon Y, Khandheria BK, Meissner I, et al.. Is aortic dilatation an atherosclerosis-related process? Clinical, laboratory, and transesophageal echocardiographic correlates of thoracic aortic dimensions in the population with implications for thoracic aortic aneurysm formation. J Am Coll Cardiol. 2003;42:1076-1083.

134 Jondeau G, Boutouyrie P, Lacolley $\mathrm{P}$, et al. Central pulse pressure is a major determinant of ascending aorta dilation in Marfan syndrome. Circulation. 1999;99:2677-2681.

135 Mitchell GF, Lacourciere Y, Ouellet JP, et al. Determinants of elevated pulse pressure in middle-aged and older subjects with uncomplicated systolic hypertension: the role of proximal aortic diameter and the aortic pressureflow relationship. Circulation. 2003;108:1592-1598. 


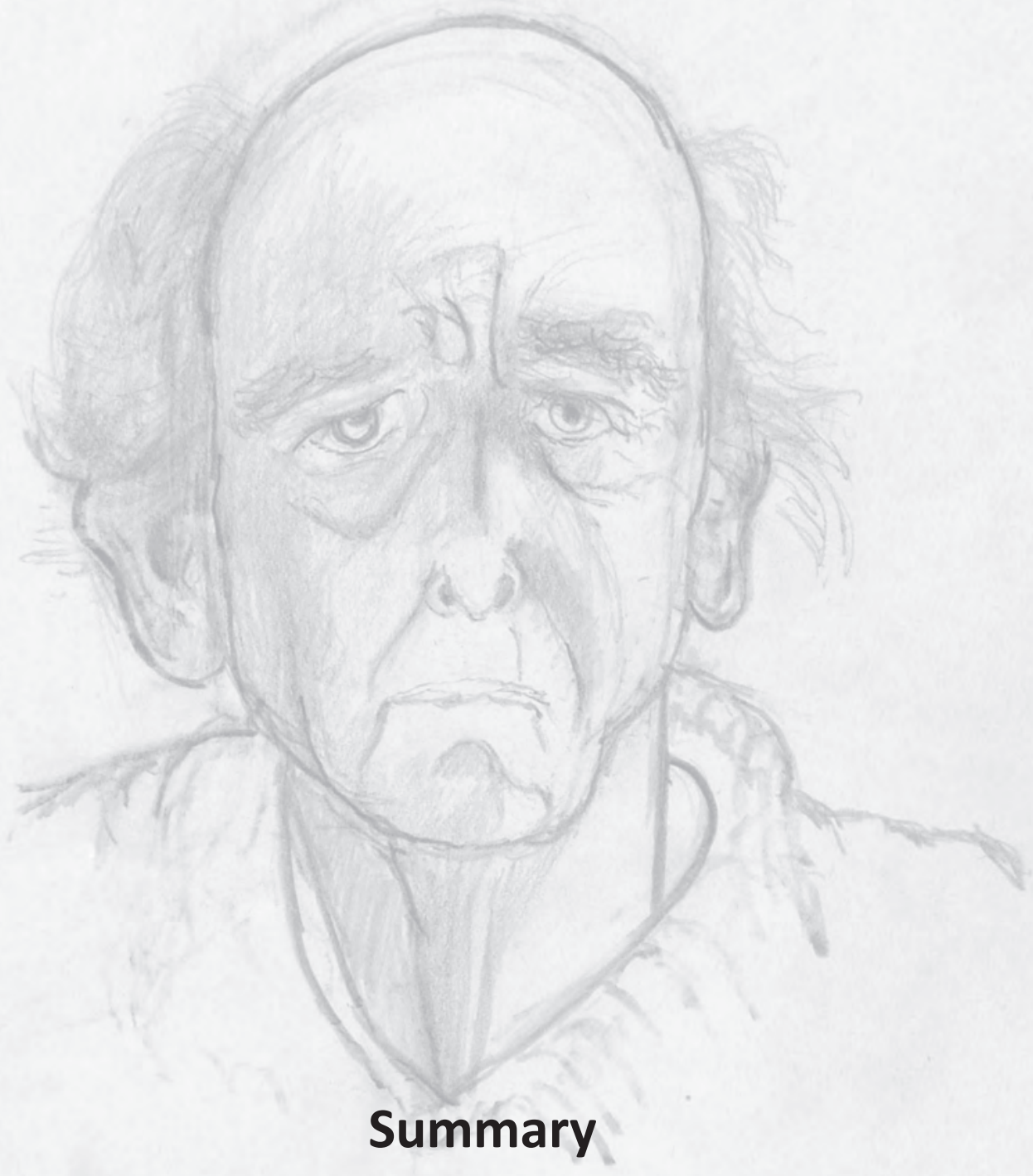



The proportion of the world's older adults is estimated to almost double from $12 \%$ to $22 \%$ between 2015 and 2050 [1]. More than 20\% of adults aged 60 and over suffer from at least one neuropsychiatric disorder, which account for $17.4 \%$ of Years Lived with Disability (YLDs). The most common of these neuropsychiatric disorders are dementia and depression [1]. Both disorders are highly invalidating, due to their chronic course, poor prognosis and lack of successful treatments [2,3]. Thus, additional research into their pathophysiology is required in order to uncover additional treatment and preventive targets. Arterial stiffness is a novel cardiovascular disease risk factor that may be causally related to depression and cognitive dysfunction in elderly individuals. Growing evidence suggests that arterial stiffening is involved in the development of cerebral (micro) vascular disease, which is known to contribute to the development of depression, cognitive dysfunction and dementia in late life [4,5]. Arterial stiffness is a treatable cardiovascular disease risk factor, which has been associated with cerebral micro- and macrovascular disease independently of traditional cardiovascular disease risk factors $[6,7]$.

In part 1 of this thesis we examined whether arterial stiffness is associated with depression and cognitive dysfunction. Most previous research on this topic has concentrated on the role of aortic stiffness, which is the gold standard of arterial stiffness measurement. However, the carotid artery is the main blood supplier to the brain, therefore its stiffening could affect the cerebral (micro)vascular circulation more directly than aortic stiffening. We therefore investigated both aortic and carotid artery stiffness. In part $\mathbf{2}$ of this thesis we focused on potential causes of arterial stiffening by investigating the associations of advanced glycation end products (AGEs) with elastic and muscular artery stiffness. Any associations may offer a target for lowering arterial stiffness.

\section{PART 1:}

\section{Arterial stiffness and Neuropsychiatric Disease}

In chapter two of this thesis we assessed whether aortic stiffness is associated with a major depressive disorder or depressive symptoms in a population of middle-aged and elderly individuals (age 40-78 years) from the Maastricht Study. In addition, we investigated whether these associations differ according to age and sex. We found that aortic stiffness was associated cross-sectionally with depressive symptoms and a major depressive disorder in middle-aged ( $40-60$ years) men and to a lesser extent in middle-aged women. However, we did not find a significant association in elderly (> 60 years) men or women. Most previous studies have concentrated on elderly populations ( $>60$ years). We were, therefore, the first to show that aortic stiffness could contribute to the development of depression in individuals as young as $40-60$ years. 
In chapter three we investigated whether carotid artery stiffness is prospectively associated with depressive symptoms in elderly individuals from the Hoorn Study. In addition, we investigated whether these associations differ according to age and sex. All currently published evidence [8-11] is cross-sectional, and thus cannot confirm that arterial stiffness precedes the development of depression. We, therefore, investigated in a sample of elderly individuals (age $69.3 \pm 6.3$ years) whether (changes in) carotid stiffness were associated with self-reported depressive symptoms over eight years of follow-up. We found that neither higher carotid stiffness, nor an accelerated stiffening of the carotid artery were associated with more depressive symptoms after eight years of follow-up. We also did not find any differences according to age and sex. However, our study may have been underpowered by the low number of clinical depression cases and the high percentage of selective attrition throughout follow-up to assess any association. Nevertheless, the associations were weak and did not indicate any clinical relevance.

In chapter four we assessed whether either carotid artery or aortic stiffening is prospectively associated with cognitive dysfunction in elderly individuals from the Hoorn Study. We investigated, in a sample of elderly individuals (age $67.6 \pm 5.4$ years), the longitudinal associations of carotid artery and aortic stiffness at baseline with three main cognitive performance domains after six years of follow-up. In this study carotid artery stiffness was not associated with attention and executive function, information processing speed or memory. In a smaller sample of the same study we found that aortic stiffness was, however, independently associated with lower processing speed. We concluded, therefore, that aortic stiffness may precede the development of cognitive dysfunction in elderly individuals. However, our study was small, and we could not analyse whether our associations were driven by changes in influential groups, such as type 2 diabetes patients or by the high percentage of selective attrition throughout follow-up.

\section{PART 2:}

\section{AGEs and Arterial Stiffness}

In chapter five we investigated whether advanced glycation end products (AGES) are associated with elastic and muscular artery stiffening in the Maastricht Study. We also investigated whether the associations differed according to age, sex and type 2 diabetes. AGEs could accelerate arterial stiffening in old age and type 2 diabetes and the Maastricht Study has already shown that both tissue and plasma AGEs are associated with aortic stiffness and (ascending) aortic pulse pressure [12]. The cfPWV, however, represents the properties of the highly elastic descending and distal aortas; as well as of the muscular iliac and femoral arteries. AGEs may, however differentially affect elastic and muscular arteries; 
however, this has scarcely been researched. We, therefore, investigated whether either tissue or plasma AGEs are associated with the stiffening of the solely elastic (ie. carotid) or the solely muscular (ie. femoral and brachial) arteries. We did not find any robust associations of either tissue or plasma AGEs with any of the stiffness indices; although tissue AGEs as measured by Skin Autfluorescence (SAF) was associated with carotid artery dilation. We concluded that our lack of significant associations of AGEs and the significant associations with aortic stiffness within the same Maastricht Study population could imply that the most elastic thoracic and abdominal aortas are more prone to AGE accumulation than the stiffer elastic carotid artery or the muscular femoral or brachial arteries. We also concluded that AGE accumulation could induce maladaptive changes of the carotid artery that may ultimately lead to its stiffening, as well as to atherosclerotic plaque formation. However, these theories have yet to be confirmed in larger, prospective studies.

In chapter six we discussed the key findings of the present thesis, their clinical and future research implications, as well as the any methodological shortcomings that may have hampered our studies. 


\section{References}

1 World Health Organization. Fact sheet $\mathrm{N}^{\circ} 381$ on Mental health and older adults. (available from: http://www.who. int/mediacentre/factsheets/fs381/en/)

2 Mitchell AJ, Subramaniam H. Prognosis of depression in old age compared to middle age: a systematic review of comparative studies. Am J Psychiatry. 2005;162:1588-601.

3 Reisberg B et al. The Global Deterioration Scale for Assessment of Primary Degenerative Dementia. American Journal of Psychiatry. 1982;139(9):1136-1139.

4 Alexopoulos GS. The vascular depression hypothesis: 10 years later. Biol Psychiatry. 2006; 60(12):1304-5.

5 Gorelick PB, Scuteri A, Black SE et al. Vascular Contributions to Cognitive Impairment and Dementia: A statement for Healthcare Professionals from the American Heart Associations/ American Stroke

6 Van Sloten TT, Protogerou AD, Henry RM, Schram MT, Launer LJ, Stehouwer CD. Association between arterial stiffness, cerebral small vessel disease and cognitive impairment: A systematic review and meta-analysis. Neurosci Biobehav Rev. 2015; 53:121-30.

7 Liu M, Li GL, Li Y, Wang JG. Effects of Various Antihypertensive Drugs on Arterial Stiffness and Wave Reflections. Pulse 2013;1:97-107

8 Van Sloten TT, Mitchell GF, Sigurdsson S, et al. Associations between arterial stiffness, depressive symptoms and cerebral small vessel disease: cross-sectional findings from the AGES-Reykjavik Study. J Psychiatry Neurosci. 2016; 14 (3): $162-8$.

9 Tiemeier H, Breteler MM, van Popele NM, et al. Late-life depression is associated with arterial stiffness: a population-based study. J Am Geriatr Soc 2003; 51:1105-1110

10 Paranthaman R, Greenstein AS, Burns AS, et al. Vascular function in older adults with depressive disorder. Biol Psychiatry 2010; 68: 133-139.

11 Lewis TT, Sutto-Tyrell K, Penninx BW, et al. Race, Psychosocial Factors, and Arortic Pulse Wave Velocity: The Health, Aging, and Body Coposition Study. J Gerontol A Biol Sci Med Sci. 2010 ; 65(10): 1079-1085

12 van Eupen MG, Schram MT, van Sloten TT, et al. Skin Autoflorescence and Pentosidine Are Associated With Aortic Stiffening: The Maastricht Study. Hypertension. 2016; 68(4): 956-63 


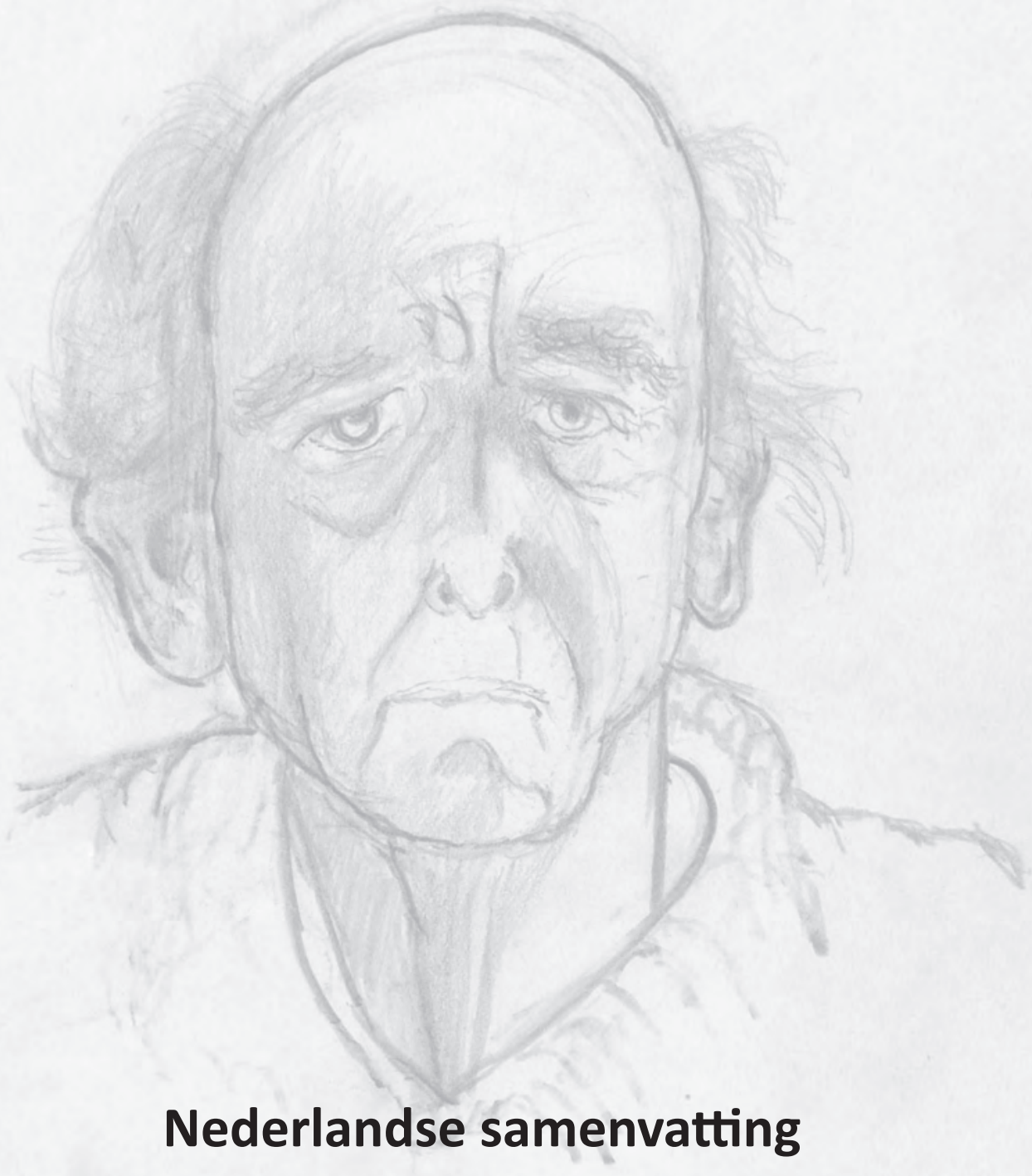



Depressie, cognitieve dysfunctie en dementie zijn drie van de meest invaliderende en frequente hersenziekten op oudere leeftijd. Wereldwijd, krijgt meer dan $20 \%$ van personen ouder dan 60 jaar last van tenminste één van deze ziekten. Deze aandoeningen zijn verantwoordelijk voor $17,4 \%$ van de afname in kwaliteit van leven op oudere leeftijd en voor $6,6 \%$ van het verlies in gezonde levensjaren [1]. Dit is te wijten aan het chronisch beloop, de slechte prognose en de beperkte behandelmogelijkheden van deze ziekten $[2,3]$. De behandeling van depressie is bijvoorbeeld minder effectief op oudere dan op jongere leeftijd [2] waardoor meer patiënten last van depressieve symptomen houden ondanks hun behandeling. Bovendien kunnen aanhoudende depressieve klachten uiteindelijk tot een afname van cognitieve functie en zelfs tot dementie leiden [4,5]. Een milde cognitieve stoornis leidt in meer dan $20 \%$ van de gevallen tot dementie [6]. Dementie is onomkeerbaar progressief en leidt tot volledige zorgafhankelijkheid en vroegtijdig overlijden [2]. Meer onderzoek is dus nodig om behandelbare oorzaken van depressie en dementie uit te zoeken.

Steeds meer onderzoek wijst uit dat verstijving van de slagaders en schade aan de kleine vaatjes in de hersenen een potentiële oorzaak van depressie, cognitieve achteruitgang en dementie zouden kunnen zijn. Slagaderverstijving verhoogt de kans op het ontwikkelen van hart- en vaatziekten (HVZ) en kan bovendien de kleine vaatjes in de hersenen beschadigen. In deel 1 van dit proefschrift hebben wij onderzocht of verstijving van de grote slagaders, zoals de lichaamsslagader (de aorta) en de halsslagaders (de carotiden) een oorzaak van depressieve klachten en cognitieve dysfunctie kan zijn. De meest betrouwbare maat van vaatstijfheid wordt gemeten in de grote lichaamsslagader; echter de halsslagader voorziet de hersenen van bloed; en zou dus het risico op het verkrijgen van hersenziekten meer direct kunnen beïnvloeden. In deel $\mathbf{2}$ hebben wij gezocht naar additionele mogelijkheden voor de behandeling van vaatstijfheid door te onderzoeken of versuikerde eiwitten, die in hogere concentraties voorkomen op oudere leeftijd en bij diabetes, geassocieerd zijn met verstijving van de vaatwand in de grote hals-, lies- en armslagaders.

\section{DEEL 1:}

\section{Vaatstijfheid en het ontstaan van depressie en een milde cognitieve stoornis}

In hoofdstuk 2 hebben wij onderzocht of verstijving van de lichaamsslagader geassocieerd is met een depressieve stoornis of met meer depressieve klachten bij mensen van middelbare en oudere leeftijd in De Maastricht Studie. Wij onderzochten daarnaast of deze verbanden verschillen tussen mannen en vrouwen of variëren met leeftijd. Wij vonden dat verstijving van de lichaamsslagader geassocieerd is met zowel een depressieve stoornis, als met meer depressieve symptomen bij mannen, en, in mindere mate, vrouwen 
van middelbare leeftijd. Wij vonden echter geen verbanden bij oudere personen (> 60 jaar oud). Alle voorgaande studies hebben zich gericht op oudere personen; wij toonden voor het eerst aan dat verstijving van de lichaamsslagader een rol zou kunnen spelen in het ontstaan van depressie bij personen van middelbare leeftijd. Echter wij kunnen op basis van deze studie niet uitsluiten dat deze bevindingen op toeval berusten of dat de associaties juist de omgekeerde relatie weerspiegelen, waarbij depressie tot vaatverstijving leidt. Longitudinale studies kunnen wel laten zien dat vaatstijfheid voorafgaat aan het ontwikkelen van een depressieve stoornis. Dit sluit 'reverse causality' uit en zou daarmee, de aanname van een oorzakelijk bestand tussen vaatstijfheid en depressie ondersteunen.

In hoofdstuk 3 hebben wij onderzocht of een (versnelde) verstijving van de halsslagader geassocieerd is met een toename van depressieve klachten over een vervolgperiode van acht jaar bij oudere mensen (> 60 jaar) die deelnamen aan de Hoorn Studie. Een dergelijk verband zou de aanname dat vaatstijfheid een oorzaak van depressie is ondersteunen. Wij vonden dat verstijving van de halsslagaders niet geassocieerd is met een toename van depressieve klachten acht jaar later. Een versnelde verstijving van de halsslagader tijdens de vervolg periode was evenmin geassocieerd met het ontwikkelen van meer depressieve klachten. Wij waren de eersten die deze relatie in longitudinaal verband hebben onderzocht. Echter hadden wij te weinig patiënten met een depressieve stoornis om dit verband volledig uit te kunnen sluiten; dus grotere studies zouden alsnog deze associatie kunnen aantonen.

In hoofdstuk 4 hebben wij onderzocht of het hebben van meer verstijfde hals- of lichaamsslagaders in 2000-2001 geassocieerd is met een lagere prestatie op cognitieve testen ongeveer zes jaar later (in 2005-2009) in een oudere (> 60 jaar) groep deelnemers van de Hoorn Studie. Wij vonden dat verstijving van de halsslagader niet geassocieerd is met een lagere prestatie op testen voor de informatieverwerkingssnelheid, aandacht- en uitvoerende functies en geheugen. Verstijving van de lichaamsslagader was wel geassocieerd met een lagere prestatie op taken voor informatieverwerkingssnelheid zes jaar later. Wij concludeerden dat verstijving van de lichaamsslagader betrokken zou kunnen zijn bij het ontwikkelen van milde cognitieve stoornissen bij oudere mensen. Echter onze studie was te klein om vast te stellen of dit verband gedreven was door patiënten met diabetes.

\section{DEEL 2:}

\section{Versuikerede eiwitten en verstijving van de hals-, lies- en armslagadders}

In hoofdstuk 5 hebben wij in de Maastricht Studie onderzocht of versuikerde eiwitten geassocieerd zijn met verstijving van de hals-, lies- en armslagader. De Maastricht Studie heeft eerder al aangetoond dat versuikerde eiwitten gemeten in weefsels of bloed 
geassocieerd is met de verstijving van de lichaamsslagader [7]. Echter de grote slagaders bestaan uit meerdere segmenten met verschillende elastische eigenschappen: de elastische afdalende borst slagader, de buikslagader en de meer musculaire bekken- en liesslagaders. Versuikerde eiwitten zouden een verschillend effect kunnen hebben op het elastische en musculaire deel van de grote slagaders; echter dit is tot nu toe niet onderzocht. Toch is dit potentiele verschil van belang omdat de verstijving van zowel voornamelijk elastische als meer musculaire slagaders het risico op het ontwikkelen van Hart- en Vaatziekte (HVZ) kan verhogen [8]. Wij hebben dus onderzocht of versuikerde eiwitten gemeten in weefsels of in bloed geassocieerd zijn met de verstijving of met de diameter van de voornamelijk elastische halsslagader of de musculaire lies- en armslagaders. Wij vonden dat versuikerde eiwitten noch in weefsel noch in bloed geassocieerd waren met de verstijving van elastische of musculaire slagaders. Mogelijk hadden wij te weinig deelnemers om verbanden aan te tonen; echter, een eerdere studie [7] heeft in dezelfde populatie van de Maastricht Studie aangetoond dat versuikerde eiwitten wél geassocieerd zijn met de verstijving van de lichaamsslagader en met de polsdruk in de opstijgende borst lichaamsslagaders. Hieruit hebben wij herleid dat waarschijnlijk de meest elastische slagaderen, zoals de borst- en buikslagaders, het meest vatbaar voor de nadelige effecten van versuikerde eiwitten zijn. Deze hypothese zou nader onderzocht moeten worden. Wij vonden wél dat de hoeveelheid versuikerde eiwitten in weefsels geassocieerd is met een verwijding van de halsslagader. Dit zou mogelijk tot aderverkalking of verstijving van de halsslagader door de tijd kunnen leiden, maar deze mogelijke toevalsbevinding moet in grotere vervolgstudies bevestigd worden.

In hoofdstuk 6 worden de resultaten van dit proefschrift samengevat en de mogelijke tekortkomingen van onze meet- en analytische methodes besproken. Bovendien worden de conclusies van onze bevindingen in dit hoofdstuk besproken, in relatie tot patiëntenzorg en wetenschappelijk onderzoek. 


\section{References}

1 World Health Organization. Fact sheet N³81 on Mental health and older adults. (available from: http://www.who. int/mediacentre/factsheets/fs381/en/)

2 Mitchell AJ, Subramaniam H. Prognosis of depression in old age compared to middle age: a systematic review of comparative studies. Am J Psychiatry. 2005;162:1588-601.

3 Reisberg B et al. The Global Deterioration Scale for Assessment of Primary Degenerative Dementia. American Journal of Psychiatry. 1982;139(9):1136-1139.

4 Jorm AF. History of depression as a risk factor for dementia: an updated review. Aust N Z J Psychiatry. 2001;35:776781.

5 Ownby RL, Crocco E, Acevedo A, John V, Loewenstein D. Depression and risk for Alzheimer disease: systematic review, meta-analysis, and metaregression analysis. Arch Gen Psychiatry. 2006;63:530-538.

6 Mitchell AJ, Shiri-Feshki M. Rate of progression of mild c

7 van Eupen MG, Schram MT, van Sloten TT, et al. Skin Autoflorescence and Pentosidine Are Associated With Aortic Stiffening: The Maastricht Study. Hypertension. 2016; 68(4): 956-63

8 Van Sloten, Schram MT, van der Hurk K, et al. Local stiffness of the carotid and femoral artery is associated with incident cardiovascular events and all-cause mortality: the Hoorn Study. J Am Coll Cardiol. 2014; 63(17): 1739-1747 


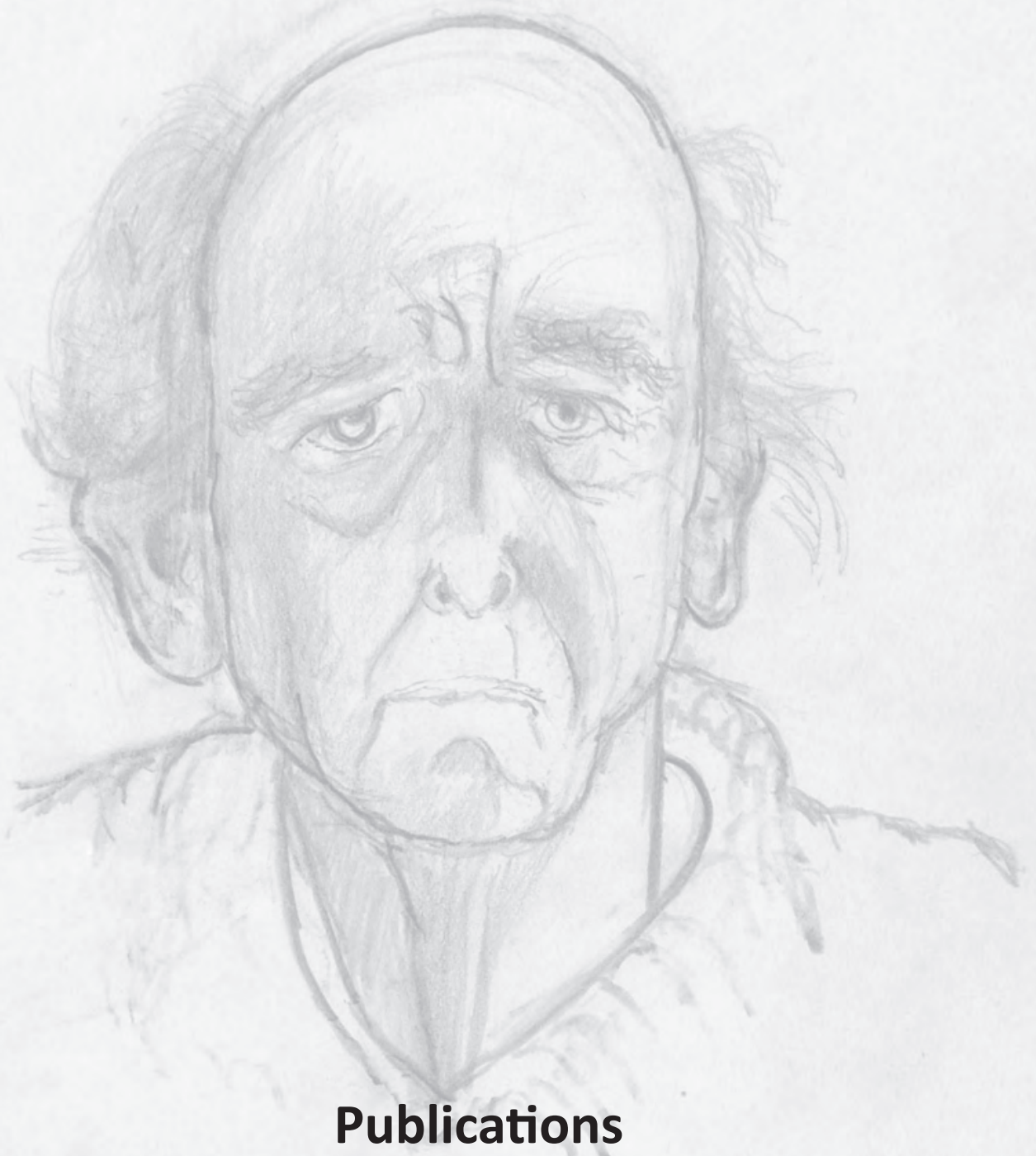





\section{Thesis}

Onete GV, Henry RM, Sep SJS, Koster A, van der Kallen CJ, Dagnelie PC, Schaper N, Köhler $\mathrm{S}$, Reesink K, Stehouwer CDA, Schram MT. Arterial stiffness is associated with depression in middle-aged men - the Maastricht Study. J Psychiatry Neurosci. 2017; 42 (6): 160246

\section{Other}

Van der Berg JD, Koster A, Bosma H, Onete GV, Savelberg HHCM, Reesink KD, Schram MT, Sep SJS, van der Kallen CJH, Dagnelie, Schaper NC, Henry RMA, Stehouwer CDA. Association of total amount and patterns of physical activity and sedentary behaviour with aortic pulse wave velocity: The Maastricht Study. Published in: van der Berg JD. Sedentary behaviour and cardio-metabolic health: a study into the hazards of sitting too much. 2016, chapter 8

Onete GV, Besselink MG, Salsbach CM, van Eijck CH, Busch OR, Gouma DJ, de Hingh IH, Sieders E, Dejong CH, Offerhaus JG, Molenaar IQ, Dutch Pancreatic Cancer Group. Impact of centralization of pancreatoduodenectomy on reported radical resections rates in a nationwide pathology database. HPB (Oxford). 2015 Aug;17(8):736-42. 



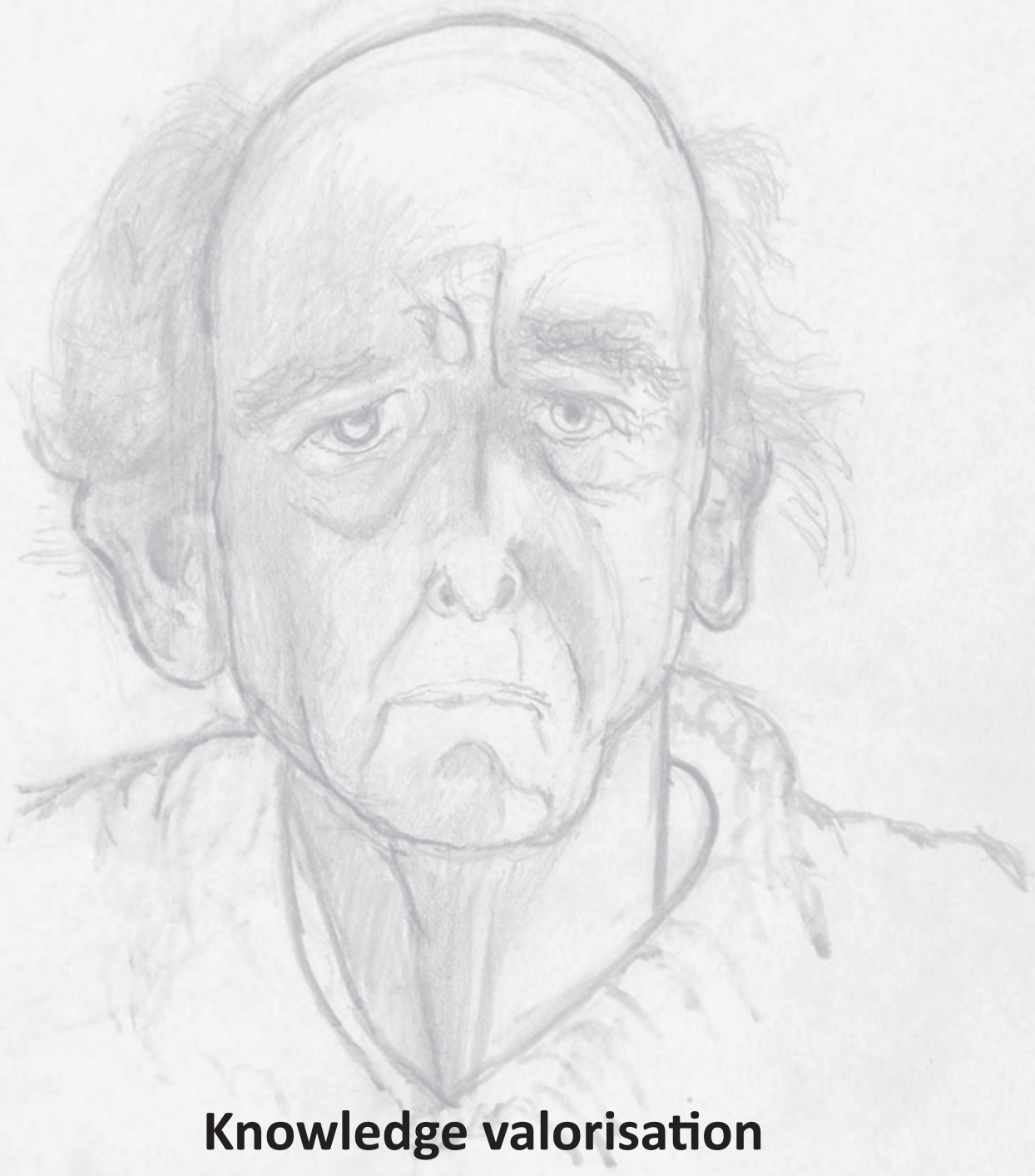



Knowledge valorisation can be defined as the "process of creating value from knowledge, by making knowledge suitable and/or available for societal purposes, and suitable for translation into competitive products, services, processes, and new commercial activities" (adapted definition based on the National Committee Valorisation 2011:8). In this addendum we describe how society may benefit from the work conducted in this dissertation.

This two-part thesis focused on arterial stiffness, which has recently emerged as a risk factor for cardiovascular disease (CVD) [1,2], including coronary artery disease [3,4], stroke $[4,5]$ and cerebral small vessel disease (CSVD) [6], and its role in the development of two of the most debilitating neuropsychiatric disorders of old age, namely late-life depression and cognitive dysfunction, as well as on its pathophysiology. The proportion of elderly individuals is expected to almost double from 12\% to 22\% between 2015 and 2050 [7] and more than $20 \%$ of these individuals will suffer from at least one neuropsychiatric disorder, such as late life depression, cognitive dysfunction or dementia [7]. In past years, the vascular etiology of these disorders, has received growing scientific attention. According to these vascular hypotheses [8,9], accumulation of sub-cortical and peri-ventricular CSVD disrupts neuronal circuits, which, in turn, impairs cerebral affective and executive functions, thus resulting in depression and cognitive decline. In support of these theories, the development and the accumulation of CSVD has been cross-sectionally and longitudinally associated with depression [10], cognitive impairment [9], vascular-type dementia [9] and, in some cases, even Alzheimer dementia [11]. In the part 1 of this thesis we, therefore, expanded on these hypotheses by analysing the role of arterial stiffness in the development of depression and cognitive dysfunction in the hope to uncover additional targets for their treatment or prevention. In part $\mathbf{2}$ we then focused on the pathophysiology of arterial stiffening, in particular on the role of advanced glycation end products (AGEs), which may offer a target for lowering arterial stiffness in addition to blood pressure lowering medication.

Our findings were largely inconclusive as most of the associations were modest and predominantly non-significant. This may suggest that only very large reductions in arterial stiffness could effectively reduce the risk of developing neuropsychiatric disorders in the general population; though currently available arterial de-stiffening strategies may improve the treatment outcomes of depressive patients. This thesis nevertheless emphasises the need to develop more effective arterial de-stiffening strategies and, in the second part we showed that AGEs may preferentially influence the most elastic descending thoracic and abdominal aortas, but not the less elastic carotid or the muscular femoral and brachial arteries. Thus, the implementation of our results in additional scientific research might improve patient care in the future. 


\section{Arterial stiffness and depression}

The first key finding of our dissertation is that aortic stiffness, as measured by the carotidfemoral pulse wave velocity (cfPWV), may contribute to the development of depression and depressive symptoms in middle-aged (40 - 60 years) men and to a lesser extent in middle-aged women. Unfortunately, due to the cross-sectional design of the Maastricht Study we cannot prove causality, nor can we exclude reverse causality, thus, our results need to be confirmed by other (longitudinal) population-based studies before they are implemented in clinical practice. Nevertheless, this thesis does highlight the need to incorporate arterial de-stiffening therapies in the treatment of depression in middle-aged patients. Anti-hypertensive drugs, such as ACE-inhibitors, angiotensin receptor blockers and calcium-channel blockers lower arterial stiffness most effectively beyond blood pressure $[12,13]$. To date, two trials $[14,15]$ have shown that in patients with MRI-confirmed vascular depression, the use of the calcium-channel blocker nimodipine in order to achieve optimal blood pressure in addition to anti-depressive medication reduces the time to remission of a major depression episode; however, these studies were small and should be confirmed in larger settings. Life-style interventions, such as aerobic exercise [16-19], dairy enriched [20] and low-sodium diets [21,22] can also decrease aortic stiffness; however, it is yet unknown whether these effects are clinically relevant. Therefore, depressive middle-aged patients with hypertension and a high aortic stiffness (ie. cfPWV $>10 \mathrm{~m} / \mathrm{s}$ [23]) should be treated with de-stiffening antihypertensives in addition to adopting a healthy lifestyle in order to achieve maximal treatment effects. A possible issue in middle age is that aortic stiffness may occur in the absence of hypertension [24], in which case blood pressure lowering therapies should be carefully titrated in order to avoid hypotension and cerebral hypoperfusion. Furthermore, additional research is required to identify new drugs that lower arterial stiffness without affecting mean arterial pressure, such as compound 21 [25] and AGE-reducing therapies [26]. The second key finding of this thesis was that in elderly individuals (> 60 years) aortic stiffness is not cross-sectionally associated with depression; nor is carotid artery stiffening either cross-sectionally or longitudinally associated with more self-reported depressive symptoms after eight years follow-up. However, we cannot exclude that arterial de-stiffening therapies may have a positive impact on the outcome and prognosis of depression in the elderly as the studies included in this thesis may have been hampered by the small number of depression cases. Possibly restricting any arterial de-stiffening interventions to patients with MRI-confirmed vascular depression may be beneficial. Indeed, in his two studies with nimodipine, Taragano et al. [14,15] included only middle-aged and elderly patients with MRI-confirmed vascular depression.

Besides its therapeutic implications, additional population-based studies are needed to analyse whether aortic de-stiffening medication can prevent depression in middleaged and elderly individuals. Current data suggests that the mental health status of the 
Dutch population aged 65 or younger over the previous decade has not changed, despite improvements in the treatment and prevention of CVD [27]. Similarly, despite intensified CVD risk factor management in the past 20 years, the prevalence of depression was similar in our study as to that reported by Beekman et al. in a systematic review in 1999 [28] and to that reported by Tiemeier et al. in the Rotterdam population between the years 1997-1999 [29]. In line with these findings, the associations in this thesis were modest and predominantly non-significant, which might suggest that only very large reductions in arterial stiffness could effectively reduce the risk of developing depressive disorders in the general population. Therefore, this thesis emphasises the need to develop more effective arterial de-stiffening therapies, such as A-II type 2 receptor agonists and AGE inhibitors $[25,26]$.

\section{Arterial stiffness and cognitive dysfunction}

The third key finding of this thesis is that in elderly (> 60 years) individuals, carotid artery stiffness is not associated with any of three main cognitive performance domains of cognitive dysfunction after six years of follow-up. Aortic stiffening, however, was associated with a lower information processing speed, but not with a lower attention and executive function, or memory in a small sub-population. These differential associations should be confirmed in much larger study samples, as our study was too small to compensate for the selective attrition during follow-up and, also did not allow for the testing of interactions with age, sex and type 2 diabetes. Also, the lack of associations of carotid artery stiffness with cognitive dysfunction in our study is in accordance with the only other available community-based study [30]; however, both studies may have been hampered by the measurement of these two variables at only two time points. Possibly, larger observational studies that measure carotid artery stiffness and cognitive function at multiple time points would offer a better chance of identifying any associations. Also, some have suggested that cognitive dysfunction and dementia may not necessarily form a continuum [31], therefore the association of arterial stiffness with dementia should also be researched longitudinally in a similar fashion.

Nevertheless, our current results may stimulate clinicians to lower blood pressure in elderly individuals with a high aortic stiffness. As opposed to depression, several large populationbased randomised controlled trials (RCTs) [32,33] have already shown that blood pressure reduction could modestly preserve cognitive function in the elderly. These small effects could be attributed to the adverse effects of intensive blood pressure lowering, which may excessively lower diastolic and mean arterial pressure [34-36], which, in turn, may adversely affect cognitive function [37]. This may be of especial importance in patients with arterial stiffness who may also suffer from impaired reactivity of the cerebral vasculature [38] and may thus be unable to maintain constant cerebral flow at lower blood pressure 
levels [39]. Specific AGE reducing therapies and AT-II type 2 receptor agonists [25,26] could reduce arterial stiffness without affecting mean arterial pressure de however, additional research is required to confirm their safety and effectiveness.

\section{AGEs and the stiffening of the carotid, femoral and brachial arteries}

The fourth key finding of this thesis is that neither tissue nor plasma Advanced Glycation End Products (AGEs) were associated with the stiffening of either the elastic carotid artery or the muscular femoral or brachial arteries. Although non-significant, our results offer additional insight in the pathophysiology of arterial stiffness and could have several clinical implications. The Maastricht Study already showed that both tissue and plasma AGEs are associated with higher aortic stiffness as measured by the cfPWV and central (ascending aortic) pulse pressure [40]. The cfPWV, however, represents the properties of the highly elastic descending thoracic and abdominal aortas, as well as of the muscular iliac and femoral arteries. Our lack of significant associations of AGEs within the same Maastricht Study population could imply that the most elastic thoracic and abdominal aortas are more prone to AGE accumulation than the less elastic carotid artery or the muscular femoral or brachial arteries. Thus, if confirmed in larger populations, our results may suggest that AGE-reducing therapies may be more effective in lowering aortic rather than carotid artery stiffness; and that they should therefore be included in CVD risk management strategies. Amongst others, ACE-inhibitors, statins and vitamins B 1 and 6 have been shown to have some AGE reducing properties [26]; however, no specific AGE-reducing drugs are yet available on the market. Clinicians could however inform individuals with a moderate and high CVD risk, as well as type 2 diabetes patients about the need to reduce dietary AGEs by cooking foods with water-based moisture (ie. steaming, stewing, poaching, and braising) and by avoiding processed, barbecued, grilled or fried meat. If these dietary changes are also shown to be beneficial in population-based settings [41], informational campaigns could be co-ordinated in order to raise awareness concerning this topic. Also, we cannot exclude that AGE reduction could also positively influence carotid artery stiffness, as our study was quite small and included relatively healthy $T 2 D$ patients that were systematically treated with more antihypertensive and lipid-modifying therapies. Speculatively more prolonged exposure to higher concentrations of AGEs, such as occur in kidney failure patients or patients with poorly controlled T2D with micro-and macrovascular complications [42] could accelerate carotid artery stiffening. Indeed, plasma pentosidine was associated with carotid artery stiffness in a small sample of dialysis patients [43]. These hypotheses need to be confirmed first before they can be implemented in clinical practice.

Lastly, we also found that tissue AGE accumulation as measured by Skin Autofluorescence (SAF) was robustly associated with a dilation of the carotid wall but not with its thickening, which implies a relative thinning of its wall. These changes are accompanied by a higher 
wall stress; which will ultimately lead to arterial stiffening by accelerating elastic fibre degradation. Furthermore, carotid artery dilation could also decrease the wall shear stress [44], which, in turn could stimulate atherosclerotic plaque formation [45]. We cannot exclude that our findings are due to the play of chance, however if our results are confirmed in larger population-based studies it could be speculated that AGE-reducing therapies may reverse carotid artery stiffening and atherosclerotic plaque formation in its incipient stages prior to elastic fibre degradation.

\section{Future research avenues}

In conclusion, in this valorisation addendum we expanded on the possible societal and clinical relevance of our findings. In this thesis we attempted to improve current understanding of the role played by arterial stiffening in the development of late-life depression and cognitive dysfunction. Most of the associations observed were modest and predominantly non-significant, which may suggest that only very large reductions in arterial stiffness could effectively reduce the risk of developing neuropsychiatric disorders in the general population. Physicians should nevertheless be aware of the possible adverse effects of aortic stiffening on the development of depression in middle-aged individuals and should encourage middle-aged depressive patients to adopt a healthy life-style and could consider adding de-stiffening antihypertensives in order to improve treatment outcomes. Furthermore, physicians should consider optimising systolic hypertension with de-stiffening antihypertensives in order to delay the development of cognitive dysfunction in the elderly. In the second part of this thesis we explored additional de-stiffening therapies and showed that AGEs could accelerate the stiffening of the most elastic descending thoracic and abdominal aortas. Physicians therefore also consider informing individuals with a moderate and high CVD risk, as well as type 2 diabetes patients about the need to reduce dietary AGEs.

Although the conclusions of this dissertation have several clinical and social applications, it should be noted that our significant results were based on cross-sectional data and that our longitudinal associations were largely inconclusive; thus, our knowledge is momentarily best implemented in additional scientific research that might improve patient care in the future. The Maastricht Study could offer some opportunities to analyse these research questions as it is one of the world's largest observational, prospective populationbased cohort studies that focuses on the aetiology, pathophysiology, complications and comorbidities of type 2 diabetes mellitus [46]. 


\section{References}

1 Laurent S, Boutouyrie P, Asmar R, Gautier I, Laloux B, Guize L, Ducimetiere P, Benetos A. Aortic stiffness is an independent predictor of all-cause and cardiovascular mortality in hypertensive patients. Hypertension. 2001;37:1236 -1241.

2 Michell GF, Hwang SJ, Vasan RS, et al. Arterial Stiffness and cardiovascular events: the Framingham Heart Study. Circulation. 2010;1221(4): 501-11

3 Boutouyrie P, Tropeano Al, Asmar R, Gautier I, Benetos A, Lacolley P, Laurent S. Aortic stiffness is an independent predictor of primary coronary events in hypertensive patients: a longitudinal study. Hypertension. 2002;39:10 -15. van Sloten TT, Sedaghat S, Laurent S, London GM, Pannier B, Ikram MA, Kavousi M, Mattace-Raso F, Franco OH, Boutouyrie P, Stehouwer CD. Carotid stiffness is associated with incident stroke: a systematic review and individual participant data meta-analysis. J Am Coll Cardiol. 2015 ;66(19):2116-25.

5 Laurent S, Katsahian S, Fassot C, Tropeano Al, Gautier I, Laloux B, Boutouyrie P. Aortic stiffness is an independent predictor of fatal stroke in essential hypertension. Stroke. 2003;34:1203-1206.

6 Van Sloten TT, Protogerou AD, Henry RM, Schram MT, Launer LJ, Stehouwer CD. Association between arterial stiffness, cerebral small vessel disease and cognitive impairment: A systematic review and meta-analysis. Neurosci Biobehav Rev. 2015; 53:121-30.

7 World Health Organization. Fact sheet $\mathrm{N}^{\circ} 381$ on Mental health and older adults. (available from: http://www.who. int/mediacentre/factsheets/fs381/en/)

8 Alexopoulos GS, Meyers BS, Young RC, et al. Vascular depression hypothesis. Arc Gen Psychiatry 1997; 54: $915-922$

9 Gorelick PB, Scuteri A, Black SE et al. Vascular Contributions to Cognitive Impairment and Dementia: A statement for Healthcare Professionals from the American Heart Associations/ American Stroke

10 Van agtmaal: CSVD and depression

11 Van Rooden S, Goos JD, van Opstal AM, et al. Increased number of microinfarcts in Alzheimer disease at 7-T MR imaging. 2014; 270 (1): 2015-11

12 Shahin Y, Khan JA, Chetter I. Angiotensin converting enzyme inhibitors effect on arterial stiffness and wave reflections: a meta-analysis and meta-regression of randomised controlled trials. Atherosclerosis. 2012; 221:18-33.

13 Vlachopoulos C, Terentes-Printzios D, Tousoulis D. The pharmacodynamics of arterial stiffness. In: Laurent S, Cockcroft J, eds. Central Aortic Blood Pressure. Paris, France: Servier; 2015.

14 Taragano FE, Bagnatti P, Allegri RF. A double-blind, randomized clinical trial to assess the augmentation with nimodipine of antidepressant therapy in the treatment of "vascular depression". Int Psychogeriatr. 2005;17:487-498.

15 Taragano FE, Allegri R, Vicario A, Bagnatti P, Lyketsos CG. A double-blind, randomized clinical trial assessing the efficacy and safety of augmenting standard antidepressant therapy with nimodipine in the treatment of 'vascular depression'. Int J Geriatr Psychicatry. 2001; 16(3): 254-60

16 van de Laar RJ, Ferreira I, van Mechelen W, Prins MH, Twisk JW, Stehouwer CD. Lifetime vigorous but not light-tomoderate habitual physical activity impacts favorably on carotid stiffness in young adults: the amsterdam growth and health longitudinal study. Hypertension. 2010; 55:33-39

17 Gando Y, Yamamoto K, Murakami H, Ohmori Y, Kawakami R, Sanada K, Higuchi M, Tabata I, Miyachi M. Longer time spent in light physical activity is associated with reduced arterial stiffness in older adults. Hypertension. 2010; 56:540-546. 
18 Kitzman DW, Herrington DM, Brubaker PH, Moore JB, Eggebeen J, Haykowsky MJ. Carotid arterial stiffness and its relationship to exercise intolerance in older patients with heart failure and preserved ejection fraction. Hypertension. 2013; 61:112-119.

19 van der Berg JD. Sedentary behavior and cardio-metabolic health: a study into the hazards of sitting too much. 2016. Chapter 8: Associations of total volume and patterns of physical activity and sedentary behaviour with aortic pulse wave velocity - The Maastricht Study

20 Crichton GE, Elias MF, Dore GA, Abhayaratna WP, Robbins MA. Relations between dairy food intake and arterial stiffness: pulse wave velocity and pulse pressure. Hypertension. 2012; 59:1044-1051.

21 He FJ, Marciniak M, Carney C, Markandu ND, Anand V, Fraser WD, Dalton RN, Kaski JC, MacGregor GA. Effects of potassium chloride and potassium bicarbonate on endothelial function, cardiovascular risk factors, and bone turnover in mild hypertensives. Hypertension. 2010; 55:681-688.

22 Hummel SL, Seymour EM, Brook RD, Kolias TJ, Sheth SS, Rosenblum HR, Wells JM, Weder AB. Low-sodium dietary approaches to stop hypertension diet reduces blood pressure, arterial stiffness, and oxidative stress in hypertensive heart failure with preserved ejection fraction. Hypertension. 2012; 60:1200-1206.

23 Van Bortel LM, Laurent S, Boutouyrie P, et al. Expert consensus document on the measurement of aortic stiffness in daily practice using carotid-femoral pulse wave velocity. J Hypertens. 2012; 30(3):445-8

24 Mitchell GF. Arterial Stiffness and Wave Reflections: Biomarkers of Cariovascular Risk. Artery Res. 2009; 3(2): 56-64

25 Paulis L, Becker ST, Lucht K, Schwengel K, Slavic S, Kaschina E, Thone-Reineke C, Dahlof B, Baulmann J, Unger T, Steckelings UM. Direct angiotensin II type 2 receptor stimulation in Nomega-nitro-L-arginine-methyl ester-induced hypertension: the effect on pulse wave velocity and aortic remodeling. Hypertension. 2012; 59:485-492. 149

26 Nenna A, Nappi F, Singh SSA, et al. Pharmacologic Approaches Against Advanced Glycation End Products (AGEs) in Diabetic Cardiovascular Disease. Res Cardiovasc Med 23; 4(2):e26949

27 de Graaf R, Ten Have M, van Gool C, van Dorsselaer S. Prevalence of mental disorders, and trends from 1996 to 2009. Results from NEMESIS-2. Tijdschr Psychiatr 2012;54:27-38.

28 Beekman, A. T., Copeland, J. R. \& Prince, M. J. (1999) Review of community prevalence of depression in later life. British Journal of Psychiatry, 174, 307-311.

29 Tiemeier H, Breteler MM, van Popele NM, et al. Late-life depression is associated with arterial stiffness: a population-based study. J Am Geriatr Soc. 2003; 51:1105-1110

30 Poels MM, van Oijen M, Mattace-Raso FU et al. Arterial stiffness, cognitive decline, and risk of dementia: the Rotterdam study. Stroke J Cereb circ. 2007; 38: 888-892

31 Biessels GJ, Strachan MW, Visseren FL, Kapelle LJ, Whitmer RA. Dementia and cognitive decline in type 2 diabetes and prediabetic stages: towards targeted interventions. Lancet Diabetes Endocrinol. 2014; 2(3): 246-55

32 Staessen JA, Thijs L, Richart T, Odili AN, Birkenhager WH. Placebo-controlled trials of blood pressure-lowering therapies for primary prevention of dementia. Hypertension 2011; 57:e6-7.

33 Levi Marpillat N, Macquin-Mavier I, Tropeano Al, Bachoud-Levi AC, Maison P. Antihypertensive classes, cognitive decline and incidence of dementia: a network meta-analysis. J Hypertens. 2013;31(6):1073-1082.

34 Protogerou AD, Safar ME, laria P, et al. Diastolic blood pressure and mortality in the elderly with cardiovascular disease. Hypertension 2007; 50:172. 
35 Somes GW, Pahor M, Shorr RI, et al. The role of diastolic blood pressure when treating isolated systolic hypertension. Arch Intern Med 1999; 159: 2004

36 Messerli FH, Mancia G, Conti CR, et al. Dogma disputed: can aggressively lowering blood pressure in hypertensive patients with coronary artery disease be dangerous? Ann Intern Med 2006; 144:884

37 Spauwen PJJ, van Boxyel MPJ, Verhey FRJ, et al. Both low and high 24-hour diastolic blood pressure are associated with worse cognitive performance in type 2 diabetes: the Maastricht Study. Diabetes Care 2015; 38:1473-80

38 Kim YS, Immink RV, Stok WJ, Karemaker JM, Secher NH, van Lieshout JJ. Dynamic cerebral autoregulatory capacity is affected early in Type 2 diabetes. Clin Sci (Lond) 2008;115:255-62

39 Cipolla MJ. Control of Cerebral Blood Flow. In: Cerebral Circulation. San Rafael (CA): Morgan \& ClaypoolLife Science; 2009.

40 van Eupen MG, Schram MT, van Sloten TT, et al. Skin Autoflorescence and Pentosidine Are Associated With Aortic Stiffening: The Maastricht Study. Hypertension. 2016; 68(4): 956-63

41 Di Pino A, Currenti W, Urbano F, et al. High intake of dietary advanced glycation end-products is associated with increased arterial stiffness and inflammation in subjects with type 2 diabetes. Nutr Metab Cardiovasc Dis. 2017; 27(11): 978-984

42 Lutgers HL, Graaff R, Links TP, et al. Skin Autoflorescence as a noninvasive marker of vascular damage in patients with type 2 diabetes. Diabetes Care 2006; 29(12): 2654-9

43 Zhou Y, Yu Z, Jia H, et al. Association of serum pentosidine with arterial stiffness in hemodialysis patients. Artif Organs. 2010;34(3):193-9.

44 Samijo SK, Willigers JM, Barkhuysen R, et al. Wall shear stress in the human common carotid artery as function of age and gender. Cardiovasc Res. 1998; 39(2): 515-22

45 Caro C, Fitz-Gerald J, Schroter R. Arterial wall shear and distribution of early atheroma in man. Nature. 1969;223:115-160. The first study to show that low wall shear stress predisposes to atheroma formation.

46 Schram MT, Sep SJ, van der Kallen CJ, et al. The Maastricht Study: an extensive phenotyping study on determinants of type 2 diabetes, its complications and its comorbidities.Eur J Epidemiol.2014;29(6):439-51. 


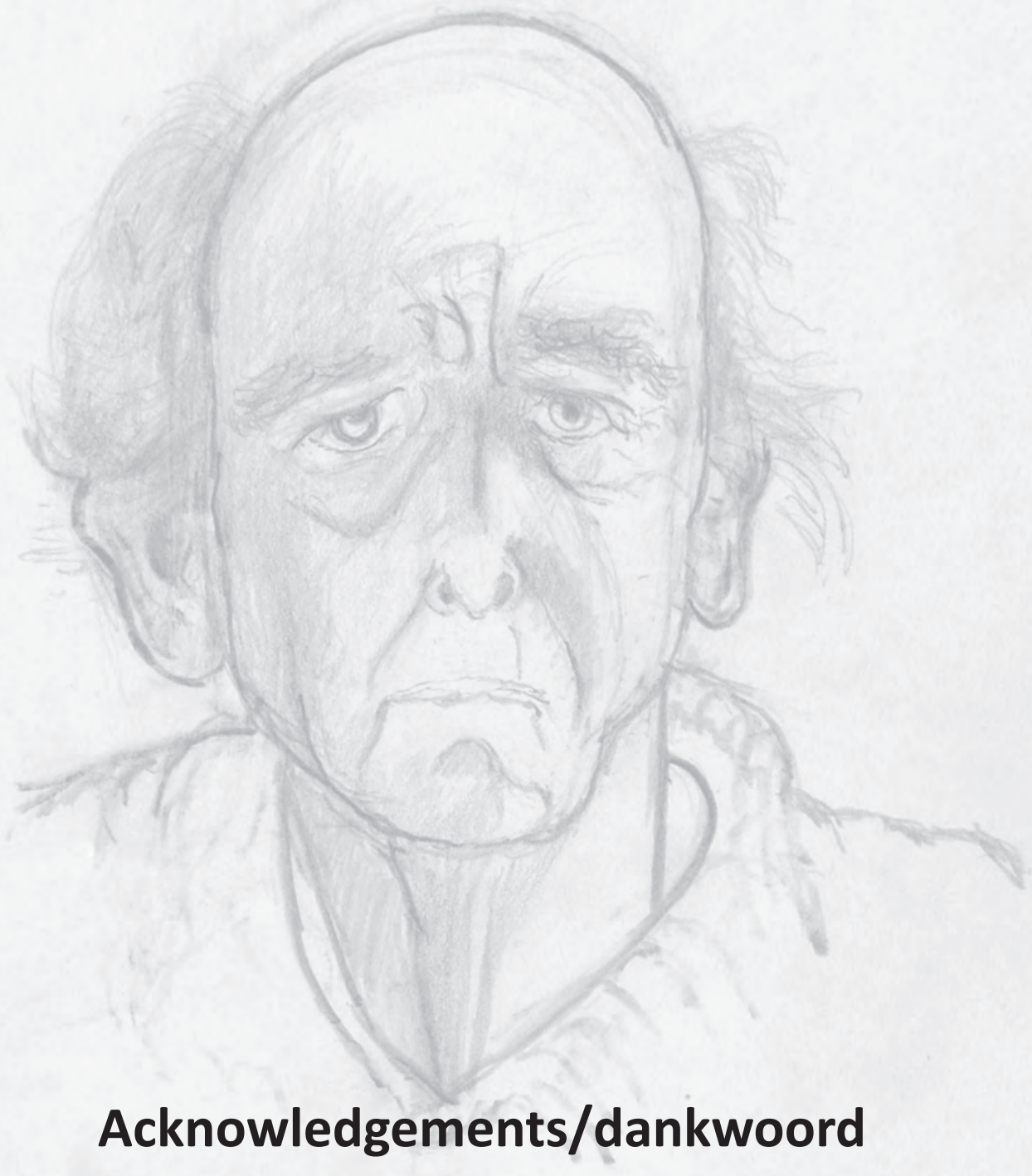



Als eerste zou ik graag het promotieteam: prof. dr. C.D.A Stehouwer, dr. M.T. Schram en dr. R.M.A. Henry willen bedanken.

\section{Mijn promotor, prof. dr. C.D.A. Stehouwer}

Beste prof. Stehouwer,

Hartelijk dank voor het proeflezen van mijn schriftwerk: artikelen, rapports en dit proefschrift. Ik heb altijd op uw snelheid kunnen rekenen, en ik vond onze discussies ook altijd verhelderend. Hartelijk dank, bovendien, voor uw steun tijdens de epidemiologie master en voor al uw ideeën voor mogelijke artikelen. Hopelijk zullen de door mij begonnen projecten, welke niet in mijn proefschrift terecht gekomen zijn, zoals de 2000 geanalyseerde carotis echo data en het "co-morbiditeiten" artikel door andere promovendi afgerond en gepubliceerd worden.

\section{Mijn co-promoteren, dr. M.T. Schram en dr. R.M.A. Henry}

Beste Miranda,

Deze laatste jaren heb ik vooral met je samengewerkt. Bedankt voor alle overleg momenten en voor het grondelijk proeflezen van mijn schriftwerk.

\section{Beste Ronald,}

Hartelijk dank voor je uitstekende begeleiding in het eerste deel van mijn promotietraject. Je schrijfsessies zijn een uitstekende basis geweest voor het structureren van wetenschappelijke teksten. Het is jammer dat de resultaten van de carotis remodelering stuk uiteindelijk niet significant zijn gebleken na het verwijderen van die twee outliers; hopelijk zal je vinden dat het laatste artikel van dit proefschrift een mooie remodelering stuk is geworden.

De leden van de beoordelingscommissie

Ik wil graag de leden van de beoordelingscommissie, prof. dr. A.A. Kroon, prof. dr. F. Verhey, prof. dr. L.M. van Bortel, dr. M.M.J. van Greevenbroek, dr. P.J.J. Spauwen bedanken voor het lezen en het beoordelen van mijn proefschrift. Prof. dr. L.M. van Bortel: it is a great honour that the developer of "de truc van Luc" joined the Assessment Committee of this thesis. Thank you very much for your prompt and valuable feedback!

\section{Alle co-auteurs en alle medewerkers van de Maastricht en Hoorn Studies}

Graag wil ik ook al mijn co-auteurs van de Maastricht- en Hoorn Studies bedanken voor hun commentaar en feedback. Hartelijk dank ook aan alle medewerkers van de Maastricht Studie die mijn de weg tijdens mijn promotie traject hebben gewezen. In het bijzonder zou ik graag Jos op het Roodt willen bedanken voor het aanleren van de vaatmetingen en voor al zijn hard werk tijdens het analyseren van vaatecho's. 
De polyneuropathie groep: Prof. dr. N. Schaper, dr. A. Koster, dr. D. Hilkman, dr. R. Henry en Ben. Hartelijk dank aan jullie omdat ik mee in het polyneuroapthie groepje kon doen. Onze afspraken zijn een mooie mogelijkheid geweest om nuttige statistische technieken te leren. Ook het volgen van jullie redenering stappen is heel nuttig geweest. Wij hebben een eerste poging gemaakt om polyneuropathie te definiëren op basis van vragenlijst en neurothesiometer data. Hopelijke zal de definitie aangevuld worden met EMG data en, uiteindelijk, ook in een eigen artikel gepubliceerd worden.

Graag zou ik ook alle administratief personeel van de Maastricht Studie en van het MUMC+ willen bedanken voor de benodigde ondersteuning tijdens mijn promotie. Chantalle: dank je wel voor het plannen van alle polyneuropathie afspraken en heel veel beterschap! Maggie: hartelijk dank voor de goede begeleiding voor het plannen voor de opleiding. Ivonne: hartelijk dank voor je hulp met alle bureaucratie rondom het afronden van de promotie traject.

\section{Het EpidM onderwijs in Amsterdam}

Hartelijk dank voor het maken van een nuttig en duidelijk curriculum over epidemiologisch onderzoek. Bovendien zou ik graag jullie willen danken voor de tijd dat jullie hebben ingestoken voor het begeleiden van ons stages. Met jullie hulp en steun heb ik een basiskennis gekregen over het verrichten van epidemiologisch onderzoek.

\section{Alle mede-promovendi}

Stefan: ik vond het geweldig om vaatstijfheid en remodelering met je te bespreken, ook al dit onderwerp voor geen van ons beide nuttig bleek te zijn. Marja: gefeliciteerd voor het verkrijgen van de co-morbitieiten artikel, ik hoop dat je hiervan zal blijven genieten tijdens je opleiding. Ben: je bent een van de grappigste kamergenoten die ik ooit heb gehad. Het was leuk om met je over alle mogelijke wetenschappelijke en niet-wetenschappelijke onderwerpen, inclusief Roemenië, te spreken. Ook Thomas, Pauline, Peggy, Fleur, Annemariek, Eline, Tan-Lai en Sytze: heel veel succes in jullie toekomstige carrières.

\section{Mijn vrienden}

I would like to start by thanking two individuals who are completely unaware of my friendship, but who are scientifically as close to me as any member of my promotion team: dr. G.F. Mitchell and prof. dr. S. Laurent.

\section{Dear Garry F. Mitchell (aka. The GFM),}

My BFG or BFA (Big Friendly (Scientific) Giant/ American) as I usually think of you. Your straightforward and clearly formulated articles have helped me understand arterial stiffness at every stage of my (scientific) development. Your passion for arterial stiffness has fuelled 
my own interest for this topic. I regret not being able to meet you face-to-face, but I am glad we met in writing at least.

Dear prof. S. Laurent,

Your considerable work on arterial stiffness has added to my own understanding of the topic. Most importantly, however, I found that your style of publishing results of scientific inquires clearly and without bias a very good guideline for my own articles.

\section{Mijn familie}

Mijn familie: dank jullie wel voor alle hulp en ondersteuning tijdens dit promotie traject. Mijn lieve moeder: je integriteit en je heldere interpretatie van de resultaten van epidemiologische onderzoeken hebben mij vanaf het begin van mijn leven vooruitgeholpen. Je hebt mij geleerd om het leveren van goede patiënt zorg nooit te vervangen door epidemiologisch onderzoek, hoe aantrekkelijk dat soms lijkt. Ik hoop dat je nu het afronden van dit promotietraject vanaf de hemel zult genieten. 


\section{Curriculum Vitae}

Veronica Onete was born on August $19^{\text {th }} 1986$ in Iasi, Romania. She studied Medicine at Utrecht University between 2005 and 2011, after which she worked as a resident in Internal Medicine at the Maxima Medical Centre. In June 2013 she started working as a PhD student in Internal Medicine at the Maastricht Study and the Academic Hospital in Maastricht, under the supervision of Prof. dr. C.D.A Stehouwer. During this research period she also obtained a cum laude degree of Master of Health Sciences in Clinical Epidemiology at the VU University, Amsterdam. She is currently working as a resident in Cardiology at the Amphia Hospital in Breda. 